\title{
El yacimiento arqueológico de Praileaitz I (Deba, Gipuzkoa, Euskal Herria). Metodología de la excavación, estratigrafía, estructuras y dataciones arqueológicas
}

\author{
Praileaitz leko (Deba, Gipuzkoa, Euskal Herria) aztarnategi arkeologikoa. Indusketaren \\ metodologia, estratigrafia, egiturak eta datazio arkeologikoak \\ The archaeological site of Praileaitz I (Deba, Gipuzkoa, Basque Country). Excavation \\ methodology, stratigraphy, structures and archaeological dating
}

PALABRAS CLAVE: Praileaitz I, Euskal Herria, Metodología, Estratigrafía, Dataciones.

GAKO-HITZAK: Praileaitz I, Euskal Herria, Metodologia, Estratigrafia, Datazioak.

KEYWORDS: Praileaitz I, Basque Country, Methodology, Stratigraphy, Dating.

\section{Xabier PEÑALVER ${ }^{(1)}$, Sonia SAN JOSE(2), Jose Antonio MUJIKA-ALUSTIZA ${ }^{(3)}$}

\section{RESUMEN}

La cueva de Praileaitz I, situada en el término municipal de Deba, ha sido excavada entre los años 2000 y 2009, afectando los trabajos a diversas áreas de la misma, documentándose niveles del Gravetiense, Solutrense, Magdaleniense Inferior, Magdaleniense Superior-Final y Epipaleolítico. La metodología aplicada está basada en la excavación en cuadrícula de lechos y niveles. Las 26 dataciones obtenidas oscilan entre el $8840 \pm 45$ B.P. y el $35010 \pm 280$ B.P.

\section{LABURPENA}

Debako udalerrian kokatzen den Praileaitz I haitzuloa, 2000 eta 2009 urteen tartean indusi da. Lan hauek, bertako gune ezberdinetan egin ziren, Gravetiar, Solutriar, Behe Madaleniar, Goi-Azken Madaleiniar eta Epipaleolitoko mailak dokumentatuz. Indusketa metodologia laukiteria azaletan eta mailetan oinarritu da. Lortu diren datazioak $8840 \pm 45$ eta $35010 \pm 280 \mathrm{BP}$ tartean kokatzen dira.

\section{ABSTRACT}

The cave of Praileaitz I, located in the municipality of Deba, was excavated between 2000 and 2009. The work carried out in different areas of the cave made it possible to identify Gravettian, Solutrean, Lower and Late Upper Magdalenian and Epipaleolithic levels. The cave was excavated using a grid in the different beds and levels. The 26 dates obtained ranged from $8840 \pm 45$ B.P. to $35010 \pm 280$ B.P.

\section{1.- INTRODUCCIÓN}

La intervención arqueológica llevada a cabo entre el año 2000 y el 2009 (PEÑALVER, de 2001 a 2008a, 2009a) ha afectado a una superficie total de $191 \mathrm{~m}^{2}$, situados en su mayor parte en el interior de la cavidad y en menor medida en el rellano situado inmediatamente al exterior de la misma. En la cueva los espacios excavados son diversos: el vestíbulo, la galería noroeste, el tránsito entre el vestíbulo y la primera sala interior, la primera sala interior y la segunda sala interior.

Las actuaciones se han practicado en distintas fases realizándose sucesivas ampliaciones en función de los resultados obtenidos. Esta organización venía impuesta por el hecho de que la excavación tenía como objetivo final vaciar la totalidad del sedimento fértil. Una vez concluido el trabajo la cantera que explota el lugar destruiría la cueva.

Pero tras el descubrimiento de 29 colgantes decorados correspondientes al Magdaleniense Inferior, agrupados en diferentes conjuntos, tanto en el vestíbulo como en la primera sala interior, así como de otras piezas de arte mueble que apuntaban hacia la utilización de la cavidad como un espacio de tipo cultual o ritual, se planteó

\footnotetext{
(1) Departamento de Arqueología Prehistórica. Sociedad de Ciencias Aranzadi Zorroagaina, z.g. 20014 Donostia. praileaitz@gmx.com (2) Departamento de Arqueología Prehistórica. Sociedad de Ciencias Aranzadi.

(3) Facultad de Letras (Universidad del País Vasco/Euskal Herriko Unibertsitatea UPV/EHU).
} 
al Gobierno Vasco que la Dirección de Patrimonio Cultural debía protegerlo (PEÑALVER, SAN JOSE, 2009). La negativa por parte del Departamento de Cultura de ese Gobierno a la propuesta hizo que los trabajos tuviesen que proseguir con el mismo objetivo final y la misma metodología, practicándose sucesivas ampliaciones en función de los restos y niveles hallados, siempre con el objetivo de excavar íntegramente el yacimiento.

Fue en el año 2006 con la confirmación del hallazgo de varias agrupaciones de pinturas rupestres cuando se modificó la situación, debiéndose conservar a partir de este momento el lugar por ley aunque con una protección de $50 \mathrm{~m}$ "a partir de las zonas conocidas de la cueva”, según se hizo público en el Decreto ${ }^{1}$ del Gobier-
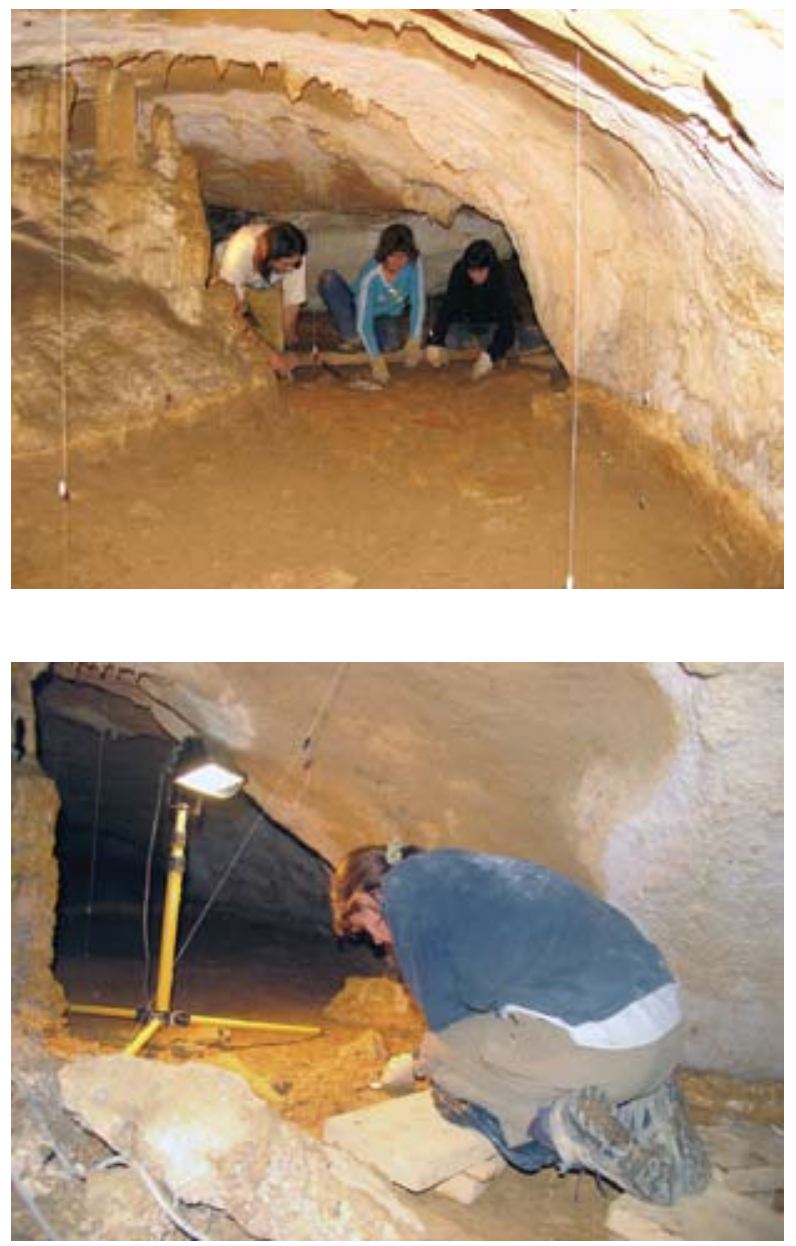

únicamente de las zonas y niveles que se consideraban necesarios para el conocimiento de las sucesivas ocupaciones del lugar.

No obstante, y a pesar de las diferentes situaciones administrativas que afectaban a la intervención entre el 2000 y el 2009, el método de excavación empleado fue el que se viene aplicando habitualmente en este tipo de yacimientos, siguiendo los ritmos adecuados para una correcta realización del trabajo, si bien, en los años previos al hallazgo de las pinturas las sucesivas ampliaciones que era preciso practicar hacían más complejo el trabajo, sobre todo en lo que se refiere a la interpretación de los niveles arqueológicos.
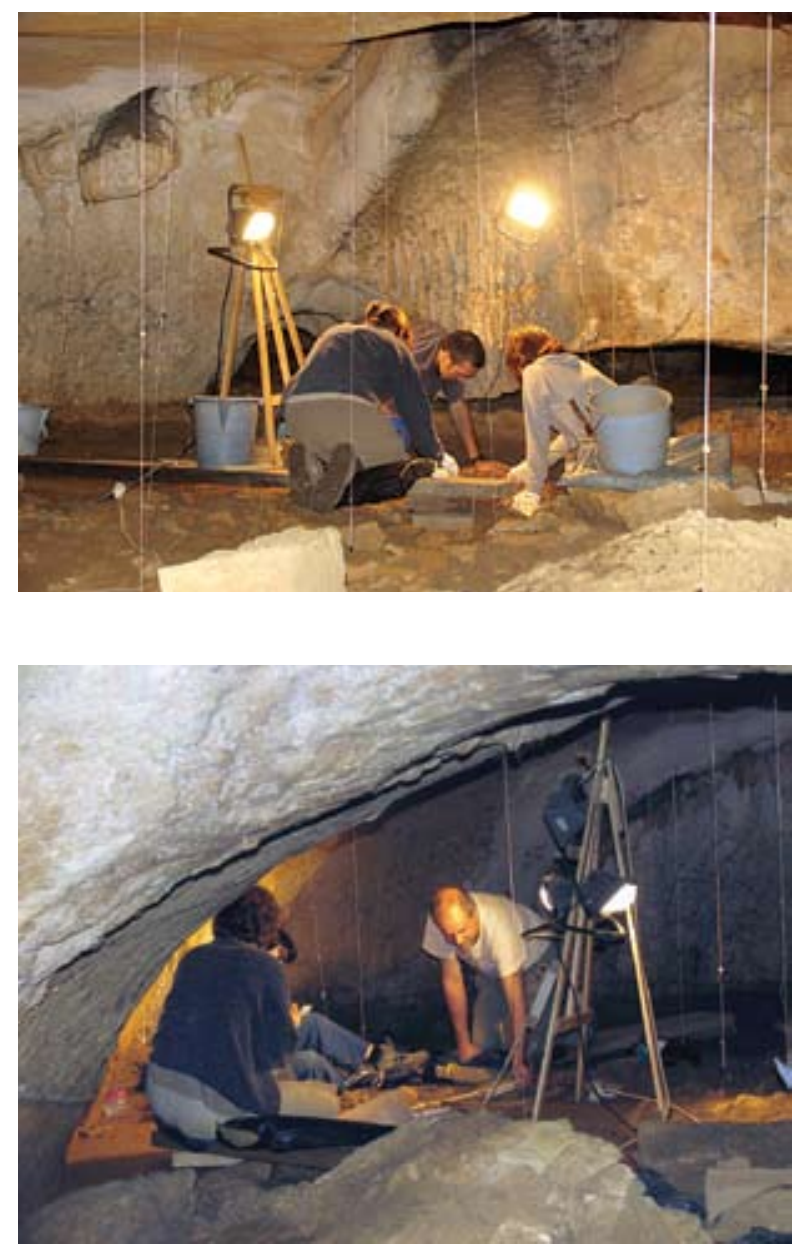

Figs. 1-4. Diversos trabajos de la excavación. / Some excavation works.

no Vasco 120/2007 del 17 de julio de 2007 y publicado el 26 de julio de ese mismo año. A partir de ese momento la intervención arqueológica no se contemplaba como una excavación de la totalidad del yacimiento, sino

\footnotetext{
${ }^{1}$ DECRETO 120/2007, de 17 de julio, por el que se califica como Bien Cultural, con la categoría de Monumento, la Cueva de Praileaitz I, sita en Deba (Gipuzkoa). BOPV nº 143 de 26 de julio de 2007.
}

La duración total de la intervención de campo, 31 meses y medio, ha permitido desarrollar un importante trabajo en esos años, continuándose a día de hoy tras una interrupción de algo más de dos años. Las tareas de laboratorio se han efectuado en algunos casos de forma paralela a las excavaciones, intensificándose tras el año 2009. El equipo de campo diario en el yacimiento ha sido, por lo general, de cinco personas. 


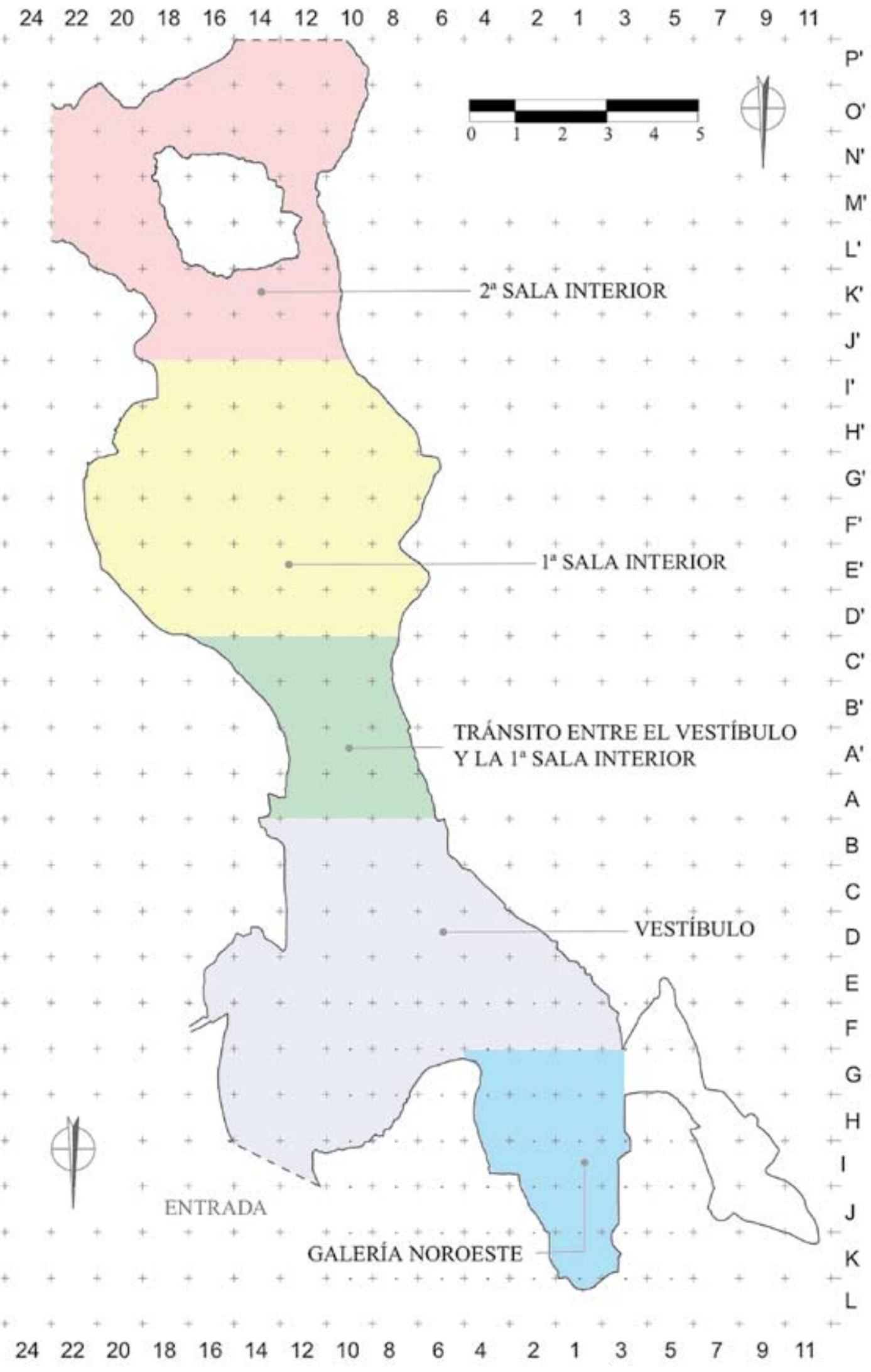

Fig. 5. Cuadrícula de las diferentes zonas del interior de la cueva intervenidas (Dibujo: X. Peñalver/Digitalización: J. Calvo). / Grid of the cave inner zones that have been excavated (Drawing: X. Peñalver/Digitalisation: J. Calvo). 


\section{2.- METODOLOGÍA DE LA EXCAVACIÓN}

En la excavación se ha seguido el método de cuadriculación de zonas mediante coordenadas cartesianas estableciéndose cuadrículas de 1 metro cuadrado, denominando al eje que define la dirección norte-sur con letras y al orientado en sentido este-oeste con números (Fig. 5). Cada una de estas cuadrículas se ha dividido a su vez en 9 sectores de $33,33 \mathrm{~cm}$ cada uno. El punto 0 del nivel está representado en la parte oeste de la entrada.

El sedimento se ha ido levantando en lechos convencionales de distinto espesor según los casos, aunque por lo general su potencia ha sido de $2 \mathrm{~cm}$ (Figs. 1-4). Esta eliminación por lechos ha ido permitiendo detectar niveles geológicos y arqueológicos diferenciados que serán la base del estudio estratigráfico. La totalidad del sedimento excavado se ha cribado con cedazos de 3 y $4 \mathrm{~mm}$ de luz. Así mismo, se han recogido muestras de tierra para la realización de diferentes análisis como sedimentología, palinología, macrorrestos vegetales, micromamíferos, etc. (Fig. 6).

Los lechos y niveles se han dibujado, en su mayor parte, a escala 1:10 directamente sobre el yacimiento, realizándose fotografías a todos ellos además de a los elementos y zonas más significativas. Los materiales obtenidos a lo largo de las sucesivas campañas han sido lavados y siglados, realizándose un inventario de los mismos, así como su posterior estudio. Las piezas referenciales o de mayor importancia han sido así mismo dibujadas y fotografiadas.

\section{3.- LA ESTRATIGRAFÍA Y LAS ESTRUCTURAS}

El hecho de que la excavación arqueológica en la cueva de Praileaitz I se haya llevado a cabo en sucesivas fases y en condiciones diferentes según los años (excavación de intervención y excavación de investigación), ha originado la apertura de cuadrículas en distintas áreas, así como frecuentes ampliaciones. Para una mejor comprensión espacial hemos diferenciado un total de seis zonas de intervención a las que hemos denominado del siguiente modo: el rellano exterior a la cueva, el vestíbulo, la galería noroeste, el tránsito entre el vestíbulo y la primera sala interior, la primera sala interior y la segunda sala interior.

Este sistema de excavación ha supuesto que las numeraciones de los lechos no se correspondan entre unas y otras zonas, por lo que se han establecido relaciones entre esas seis zonas definiendo las correspondencias de los lechos así como de los niveles.

\subsection{El rellano exterior a la cueva}

La zona excavada al inicio de los trabajos afecta a un área de $4 \times 4 \mathrm{~m}$, con lo que se abren 16 cuadrículas de $1 \times 1 \mathrm{~m}$ al este de la boca de la cueva de Praileaitz I, junto a la pared rocosa, en la pequeña explanada que se forma entre esta pared y la pendiente que desciende bruscamente hacia el río Deba (Fig. 8). Los cuadros se numeran de la forma siguiente: números $3,5,7$ y 9 , en

Fig. 6. Recogida de muestras de sedimentología. / Collection of sedimentology samples.

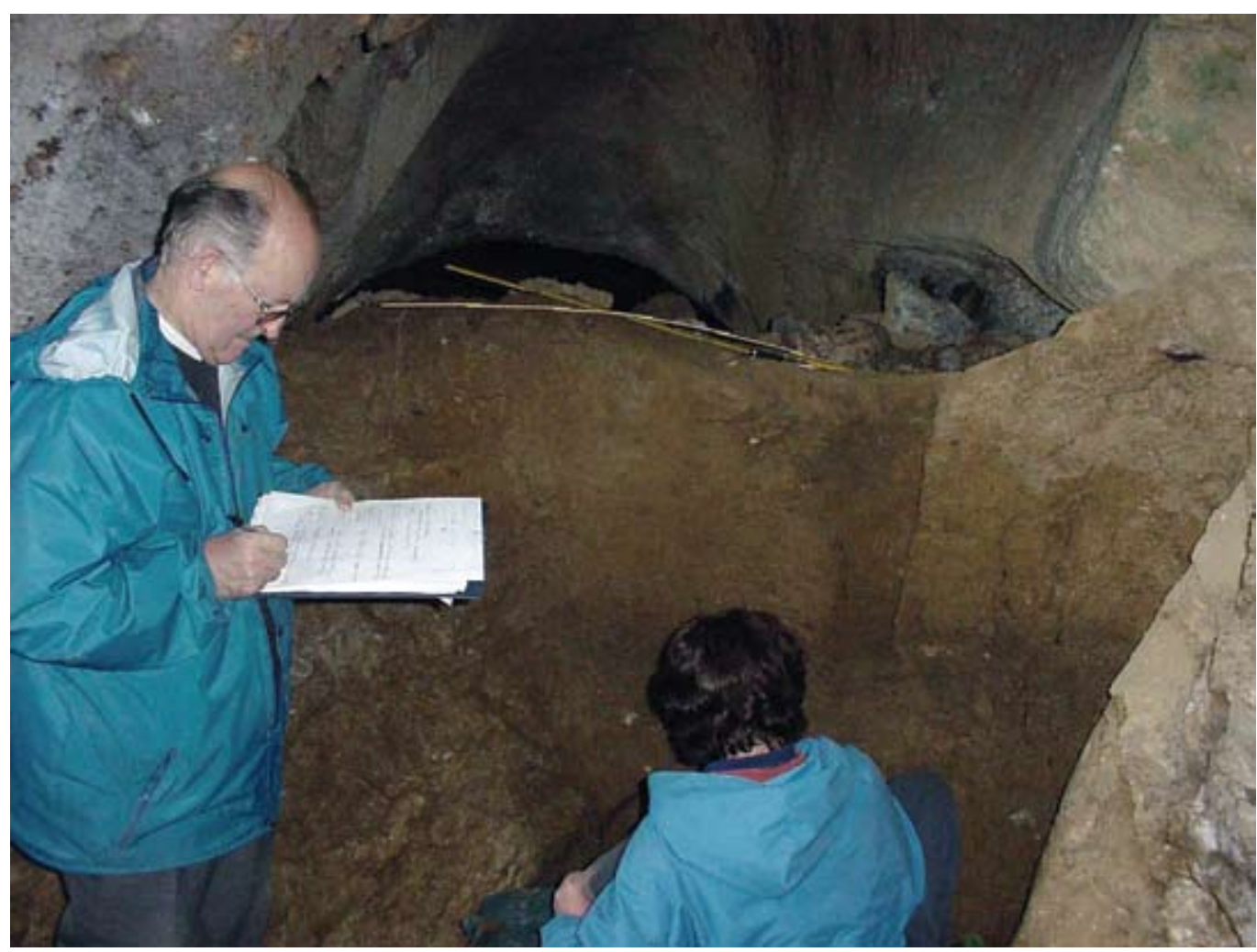




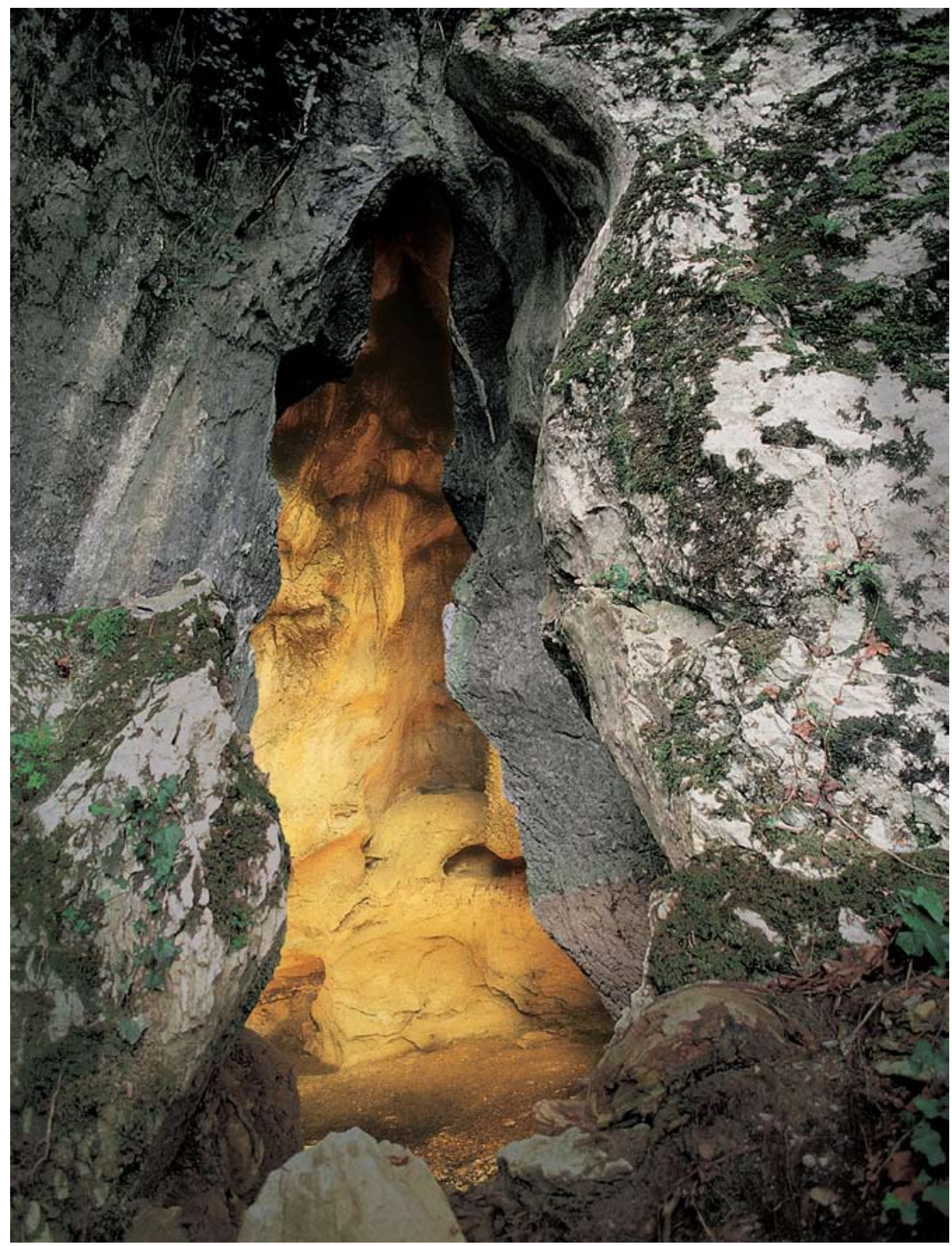

Fig. 7. Entrada de la cueva de Praileaitz I (X. Otero). / The entrance to the cave of Praileaitz I (X. Otero). 
Fig. 8. Excavación del lecho 8 en la plataforma exterior de la cueva. / Excavation of the layer 8 on the cave outside platform.

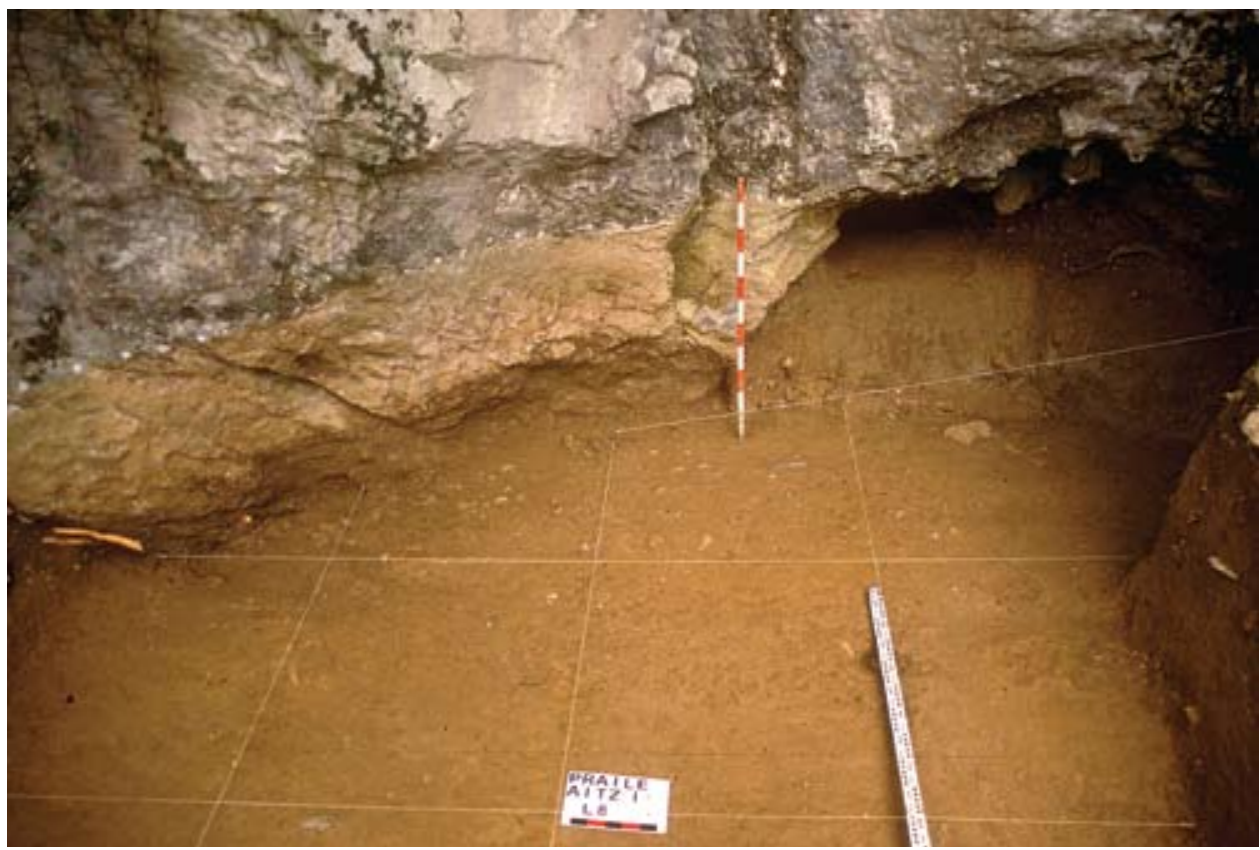

sentido de la pared rocosa hacia la pendiente, y letras $A, B, C$ y $D$, en sentido desde la boca de la cueva hacia el camino viejo de Deba. Posteriormente se amplía la banda A'. Al finalizar la excavación en esta zona se han excavado un total de 22 cuadros correspondientes a las bandas con números 1, 3, 5, 7 y 9 y a las letras $A^{\prime}$, A, B, C y D, en un total de 8 lechos (Fig. 9). Con posterioridad se ha realizado una cata en los cuadros 3B y $5 \mathrm{~B}$ en la que se han practicado 11 lechos, con el fin de determinar la estratigrafía existente bajo el paquete excavado.
Los niveles detectados en esta zona son los siguientes:

\subsubsection{El nivel I}

Está compuesto por un sedimento superficial de color marrón oscuro poco compacto, formado por tierra vegetal y que ha sido excavado en el denominado lecho 1. En él aflora un gran bloque calizo que ocupa parte de los cuadros 5B, 7B, 5C y 7C. La potencia de este nivel es de entre 5 y $25 \mathrm{~cm}$ (Figs. 10 y 11).

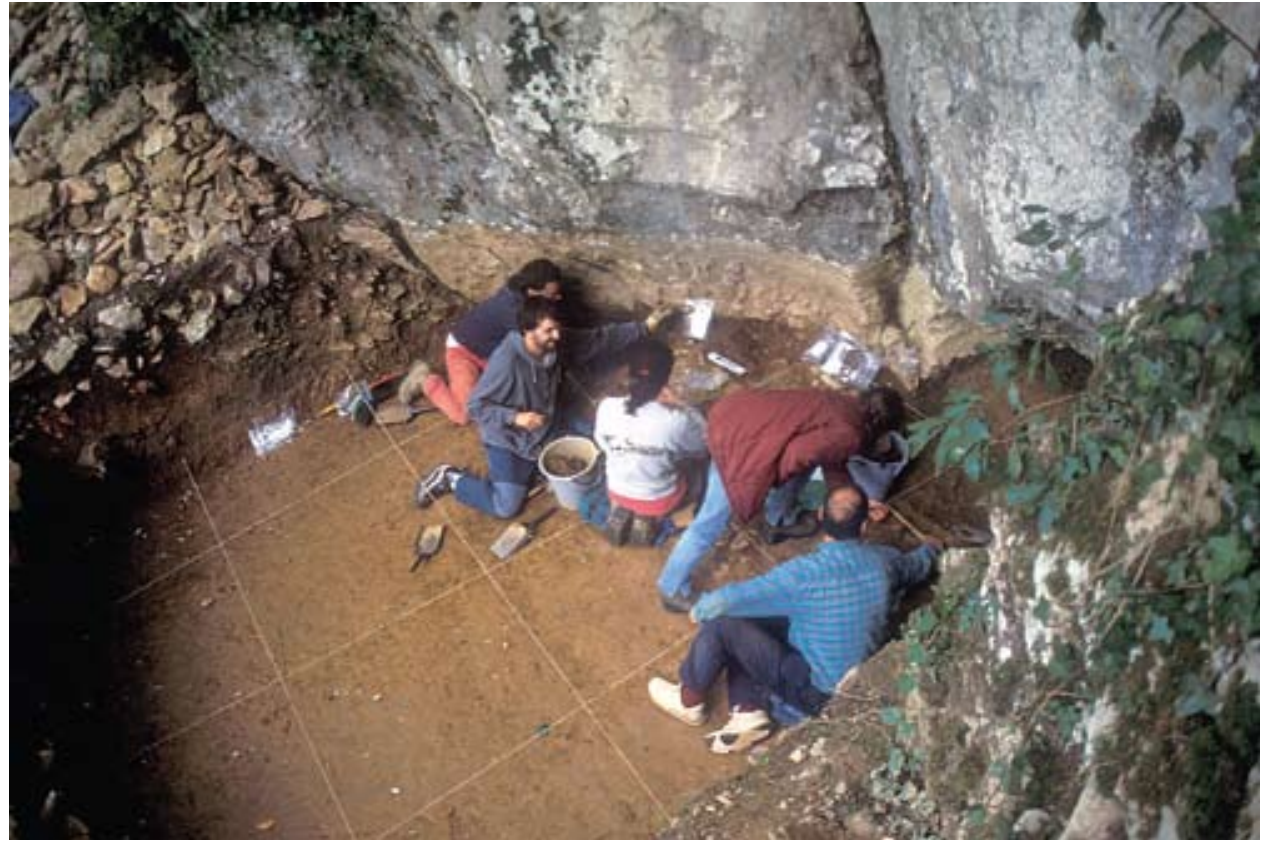

Fig. 9. Trabajos de excavación en el área exterior. / Excavation works on the outside área. 


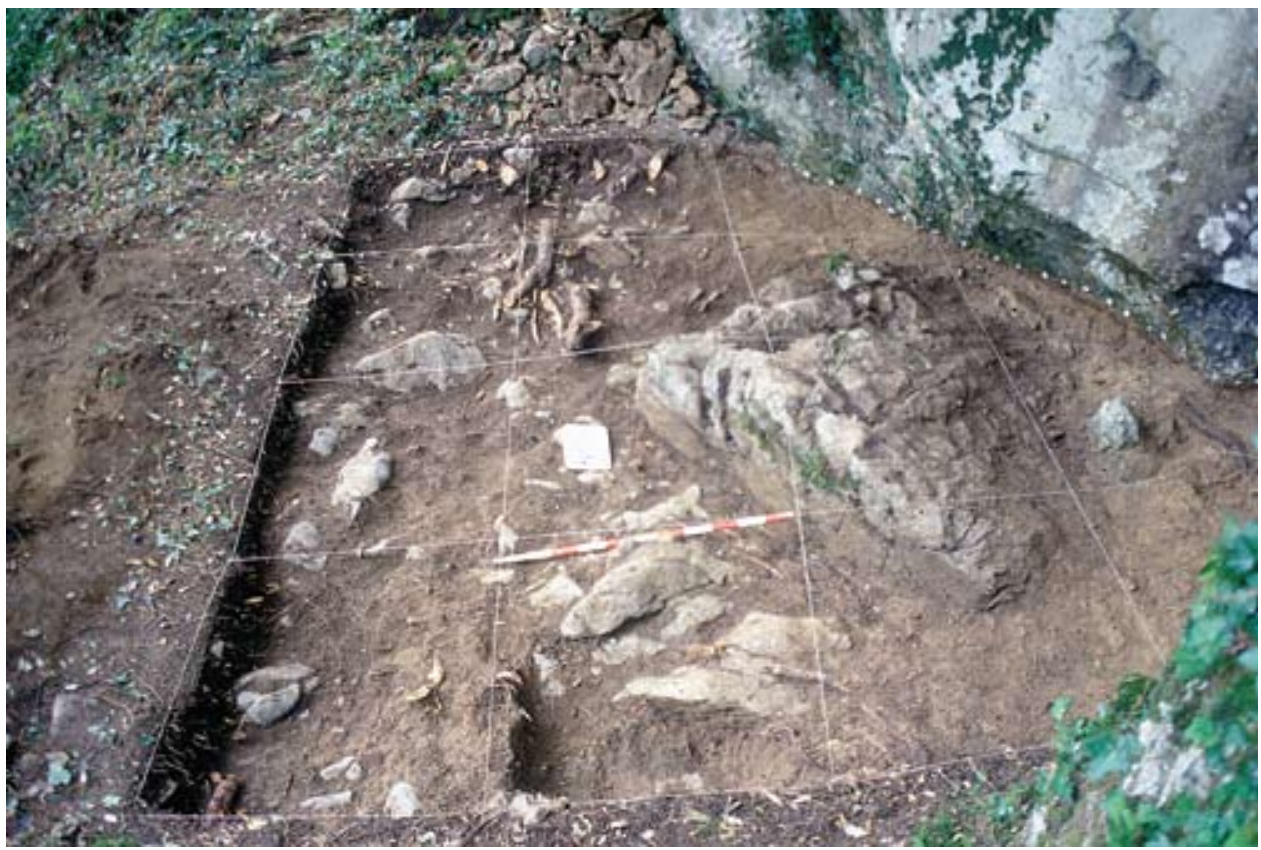

Fig. 10. Vista general de la plataforma exterior durante la excavación de los primeros lechos. / General view of the outside platform during the excavation of the first layers.

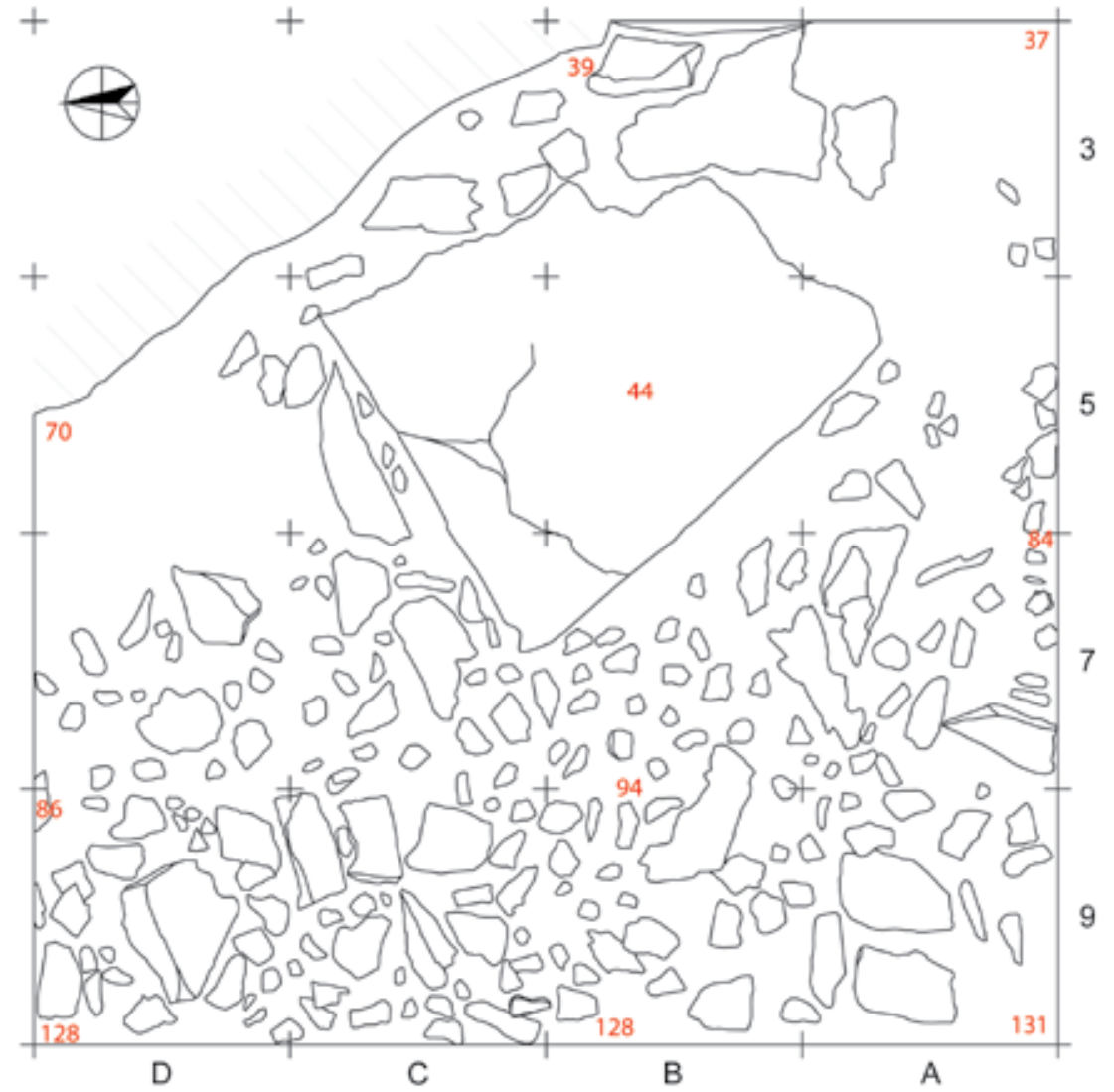

Fig. 11. Plano de la plataforma exterior, una vez excavado el lecho 1. (Dibujo: $X$. Peñalver/Digitalización: J. Calvo). / Plan of the outside platform, once the layer 1 has been excavated (Drawing: X. Peñalver/Digitalisation: J. Calvo).

\subsubsection{El nivel II}

Lo constituye un sedimento amarillo de tipo arcilloso, con numerosas piedras calizas que ocupan gran parte de la superficie, además del gran bloque citado en el nivel I. Este nivel se ha excavado en lechos del 2 al 3, siendo muy abundantes las piedras de tamaño pequeño y medio. 


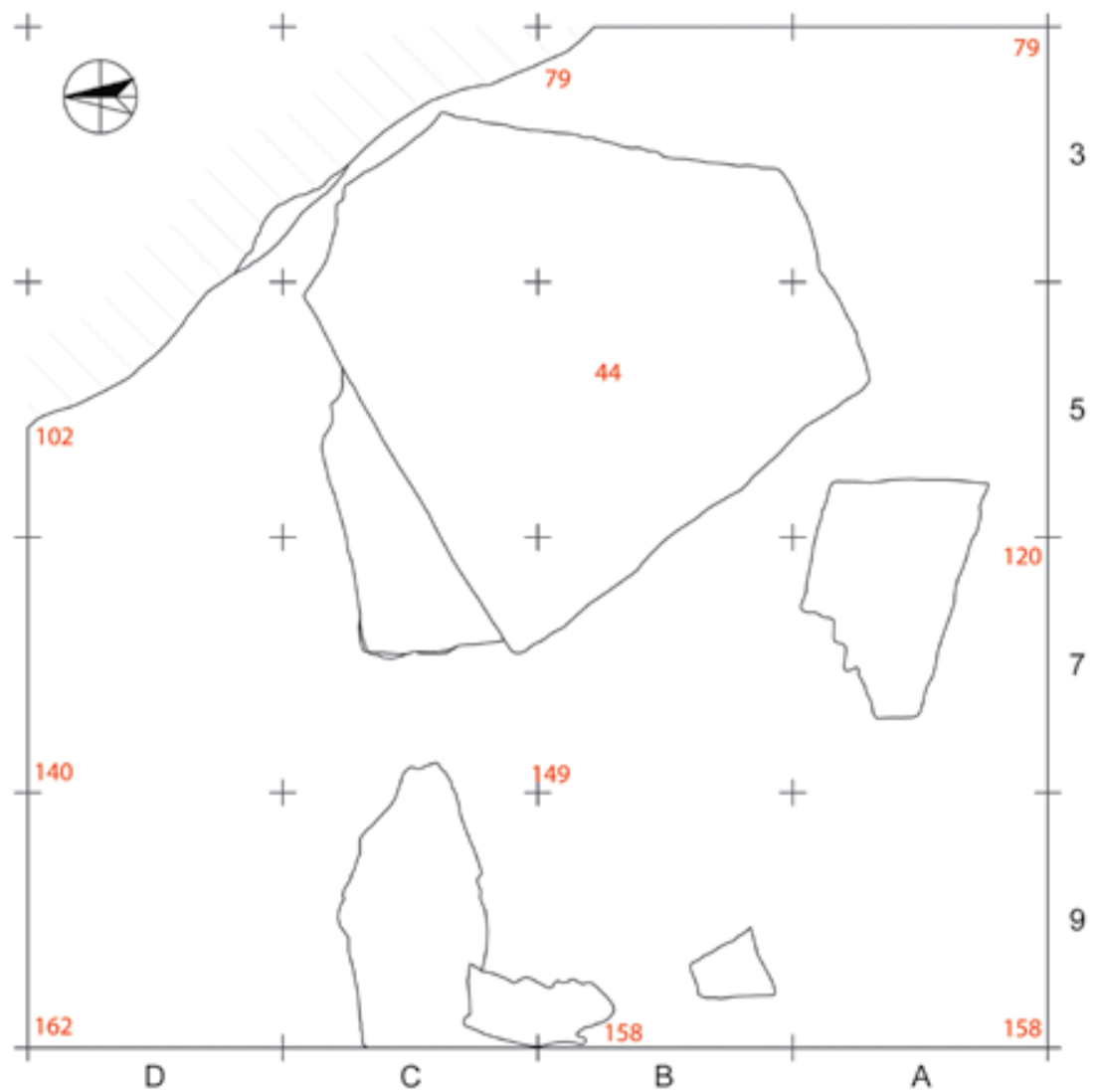

Fig. 12. Plano de la plataforma exterior una vez excavado el lecho 5. (Dibujo: X. Peñalver/Digitalización: J. Calvo). / Plan nce the layer 5 of the outside platform has been excavated (Drawing: X. Peñalver/Digitalisation: J. Calvo).

\subsubsection{El nivel III}

Este nivel lo forman dos lechos, el 4 y el 5, con una tierra de color amarillo similar a la anterior, que tiende a oscurecerse en la base del mismo; destaca la presencia de grandes bloques de piedra caliza y la ausencia de piedras de menor tamaño (Fig. 12). Contiene industria lítica y restos de fauna.

Fig. 13. Plataforma exterior tras la excavación del lecho 8. / Outside platform after the excavation of the layer 8.

\subsubsection{El nivel IV}

Está integrado por los lechos 6, 7 y 8 y presenta un sedimento de color amarillo de tipo arcilloso y plástico. En los dos primeros lechos se localizan algunas industrias y restos de fauna (Fig. 13).

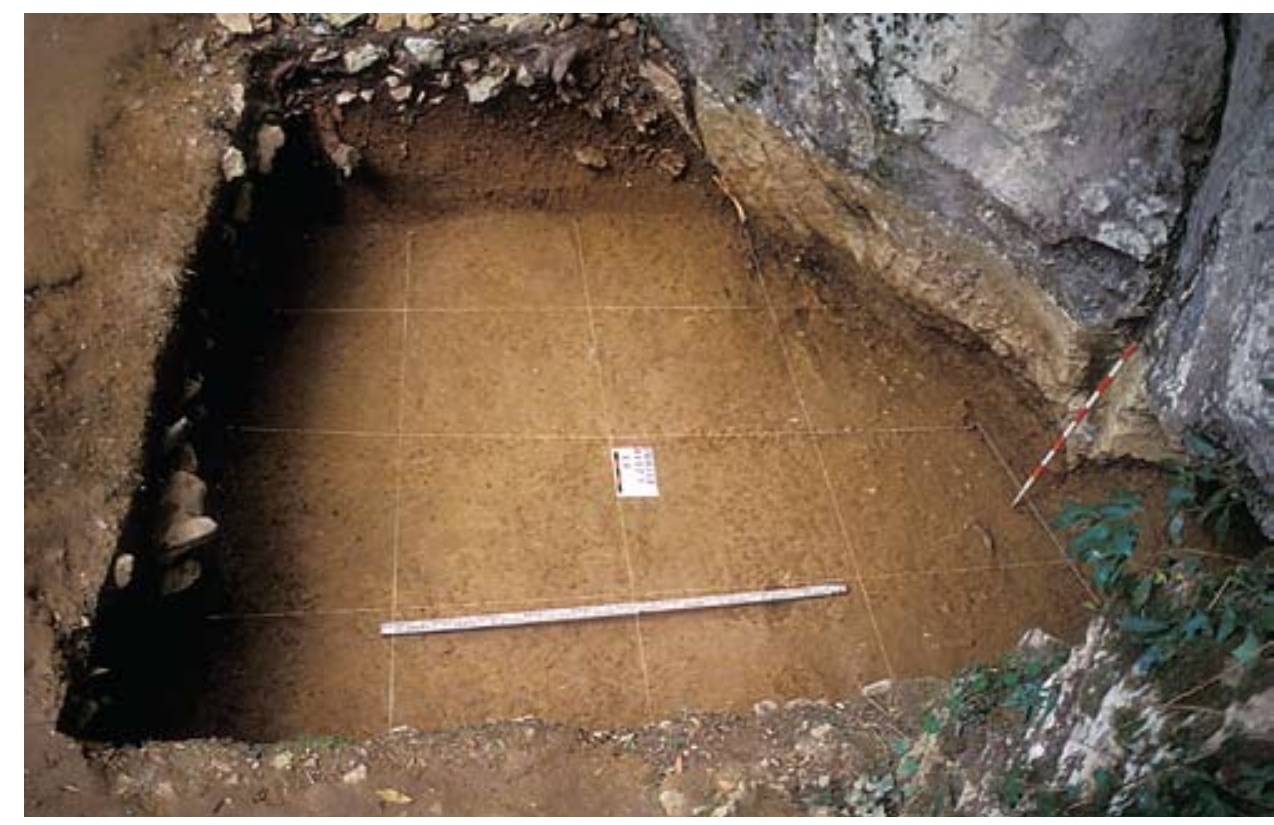


Fig. 14. Sondeo practicado en la plataforma exterior una vez finalizada la excavación de la zona. / Exploration made on the outside platform once the excavation of the area is completed.

\subsubsection{El nivel V}

Se caracteriza por una tierra de color amarillo, de tipo plástico, conteniendo escasos restos de fauna. Lo forman los lechos 9 al 15.

\subsubsection{El nivel VI}

El sedimento presenta características similares al anterior, si bien este último contiene pequeños cantos grises y verdosos, no presentando resto arqueológico alguno. Lo forman los lechos 16 al 19 (Fig. 14).

\subsubsection{Adscripción cronocultural de los niveles del rellano exterior}

A partir de la intervención en la zona y de la cata practicada, se han diferenciado seis niveles, los cuatro primeros excavados en la totalidad y los dos restantes únicamente en el área de la cata.

La escasez de industrias recuperadas en esta zona dificulta el establecimiento de una secuencia cronocultural definida, si bien, se han establecido dos fases claramente diferenciadas: una superior con industrias y fauna, que se puede situar en torno al Aziliense y Magdaleniense Final, y una inferior con restos de fauna que ha sido datada a partir de restos de Pantera pardus en los inicios del Paleolítico Superior (35010 \pm 280 B.P.).

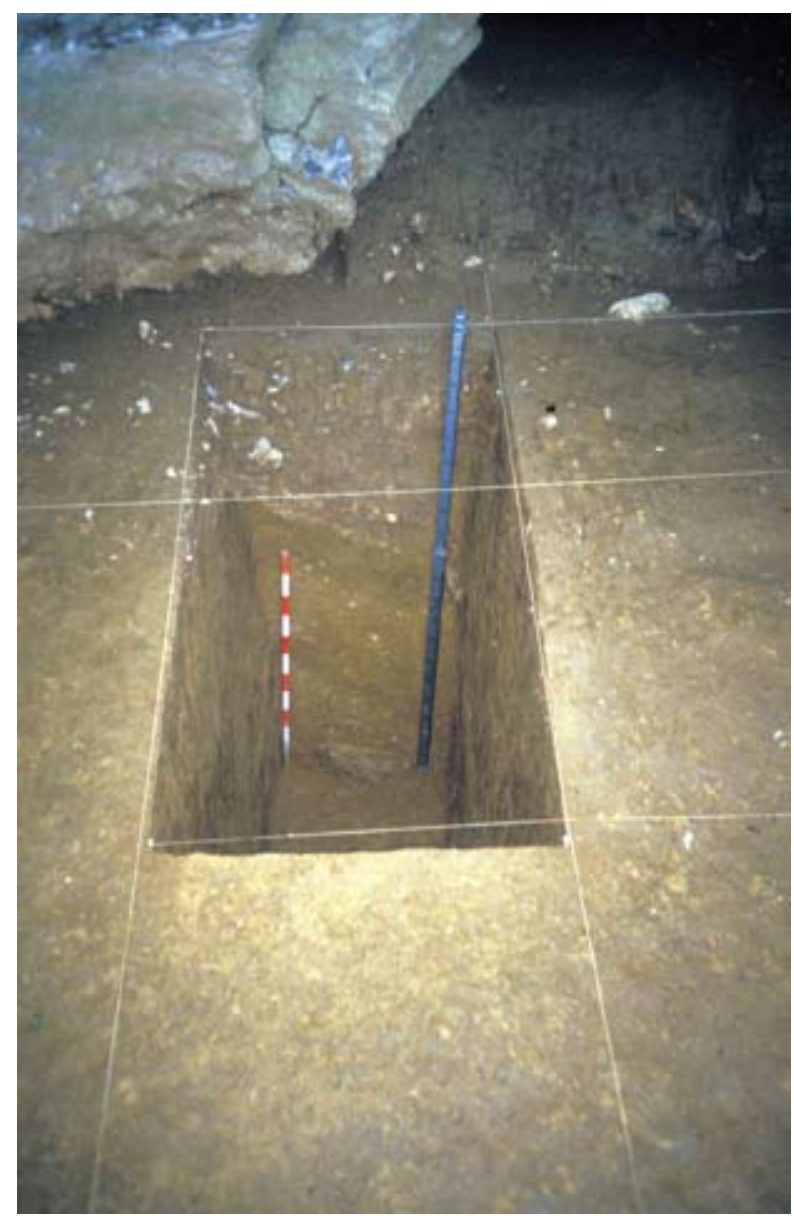

\subsection{El vestíbulo}
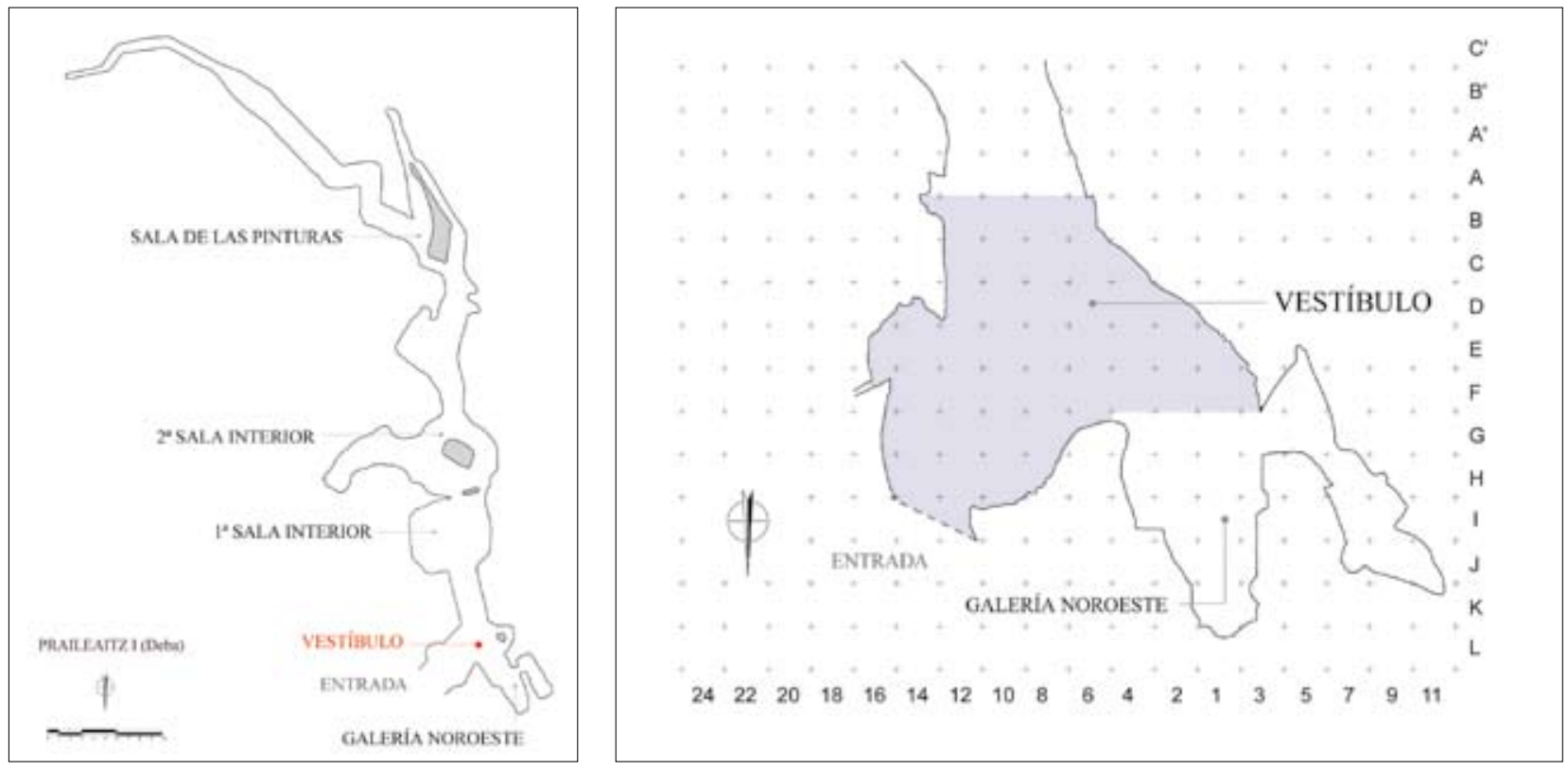

Fig. 15. Plano general de la cueva y ubicación del vestíbulo (Plano G. Studer/Tx. Ugalde -Felix Ugarte Elkartea-). / General plan ofthe cave and location of the vestibule (Plan G. Studer/Tx. Ugalde -Felix Ugarte Elkartea-). 
Fig. 16. Trabajos de excavación en la zona del vestíbulo. / Excavation wor$\mathrm{ks}$ in the area of the vestibule.

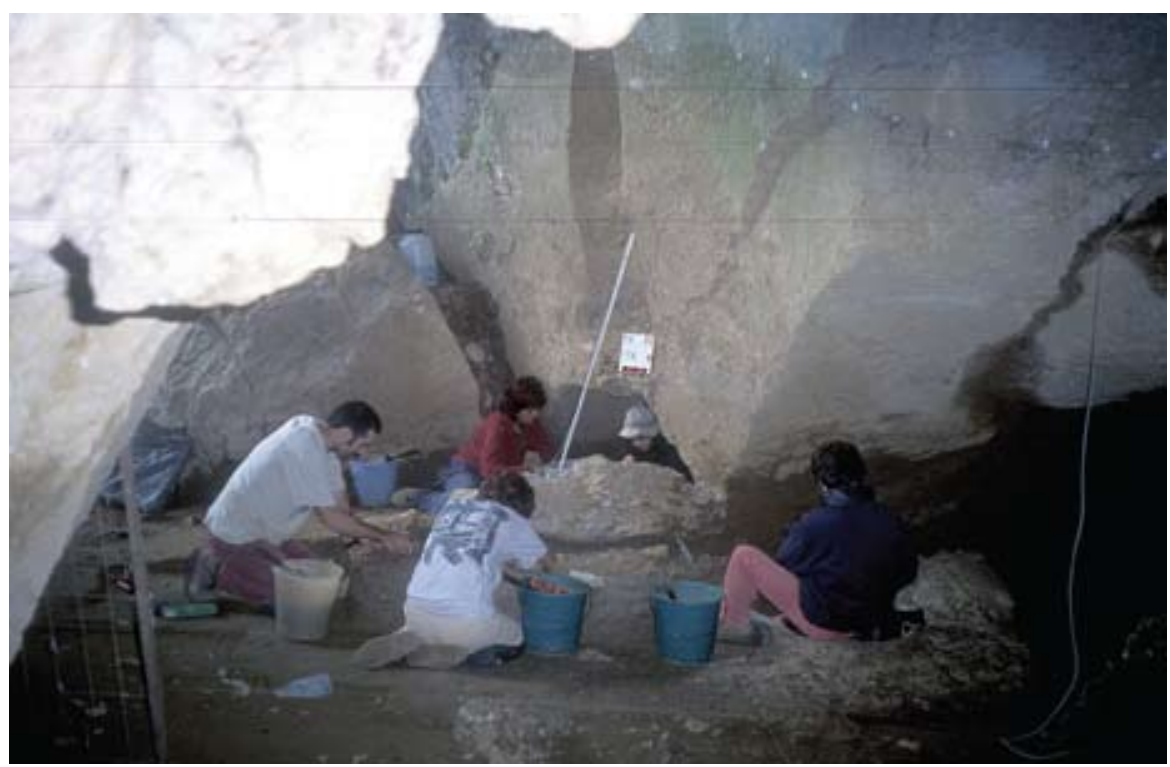

Una vez realizada la cuadriculación de la superficie a excavar y la toma de cotas del nivel superficial se comienza la excavación del primer nivel en su lecho 1 , abarcando una superficie de 8 cuadros numerados del siguiente modo: el eje norte-sur se denomina con letras $C$ y $D$ en estos cuadros iniciales, y con números pares, 4 , 6, 8 y 10 en sentido de oeste a este (Fig. 15).

Al comienzo de la segunda campaña se amplía la excavación en esta zona afectando a las bandas B, E, F y G, dentro de los números 2, 4, 6, 8 y 10, así como en una pequeña zona del 12; de este modo, los 8 cuadros de la primera campaña se convierten en 22.

Con posterioridad, y debido a las exigencias de la excavación, se realiza una serie de ampliaciones en diversas zonas de la periferia del vestíbulo hasta alcanzar la totalidad de su extensión (Fig. 16).

A continuación se detallan brevemente las características de cada una de estas ampliaciones.

\subsubsection{Ampliaciones}

\section{Ampliación en la zona noroeste del vestíbulo}

Esta ampliación afecta a la zona noroeste del vestíbulo, concretamente a las bandas $\mathrm{E}$ y $\mathrm{F}$ de los cuadros 2,4 y 6 , y en ellas se ha bajado un total de 8 lechos hasta unificarse en el lecho 20 con el resto del vestíbulo, correspondiente al nivel IV (Magdaleniense Inferior). La mayor parte de la excavación en esta zona consiste en la eliminación de sucesivas capas de concreción pertenecientes al nivel 0 que en ocasiones se alternan con una tierra marrón con piedras de tamaño medio.

\section{El tránsito entre el vestíbulo y la galería noroeste}

Se trata de la intervención en la zona de contacto entre la galería noroeste y el vestíbulo de la cueva. Abarca, dentro de las bandas $D, E$ y $F$, totalmente a los cuadros $3 \mathrm{E}, 3 \mathrm{~F}, 1 \mathrm{D}, 1 \mathrm{E}$ y $1 \mathrm{~F}$, y parcialmente a los cuadros $2 \mathrm{E}, 2 \mathrm{~F}$ y $4 \mathrm{~F}^{2}$. Una vez eliminada la capa de concreción del nivel 0 , el nivel superficial se presenta muy horizontal antes de comenzar los trabajos de excavación.

A partir del lecho 8 el sedimento es de color amarillo apareciendo al excavarlo la parte más superficial del empedrado del nivel IV.II que se describirá más adelante y que ocupa la mayor parte del resto del vestíbulo; este nivel se hace más homogéneo en el lecho 9 . A partir del lecho 10 la tierra continúa siendo de color amarillo pero carece de piedras. La excavación del último lecho, el 15bis, posibilita el igualar esta zona de tránsito entre el vestíbulo y la galería noroeste con el lecho 24 del vestíbulo, perteneciente al nivel $\mathrm{V}$ del Solutrense.

\section{Ampliación en la zona antes oculta por el gran bloque desprendido de la entrada}

\section{Primera fase}

Tras la eliminación mediante mazo y cincel de un gran bloque que ocupaba gran parte de la entrada, y que se había desprendido cayendo sobre la misma en esa zona del vestíbulo a la altura del lecho 25 , quedan visibles los cuadros $12 \mathrm{~F}$ y $12 \mathrm{E}$, en los que se puede excavar el sedimento anteriormente oculto por el bloque. Esta excavación se realiza en 30 lechos, tras los cuales se iguala esta zona con el citado lecho 25, correspondiente al nivel $\mathrm{V}$ del período Solutrense.

Siendo esta zona la parte más exterior del vestíbulo, la dinámica de deposición del sedimento ha sido ligeramente diferente al resto. Así mismo, la caída del gran bloque

\footnotetext{
2 La zona restante de estos cuadros ya había sido excavada como parte del vestíbulo.
} 


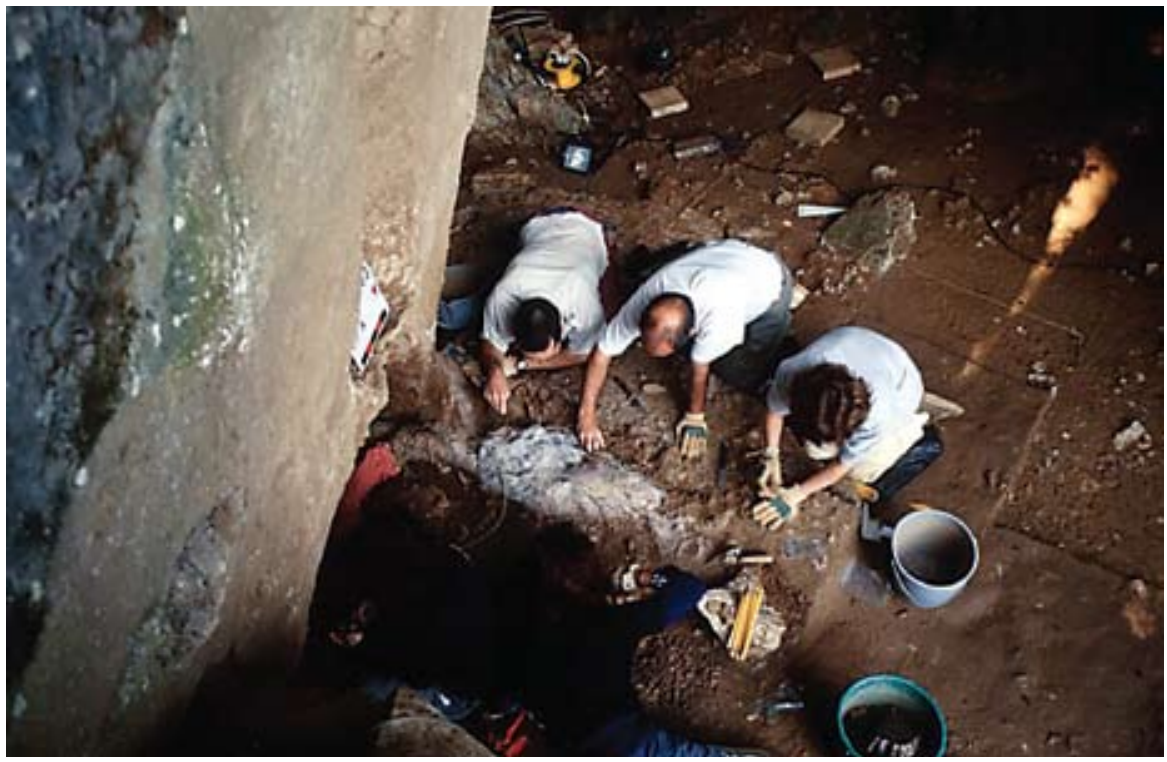

Fig. 17. Excavación de la parte final del gran bloque desprendido en la entrada de la cueva. / Excavation of the final part of the great block detached at the entrance of the cave.

mencionado anteriormente ha rehundido algunas áreas, encontrándose estratigrafía similar a la del vestíbulo, pero a cotas ligeramente inferiores. Los ocho primeros lechos ${ }^{3}$ están constituidos básicamente por limos rojizos además de por algunos bloques y brechas. Ya en el lecho 6, la inclinación de la base de algunos bloques parece apuntar hacia un buzamiento del terreno en dirección este. A partir del lecho 9 se producen cambios entre los que destaca el color de la tierra, ahora marrón, de tipo arcilloso, a la vez que desaparecen los grandes bloques, quedando muy reducidas las zonas de limos de color rojizo. En el lecho 11 se confirma el buzamiento del terreno hacia el exterior y hacia el gran bloque desprendido de la pared.

Desde el lecho 13 la tierra es más amarilla; ya en el lecho 20 aparece un pequeño nivel de piedras de entre 5 y $10 \mathrm{~cm}$, que continúa hasta el lecho 23. Llegado este punto aflora otro nivel de pequeñas piedras muy semejante al empedrado que cubre gran parte del vestíbulo correspondiente al nivel IV.II (Magdaleniense Inferior) si bien a una cota ligeramente inferior, muy probablemente por la presión ejercida por el gran bloque sobre el terreno. Bajo este empedrado, ya entre los lechos 28 y 30, la tierra es amarilla, arcillosa o plástica, según las zonas, y con muy escasas piedras.

\section{Segunda fase}

Tras la progresiva eliminación del gran bloque desprendido de la entrada, van ampliándose las zonas de excavación. En esta ocasión, tras largos trabajos de cuidadosa rotura del bloque, queda disponible un área que amplía considerablemente el espacio del vestíbulo, principalmente la zona de su entrada (Fig. 17). Se trata de los cuadros

${ }^{3}$ El sedimento de estos lechos procede directamente del exterior de la cavidad y se ha tratado independientemente al resto de la estratigrafía de la cueva. Carece de material arqueológico.
12E, 12F, 14D, 14E, 14F, 16D, 16E y 16F. Paralelamente a la excavación de estos cuadros se sigue eliminando poco a poco la parte del bloque aún existente en la zona.

Las características del sedimento entre los lechos 1 y 14 no presentan gran variedad en lo que se refiere a su coloración, que es de tipo amarillo, si bien la abundancia de piedras de tamaño pequeño y medio varía según los lechos y las zonas, aunque están presentes en casi su totalidad. La pequeña cavidad que se abre en la pared vertical de la entrada va aumentando sus dimensiones, abarcando a los cuadros 14E, 14D y 16E, principalmente.

A partir del lecho 15 hasta el 22bis se detecta el nivel IV correspondiente al Magdaleniense Inferior, con los mismos subniveles que los localizados en el resto del vestíbulo, pero condicionado por la afección del bloque caído, tal y como se ha mencionado anteriormente. Los resultados de la excavación de esta zona se detallarán dentro del nivel IV de la estratigrafía general del vestíbulo (Figs. 18 a 22).

\section{Excavación del testigo debajo del asiento y de sus calces}

Tras la retirada de un gran bloque de piedra y de sus calces, interpretado como asiento correspondiente al nivel IV.II -y del que se tratará más adelante-, se excava la tierra existente bajo él dentro del cuadro 10D y parte del 10E, así como la que se encuentra bajo la piedra de calce principal del mismo. Este sedimento ha sido rebajado en 17 lechos hasta alcanzar el nivel $V$ excavado en el resto del vestíbulo (lecho 25).

\section{Ampliación en la entrada del vestíbulo}

En la zona de acceso al vestíbulo desde la entrada a la cueva se lleva a cabo una ampliación de la excavación 
16

$+$

列
14

12

$+$

$+$

$10+$
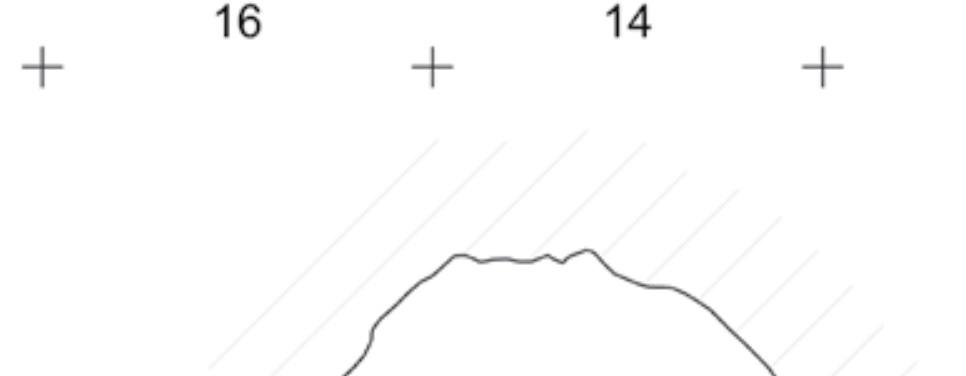

(1)

$\mathrm{D}$

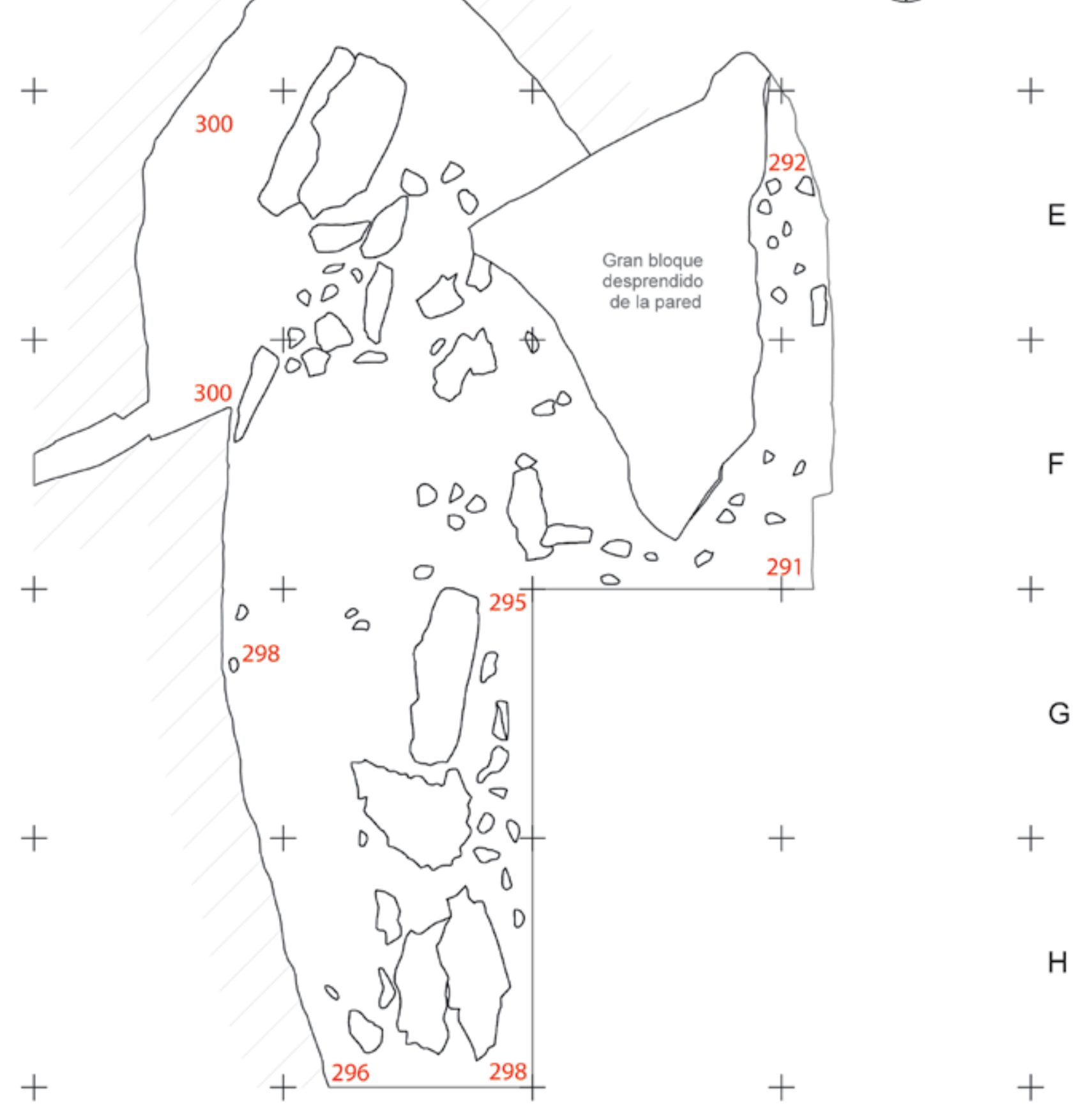

Fig. 18. Restos del gran bloque desprendido de la pared a la entrada de la cueva y zona del entorno tras excavar el lecho 16 (nivel IV) (Dibujo: X. Peñalver/Digitalización: J. Calvo). / Remains of the great block detached from the wall at the entrance of the cave and sorrounding area after excavating the layer 16 (Drawing: X. Peñalver/Digitalisation: J. Calvo). 


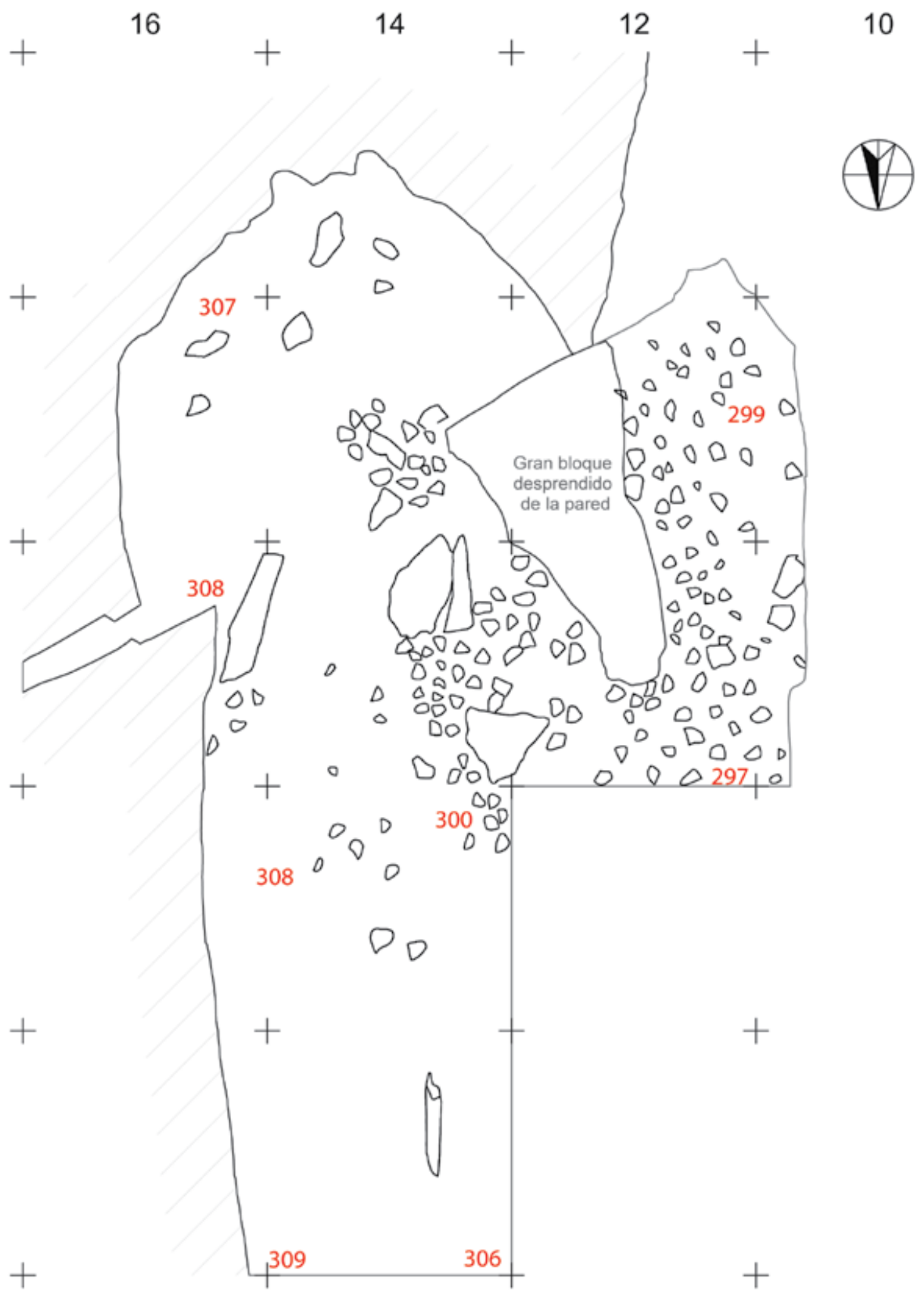

Fig. 19. Restos del gran bloque desprendido de la pared a la entrada de la cueva y zona del entorno tras excavar el lecho 18 (nivel IV) (Dibujo: X. Peñalver/Digitalización: J. Calvo). / Remains of the great block detached from the wall at the entrance of the cave and sorrounding area after excavating the layer 18 (Drawing: X. Peñalver/Digitalisation: J. Calvo). 


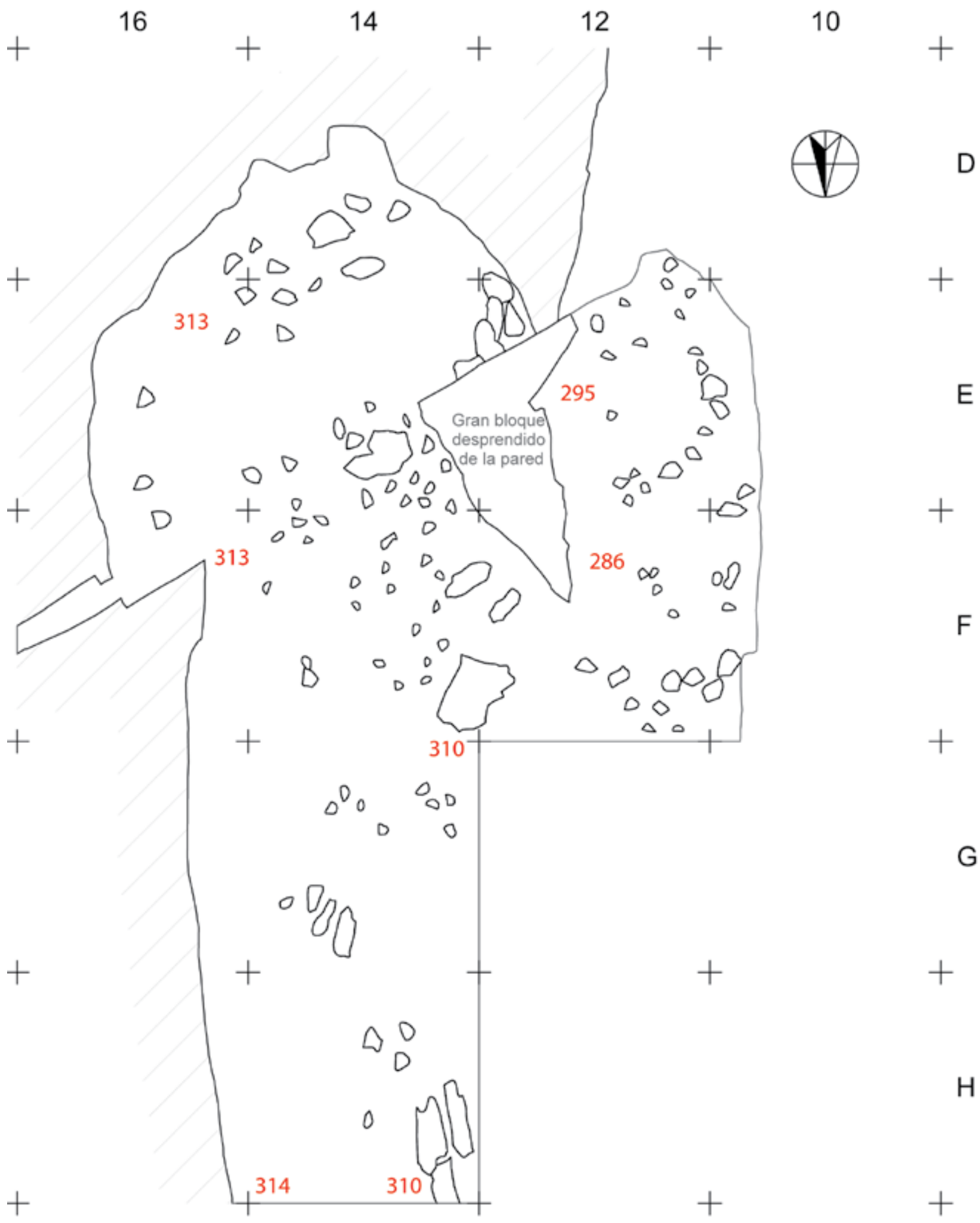

Fig. 20. Restos del gran bloque desprendido de la pared a la entrada de la cueva y zona del entorno tras excavar el lecho 19 (nivel IV) (Dibujo: X. Peñalver/Digitalización: J. Calvo). / Remains of the great block detached from the wall at the entrance of the cave and sorrounding area after excavating the layer 19 (Drawing: X. Peñalver/Digitalisation: J. Calvo). 


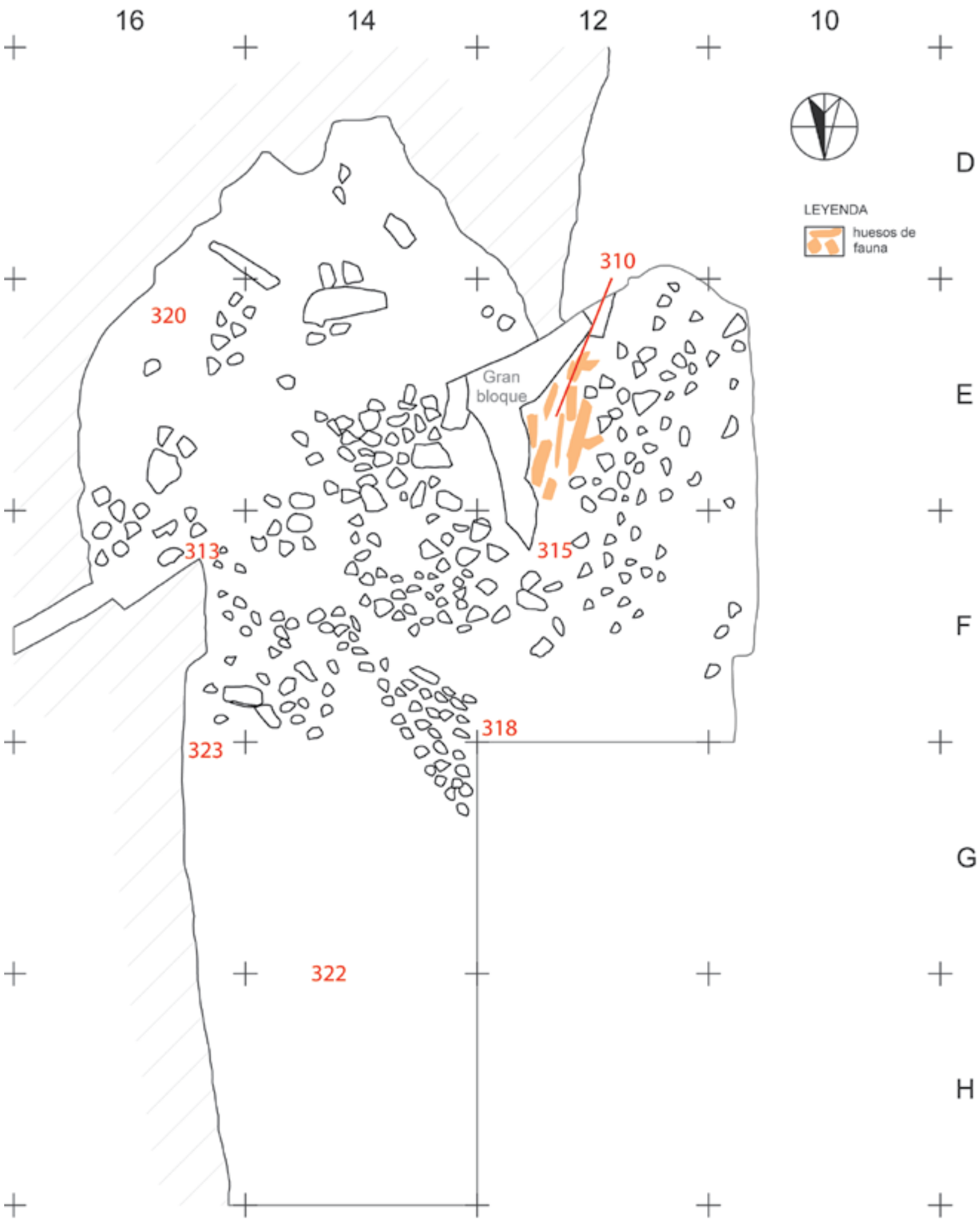

Fig. 21. Restos del gran bloque desprendido de la pared a la entrada de la cueva y zona del entorno tras excavar el lecho 21 (nivel IV). Se aprecia concentración de fauna antes aplastada por el bloque (Dibujo: X. Peñalver/Digitalización: J. Calvo). / Remains of the great block detached from the wall at the entrance of the cave and sorrounding area after excavating the layer 21. It can be seen a concentration of fauna squashed by the block (Drawing: X. Peñalver/Digitalisation: J. Calvo). 
Fig. 22. Zona de entrada a la cueva, antes ocupada por el gran bloque desprendido, una vez excavado el lecho 21. / Entranceway of the cave, previously occupied by the great block detached, once the layer 21 has been excavated.

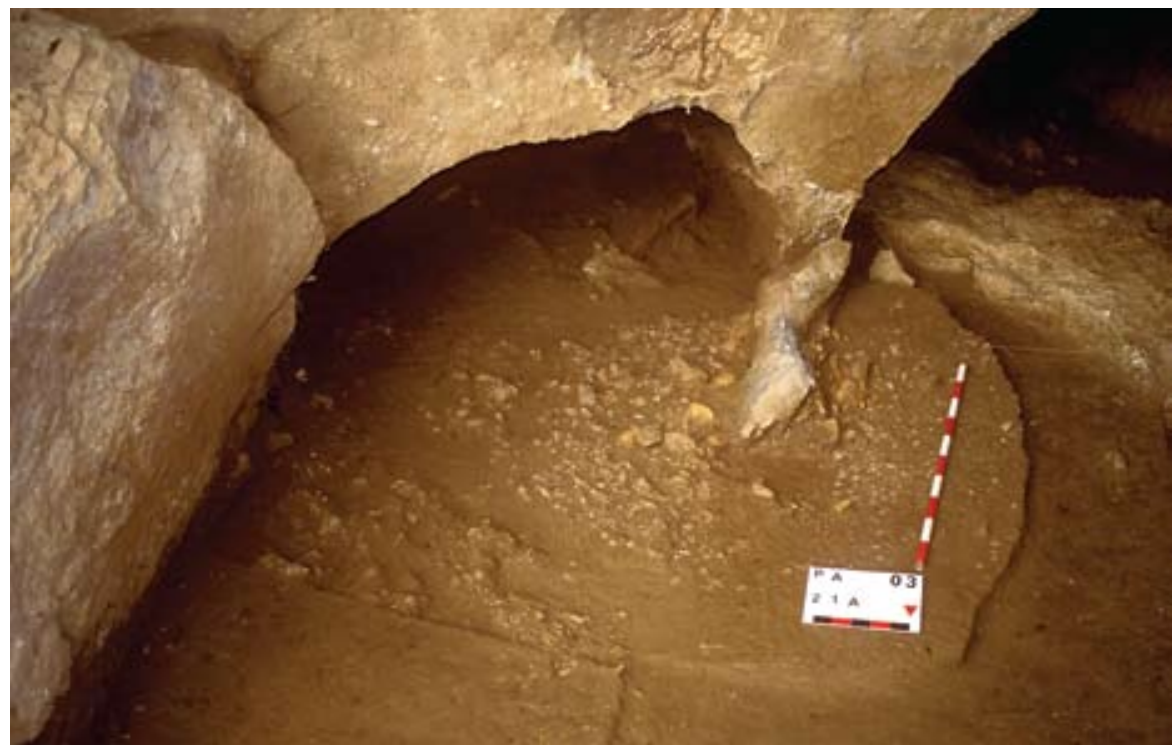

en la banda $G$, que abarca a los cuadros 8, 10 y 12 , y que tiene como fin rebajar esa parte del yacimiento hasta igualarla con el vestíbulo en su parte central. A través de 10 lechos se alcanza el nivel correspondiente al lecho 10 del vestíbulo, ligeramente por encima del nivel de empedrado correspondiente al Magdaleniense Inferior (nivel IV.II). Los dos primeros lechos presentan abundantes piedras de tamaño medio, disminuyendo en el tercer lecho y desapareciendo a continuación, dando paso a una tierra marrón clara más o menos compacta según las zonas.

\section{Ampliación en la zona más exterior del vestíbulo}

Afecta a la banda $\mathrm{H}$ así como al extremo norte de la banda $\mathrm{G}$ (números 10, 12 y parte del 8) y se ha excavado en 10 lechos hasta igualar con el lecho 20 del vestíbulo, correspondiente al Magdaleniense Inferior (nivel IV.III). Los

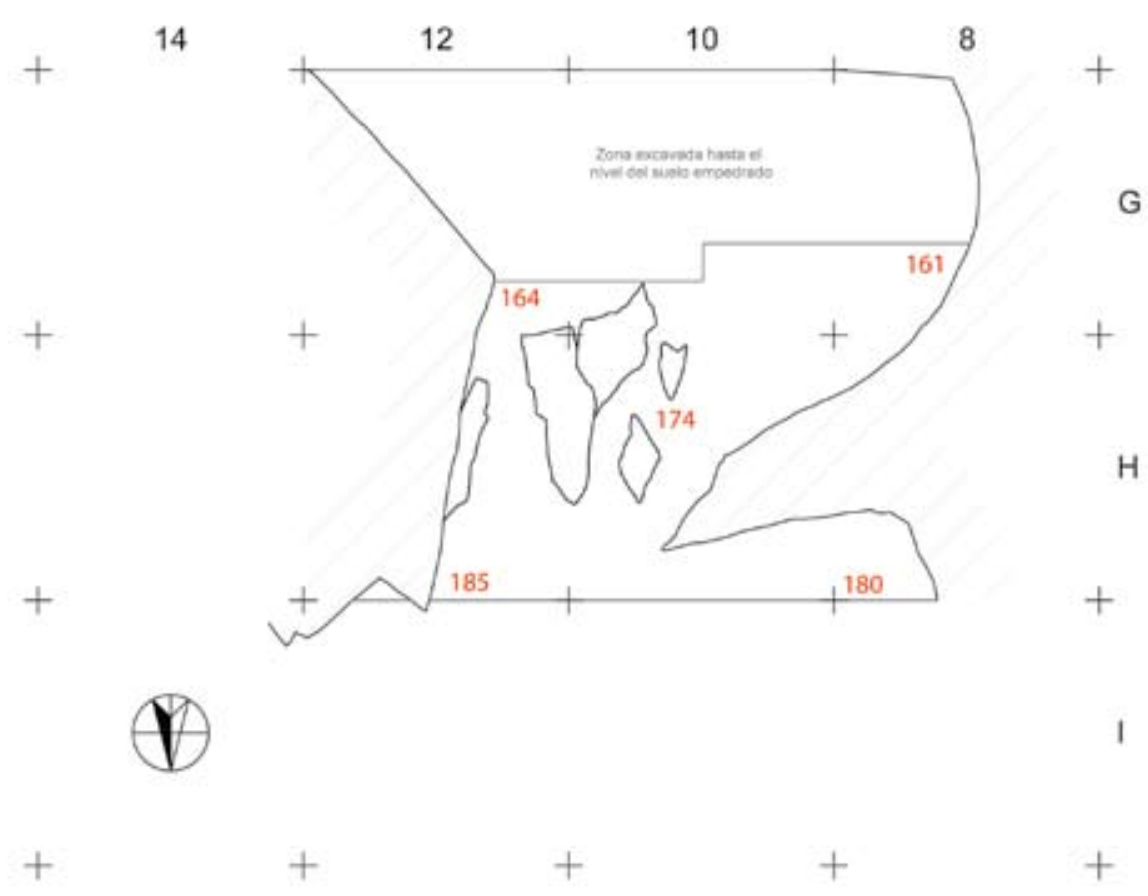

Fig. 23. Zona exterior del vestíbulo tras excavar el lecho 1 (nivel I) (Dibujo: X. Peñalver/Digitalización: J. Calvo). / Outside area of the vestibule after excavating the layer 1 (Drawing: X. Peñalver/ Digitalisation: J. Calvo). 


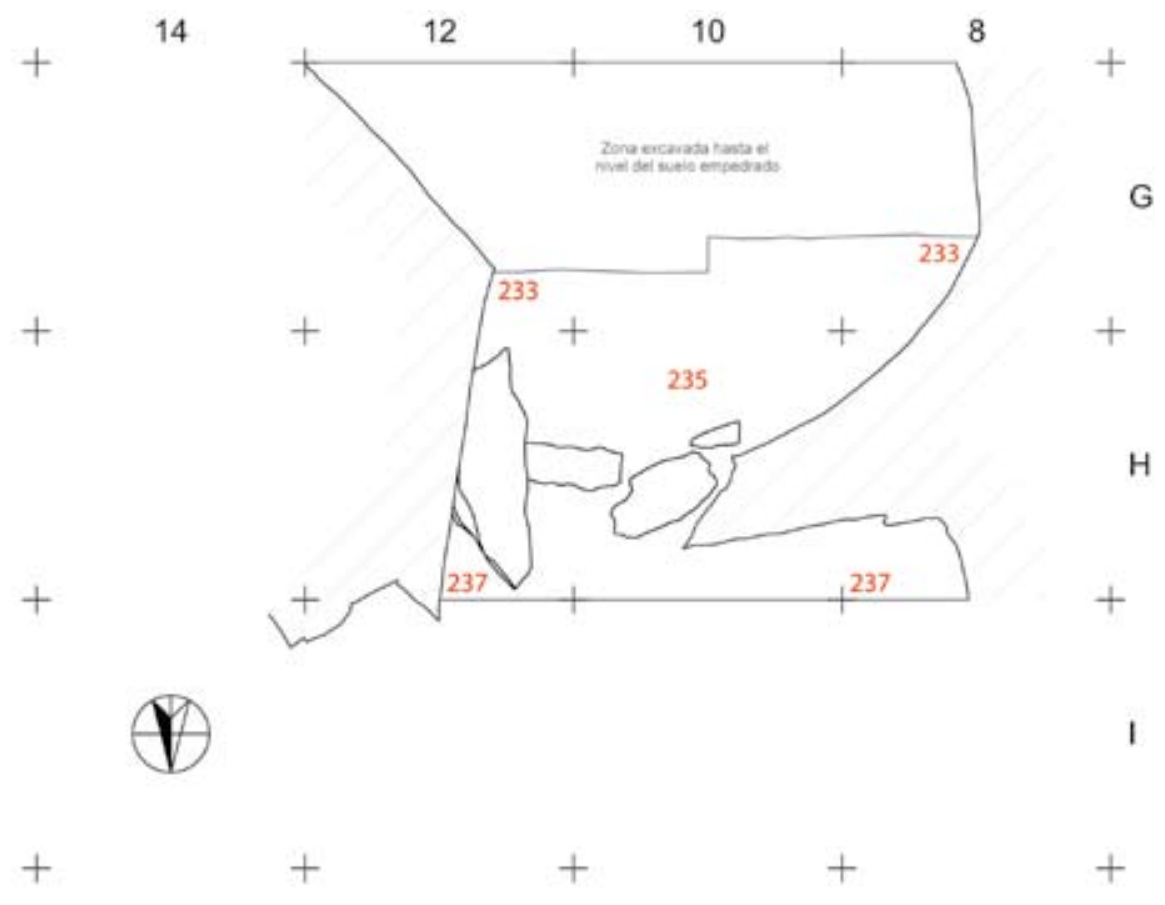

Fig. 24. Zona exterior del vestíbulo tras excavar el lecho 6 (nivel II) (Dibujo: X. Peñalver/Digitalización: J. Calvo). / Outside area of the vestibule after excavating the layer 6 (Drawing: X. Peñalver/ Digitalisation: J. Calvo).

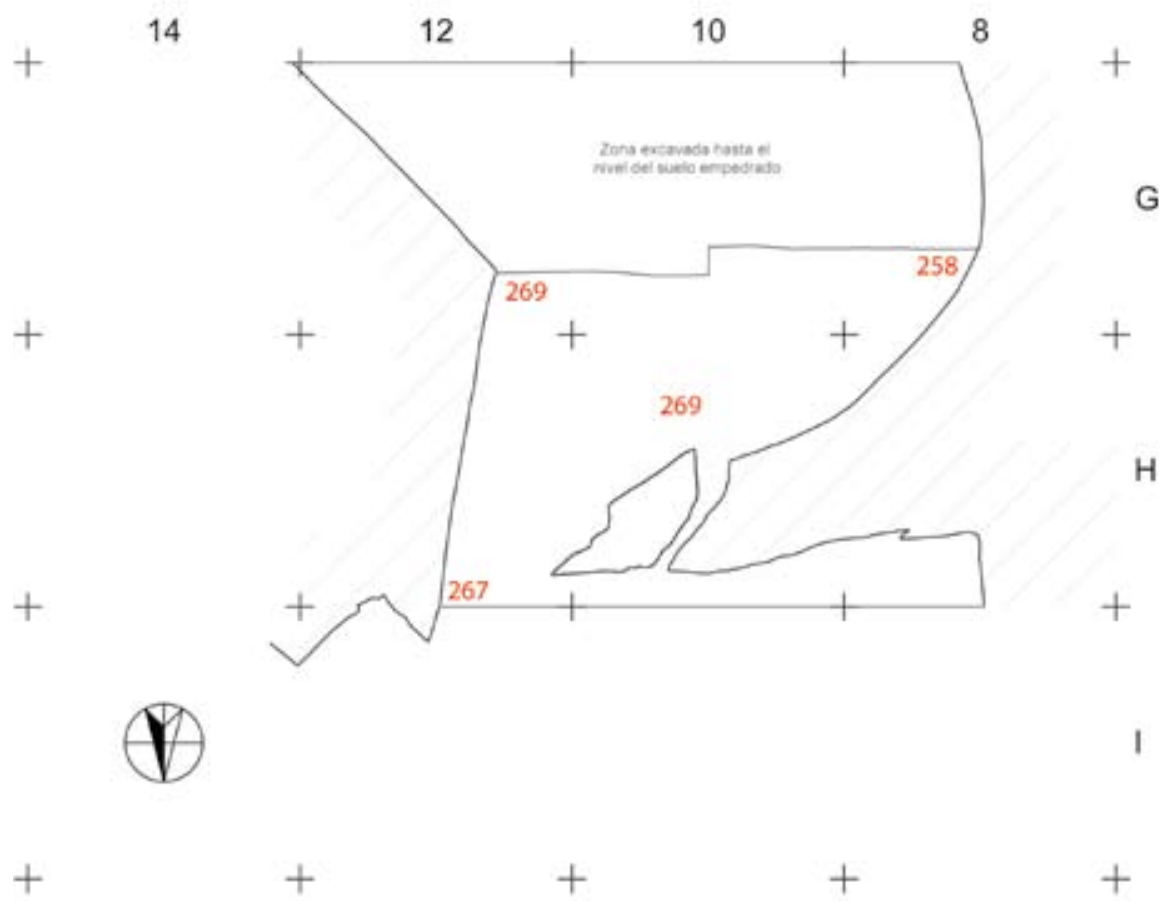

Fig. 25. Zona exterior del vestíbulo tras excavar el lecho 10 (nivel III) (Dibujo: X. Peñalver/Digitalización: J. Calvo). / Outside area of the vestibule after excavating the layer 10 (Drawing: X. Peñalver/Digitalisation: J. Calvo). 
tres lechos más superficiales presentan un sedimento oscuro con piedras de considerables dimensiones (hasta 80 $\mathrm{cm})$; a partir del lecho 4 y hasta el 10, ambos inclusive, el sedimento es en general de color amarillo y la presencia de piedras disminuye progresivamente hasta desaparecer en el último de los lechos (Figs. 23 a 25).

\section{Ampliación de la zona de unión entre el vestíbu- lo y la galería que da acceso a la primera sala interior}

La excavación de esta zona abarca la zona este de la banda A (cuadros 10A, 12A, 10B y 12B), así como la zona sur de la banda B. Se han practicado 9 lechos, hasta igualar el área con el lecho 11 del vestíbulo correspondiente al nivel IV.I del Magdaleniense Inferior.

Se trata de la zona de tránsito entre el área del vestíbulo y el área de la galería que da acceso a la primera sala interior, excavadas e interpretadas cada una de manera diferenciada, aunque el límite de cada una de ellas es difícil de determinar.

Los cuatro primeros lechos están constituidos por una capa de concreción (nivel 0.II) que en ocasiones contiene pequeñas cantidades de tierra marrón y algunas limonitas. Está concreción comienza en esta zona y se extiende por los diferentes espacios interiores de la cueva. Se ha denominado nivel I en la galería de tránsito. Ya en el lecho 5 desaparece la concreción pasando la tierra a tener un color más oscuro y mayor plasticidad; a partir del lecho 8 aparecen algunas piedras que se hacen más abundantes en el 9.

\subsubsection{Estratigrafía general del vestíbulo}

Como se ha explicado al principio del capítulo, las ampliaciones realizadas en la excavación del vestíbulo nos obligan a establecer una correspondencia entre los lechos de cada una de ellas y los definidos en la zona central de este espacio que se ha tomado como base. Estas correspondencias se detallan en la tabla 1.

En total, en el vestíbulo, se han excavado 48 cuadros correspondientes a las bandas con números 3, 1, 2, 4, 6, $8,10,12,14$ y 16 y a las letras A, B, C, D, E, F, G y H. Se han diferenciado en el vestíbulo un total de seis niveles, agrupando cada uno de ellos los siguientes lechos:

- Nivel 0: Está formado por capas de concreción superficiales detectadas en diferentes partes del vestíbulo, por lo que se han diferenciado en dos subniveles:

- Subnivel 0.I: capa de concreción que, proveniente de la galería noroeste (nivel I), afecta a la parte noroeste del vestíbulo.

- Subnivel 0.Il: capa de concreción procedente de la galería que da acceso a la primera sala interior (nivel I).

- Nivel l: comprende desde el lecho superficial al lecho 3 , ambos inclusive y se divide en dos subniveles.
- Subnivel I.I: está formado por el lecho 1.

- Subnivel I.II: está constituido por los lechos 2 y 3.

- Nivel II: abarca la estratigrafía comprendida entre el lecho 4 y el lecho 8, ambos inclusive y se subdivide en dos niveles:

- Subnivel II.I: formado por los lechos 4 a 8.

- Subnivel II.II: se corresponde con una capa de concreción debajo del subnivel II.I.

- Nivel III: comprende del lecho 9 al lecho 10, ambos inclusive.

- Nivel IV: lo conforman los lechos incluidos entre el 11 y el 20, ambos inclusive y se divide en tres subniveles.

- Subnivel IV.I: está formado por el lecho 11.

- Subnivel IV.II: lo constituye el lecho 11 bis, correspondiente a un empedrado de piedras de pequeño tamaño.

- Subnivel IV.III: está formado por el lecho 20.

- Nivel V: abarca del lecho 21 al 26, ambos inclusive y corresponde a un sedimento de tierra.

- Nivel VI: lo forman placas de concreción por debajo del nivel $\mathrm{V}$.

\section{El nivel 0}

Está formado por capas de concreción superficiales detectadas en diferentes partes del vestíbulo, por lo que se han diferenciado en dos subniveles:

\section{Subnivel 0.I}

Está constituido por sucesivas capas de concreción, que en ocasiones se alternan con un sedimento marrón con piedras de tamaño medio. Forma parte de la misma capa del nivel I de la galería noroeste y afecta a la zona noroeste del vestíbulo, concretamente a las bandas $E$ y $F$ de los cuadros 2, 4 y 6.

\section{Subnivel 0.II}

Capa espesa de concreción procedente de la galería que da acceso a la primera sala interior. Su espesor oscila entre 3 y $18 \mathrm{~cm}$ según las zonas.

\section{El nivel I}

La presencia de un orificio (chimenea) en la parte superior del techo del vestíbulo ha facilitado la caída de sedimento desde el exterior, principalmente en la zona central de este espacio (Fig. 27). Esto ha originado un cono de sedimento claramente apreciable antes de comenzar los trabajos de excavación en ese lugar. Este nivel lo conforman 2 subniveles: 


\begin{tabular}{|c|c|c|c|c|c|c|c|c|c|c|c|c|c|c|c|c|c|c|c|c|c|c|c|c|c|c|}
\hline$\gtreqless$ & 0 & - & - & & & & & $=$ & & & & & $\equiv$ & & & & & $\geq$ & & & & & & $>$ & & \\
\hline 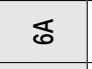 & & $-c$ & $\sim c$ & $m ?$ & $\dot{y} \frac{0}{\dot{y}}$ & & \begin{tabular}{|l}
0 \\
$口$ \\
\end{tabular} & & & & & & & & $\begin{array}{l}\text { N } \\
\text { Nิ } \\
\end{array}$ & & - & & 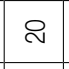 & 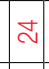 & $\curvearrowright \bar{N}$ & $\approx \approx \begin{array}{c}\sim \\
\stackrel{\infty}{\infty}\end{array}$ & \begin{tabular}{|c|c|c|c}
$\infty$ \\
$\stackrel{\infty}{\infty}$
\end{tabular} & 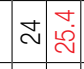 & $\stackrel{\infty}{\sim}$ & $\stackrel{\sim}{N}$ \\
\hline § & & $\stackrel{\sim}{\sim} \mathrm{C}$ & & m: & $\dot{y} \frac{0}{\dot{y}}$ & & $\begin{array}{l}0 \\
\frac{0}{亡} \\
\end{array}$ & & & & & & & & \begin{tabular}{l}
$\Re$ \\
\multirow{1}{*}{} \\
\end{tabular} & & - & & ฉ & & $\bar{\sim}$ & $\approx$ & $\stackrel{2}{\sim}$ & 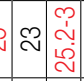 & 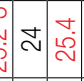 & 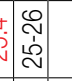 \\
\hline ฐ઼ & & $-c$ & N & $m$ & $\begin{array}{lll}\dot{y} & 0\end{array}$ & & $\wedge$ & & $\infty$ & & & & & a) & 웅 & & - & & 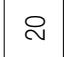 & & $\bar{N}$ & $\approx$ & 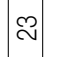 & $\stackrel{\sim}{\sim}$ & $\stackrel{\sim}{\sim}$ & $\stackrel{\infty}{\sim}$ \\
\hline 甼 & & $\stackrel{m}{+}$ & & 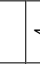 & $+\infty$ & 0 & $\wedge$ & $\infty$ & の) & 음 & & & & & $\frac{7}{1}$ & & - & & $\curvearrowright$ & & $\bar{N}$ & $\approx$ & $\stackrel{\curvearrowright}{\sim}$ & 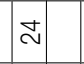 & $\stackrel{2}{\sim}$ & $\stackrel{\leftrightarrow}{\sim}$ \\
\hline ஐறீ & & $-c$ & $\sim c$ & m & $+\infty$ & & 0 & & $\sim$ & $\infty$ & & $\sigma$ & & 으 & ! & & - & & $\therefore$ & & $\bar{N}$ & $\approx$ & $\approx$ & $\stackrel{d}{\sim}$ & $\stackrel{2}{\sim}$ & $\stackrel{\leftrightarrow}{\sim}$ \\
\hline ̊ㅜㅇ윰 & & $-c$ & $\sim c$ & ๓) & $8<0$ & & 0 & & $\sim$ & $\propto$ & & の & & $\hat{c}$ & $\frac{7}{1}$ & $\begin{array}{l}0 \\
\vdots \\
1 \\
1 \\
1 \\
0 \\
0\end{array}$ & - & & $\therefore$ & & $\bar{\sim}$ & $\approx$ & $\approx$ & $\stackrel{\Delta}{A}$ & $\stackrel{2}{\sim}$ & $\stackrel{\bullet}{\sim}$ \\
\hline O & & & & & & & 0 & & 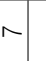 & $\infty$ & & क & & 으 & $\frac{7}{1}$ & & - & & $\therefore$ & & $\bar{\sim}$ & $\approx$ & $\approx$ & $\nexists$ & $\approx$ & 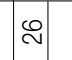 \\
\hline ్․ O & & $-c$ & $\sim c$ & $m$ & $+\infty$ & & 0 & & 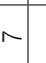 & $\propto$ & & ه & & 으 & $\vec{\nabla}$ & & - & & 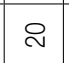 & & $\bar{\sim}$ & $\approx$ & $\cong$ & $\stackrel{\Delta}{\sim}$ & $\stackrel{2}{\sim}$ & $\stackrel{\leftrightarrow}{\sim}$ \\
\hline 으 & & & & r & $-\sim$ & & \begin{tabular}{|l|} 
\\
$m$ \\
$m$
\end{tabular} & & 6 & r & & $\infty$ & & の & & & & 둥 & $\stackrel{1}{\simeq}$ & & 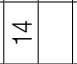 & & $\stackrel{10}{\div}$ & $\nexists$ & $\stackrel{2}{\sim}$ & $\stackrel{\sim}{\sim}$ \\
\hline ลิ & & $-c$ & $\sim c$ & $m$ - & $\checkmark$ & & \begin{tabular}{|l|} 
\\
1 \\
1 \\
\end{tabular} & & $\sim$ & $\propto$ & 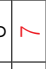 & $\infty$ & & 으 & $\frac{7}{7}$ & $\begin{array}{l} \pm \\
\vdots\end{array}$ & & & $\stackrel{\leftrightarrow}{\simeq} \stackrel{9}{\sim}$ & & 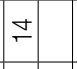 & & $\approx$ & $=\Xi$ & $\stackrel{2}{\sim}$ & $\stackrel{\sim}{\sim}$ \\
\hline 웅 & & $-c$ & $\sim c$ & m. & $+\infty$ & & 0 & & $\wedge$ & $\infty$ & & () & & 으 & 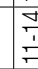 & & - & & ฉ & & $\bar{N}$ & $\approx$ & $\approx$ & $\nexists$ & $\approx$ & $\stackrel{\sim}{\sim}$ \\
\hline 이 & & $-c$ & $\sim c$ & m - & $+\infty$ & & 0 & & 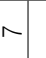 & $\propto$ & & ( ) & & 으 & $\overrightarrow{7}$ & & - & & $\curvearrowright$ & & $\bar{N}$ & $\approx$ & $\stackrel{\sim}{\sim}$ & $=\stackrel{\sim}{\Delta}$ & $\stackrel{\sim}{\sim}=$ & $=\stackrel{\sim}{\sim}$ \\
\hline 응 & & $-c$ & $\sim c$ & m. & $+\infty 0$ & & 0 & & $\sim$ & $\infty$ & & の & & 으 & 守 & 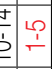 & - & $\begin{array}{l}0 \\
0 \\
0\end{array}$ & $\gtrsim$ & $\mp$ & 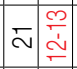 & $\approx \nabla$ & $\stackrel{\infty}{\sim}$ & $\stackrel{\sim}{\sim} \oplus$ & $\stackrel{2}{\sim}=$ & $=\cong$ \\
\hline ลิ & & $-c$ & $\sim c$ & ๓ & 8 & & 0 & & $\wedge$ & $\infty$ & & の & & 으 & $\frac{\vec{j}}{\dot{c}}$ & & & 10 & 尺 & & $\bar{\sim}$ & $\approx$ & $\approx$ & $\stackrel{\Xi}{\sim}$ & $\stackrel{2}{\sim}$ & $\stackrel{\infty}{\sim}$ \\
\hline 으웜 & & & & $\begin{array}{l}m \\
+ \\
+\end{array}$ & i & & $\infty$ & & () & 운 & & $\mp$ & & 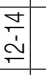 & 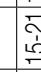 & & & & & & $\approx$ & & $\approx$ & $\stackrel{\Delta}{\sim}$ & $\stackrel{\sim}{\sim}$ & $\circledast$ \\
\hline 山्ల & & & & r & $-\sim$ & & $\left|\begin{array}{l}L \\
m \\
m\end{array}\right|$ & & 6 & N & & $\infty$ & & ه & & & - & 产 & $\simeq$ & $\stackrel{m}{-}$ & $\bar{\sim} \stackrel{\nabla}{\square}$ & & $\stackrel{2}{\sim}$ & $\mathrm{a}$ & $\stackrel{2}{\sim}$ & $\stackrel{\sim}{\sim}$ \\
\hline 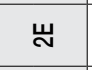 & & - & & & $\sim$ & & $\begin{array}{l}\text { में } \\
\text { ले }\end{array}$ & 104 & $\infty 0$ & & & \begin{tabular}{|l|}
0 \\
0 \\
0 \\
\end{tabular} & & の & & & - & 产 & $\frac{m}{\grave{\dot{a}}}$ & $\infty$ & 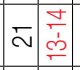 & $\approx$ & $\stackrel{2}{\sim} \cong$ & $\stackrel{a}{4}$ & $\stackrel{2}{\sim}$ & $\stackrel{\sim}{\sim}$ \\
\hline щ & $\stackrel{\sim}{\stackrel{1}{\sim}}$ & - & & & $\sim$ & $v$ & $\checkmark$ & 0. & 10 & & & $\hat{o}$ & & & & & - & & $\infty$ & o & $\overline{\mathrm{N}}$ & $\approx$ & $\approx$ & 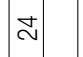 & $\stackrel{2}{\sim}$ & $\stackrel{\sim}{\sim}$ \\
\hline 嵌 & $\frac{0}{i}$ & & & & & & & & & & & & & & $\frac{\pi}{ \pm}$ & & - & & ฉ & & 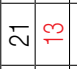 & $\approx$ & $\approx$ & $\nexists$ & $\stackrel{2}{2}$ & $\stackrel{2}{\sim}$ \\
\hline 쓰이 & & $-c$ & $\sim c$ & m. & $+\infty$ & & 0 & & $\wedge$ & $\infty$ & & ( ) & & 으 & $\frac{\pi}{1}$ & 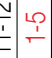 & - & $\begin{array}{l}0 \\
0 \\
0\end{array}$ & $\curvearrowright$ & 후 & $\bar{\sim}$ & $\mp \approx$ & $\stackrel{N}{\sim}$ & $\bullet$ & $\neq \curvearrowright$ & $\stackrel{\oplus}{\sim}$ \\
\hline 崩 & & & & $\begin{array}{c}\infty \\
+ \\
+\end{array}$ & \begin{tabular}{lll} 
\\
\hdashline
\end{tabular} & & $\begin{array}{l}0 \\
0 \\
\infty \\
0\end{array}$ & & & & & & & רِ & 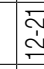 & $\bar{v}$ & & & 尺 & & $\bar{N} \approx$ & $\approx$ & $\approx$ & $\stackrel{\sim}{\sim}$ & $\stackrel{2}{\sim}$ & $\stackrel{\sim}{\sim}$ \\
\hline 岌 & & & & 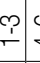 & \& & & $\infty$ & & () & 욱 & & $\mp$ & & 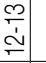 & 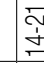 & $\begin{array}{l}\bar{y} \\
\dot{y} \\
\end{array}$ & & & & & $\approx$ & & $\approx$ & $\stackrel{\Delta}{\sim}$ & $\stackrel{\sim}{\sim}$ & $\circledast$ \\
\hline 嵌 & & & & $\stackrel{9}{1}$ & 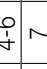 & & $\infty$ & & () & 오 & & $\mp$ & & 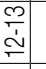 & 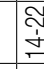 & 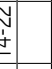 & & & & & & & $\approx$ & 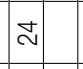 & $\stackrel{\infty}{\sim}$ & 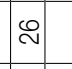 \\
\hline 넹븜 & & & & r. & $-\sim$ & & \begin{tabular}{|l|} 
\\
L \\
\end{tabular} & & 0 & r & & $\infty$ & & ه & & & - & 으 & $\doteq \cong$ & & 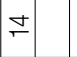 & & $\stackrel{10}{\circ}$ & $\stackrel{d}{d}$ & 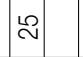 & 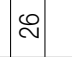 \\
\hline 㫕 & & - & & & $\sim$ & & $\begin{array}{l}\text { मे } \\
\text { ले }\end{array}$ & & $\begin{array}{l}0 \\
1 \\
1 \\
\end{array}$ & N & & $\infty$ & & () & & & - & 으 & $\doteq \cong$ & & 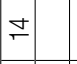 & & 10 & $\stackrel{\Xi}{\sim}$ & $\stackrel{\infty}{\sim}$ & $\stackrel{\sim}{\sim}$ \\
\hline 㞧 & & $-c$ & $\sim c$ & m) & $\triangleleft \succ$ & & & & \begin{tabular}{l} 
co \\
\multicolumn{1}{c}{} \\
\end{tabular} & N & & $\infty$ & 0 & & $\sigma$ & $\gg$ & - & 으 & $\infty$ & $\begin{array}{l}\stackrel{2}{2} \\
\frac{1}{2} \\
\end{array}$ & $\bar{\sim}$ & $\approx$ & $\stackrel{\circ}{\div}$ & $\approx$ & 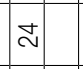 & \begin{tabular}{l}
0 \\
\multirow{N}{*}{} \\
$\stackrel{1}{\sim}$
\end{tabular} \\
\hline 嵌 & & $-c$ & $\sim c$ & m. & $\forall<$ & & 0 & & 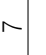 & $\infty$ & 0 & $\infty$ & $\wedge$ & 으 & & & - & & $\curvearrowright$ & $\infty$ & $\bar{N}$ & $\approx$ & $\approx$ & $\stackrel{\Xi}{\sim}$ & $\stackrel{\sim}{\sim}$ & $\stackrel{\sim}{\sim}$ \\
\hline 흔ㅎ & & $-c$ & $\sim c$ & m. & $\forall<$ & & 0 & & $\wedge$ & $\infty$ & & ( ) & & 으 & $\frac{\pi}{1}$ & $\frac{y}{2}$ & - & & $\gtrsim$ & & $\bar{\sim}$ & $\approx$ & $\approx$ & $\stackrel{\searrow}{\sim}$ & $\stackrel{2}{\sim}$ & $\stackrel{œ}{\sim}$ \\
\hline 岕守岌 & & $-c$ & $\stackrel{\substack{2 \\
\sim}}{2}$ & ك & o & & $\infty$ & & () & 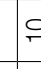 & & $\mp$ & & $\simeq$ & 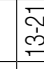 & $\begin{array}{l}\bar{v} \\
\underline{2} \\
\end{array}$ & & & & & $\approx$ & & $\widetilde{N}$ & $\stackrel{\sim}{\sim}$ & $\stackrel{\sim}{\curvearrowright}$ & $\stackrel{\sim}{\sim}$ \\
\hline ত & & & & $-c$ & $\sim m$ & $\circ \sim$ & $\checkmark$ & 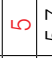 & 官 & $\infty$ & 0 & o & $\wedge$ & 으이 & $0 \simeq$ & $v \infty$ & - & & 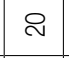 & 우 & $\bar{\sim}$ & $\approx$ & $\approx$ & $\stackrel{\Delta}{d}$ & $\stackrel{2}{\sim}$ & $\stackrel{\sim}{\sim}$ \\
\hline 음 & & - & & & $\sim m$ & مه م & $\nabla$ & Lo & 0 r & $\infty$ & 0 & $\infty$ & $\wedge$ & 으 & $0 \simeq$ & $v \infty$ & & & 尺 & 으 & $\bar{N}$ & $\approx$ & $\cong$ & $\stackrel{\Xi}{\sim}$ & $\stackrel{\infty}{\sim}$ & $\stackrel{\sim}{\sim}$ \\
\hline হ্ণ & & 운. & E & $\simeq$ & $\Rightarrow \nabla$ & & $\stackrel{10}{-}$ & & $\stackrel{0}{-}$ & 근 & & $\stackrel{\infty}{-}$ & & 오 & $\begin{array}{l}\text { व } \\
\text { خे } \\
\text { م }\end{array}$ & ثُ & & & & & $\bar{N}$ & $\approx$ & $\cong$ & $\stackrel{d}{\sim}$ & & $\stackrel{\sim}{\circledR}$ \\
\hline 종등포 & & & & & & & $\nabla$ & & \llcorner & $c$ & & $\wedge$ & & $\infty$ & os & 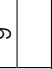 & & & 옹 & & $\bar{\sim}$ & $\approx$ & $\cong$ & 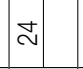 & $\stackrel{2}{\sim}$ & $\stackrel{\sim}{\sim}$ \\
\hline 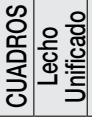 & & $-c$ & & & $\checkmark$ & مـ & $c$ & 0 & 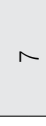 & & $\infty$ & $\sigma$ & & 으 & & $F$ & $\simeq$ & $\div$ & ㄱ & & $\bar{\sim}$ & $\approx$ & $\cong$ & $\stackrel{\sim}{\sim}$ & $\stackrel{2}{\sim}$ & $\stackrel{\sim}{\sim}$ \\
\hline
\end{tabular}



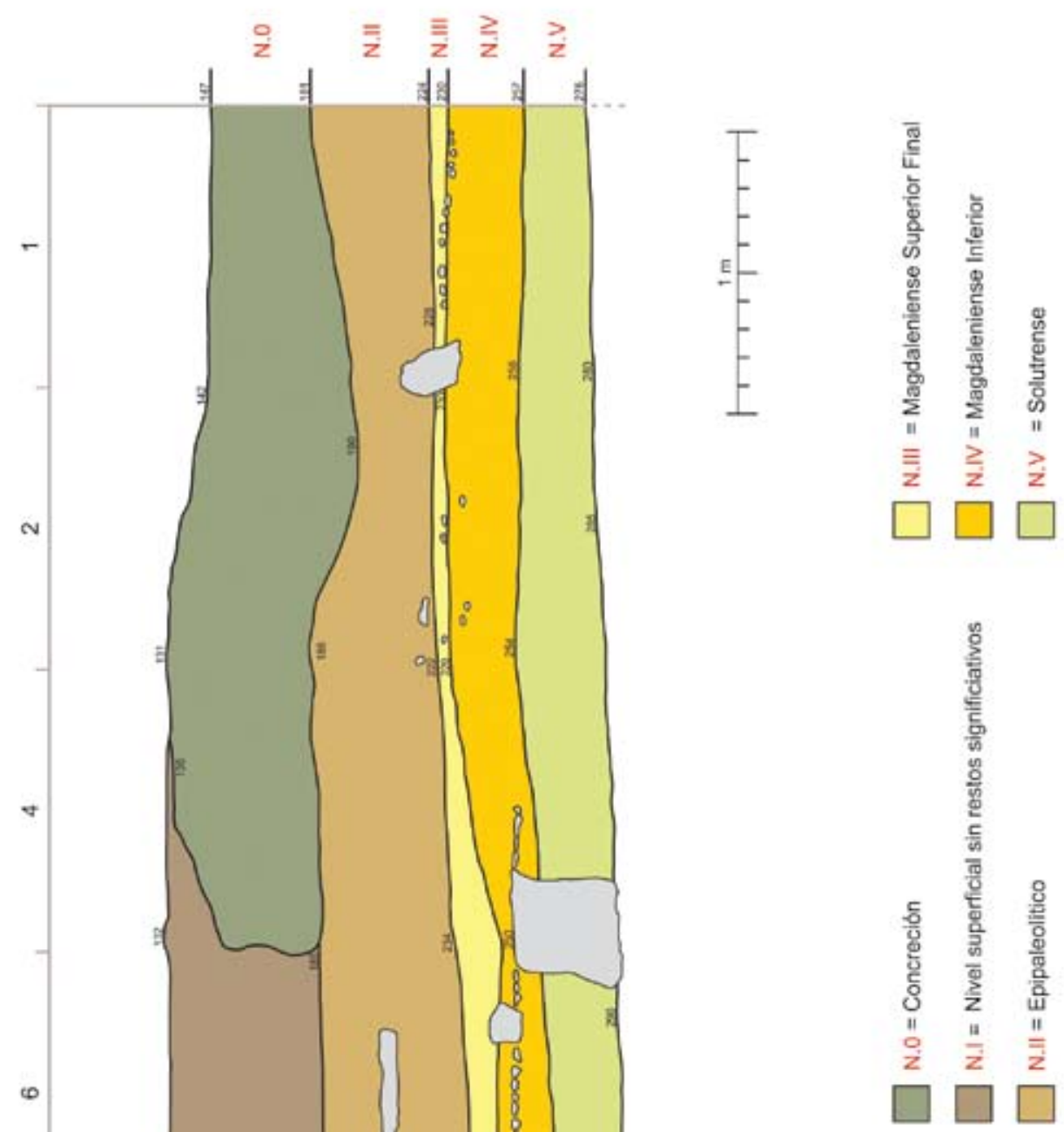

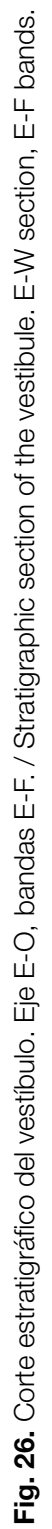




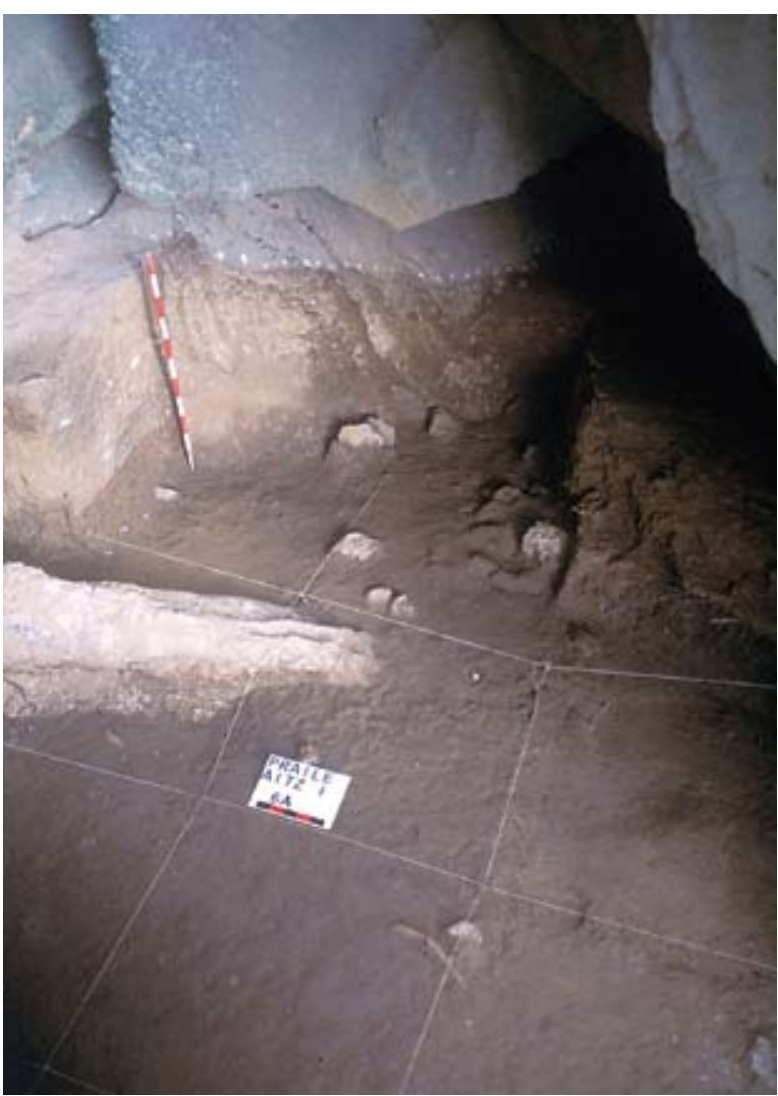

Fig. 27. Aspecto de la zona sur del vestíbulo durante la excavación del nivel I. / View of the southern area of the vestibule during the excavation of the level I.

\section{Subnivel I.I}

Se corresponde con el lecho 1 y tiene una potencia de $5 \mathrm{~cm}$. Presenta una tierra marrón oscura suelta y arenosa, con abundantes restos de micromamíferos.

\section{Subnivel I.II}

Está compuesto por los lechos 2 y 3 . Está formado por un sedimento de color amarillo. La banda B cuenta con una piedra de gran tamaño (más de $90 \mathrm{~cm}$ de longitud) entre los cuadros $6 \mathrm{~B}$ y $8 \mathrm{~B}$. En las bandas $\mathrm{C}$ y $\mathrm{D}$ la tierra se presenta suelta y no contiene piedras. En las bandas $\mathrm{E}$ y $\mathrm{F}$ la tierra cuenta con algunas piedras de tamaño considerable (entre $50 \mathrm{~cm}$ y $1 \mathrm{~m}$ ) en las bandas 6, 8 y 10, así como con placas de concreción en la banda 4 .

\section{El nivel II}

Está formado por los subniveles I y II.

\section{Subnivel II.I}

Se trata del primer nivel con material arqueológico. El sedimento de las bandas B, C y D presenta características similares al nivel anterior, y en las $E$ y $F$ se mantienen las grandes piedras del lecho precedente. El bloque que ocupa gran parte de los cuadros 6B y 8B se prolonga ahora a $6 \mathrm{C}$ y $6 \mathrm{D}$. Las bandas $\mathrm{C}$ y $\mathrm{D}$ cuentan con tierra amarilla de tipo arcilloso muy compacta, salvo en los cuadros más próximos a la pared que es más suelta $(8 \mathrm{C}$ y $10 C$, principalmente).

En este nivel se aprecia una serie de diferencias en los tipos de textura de la tierra en función de las bandas: así, en la zona más próxima a la entrada ésta es suelta; al igual que en la banda $B$; sin embargo, en la banda $D$ es muy compacta.

En el lecho 6 (Fig. 28), en las bandas C y D, el sedimento es suelto y presenta restos de caracoles terrestres blancos y algunos fragmentos de concreción, estos últimos sobre todo en el cuadro 4D.

El gran bloque, anteriormente citado, que ocupa una parte de la galería de acceso a la primera sala interior, aumenta en cada lecho sus dimensiones, afectando en el lecho 7 a los cuadros 6B, 8B, 4C, 6C, 8C, 4D y 6D. Presenta mayor anchura en su extremo sur y en la zona media, siendo más apuntado en su extremo norte. En esta zona, dentro del cuadro 6D existen varias piedras de en torno a $50 \mathrm{~cm}$. Por otra parte éstas son abundantes, con dimensiones de entre 10 y $20 \mathrm{~cm}$, en zonas próximas a la pared de la cueva dentro de los cuadros 10D y 12D.

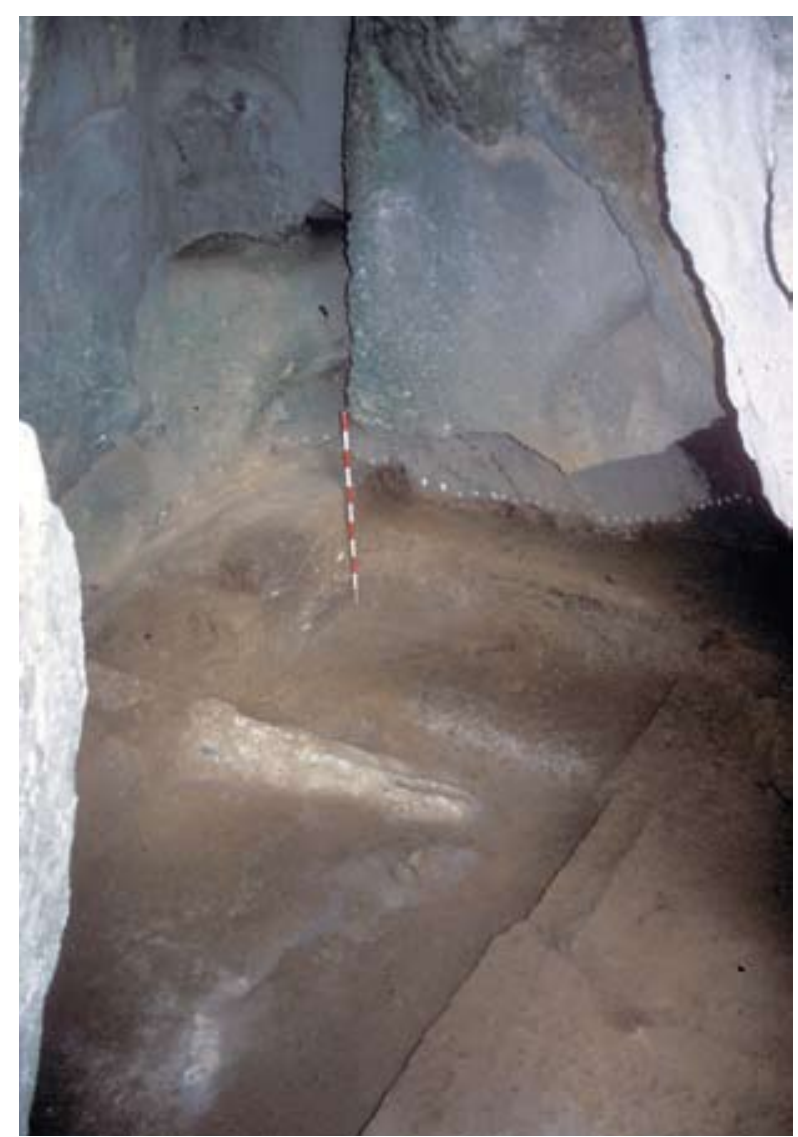

Fig. 28. Excavación del vestíbulo una vez finalizado el lecho $6 . /$ Excavation of the vestibule once completed the layer 6. 
En el lecho 8, la tierra es suelta en la banda $D$ (cuadros 2D, 4D y 8D), así como en la banda B (cuadros 8B y 10B). Las piedras de tamaño medio (entre 20 y $50 \mathrm{~cm}$ ) están presentes en varios de los cuadros $(8 \mathrm{C}, 4 \mathrm{D}, 6 \mathrm{D}$, $10 \mathrm{D}$ y $6 \mathrm{~F})$.

\section{Subnivel II.II}

Está formado por una capa de concreción de considerable potencia que, partiendo de la pared de la cueva en esa zona, se extiende por las bandas 2, 4 y 6 ( $E$ y F) con buzamiento hacia la zona central del vestíbulo.

\section{El nivel III}

En este nivel la coloración amarilla del sedimento es muy similar en todos los cuadros abiertos en el vestíbulo (Fig. 29). La tierra suelta está presente principalmente en la zona oeste del mismo, en cuadros relativamente próximos a la pared de la cueva. En algunos cuadros de las bandas D, E y F (10D, 8E, 10E, 6F y 8F) aparecen piedras calizas blanquecinas de pequeñas dimensiones.

En la base de este nivel se detecta también una masa de concreción amarilla que ocupa en parte los cuadros 4C, 6C, 4D, 6D, 4E y 6E (Fig. 30). Algunas piedras de tamaño medio (en torno a $30 \mathrm{~cm}$ ) aparecen dispersas por algunos cuadros de las bandas B, C, E y F. En los cuadros $8 E$ y $10 E$, en la capa superficial del lecho 10, aparecen numerosas lascas de sílex de pequeño tamaño.

En este nivel se ha localizado un bastón realizado en asta de ciervo con doble perforación correspondiente a la sigla P.A.10D.217.24.

\section{El nivel IV}

Está formado por los subniveles I, II y III.

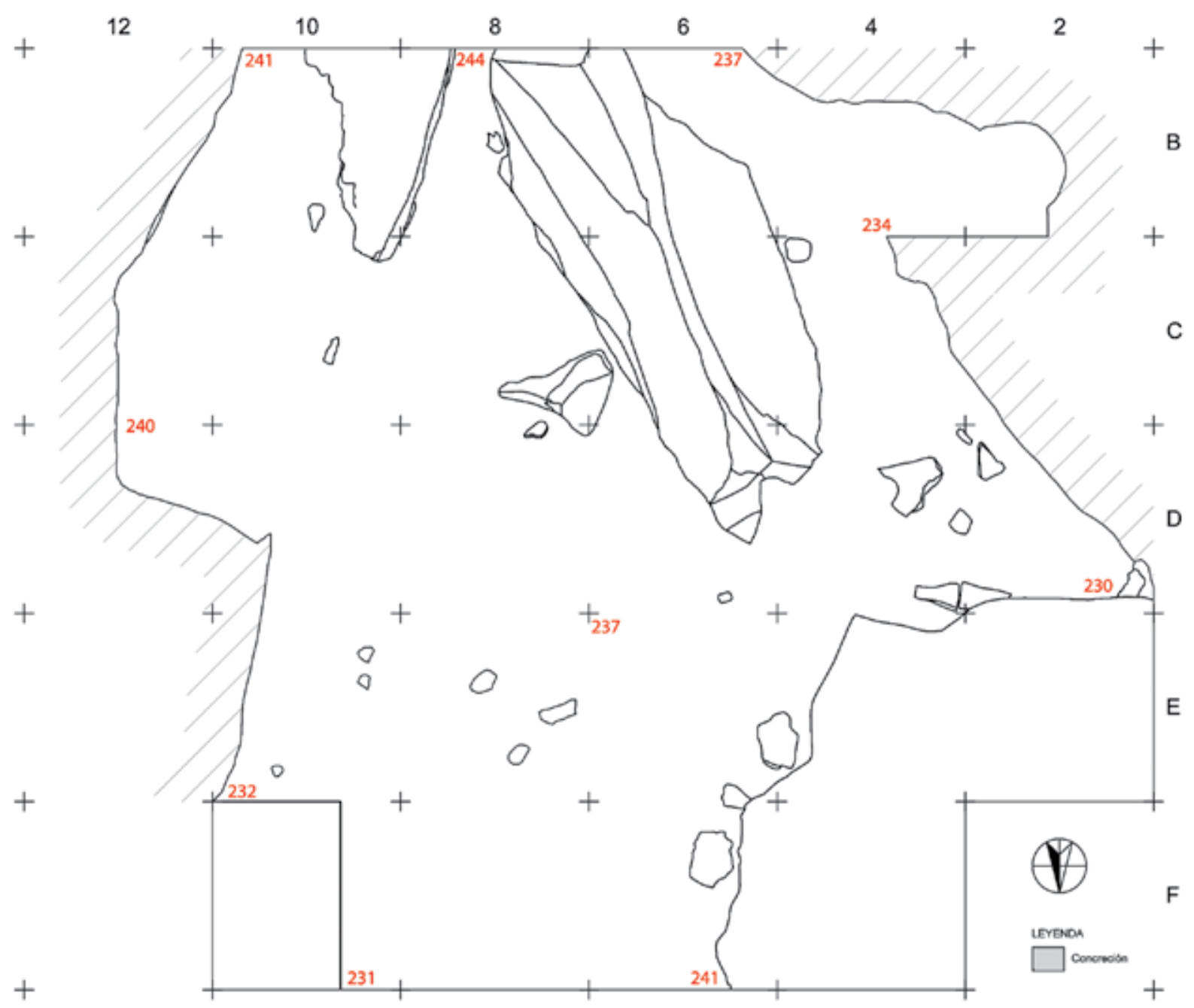

Fig. 29. Plano de la zona sur del vestíbulo tras excavar el lecho 9 (nivel III) (Dibujo: X. Peñalver/Digitalización: J. Calvo). / Plan of the southern area of the vestibule after excavating the layer 9 (Drawing: X. Peñalver/Digitalisation: J. Calvo). 


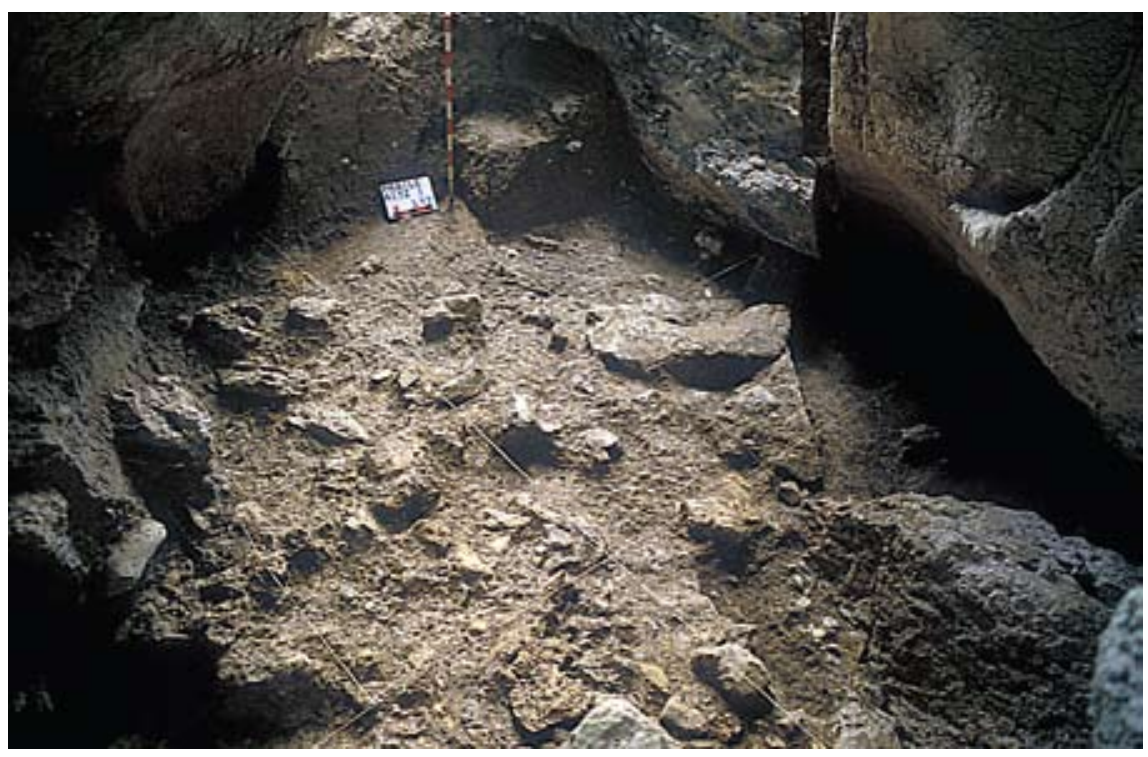

Fig. 30. Vista general del vestíbulo durante la excavación del nivel III. / General view of the vestibule during the excavation of the level III.

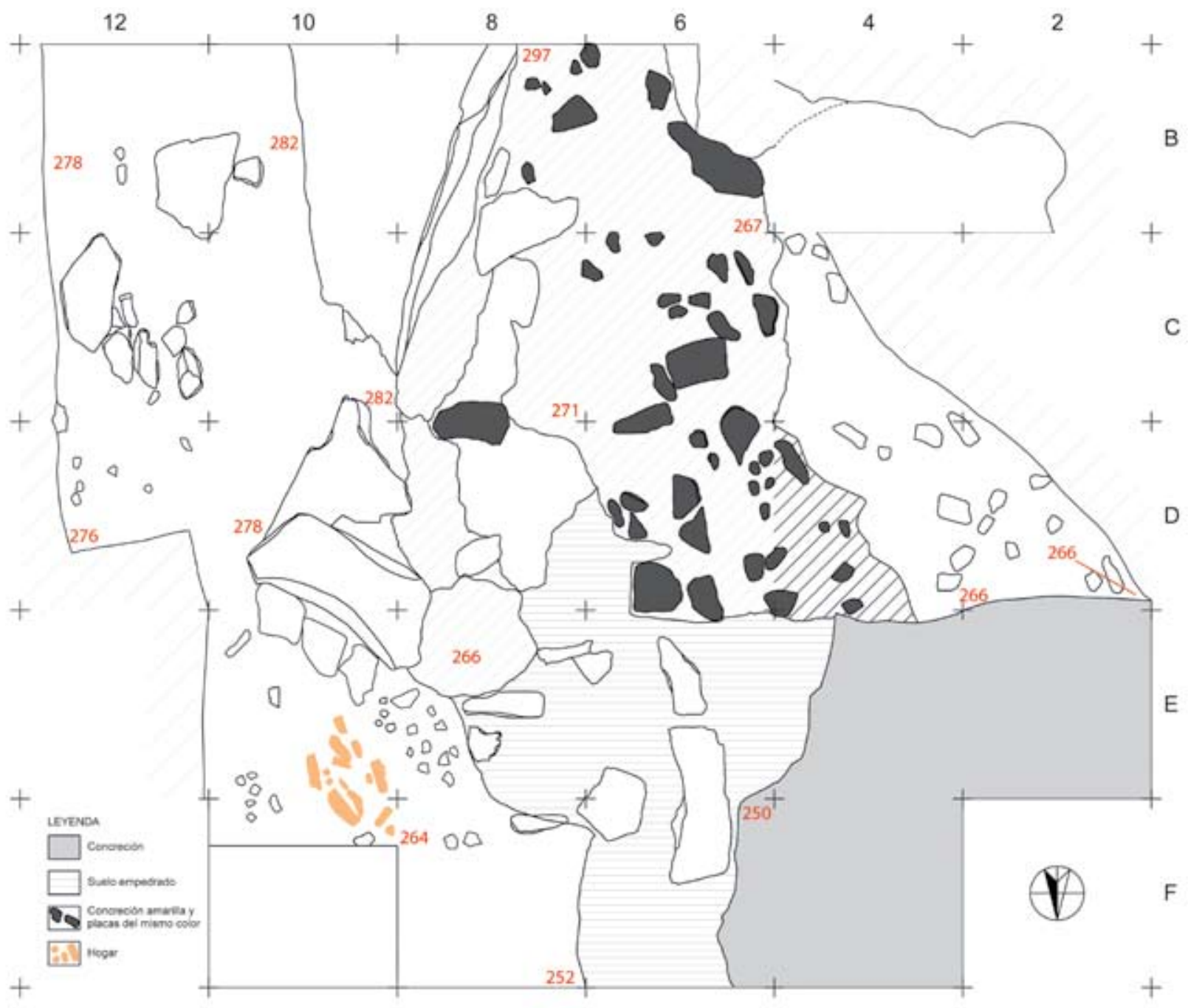

Fig. 31. Plano de la zona central del vestíbulo tras excavar el lecho 11 (nivel IV) (Dibujo: X. Peñalver/Digitalización: J. Calvo). / Plan of the central area of the vestibule after excavating the layer 11 (Drawing: X. Peñalver/Digitalisation: J. Calvo). 


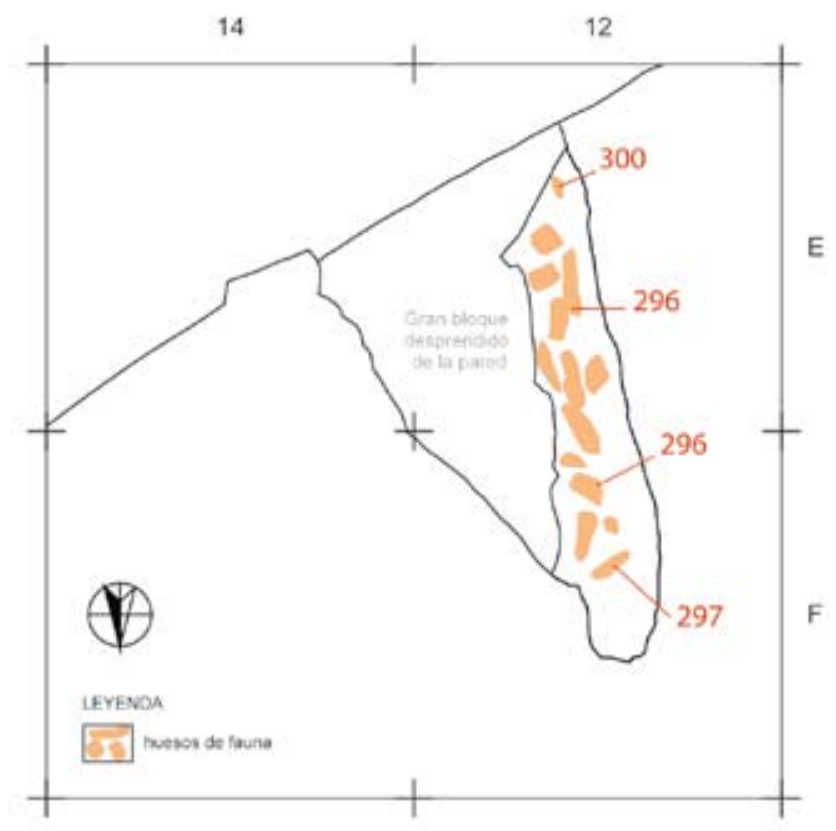

Fig. 32. Concentración de fauna aparecida bajo el gran bloque desprendido de la pared a la entrada de la cueva tras excavar el lecho 11 (nivel IV) (Dibujo: X. Peñalver/Digitalización: J. Calvo). / Concentration of fauna appeared under the great block detached from the wall at the entrance of the cave after excavating the layer 18 (layer 11 unified) (Drawing: X. Peñalver/Digitalisation: J. Calvo).
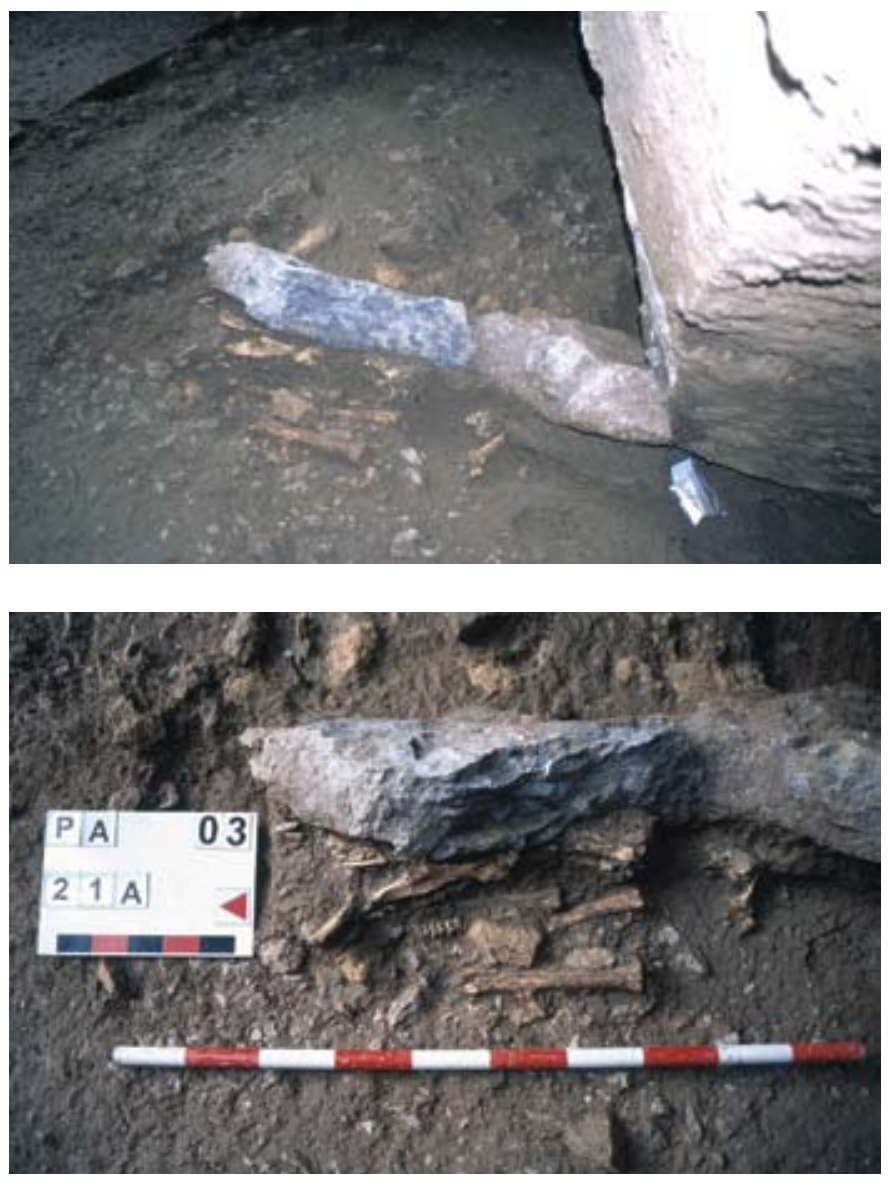

\section{Subnivel IV.I}

Lo constituye el lecho 11, correspondiente al sedimento asociado a un empedrado inmediatamente inferior, formado por una tierra de color amarillo, con tonalidades más oscuras en la banda 12 (cuadros B, C y D). En algunas zonas aparecen calizas de color blanquecino de pequeño tamaño, fundamentalmente en las zonas más próximas a un hogar que se documenta en este subnivel en los cuadros 10E, 10F y parte del 10G (Fig. 31).

Este hogar se relaciona con una serie de grandes bloques calizos que afectan principalmente a la banda 10 (cuadros $D$ y E), y que constituyen la estructura que se ha considerado como asiento y sus piedras de calce que se describirán, junto con el hogar, a continuación.

Es de resaltar la presencia dentro de este lecho de los primeros colgantes líticos y óseos, así como una azagaya decorada (PA.10F.274.32), un fragmento de costilla con incisiones (P.A.6C.271.3) y lápices de ocre (PA.8D.283.12 y PA.8D.279.14), todos ellos pertenecientes al Magdaleniense Inferior.

Figs. 33-35. Diferentes aspectos de la concentración de fauna aplastada por el gran bloque desprendido de la entrada tras su eliminación casi total. / Different views of the concentration of fauna squashed by the great block detached from the entrance after it was almost completely eliminated.

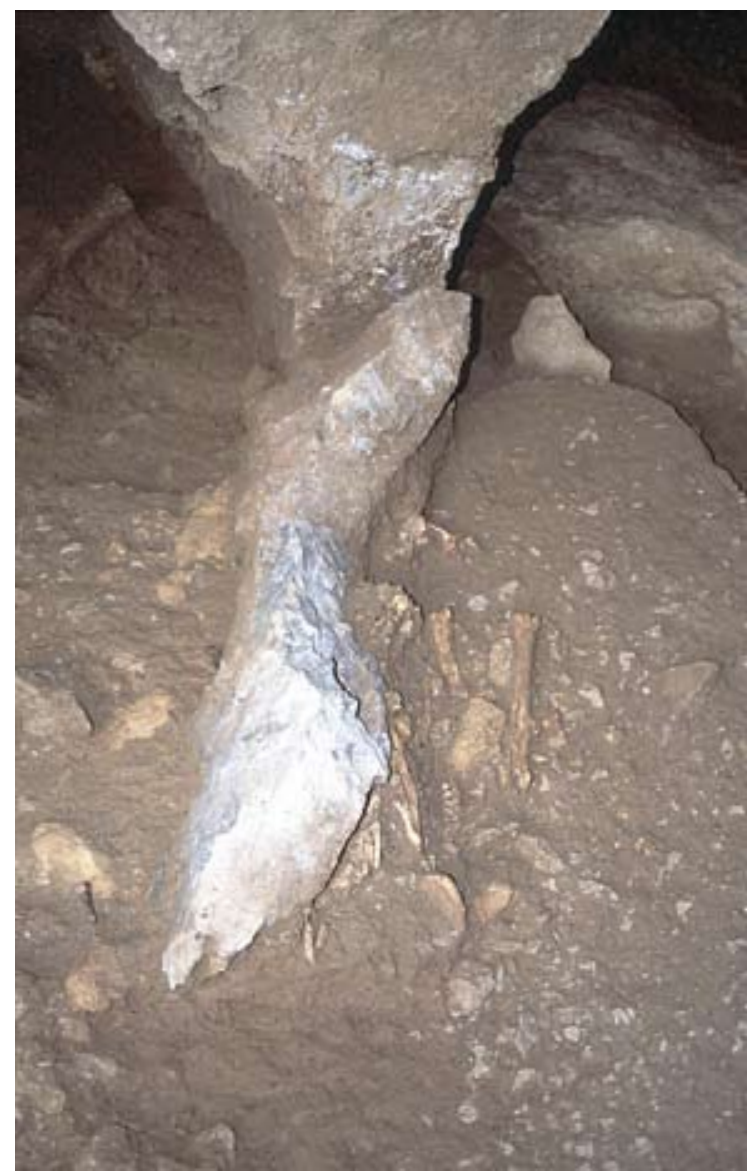




\section{Subnivel IV.II}

Se corresponde con el lecho 11bis. Está formado por pequeñas piedras calizas de entre 5 y $10 \mathrm{~cm}$, que definen un empedrado que se describirá más adelante.

\section{Particularidades de la zona situada bajo el bloque caído}

Como se ha mencionado anteriormente, en la zona correspondiente a la ampliación oculta por el gran bloque desprendido en la entrada de la cavidad, se ha reconocido la misma secuencia para el nivel IV, pero modificada por la presión de la piedra, desplazando hacia abajo el sedimento y sus contenidos en las zonas más próximas a la misma. La parte inferior de esta piedra presenta forma aquillada, por lo que al introducirse en el sedimento existente antes de la caída del bloque ha afectado a parte de los materiales, tal y como se detalla más adelante.

Si bien se detecta el nivel IV.II correspondiente al empedrado en las zonas no directamente anexas al bloque, en el área presionada directamente se ha documentado el nivel IV.I a cotas inferiores al nivel del empedrado. En esta zona se han localizado tres colgantes fabricados en piedra ${ }^{4}$ pertenecientes al Magdaleniense Inferior, de los cuales uno se encontró fragmentado con rotura abrupta en dos mitades, debido a la caída del bloque, hallándose cada mitad a ambos lados de la parte inferior del mismo.

Así mismo, en la zona oeste bajo el bloque ha aparecido una concentración de numerosos huesos de fauna, muchos de ellos en conexión anatómica (Figs. 32 a 35). Este conjunto está situado muy próximo al hogar documentado en esta zona de la cavidad, dentro del nivel IV.I, a una distancia de entre un metro, y metro y medio hacia el este.

\section{Estructuras correspondientes al nivel IV}

Recogemos a continuación de forma destacada tres elementos contemporáneos, correspondientes todos ellos al Magdaleniense Inferior (nivel IV), que definen el vestíbulo, y que, junto a las industrias halladas, dan una idea precisa de la organización espacial de ese lugar (Fig. 40). Se trata del suelo empedrado que cubre la práctica totalidad del vestíbulo, del asiento de piedra ubicado en

\footnotetext{
4 Siglas: P.A.14F.296.252, P.A.12F.289.19, P.A.12F.306.377 y P.A.12F.309.376, estos dos últimos correspondientes a un mismo colgante.
}

una zona de máxima iluminación, próximo a la entrada, y del hogar practicado mediante una cubeta en el suelo, justo delante de ese asiento.

\section{El empedrado del vestíbulo}

En las diferentes zonas del vestíbulo se observa cómo la mayor parte del mismo está ocupado por un suelo empedrado (subnivel IV.II) de escaso espesor y no uniforme en todas las áreas, quizá debido al efecto de las goteras. Lo componen piedras calizas de entre 5 y 10 $\mathrm{cm}$, alternadas esporádicamente con otras de mayor tamaño (Figs. 36 a 40). Presenta un claro buzamiento descendente tanto en dirección este como hacia el sureste. 


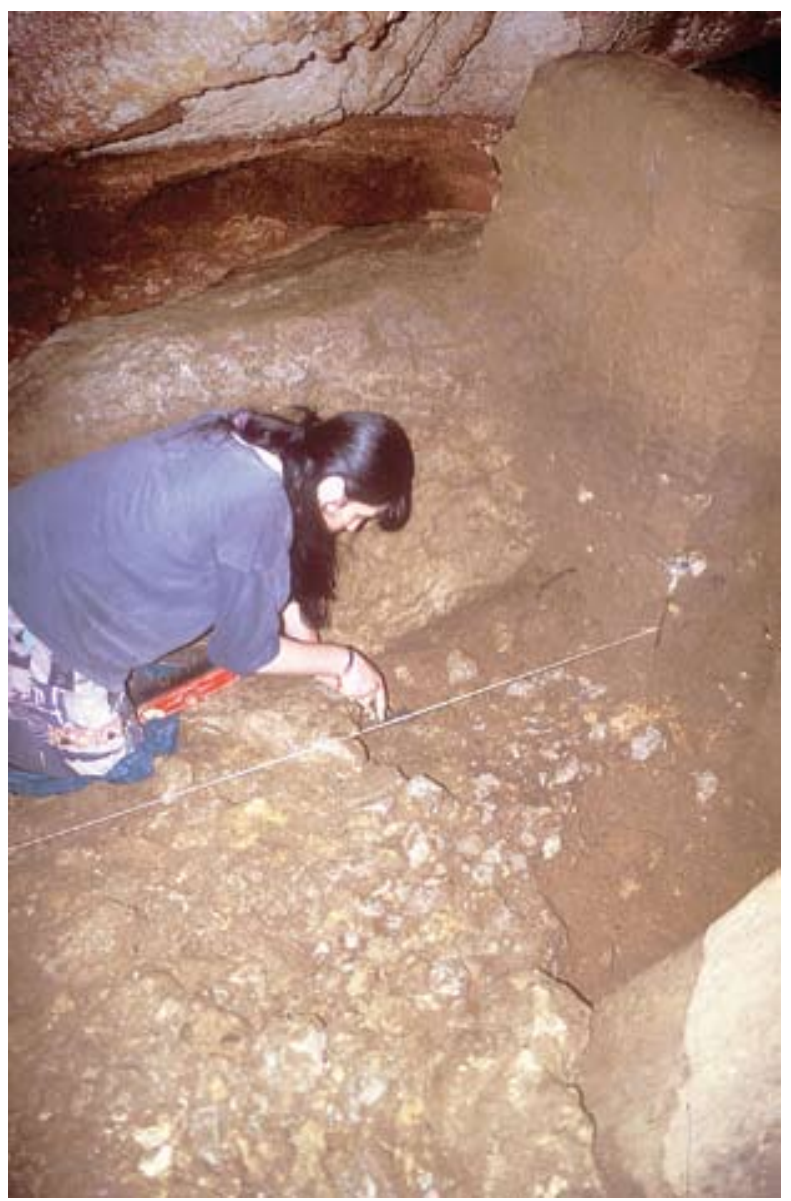

Fig. 38. Detalle de la excavación del empedrado del vestíbulo en el nivel IV. / Detail of the excavation of the vestibule's stone pavement at the level IV.

\section{El hogar del vestíbulo}

Tras la aparición de pequeños fragmentos de carbón y piedras de color blanquecino se detecta un hogar situado a la entrada del vestíbulo, dentro de los cuadros $10 E$ y $10 F$ (Figs. 41 a 47. La tierra es al comienzo marrón, algo grisácea y arenosa, aunque muy compacta en la zona más próxima a la gran roca desprendida de la entrada y menos compacta en la zona que correspondería propiamente al hogar. Abundante cantidad de huesos de microfauna se superpone al nivel de carbones.

Durante la excavación, el hogar va aumentando sus dimensiones, entremezclándose en su interior carbones vegetales, piedras enrojecidas y restos de fauna regularmente distribuidos por toda la superficie del hogar. Una vez definido en su totalidad, presenta forma ovalada con una longitud máxima de 1,50 m y una anchura máxima de en torno a $1 \mathrm{~m}$. Está realizado mediante una suave cubeta en la arcilla amarilla plástica, con una depresión máxima en la zona central de entre 10 y $12 \mathrm{~cm}$. En el extremo norte, es decir, en la parte más alejada del asiento situado al sur del hogar, se localiza una azagaya completa y decorada (PA.10F.274.32).

Este hogar ha sido datado por C14 a través de dos muestras recogidas en el cuadro 10F, obteniéndose los siguientes resultados: $15300 \pm 50$ B.P. ${ }^{6}$ y $15460 \pm 100$ B.P. .

\section{El asiento del vestíbulo}

Se trata de un gran bloque de piedra caliza situado en los cuadros $8 \mathrm{D}, 8 \mathrm{E}, 10 \mathrm{D}$ y $10 \mathrm{E}$, que alcanza una di-

\footnotetext{
${ }^{6}$ PA.10F.269.318 (Beta 162880: esquirla ósea).

${ }^{7}$ PA.10F.269.319 (GrA 20464: esquirla ósea).
}

Existen, sin embargo, dos zonas en donde no ha sido detectado ese nivel de una forma tan clara. La primera se sitúa en la entrada del vestíbulo en la cual se localiza el hogar citado en el subnivel IV.I; esta zona comprende los cuadros $10 \mathrm{E}$ y $10 \mathrm{~F}$ en su totalidad. Una segunda zona se localiza dentro del espacio recogido que se abre entre el asiento, el gran bloque y la pared este de la cavidad, donde han aparecido cinco colgantes ${ }^{5}$; la zona situada más al sur, y que abarca básicamente los cuadros 12A y $12 \mathrm{~B}$, presenta menor cantidad de piedra.

\footnotetext{
${ }^{5}$ Dos de ellos en piedra (P.A.12B.291.50 y P.A.10B.298.28) y tres en hueso (P.A.12C.270.16, P.A.12C.267.15 y P.A.12D.266.27).
}

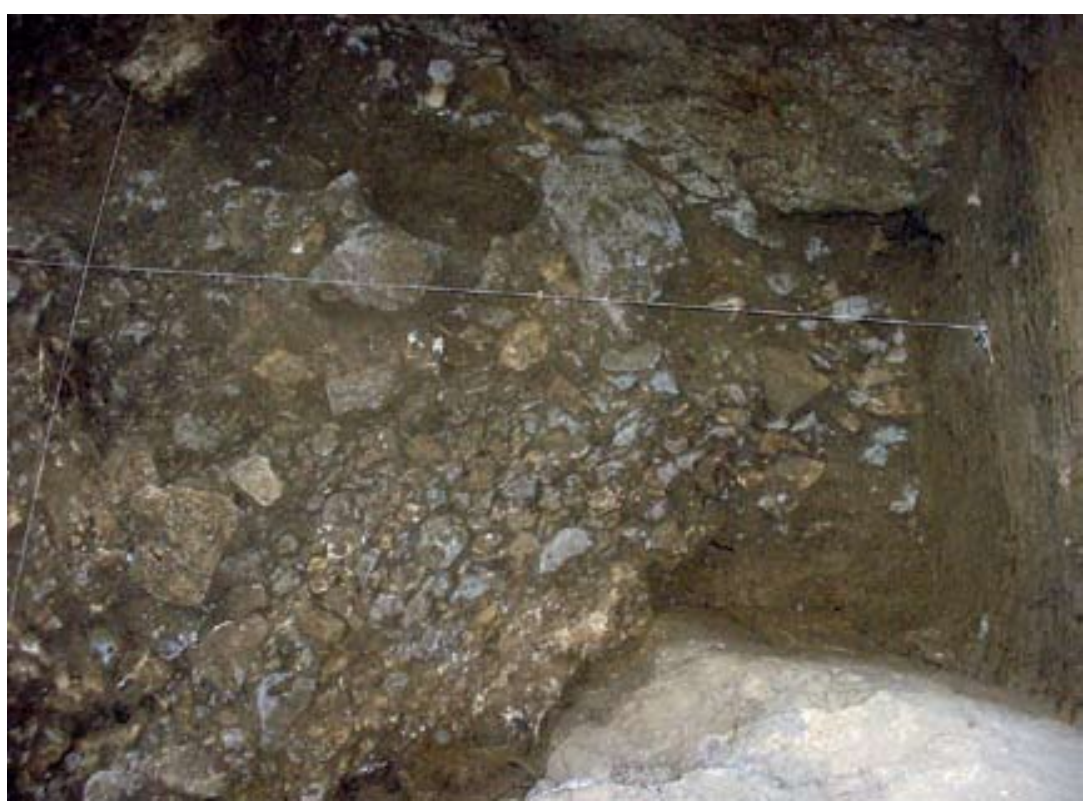

Fig. 39. Detalle de la excavación del empedrado del vestíbulo en el nivel IV. / Detail of the excavation of the vestibule's stone pavement at the level IV. 


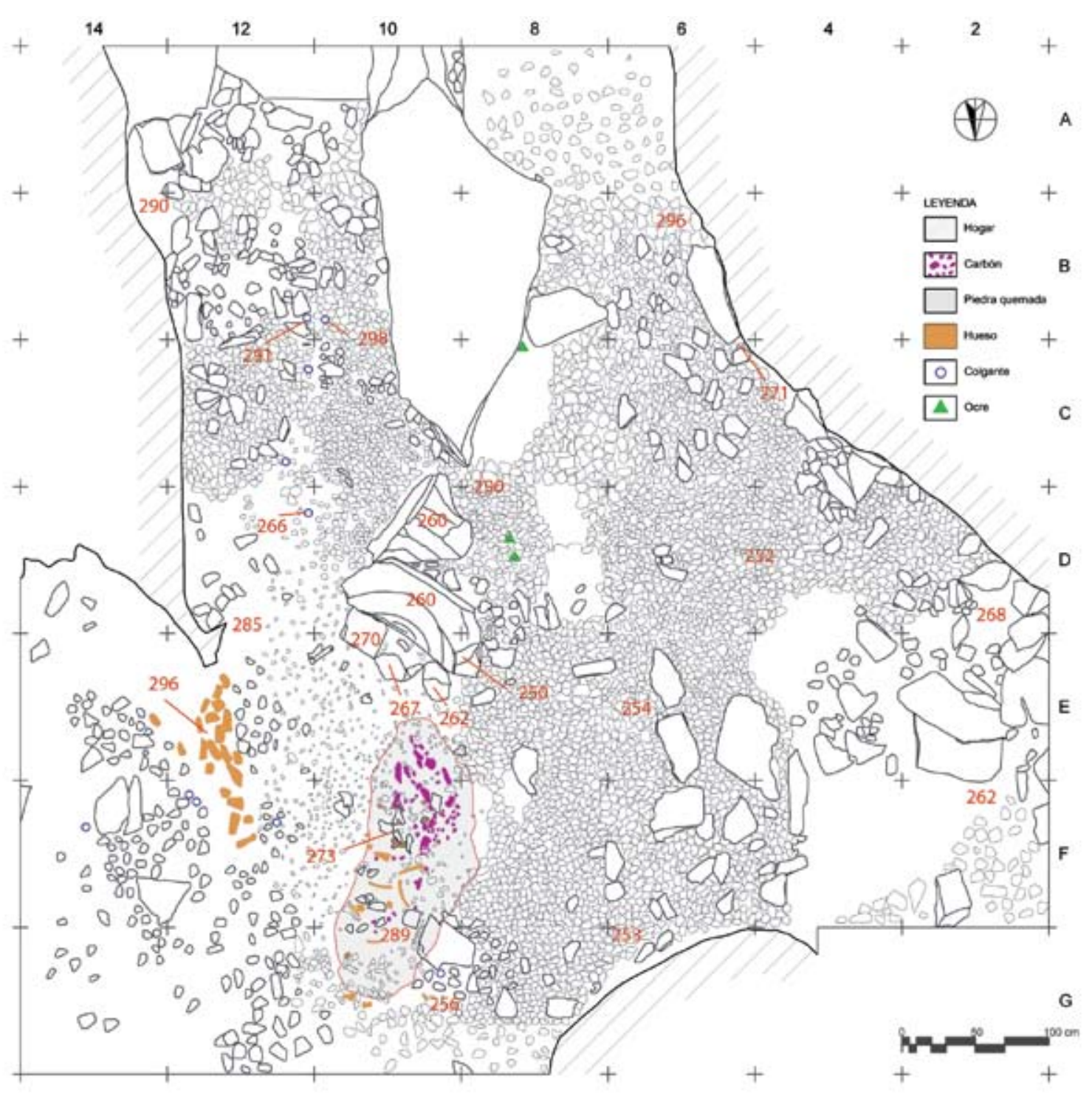

Fig. 40. Plano general del vestíbulo (nivel IV) con la localización del asiento, el hogar, la concentración de fauna bajo la roca y los colgantes (Dibujo: X. Peñalver/Digitalización: Mugarri, J. Calvo). / General plan of the vestibule (Level IV) with the location of the seat, the hearth, the concentration of fauna under the rock and the pendants (Drawing: $X$. Peñalver/Digitalisation: Mugarri, J. Calvo).

mensión máxima de 1,15 m y una anchura de 0,43 m en la mayor parte de su superficie, estrechándose en los extremos; su altura oscila entre los 0,18 y los $0,20 \mathrm{~m}$. En la parte superior, en su zona media presenta una hondonada apropiada para sentarse. Por su extremo sureste está calzado por otro gran bloque de planta triangular de $0,80 \mathrm{~m}$ de lado máximo, y de 0,60 y $0,70 \mathrm{~m}$, los dos restantes (Figs. 48 a 56). Ni la piedra que forma el asiento ni la de calce cuentan con una superficie inferior horizontal, estando las zonas más profundas en contacto con el nivel de empedrado.

En el ángulo este del cuadro 10D, aparece una piedra de calce del asiento de cierta envergadura con forma prismática de $0,30 \mathrm{~m}$ de longitud, que tiene un punto de unión con el asiento; partida en dos trozos in situ, se localiza al mismo nivel del empedrado, si bien su base se sitúa a mayor profundidad.

Por su lado norte cuenta con tres piedras planas de forma aproximadamente cuadrangular de 0,30, 0,28 y $0,26 \mathrm{~m}$ de lado respectivamente, situadas entre el asiento y el hogar próximo, propicias para apoyar los pies al sentarse en el asiento. Están colocadas entre 0,15 y 0,20 $\mathrm{m}$ más bajas que el asiento y ligeramente por encima del nivel del empedrado. 


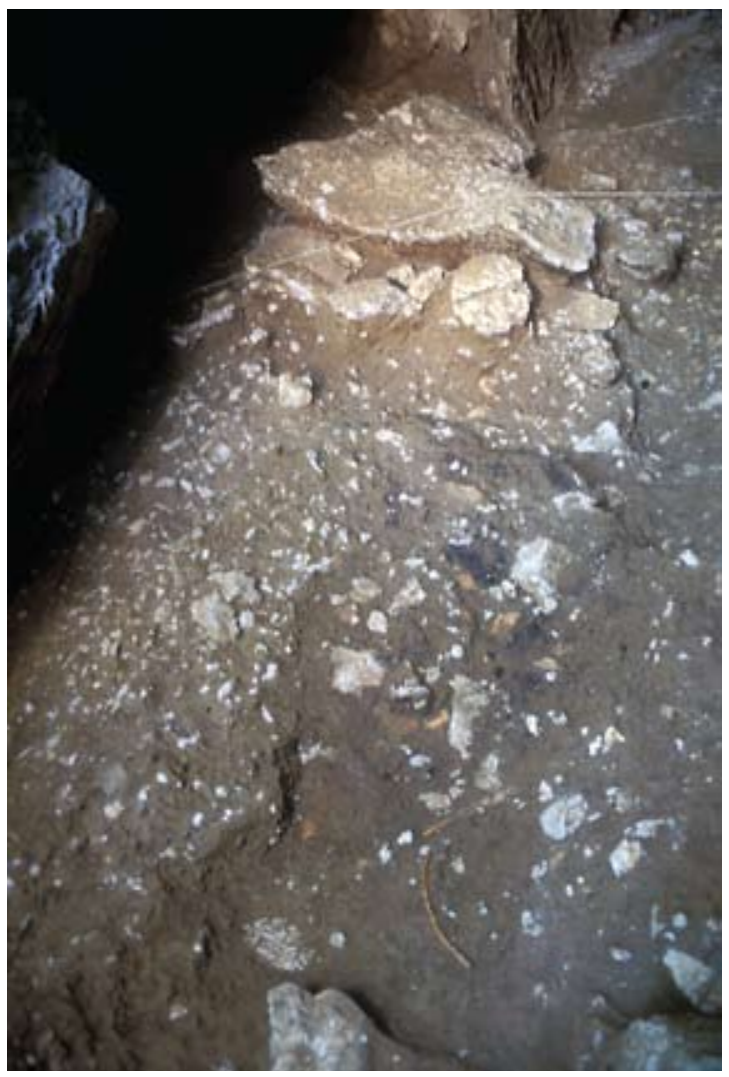

Figs. 41-44. Detalles del hogar del nivel IV (Magdaleniense Inferior) situado en el vestíbulo. / Details from the hearth of the level IV (Lower Magdalenian) located in the vestibule.
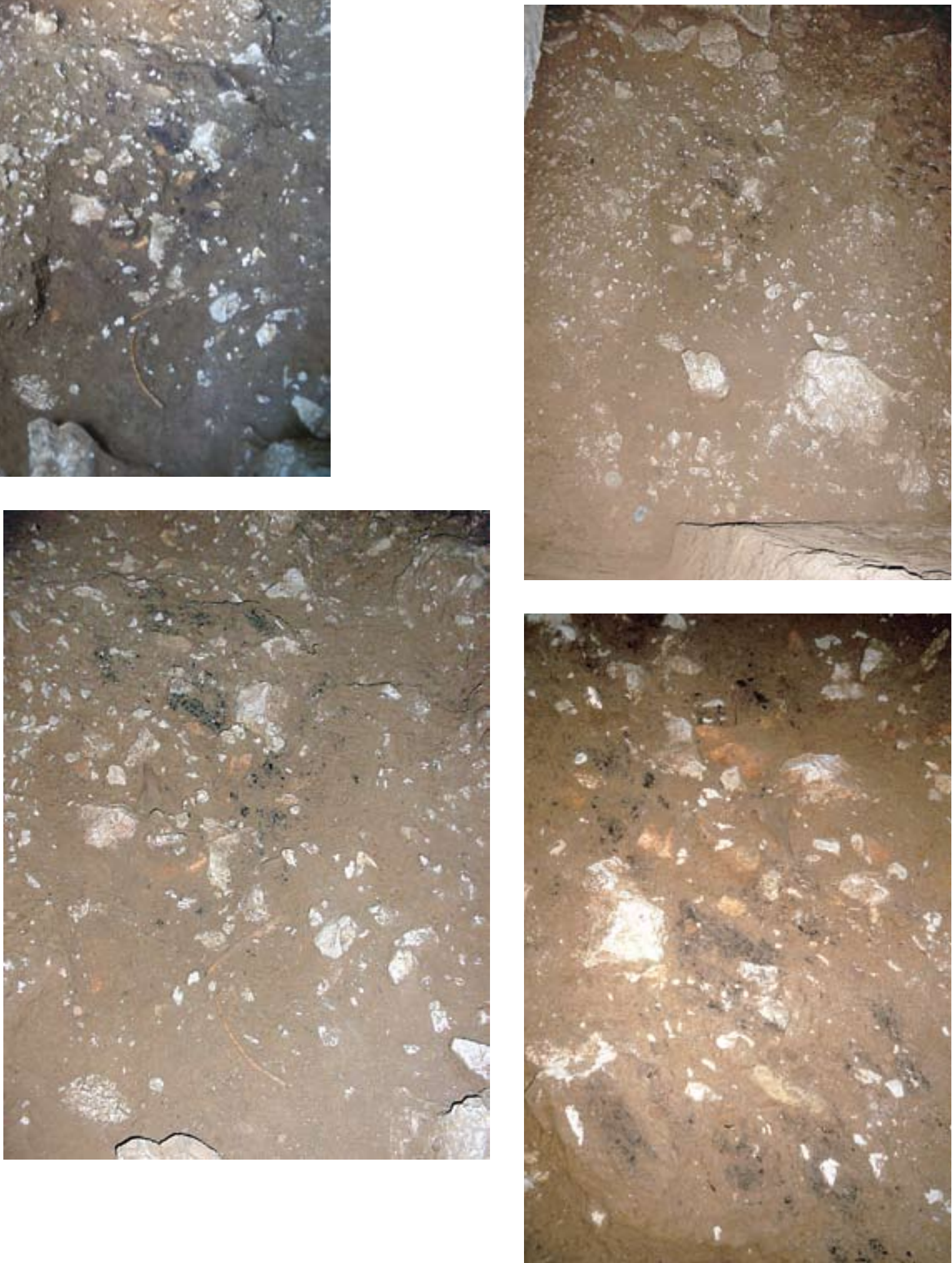
12
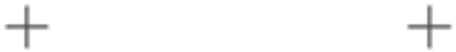

$+$

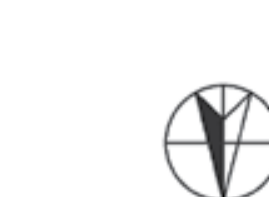

10

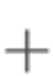

8
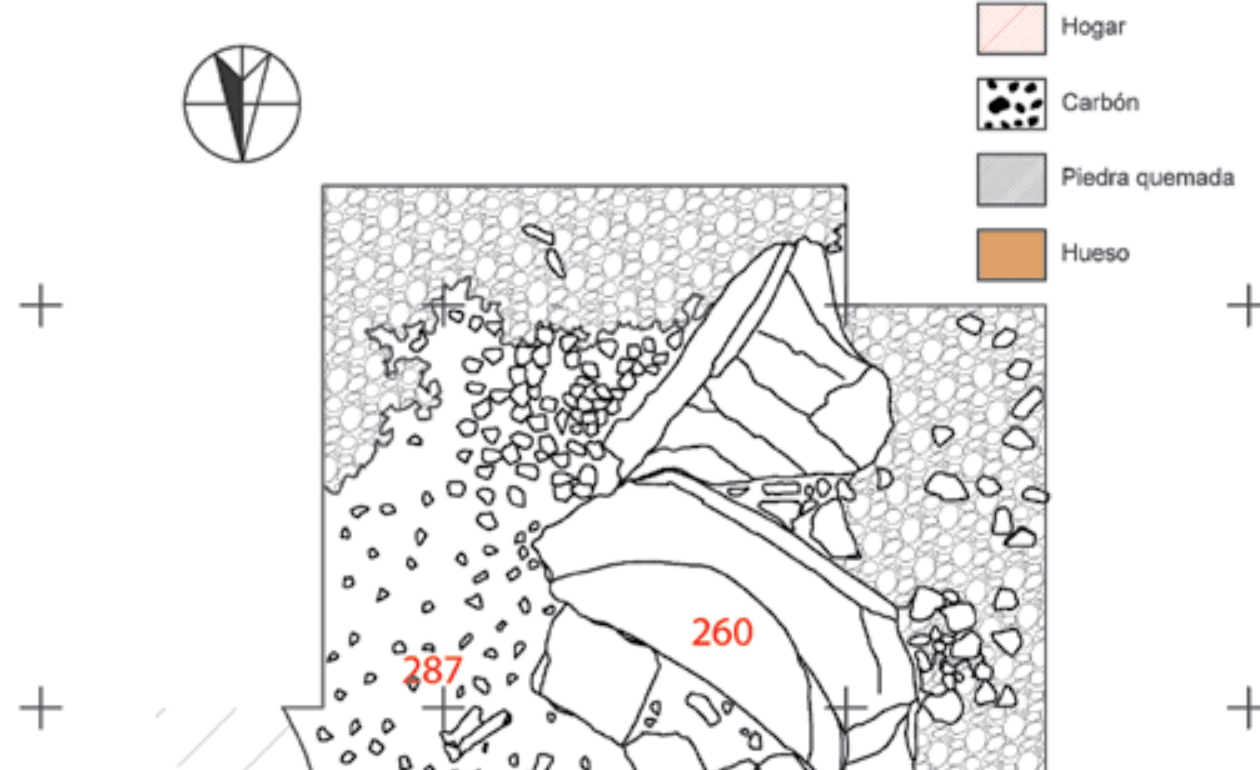

E
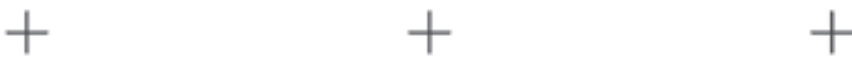

$+$

Fig. 45. Plano del asiento, parte del empedrado y la primera capa del hogar (nivel IV) (Dibujo: X. Peñalver/Digitalización: J. Calvo). / Plan of the seat, part of the stone pavement and the first layer of the hearth (Drawing: X. Peñalver/ Digitalisation: J. Calvo). 
10

8
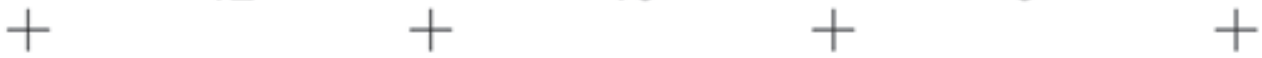

LEYENDA

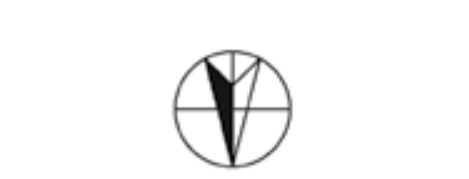

ए Hogar

[:-8arbón
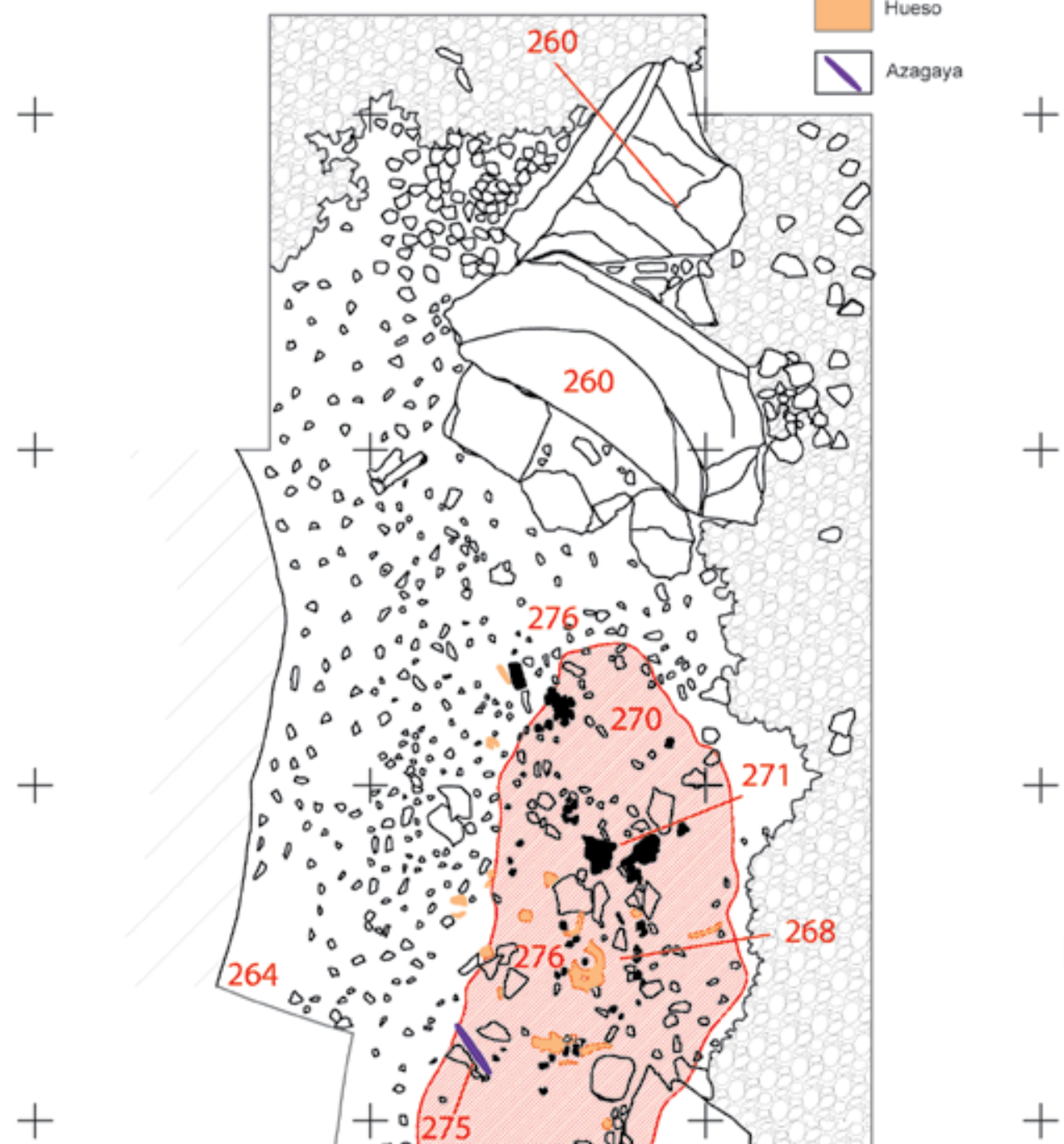

$E$

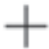

$\mathrm{F}$ 264<smiles>C1C[SiH2]1</smiles><smiles>C1CCOCC1</smiles>

00.000

- 0.5

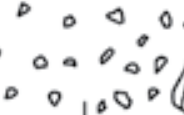
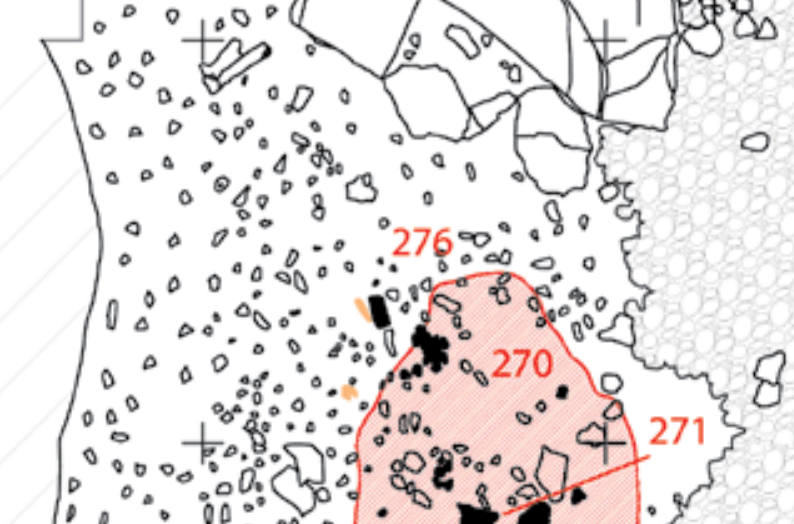

$\because 00: \because 00$ :

$\therefore 8000$

00,0
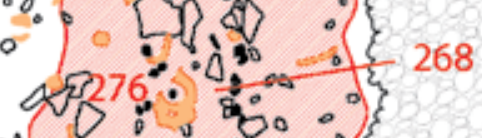

$\Delta 0.00 \%$

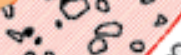

$0.0 \%$
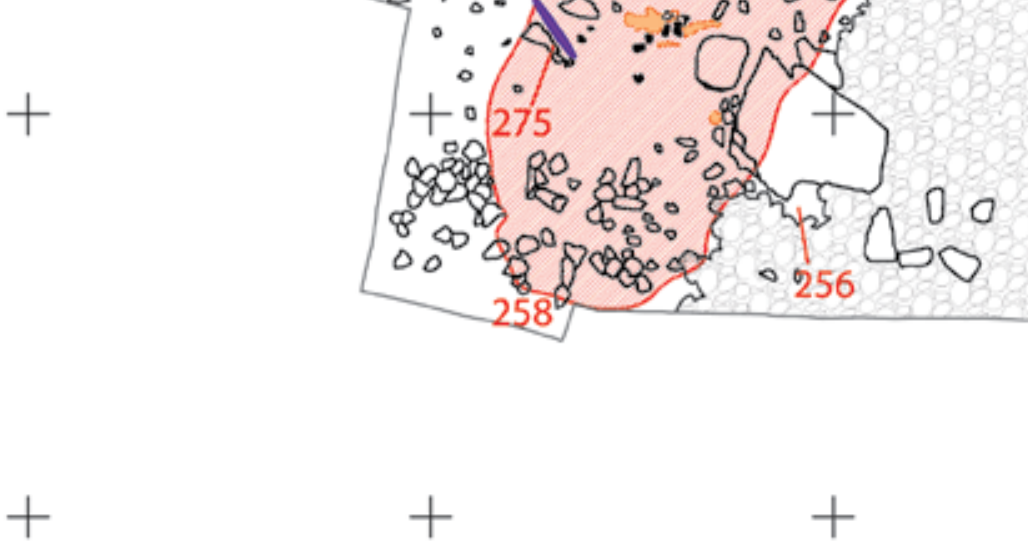

Fig. 46. Plano del asiento, parte del empedrado y la segunda capa del hogar (nivel IV) (Dibujo: X. Peñalver/Digitalización: J. Calvo). / Plan of the seat, part of the stone pavement and the second layer of the hearth (Drawing: $\mathrm{X}$. Peñalver/Digitalisation: J. Calvo). 
12

$+$

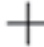

10
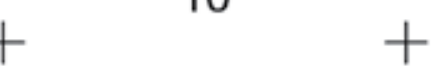

8

LEYENDA

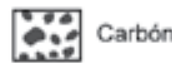
Piedra quemada
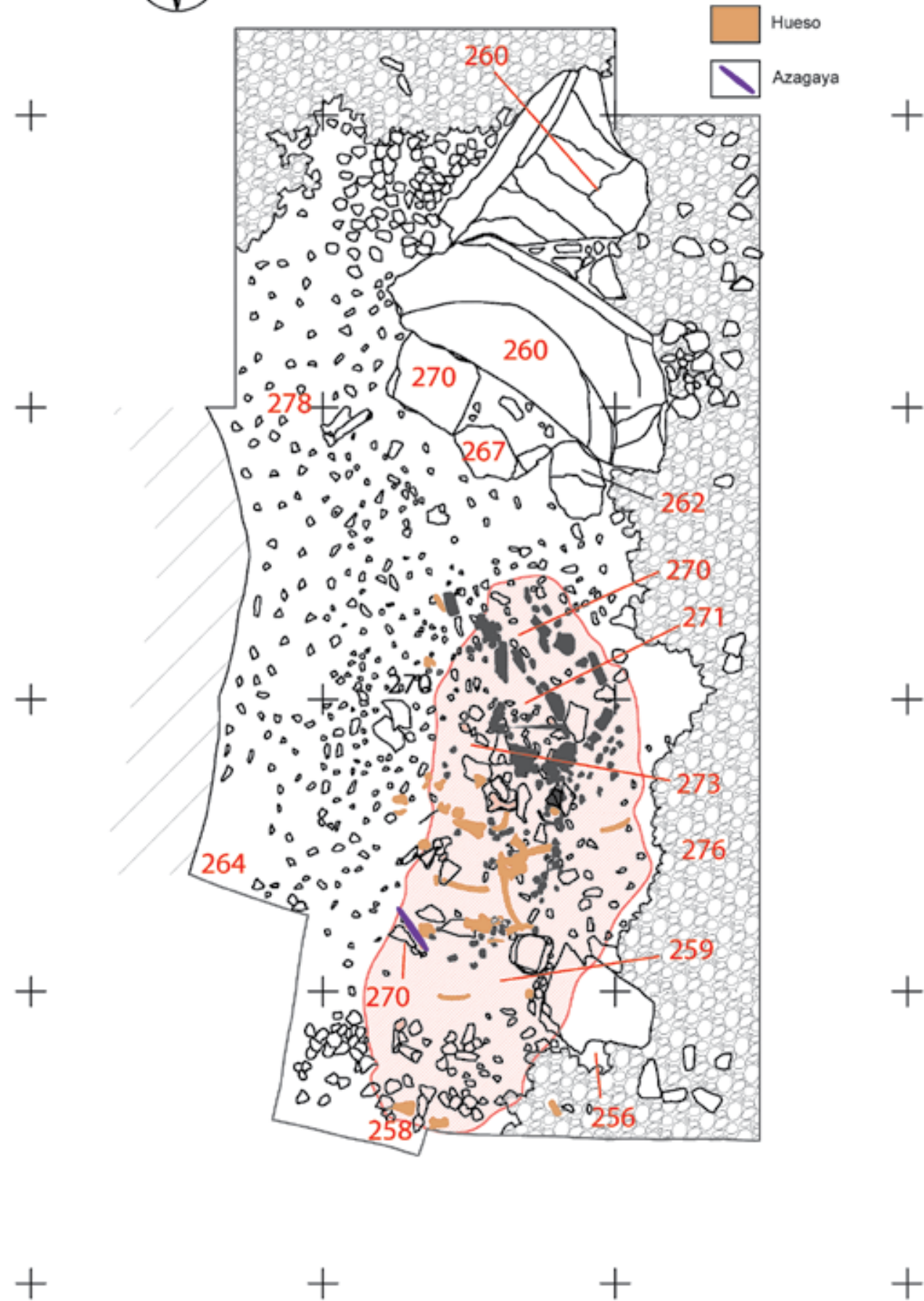

\section{0}

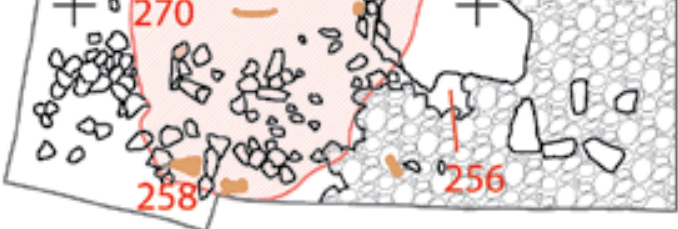

Fig. 47. Plano del asiento, parte del empedrado y superposición de las capas 1 y 2 del hogar (nivel IV) (Dibujo: $X$ Peñalver/Digitalización: J. Calvo). / Plan of the seat, part of the stone pavement and superposition of layers 1 and 2 of the hearth (Drawing: X. Peñalver/Digitalisation: J. Calvo). 


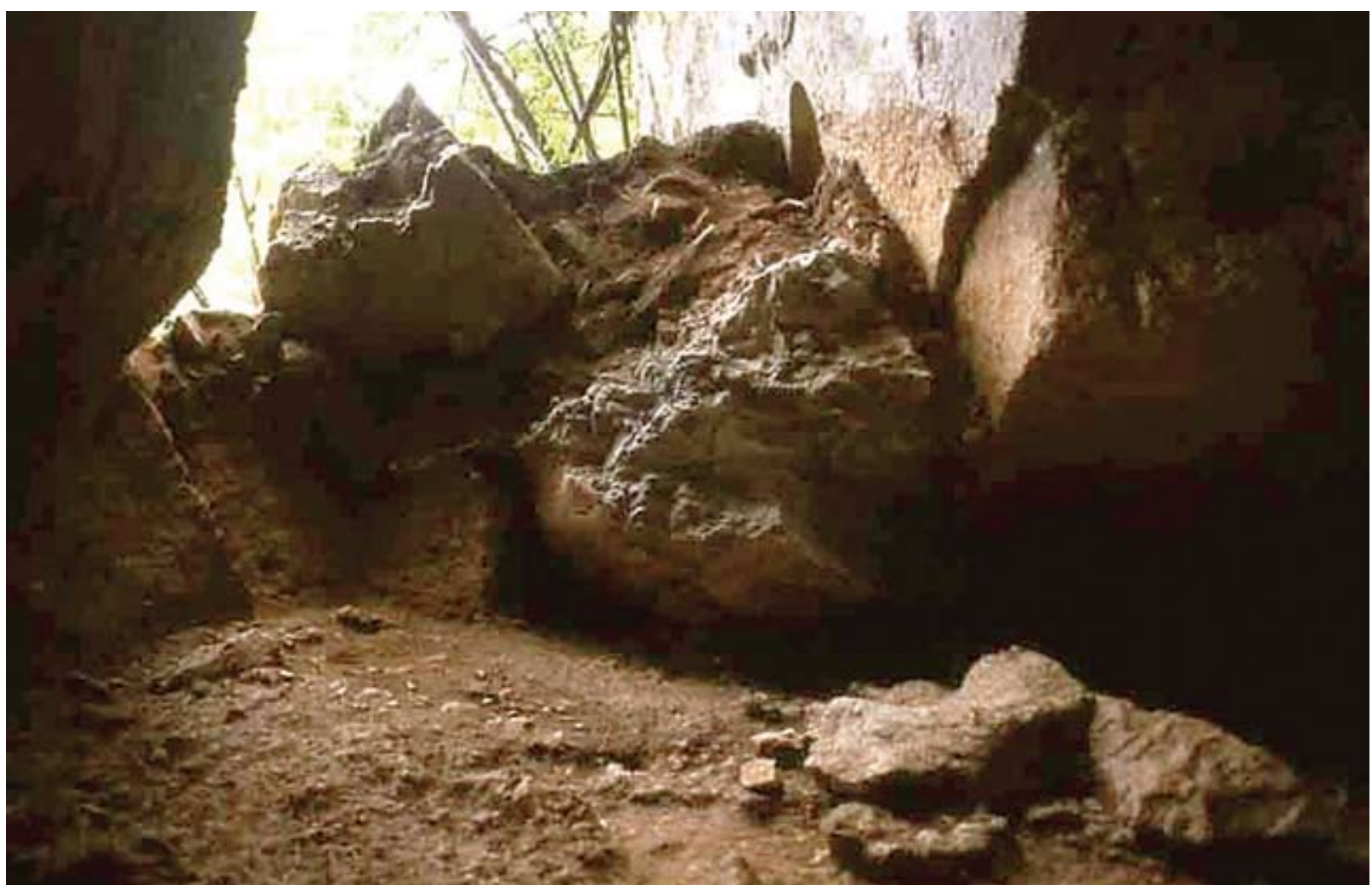

Fig. 48. Vista de la zona más exterior del vestíbulo con el gran bloque desprendido a medio eliminar. En la parte inferior derecha se distingue el asiento (E. Koch). / View of the most external area of the vestibule with the great block detached half eliminated. The seat can be distinguished at the bottom right (E. Koch).

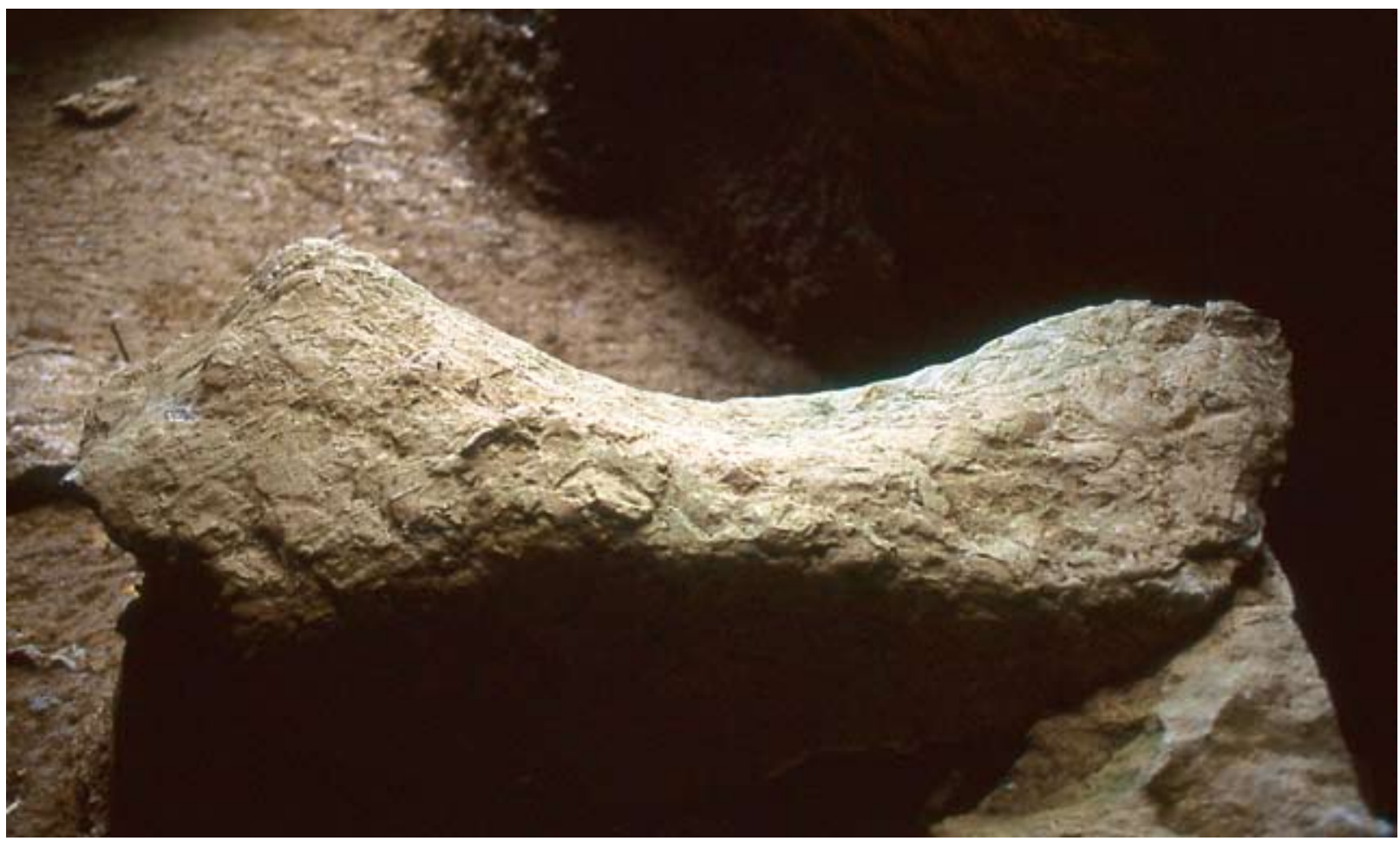

Fig. 49. Primer plano del asiento (E. Koch). / Foreground of the seat (E. Koch). 

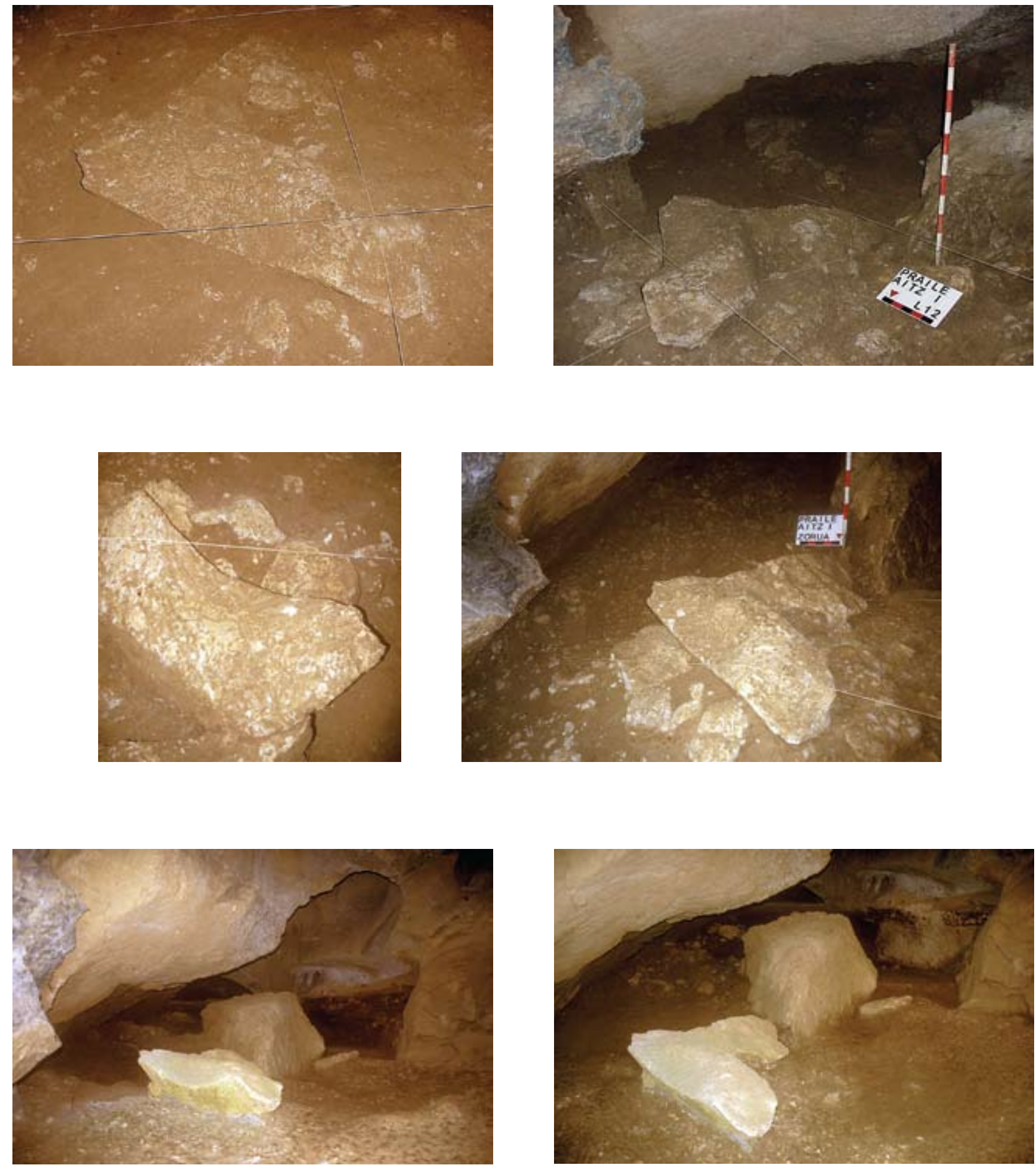

Figs. 50-55. Diversos aspectos de la piedra utilizada posiblemente como asiento frente al hogar. / Different views of the stone probably used as a seat in front of the hearth. 
Fig. 56. Dibujo del asiento situado en el vestíbulo (Dibujo: X. Peñalver/Digitalización: J. Calvo). / Drawing of the seat located in the vestibule (Drawing: X. Peñalver/Digitalisation: J. Calvo).
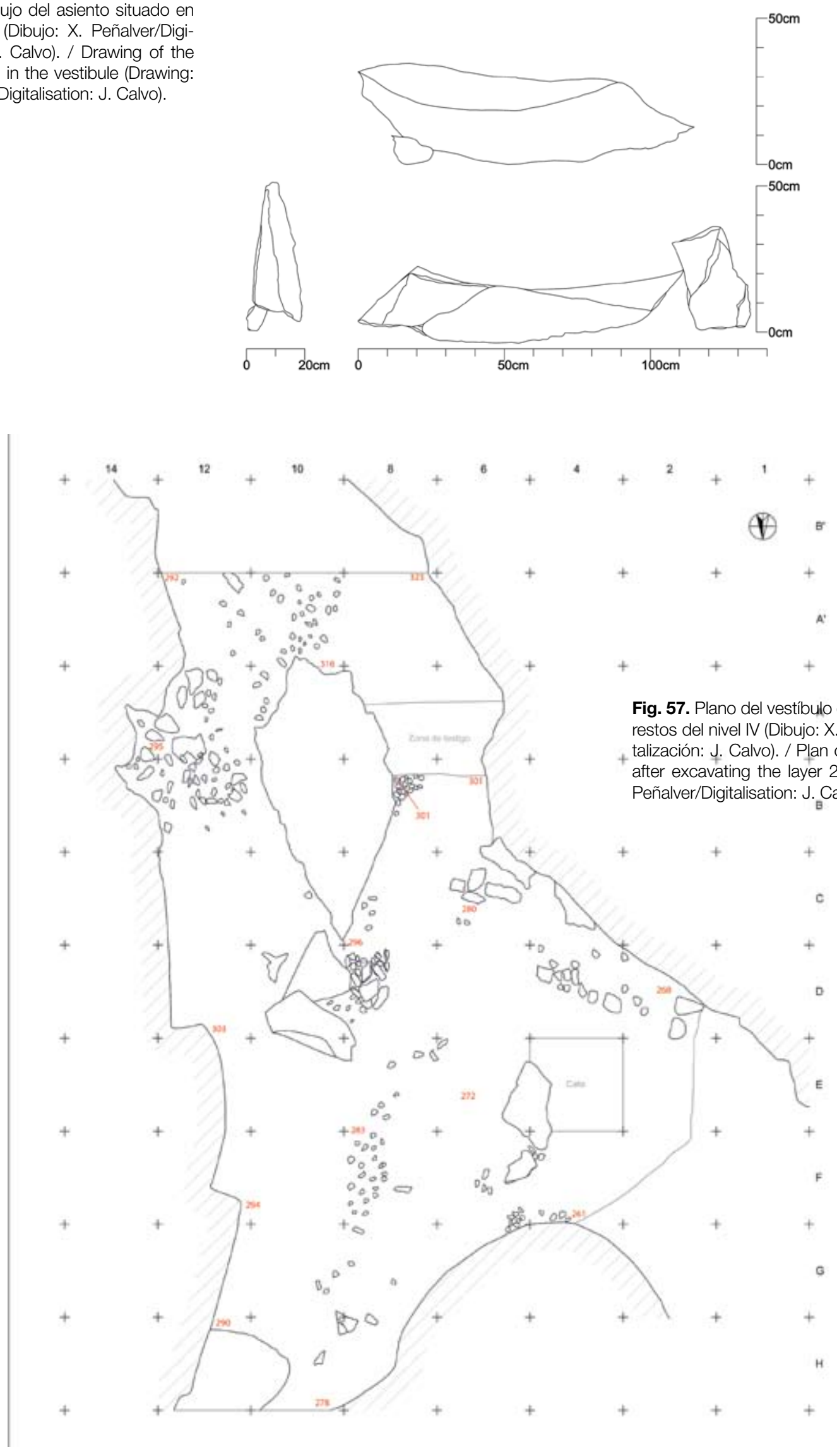


\section{Subnivel IV.III}

Está formado por el lecho 20 correspondiendo al sedimento situado inmediatamente por debajo del empedrado.

Tras la eliminación del nivel de piedras que forma un suelo en gran parte de la superficie del vestíbulo, la banda 6 presenta una tierra amarilla conteniendo algunas piedrecillas de pequeño tamaño, si bien éstas han desaparecido en su mayor parte, salvo en los cuadros
$6 \mathrm{~B}$ y $6 \mathrm{C}$. La banda 8 presenta diferencias según los cuadros; así, en la zona de la entrada a la cavidad -en los cuadros $8 \mathrm{H}$ y $8 \mathrm{G}$-, la tierra tiende a un color más oscuro y las piedras son escasas; sin embargo, en los cuadros $8 \mathrm{E}$ y $8 \mathrm{~F}$ las piedras pequeñas son muy abundantes, formando prácticamente un suelo similar al del 6B; este nivel desaparece en la banda 10 en la depresión de la cubeta del hogar. Los cuadros 8C y 8D no tienen piedras y se encuentran a una cota inferior a los de su entorno. Los cuadros 10E, 10F y 10G (los dos primeros corres-

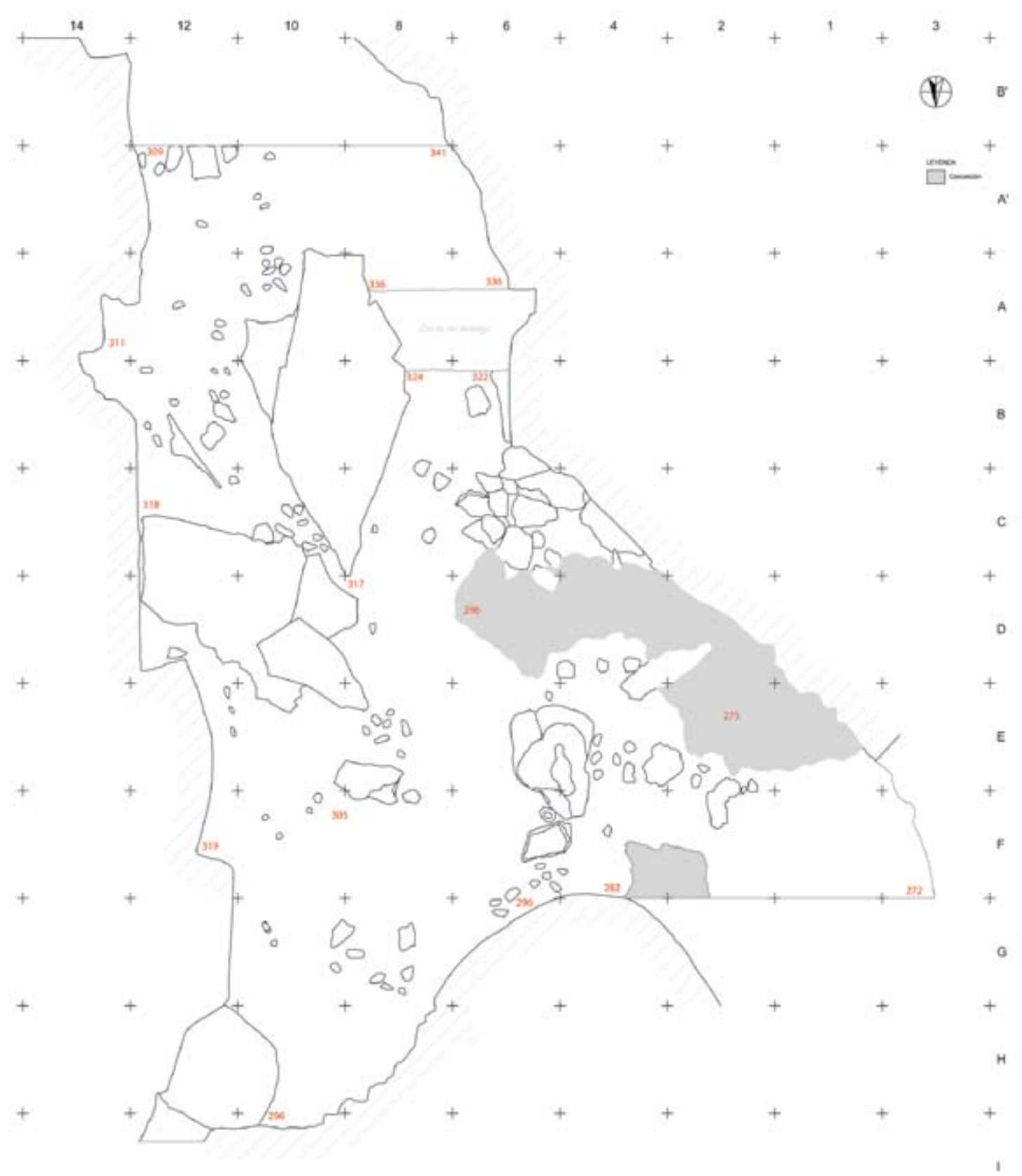

Fig. 58. Plano del vestíbulo tras excavar el lecho 25 (nivel VI) (Dibujo: X. Peñalver/Digitalización: J. Calvo). / Plan of the vestibule after excavating the layer 25 (level VI) (Drawing: X. Peñalver/Digitalisation: J. Calvo). 


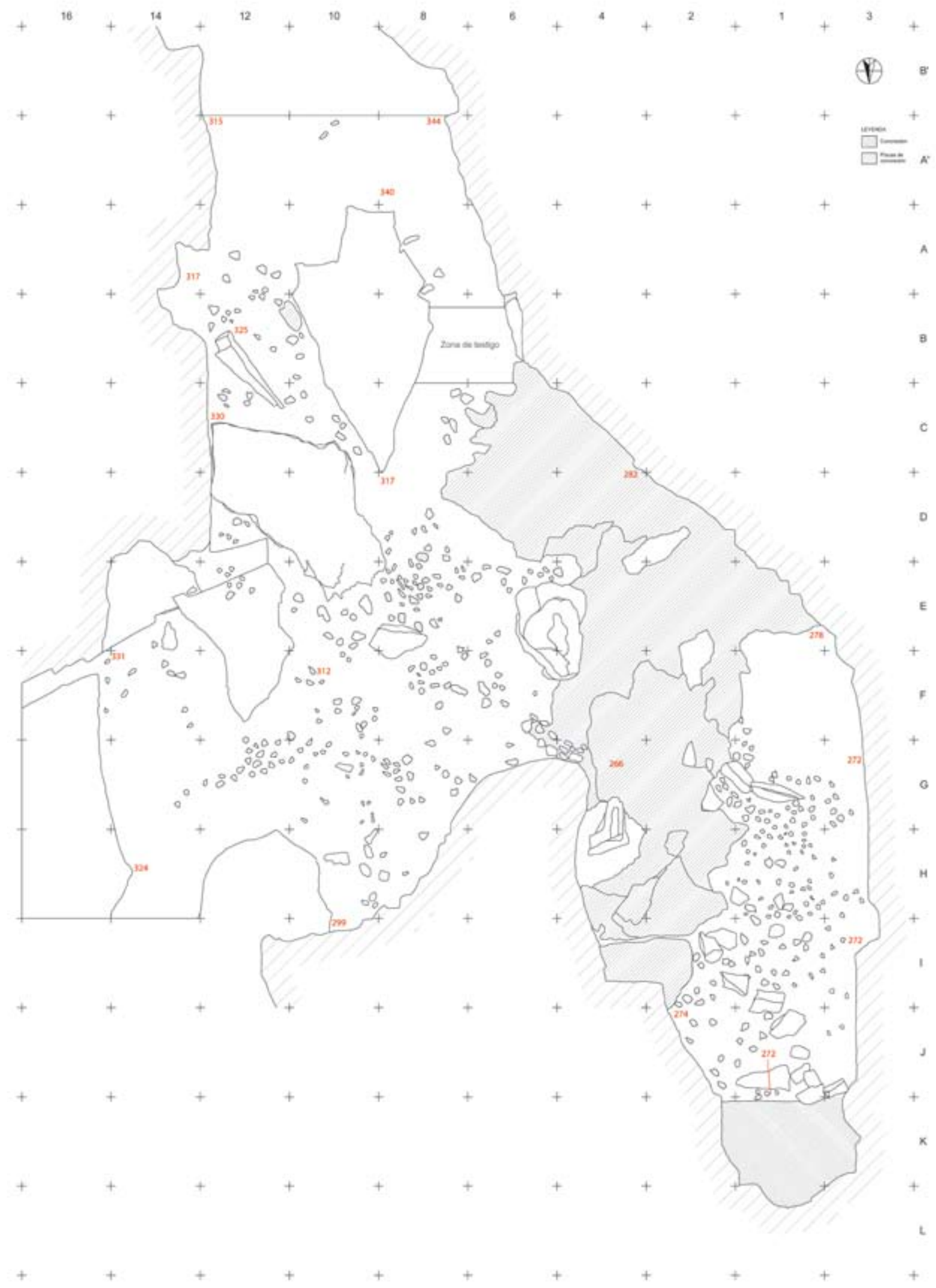

Fig. 59. Plano del vestíbulo tras excavar el lecho 26 (nivel VI) (Dibujo: X. Peñalver/Digitalización: J. Calvo). / Plan of the vestibule after excavating the layer 26 (level VI) (Drawing: X. Peñalver/Digitalisation: J. Calvo). 
pondientes al hogar ya excavado) son de tierra amarilla y cuentan con alguna piedra pequeña en las zonas limítrofes con la banda 8. En el espacio recogido existente entre el asiento y el gran bloque correspondiente a los cuadros 10A, 12A, 10B, 12B, 10C, 12C y 12D la tierra es de color amarillo y cuenta con piedras, principalmente en los cuadros $12 \mathrm{~A}, 12 \mathrm{~B}$ y $14 \mathrm{~B}$.

En la banda 10, dentro del cuadro $10 \mathrm{H}$, se detecta el agujero correspondiente a la cata-trinchera existente bajo la cota a la que se está excavando, practicada, como se ha mencionado anteriormente, en 1983.

\section{El nivel V}

Se compone de un sedimento de color amarillo y de textura arcillosa, si bien en algunas zonas tiende a limosa. Las piedras, de pequeño tamaño, van desapareciendo progresivamente según se avanza entre los lechos 21 y 26 , aunque en este último éstas aumentan en número, principalmente en algunos puntos de la zona central y norte del vestíbulo.

Durante la excavación de este nivel aflora la parte superior, relativamente plana, de dos bloques de considerable tamaño, ubicados en las bandas C, D y F. Ambos cuentan con unos 2 metros de dimensión máxima, y limitan con la pared este de la cueva.

Este nivel va reduciéndose en extensión, conforme avanza por el este del vestíbulo la placa de concreción (nivel VI) descrita en el apartado siguiente.

\section{El nivel VI}

Por debajo del sedimento que conforma el nivel V, y anexo a la pared suroeste del vestíbulo, aparece a partir de los lechos 22 y 26 un nivel formado por placas y bloques de concreción, muy compactadas, procedentes de las paredes próximas y arrastradas por deslizamiento (Figs. 58 a 59). Estas placas alcanzan hasta $80 \mathrm{~cm}$ de longitud en algunos casos.

Este nivel presenta un marcado buzamiento descendente de norte a sur entre 10 y $20 \mathrm{~cm}$, y de oeste a este, de 10 a $15 \mathrm{~cm}$, alcanzando, una vez finalizada la excavación del lecho 26 (último lecho excavado en extensión en el vestíbulo), los cuadros 1E, 1F, 2D, 2E, 2F, 2G, 2H, 2l, $4 \mathrm{C}, 4 \mathrm{D}, 4 \mathrm{E}, 4 \mathrm{~F}, 4 \mathrm{G}, 4 \mathrm{H}, 4 \mathrm{I}, 6 \mathrm{~B}, 6 \mathrm{C}, 6 \mathrm{D}, 6 \mathrm{~F}$ y $8 \mathrm{D}$.

\subsubsection{Adscripción cronocultural de los niveles del vestíbulo}

Tras la unificación de los sucesivos lechos en las distintas ampliaciones de esta zona del vestíbulo se han establecido siete niveles con las siguientes asignaciones culturales:

- Nivel 0: se relaciona con la capa de concreción que, proveniente de la galería noroeste, afecta a la parte del noroeste del vestíbulo.
- Nivel I: corresponde a un paquete de sedimento estéril, dividido en dos subniveles:

- Subnivel I.I: formado por el lecho 1 sin restos significativos.

- Subnivel I.Il: constituido por los lechos 2 y 3, se corresponde con un paquete estratigráfico sin restos significativos.

- Nivel II: se trata de un paquete estratigráfico que va del lecho 4 al lecho 8, ambos inclusive, perteneciente al período Epipaleolítico. Está dividido en dos subniveles | y ||:

- Subnivel II.l: formado por los lechos del 4 al 8.

- Subnivel II.II: capa de concreción de considerable entidad por debajo del subnivel II.I. Afecta solo a la parte este del vestíbulo.

- Nivel III: abarca el paquete estratigráfico que va del lecho 9 al lecho 10, perteneciente al Magdaleniense Superior-Final.

- Nivel IV: comprende el paquete estratigráfico correspondiente a los lechos 11, 11 bis y 20; este nivel corresponde al Magdaleniense Inferior. Se subdivide en tres subniveles: I, II y III.

- Subnivel IV.I: está formado por el sedimento correspondiente al lecho 11.

- Subnivel IV.II: lo conforma el lecho 11bis, interpretado como un suelo formado con pequeñas piedras que comprende prácticamente toda la extensión del vestíbulo.

- Subnivel IV.III: se corresponde con el sedimento del lecho 20.

- Nivel V: corresponde al paquete estratigráfico que va del lecho 21 al lecho 26 en la mayor parte de la superficie del vestíbulo, salvo en la zona de la entrada afectada por la caída del gran bloque, en donde no se ha alcanzado hasta la fecha. Este nivel pertenece al Solutrense.

- Nivel VI: se corresponde con una capa de concreción por debajo del nivel V.

\subsection{La galería noroeste}

La zona excavada afecta a un total de 17 cuadros correspondientes a las bandas número 3, 1, 2 y 4 y a las letras G, H, I, J y K (Fig. 60). Toda esta superficie ha sido levantada en 19 lechos que han sido agrupados en 7 niveles presentando por lo general una gran horizontalidad. En el lateral noroeste de esta galería se abre otra de grandes dimensiones, colmatada de sedimento, dejando únicamente un pequeño acceso en su parte superior ${ }^{8}$. Al inicio de la excavación, la galería noroeste contaba con

\footnotetext{
${ }^{8}$ Durante las últimas campañas de esta presente memoria se iniciaron los trabajos en esta galería colmatada, aportando importantes novedades a partir del 2013.
} 

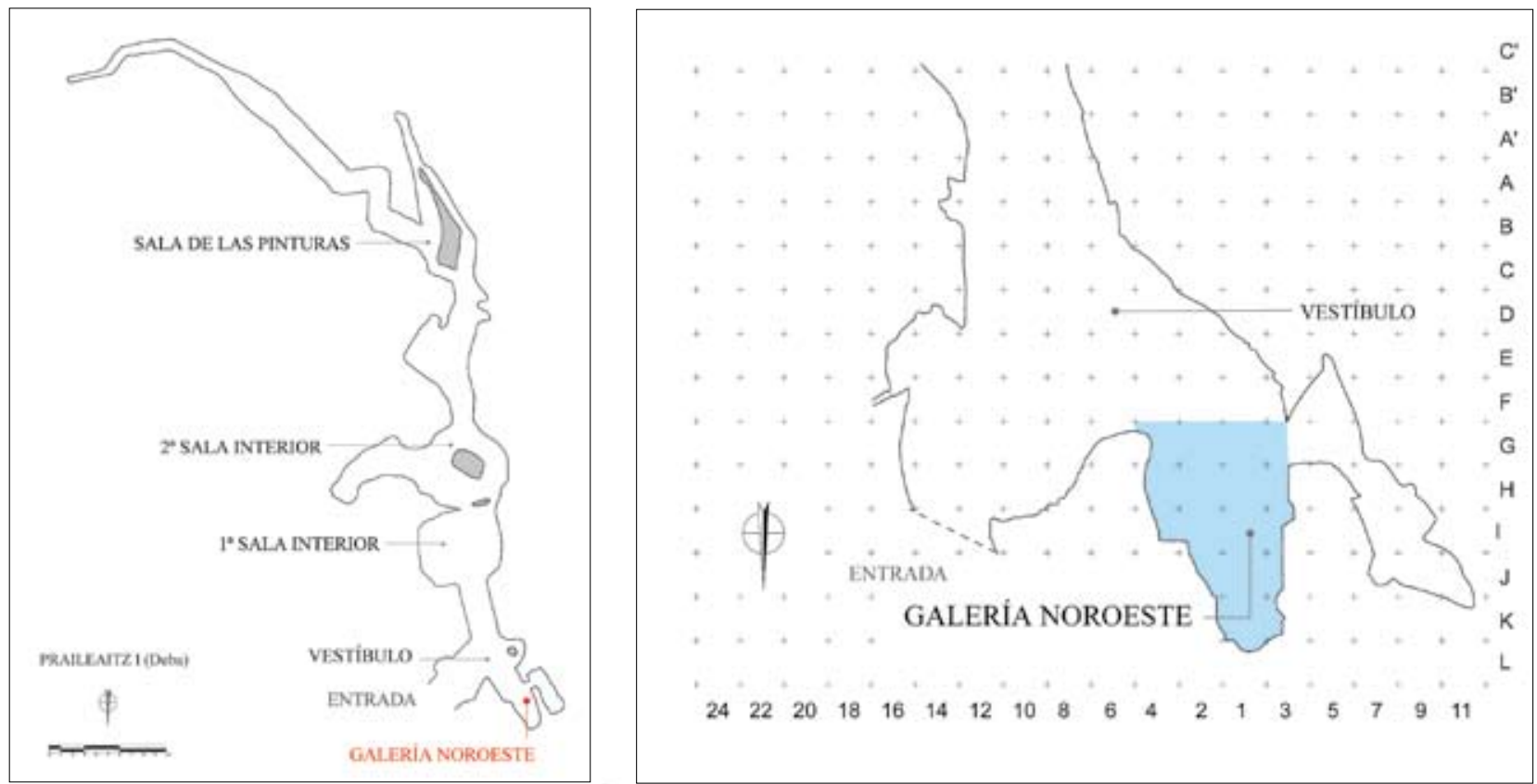

Fig. 60. Plano general de la cueva y ubicación de la galería noroeste (Dibujo: G. Studer/Tx. Ugalde -Felix Ugarte Elkartea-). / General plan of the cave and location of the northwestern gallery (Plan: G. Studer/Tx. Ugalde -Felix Ugarte Elkartea-).

un desarrollo transitable de $3 \mathrm{~m}$. La acumulación de materiales arqueológicos contra la pared enfrentada a esta galería colmatada parece indicar la existencia de arrastre de éstos desde la segunda galería, quizá por medio del agua, en algunos de los momentos más antiguos de la ocupación de la cueva.

Por ello, y por las características específicas de este espacio, los lechos excavados no guardan una relación directa con los practicados en el vestíbulo, si bien el nivel V de la galería parece constituir una unidad con el IV del vestíbulo (empedrado antrópico del Magdaleniense Inferior).

\subsubsection{El nivel I}

Lo forma una capa de concreción compacta con un espesor que oscila entre los 20 y los $40 \mathrm{~cm}$, alcanzando la mayor potencia en el extremo sur de la galería. Esta capa no ha sido eliminada en la banda K. Tras la eliminación de esa capa en el resto de la galería, correspondiente al lecho 1 (Fig. 61), afloran algunas piedras calizas aisladas en las bandas $\mathrm{G}, \mathrm{He}$.

\subsubsection{El nivel II}

Corresponde a la capa de sedimento existente entre los dos niveles de concreción asignados como I y III. Está excavado en cinco lechos (del 2 al 6, ambos inclusive), y se subdivide en cuatro subniveles.

\section{Subnivel II.I}

Consta de una tierra limosa y suelta, carente de piedras, correspondiente al lecho 2. Esta tierra está en parte

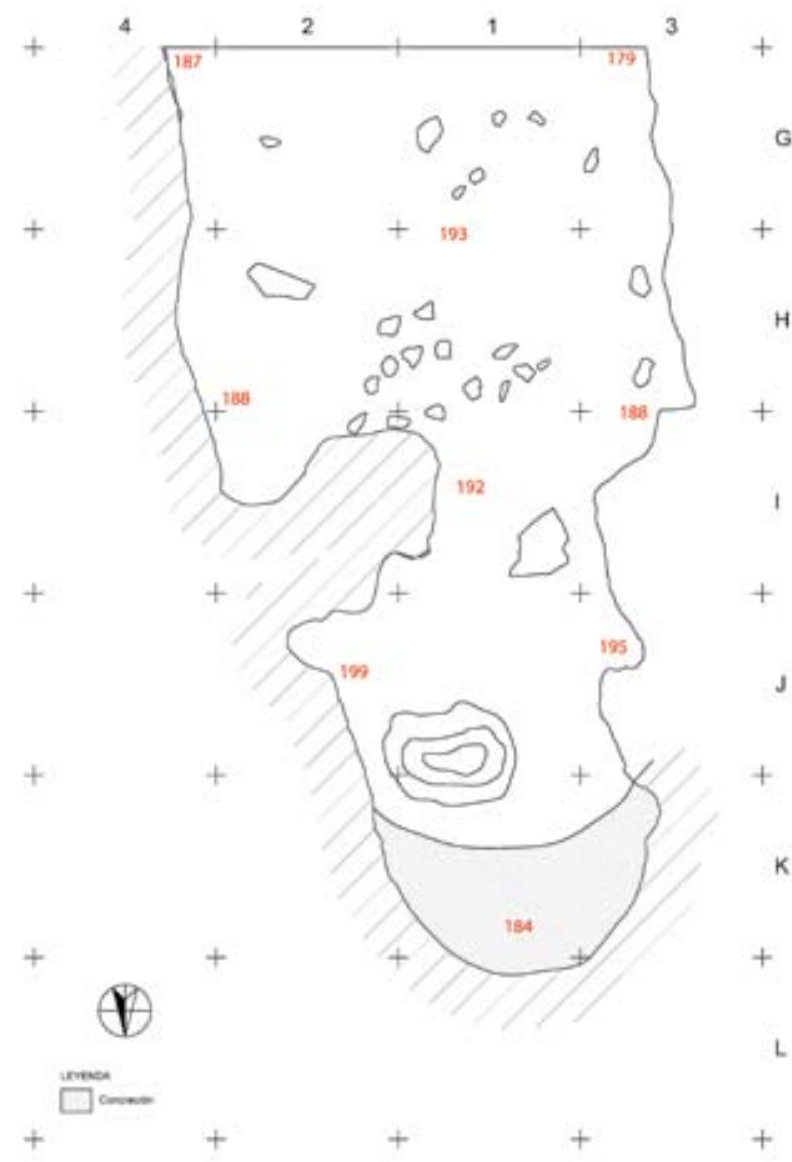

Fig. 61. Plano tras excavar el lecho 1 en la galería noroeste (Dibujo: $X$. Peñalver/Digitalización: J. Calvo). / Plan after excavating the layer 1 at the northwestern gallery (Drawing: X. Peñalver/Digitalisation: J. Calvo). 
concrecionada por la infiltración de la concreción del nivel I, y su superficie presenta forma irregular debido a la eliminación de las placas del citado nivel.

\section{Subnivel II.II}

Está formado por un sedimento similar al del subnivel anterior, pero esta vez con presencia de piedras calizas de tamaño medio (entre 10 y $20 \mathrm{~cm}$ ), más abundantes en la zona centro-sur. Presenta algún resto lítico. Corresponde al lecho 3.

\section{Subnivel II.III}

Excavado en los lechos 4, 5 y 6 (Fig. 62); consta de tierra amarilla concrecionada, así como un sedimento más plástico con algunas piedras. También hay presencia de material arqueológico. En la base de este subnivel (lecho 6) abundan las piedras calizas y los fragmentos de concreción en muchas de las zonas.

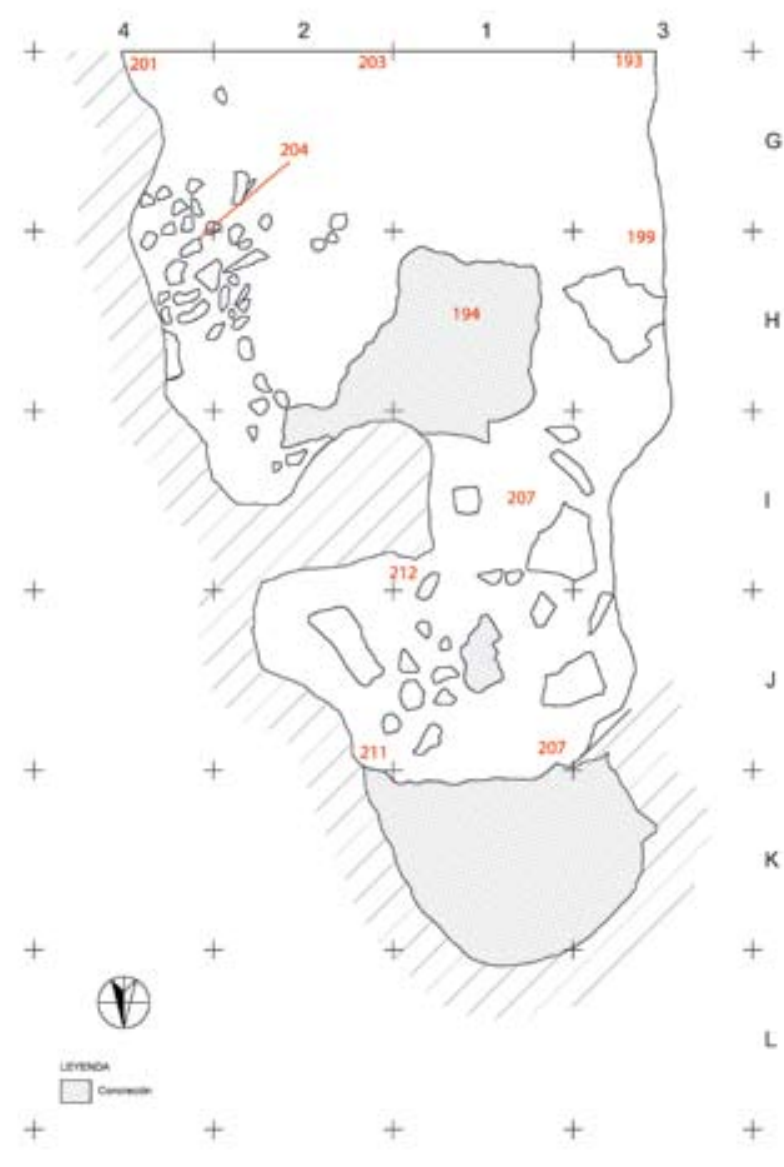

Fig. 62. Plano tras excavar el lecho 4 en la galería noroeste (Dibujo: X. Peñalver/Digitalización: J. Calvo). / Plan after excavating the layer 4 at the northwestern gallery (Drawing: $X$. Peñalver/Digitalisation: J. Calvo).

\section{Subnivel II.IV}

En el lado este de la banda $G$ (cuadros $2 G$ y $4 G$ ) se diferencia un subnivel formado por tierra oscura y limosa. En el mismo aparece gran cantidad de restos de fauna, sobre todo en el cuadro 4G, en su mayor parte adosados a la pared este de la cueva.

\subsubsection{El nivel III}

Lo constituye una placa de concreción de entre 4 y $5 \mathrm{~cm}$ de potencia, que afecta principalmente a la banda G. Esta placa presenta una considerable horizontalidad. En el cuadro 2G aparece una tenue hondonada circular en la superficie de esta capa, sin perforarla. Presenta $50 \mathrm{~cm}$ de diámetro y una profundidad máxima de $5 \mathrm{~cm}$. Probablemente se corresponde con un charco.

\subsubsection{El nivel IV}

Constituido por los lechos 7 y 8 , en este nivel se aprecian diferentes variaciones en dependencia de las zonas de la galería, combinándose áreas de tierras amarillas plásticas con otras más marrones, con o sin piedras calizas. Las dimensiones de estas piedras angulosas también oscilan entre pequeñas y medianas. Así mismo, son abundantes en algunas áreas los fragmentos y plaquitas de concreción.

\subsubsection{El nivel V}

Está formado por el lecho 9, y consiste en un suelo empedrado a base de piedras calizas de tamaño mediano y pequeño, similar al que ocupa la mayor parte del vestíbulo en su nivel IV. Se detecta exclusivamente en la zona de esta galería más próxima al vestíbulo (banda G).

\subsubsection{El nivel VI}

Lo forman los lechos 10 al 14 y destacan en él grandes bloques calizos que, por lo general, se sitúan en la zona central de la galería (principalmente bandas $\mathrm{G}$ y H). En el resto de las zonas se combinan calizas de tamaño pequeño y medio, y fragmentos de concreción amarilla (Figs. 63 y 64). El sedimento presenta las mismas características que en el nivel IV.

\subsubsection{El nivel VII}

Lo constituyen los lechos 15 al 18 (Fig. 65), así como el 26, apreciándose dos áreas diferenciadas en dos subniveles. Por lo general se detecta una considerable horizontalidad en este nivel dentro de la galería.

\section{Subnivel VII.I}

Se corresponde con la mitad sureste de la galería, con gran cantidad de plaquitas de concreción y pequeños puntos del mismo material. 


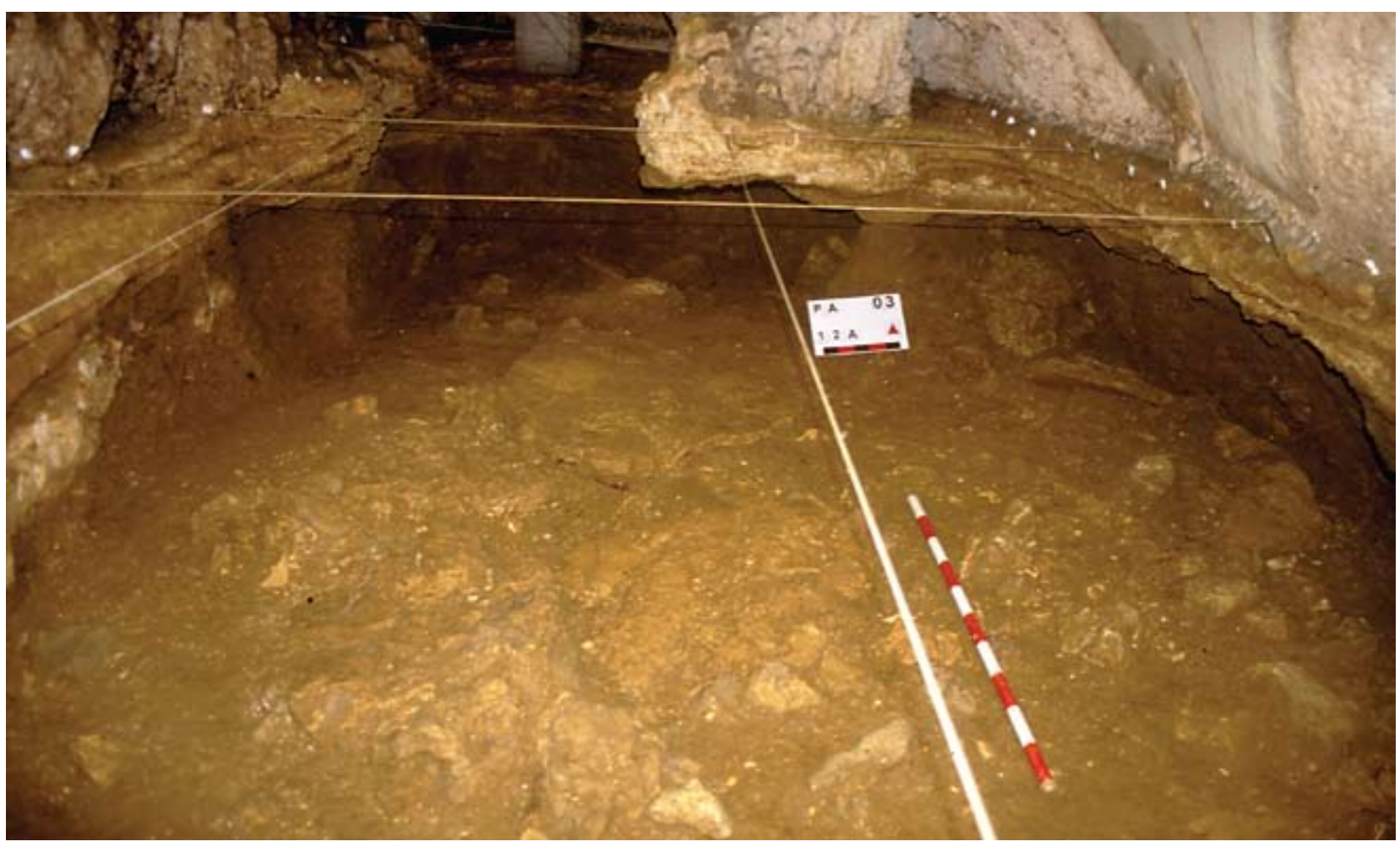

Fig. 63. Excavación del lecho 12 en la galería noroeste. / Excavation of the layer 12 at the northwestern gallery.

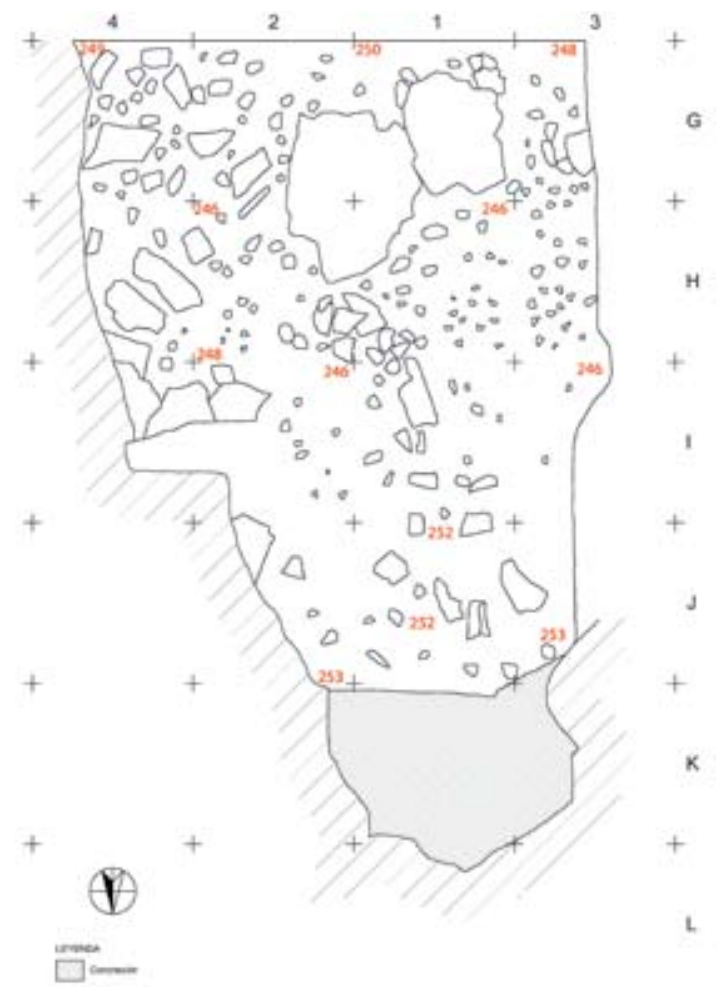

Fig. 64. Plano tras excavar el lecho 14 en la galería noroeste (Dibujo: X. Peñalver/Digitalización: J. Calvo). / Plan after excavating the layer 14 at the northwestern gallery (Drawing: X. Peñalver/ Digitalisation: J. Calvo).

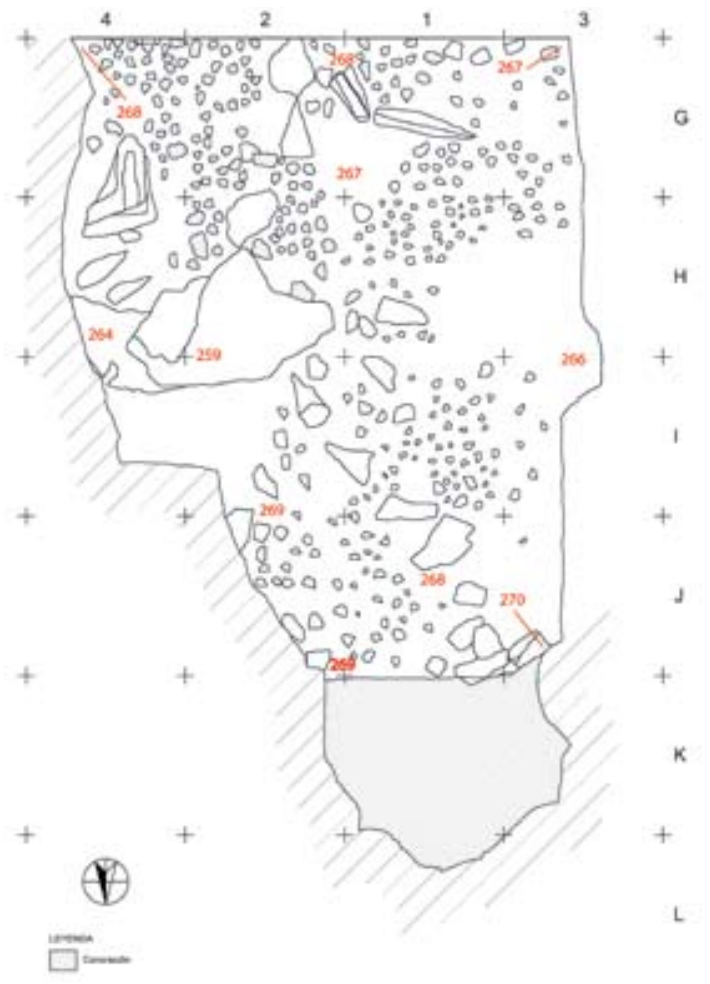

Fig. 65. Plano tras excavar el lecho 18 (unificado con el lecho 21 del vestíbulo) (Dibujo: X. Peñalver/Digitalización: J. Calvo). / Plan after excavating the layer 18 (united with the layer 21 of the vestibule) (Drawing: X. Peñalver/Digitalisation: J. Calvo). 

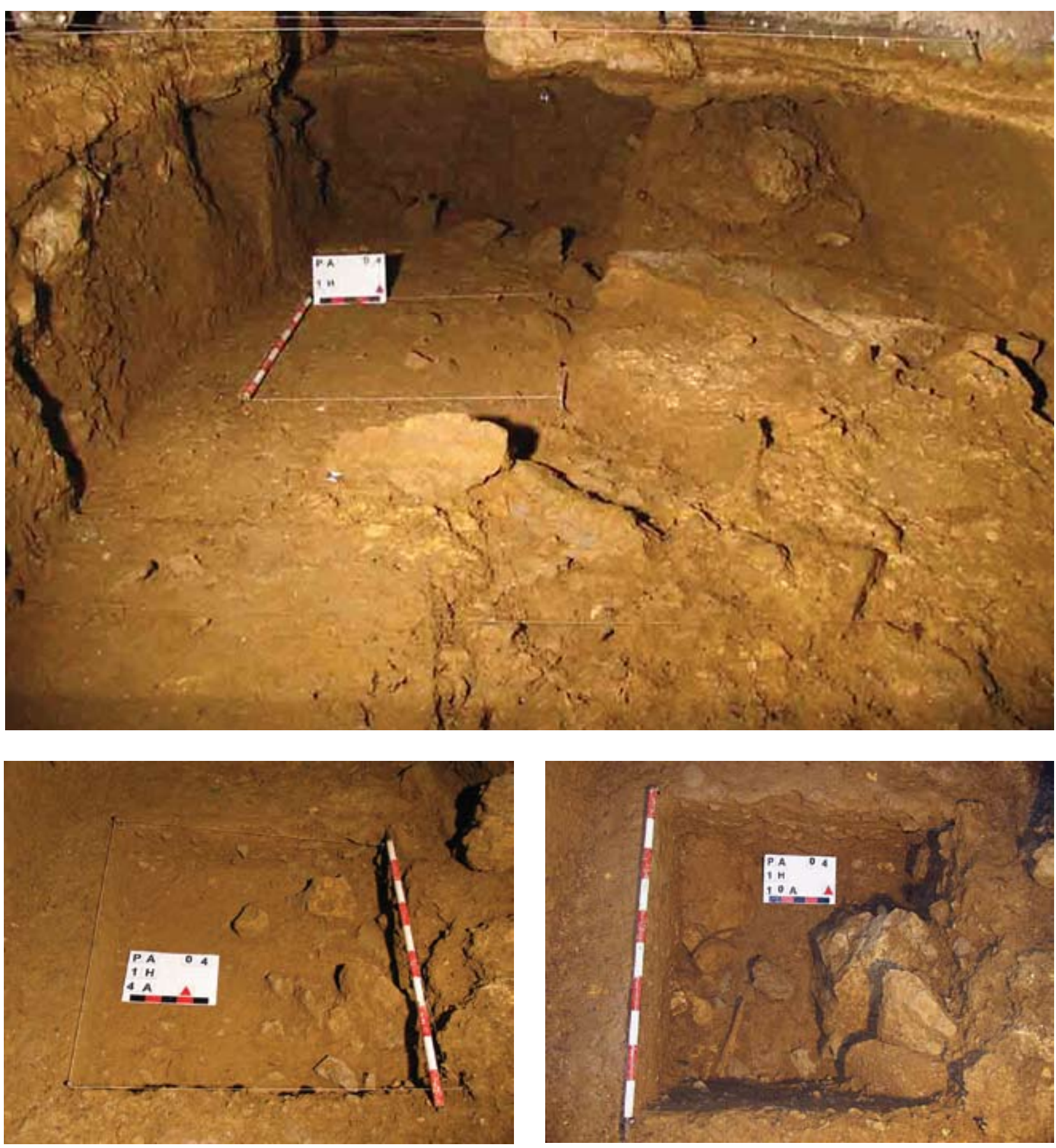

Figs. 66-68. Ubicación de la cata abierta en la galería noroeste tras finalizar la excavación de la zona. En detalle los lechos 4 y 13. / Location of the open trial at the northwestern gallery after completing the excavation on that area. In detail the layers 4 and 13.

\section{Subnivel VII.II}

Localizado en las bandas 1 y 3 , presenta pequeños cantos de caliza gris y tierra marrón. En la banda $\mathrm{J}$ las piedras son de mayor tamaño.

A modo de síntesis, hay que destacar que en todos los lechos, salvo los consistentes en una capa de concreción, se recogen materiales arqueológicos. Se apre- cia claramente, principalmente entre los lechos 8 y 12 , cómo estos restos, básicamente óseos, se acumulan junto a la pared este en las bandas 2 y 4 . Tal y como se ha mencionado anteriormente, este hecho parece estar motivado por el arrastre de esos materiales por el agua proveniente de la galería que, justo en frente, se abre hacia el oeste, si bien no ha podido delimitarse estratigráficamente. 
Una vez finalizada la excavación de esta galería se practicó una cata de $1 \times 1$ m en el cuadro $1 \mathrm{H}$, realizándose 13 lechos hasta alcanzar una profundidad a partir del último lecho excavado de entre 70 y $75 \mathrm{~cm}$ (Figs. 66 a 68).

El sedimento de esta cata es amarillo plástico con abundantes piedras de pequeño tamaño en los 4 primeros lechos; a partir del quinto lecho comienzan a aparecer grandes bloques calizos que llegan a ocupar la mitad del sondeo, y a partir del lecho 9 y hasta la base de la cata, afloran capas de concreción. Así, este último lecho se presenta ocupado totalmente por grandes bloques y concreción.

En cuanto a los materiales, los nueve primeros lechos cuentan con restos de fauna, siendo muy abundantes en el lecho 4. A partir del lecho 9 es estéril. No se ha localizado ninguna evidencia de industria en esta cata, por lo que no se han podido definir niveles culturales.

\subsubsection{Adscripción cronocultural de los niveles de la galería noroeste}

En lo que se refiere a la distribución de los restos de industrias y de fauna, en esta zona del yacimiento se diferencian dos áreas: una correspondiente a la parte final de la galería (bandas $\mathrm{J}$ y $\mathrm{K}$ ) y otra que afecta a las bandas G, H e I, destacando esta última por el mayor número de restos de fauna.

La mayor concentración de restos de industrias se produce en las bandas $\mathrm{G}$ y $\mathrm{H}$, sobre todo en las bandas 1, 2 y 4 . Igualmente, los restos de fauna se acumulan en las bandas $\mathrm{G}, \mathrm{H}$ e I, principalmente, destacando muy claramente la banda 4 en la que los huesos se amontonan contra la pared de la galería. Por el contrario, en la banda opuesta (banda 3) estos restos son escasos. Este fenómeno es más evidente entre los lechos 11 y 14, todos ellos correspondientes a lo que hemos denominado nivel Vl; en éste se ha datado una muestra por C14 en el 25320 \pm 140 B.P.

El conjunto de datos disponibles de esta galería que arranca del vestíbulo apunta a una mayor ocupación en la zona de entrada de la misma, en las bandas $\mathrm{G}$ y $\mathrm{H}$, adyacentes al citado vestíbulo, con una mayor luminosidad. Sin embargo, la presencia de gran número de restos, principalmente faunísticos, acumulados junto a la pared de la galería, justo enfrentados al arranque de una amplia galería colmatada de sedimento, apunta a la existencia de aportes de esa zona, cuya excavación se ha iniciado en el año 2012, proporcionando materiales de tipología musteriense.

Pero a pesar del movimiento de algunos restos, probablemente a causa del arrastre procedente de la galería colmatada a que hemos hecho referencia, el nivel V, consistente en un empedrado, realizado seguramente por los ocupantes de la cueva, es una continuación del detectado en la mayor parte de la superficie del vestíbulo, afectando aquí a una pequeña parte del arranque de esta galería noroeste. Este nivel está datado en el Magdaleniense Inferior, en torno al 15500 B.P. y separa dos paquetes, uno por encima y otro por debajo del mismo. Los escasos restos de industrias y el contexto cultural del vestíbulo podrían apuntar a una parte, superior al nivel V, correspondiente al período comprendido entre el Epipaleolítico y el Magdaleniense Inferior y a una inferior al nivel $V$ en la que disponemos de algunos restos líticos de tipología antigua,

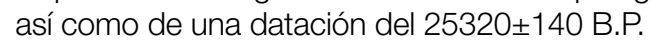

\subsection{El tránsito entre el vestíbulo y la primera sala interior}

La zona excavada ha afectado a un total de 17 cuadros, correspondientes a las bandas con números 6,8 , $10,12,14$ y 16 y a las letras A, A', B' y C'. Al igual que en el vestíbulo, esta superficie fue excavada en varias fases mediante sucesivas amplia-

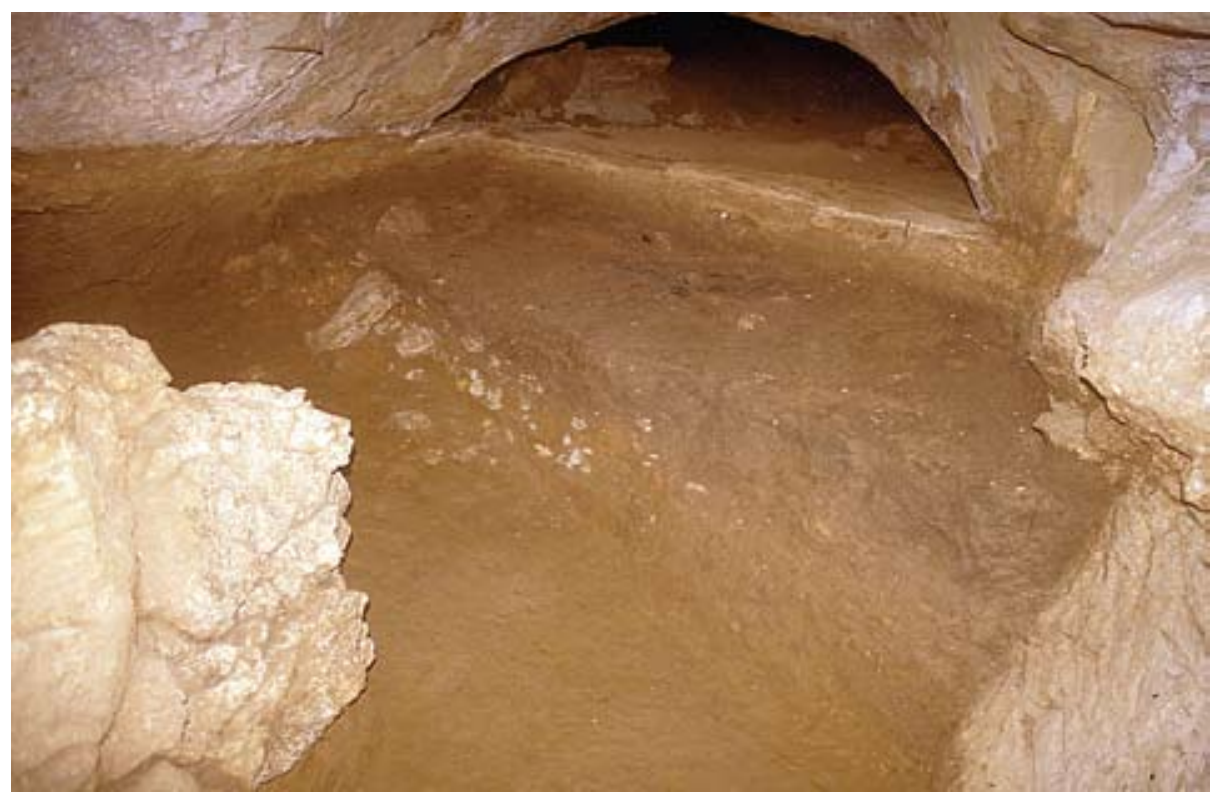
ciones (Figs. 69 a 71 y Tabl. 2). La presencia de un hogar con una considerable extensión hizo más compleja la excavación de este pequeño espacio de tránsito.

Fig. 69. Zona de tránsito entre el vestíbulo y la primera sala interior. Diferentes niveles (superficial de concreción, hogar epipaleolítico y suelo Magdaleniense). / Transit zone between the vestibule and the first inner room. Different levels (superficial of concretion, epipaleolithic hearth and Magdalenian ground). 


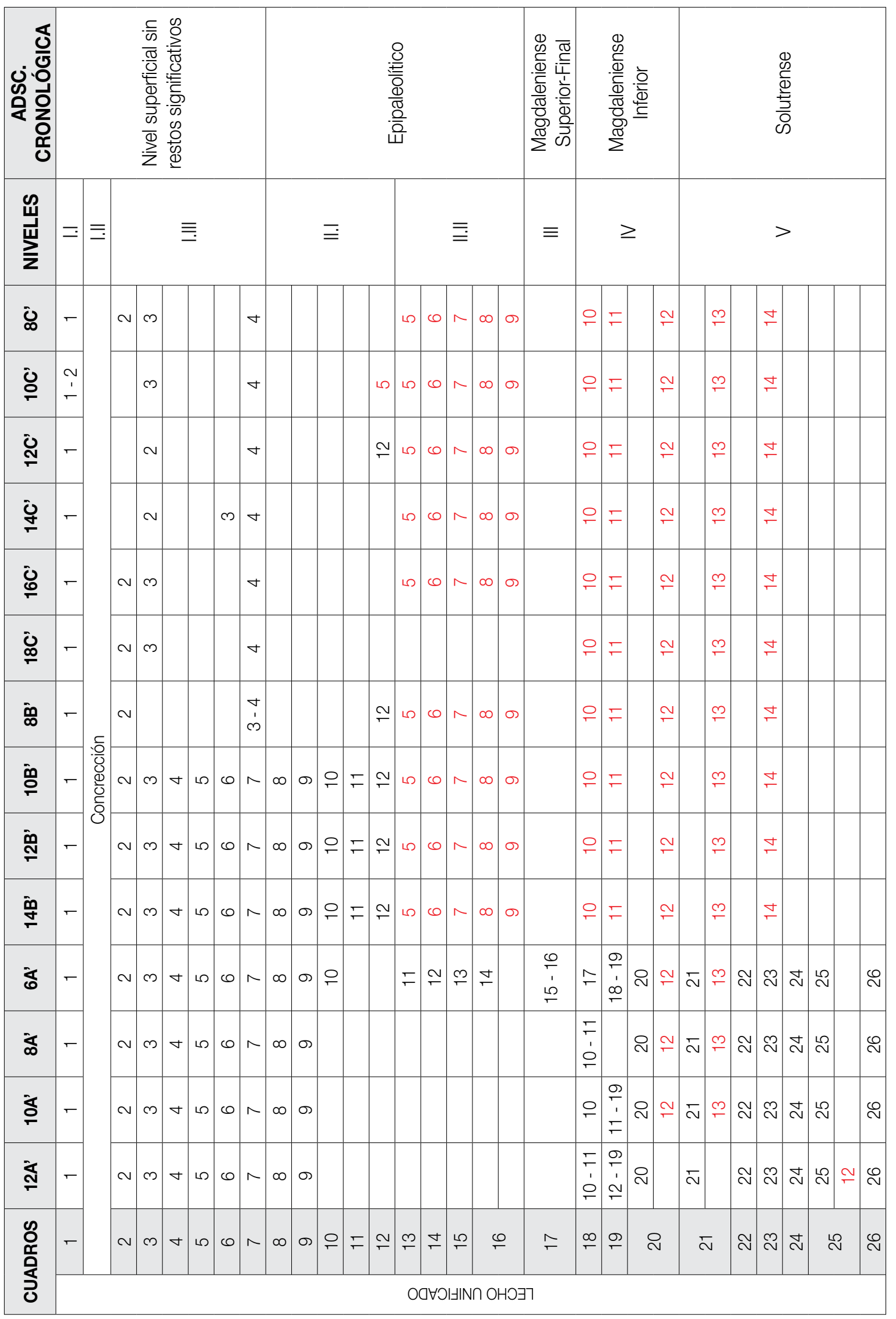

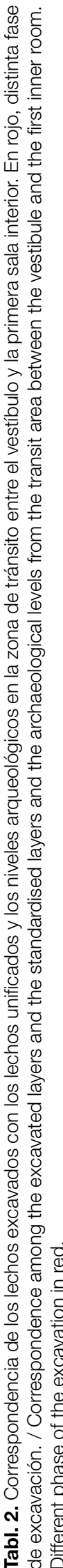



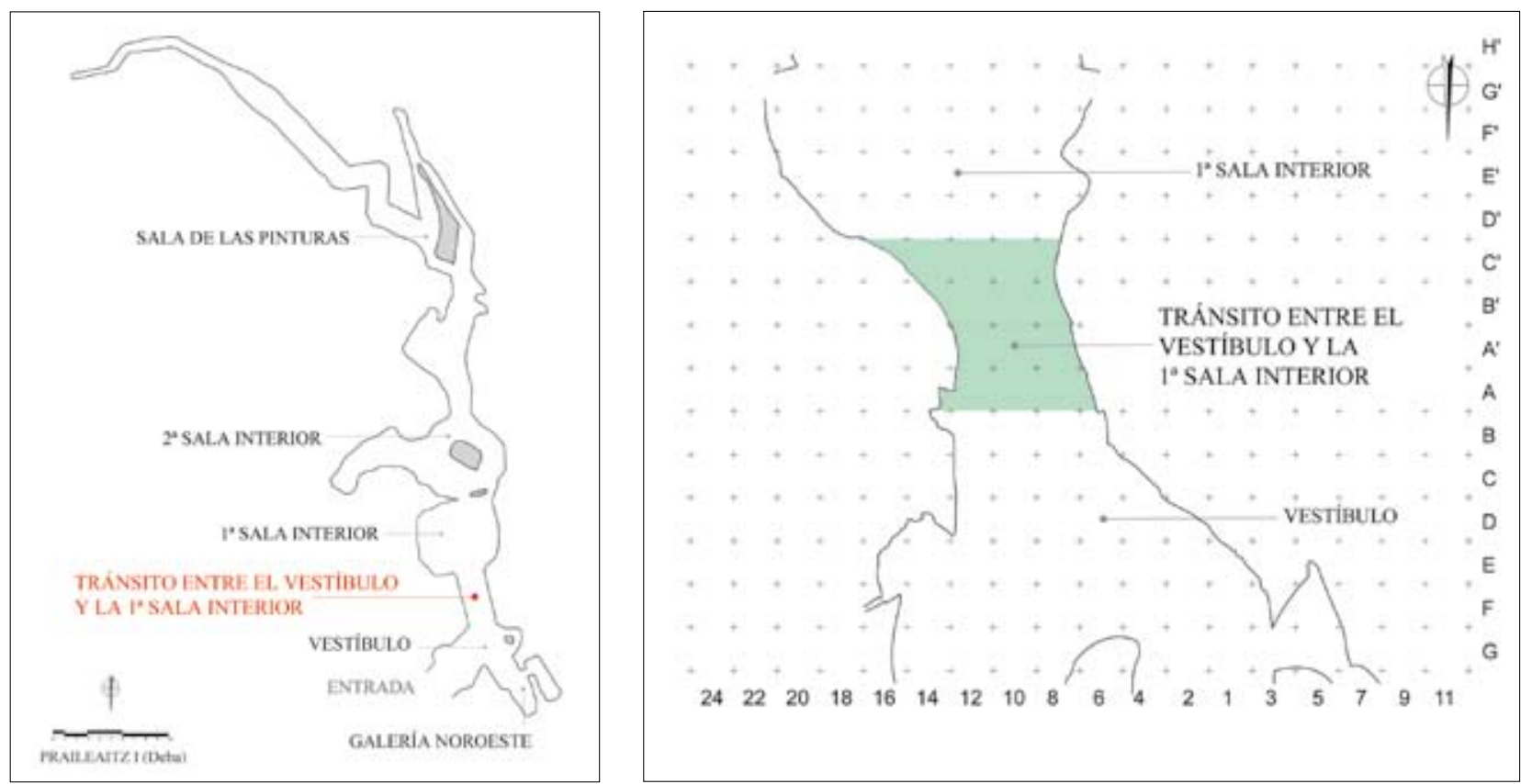

Figs. 70. Plano general de la cueva y ubicación del tránsito entre el vestíbulo y la primera sala interior (Dibujo: G. Studer/Tx. Ugalde -Felix Ugarte Elkartea-). / General plan of the cave and location of the transit zone between the vestibule and the first inner room (Drawing: G. Studer/Tx. Ugalde -Felix Ugarte Elkartea-).

Al describir los trabajos realizados en esta zona de la cueva, en algún caso se han incluido las bandas A y D', la primera, perteneciente propiamente al vestíbulo, y la segunda, a la primera sala interior. El motivo no es otro que el de poder presentar con mayor coherencia algunos de los niveles en los que determinadas estructuras (hogares) afectaban total o parcialmente a las bandas citadas.

\subsubsection{La zona de tránsito en su conjunto}

Los niveles que han sido diferenciados en esta zona de la cueva son los siguientes:

- Nivel I: compuesto por los subniveles I, II y III y consistente en capas de tierra y concreción superficiales sin restos significativos.
Fig. 71. Corte estratigráfico dentro de la zona norte del tránsito entre el vestíbulo y la primera sala interior. / Stratigraphic cut inside the northern zone of the transit between the vestibule and the first inner room.

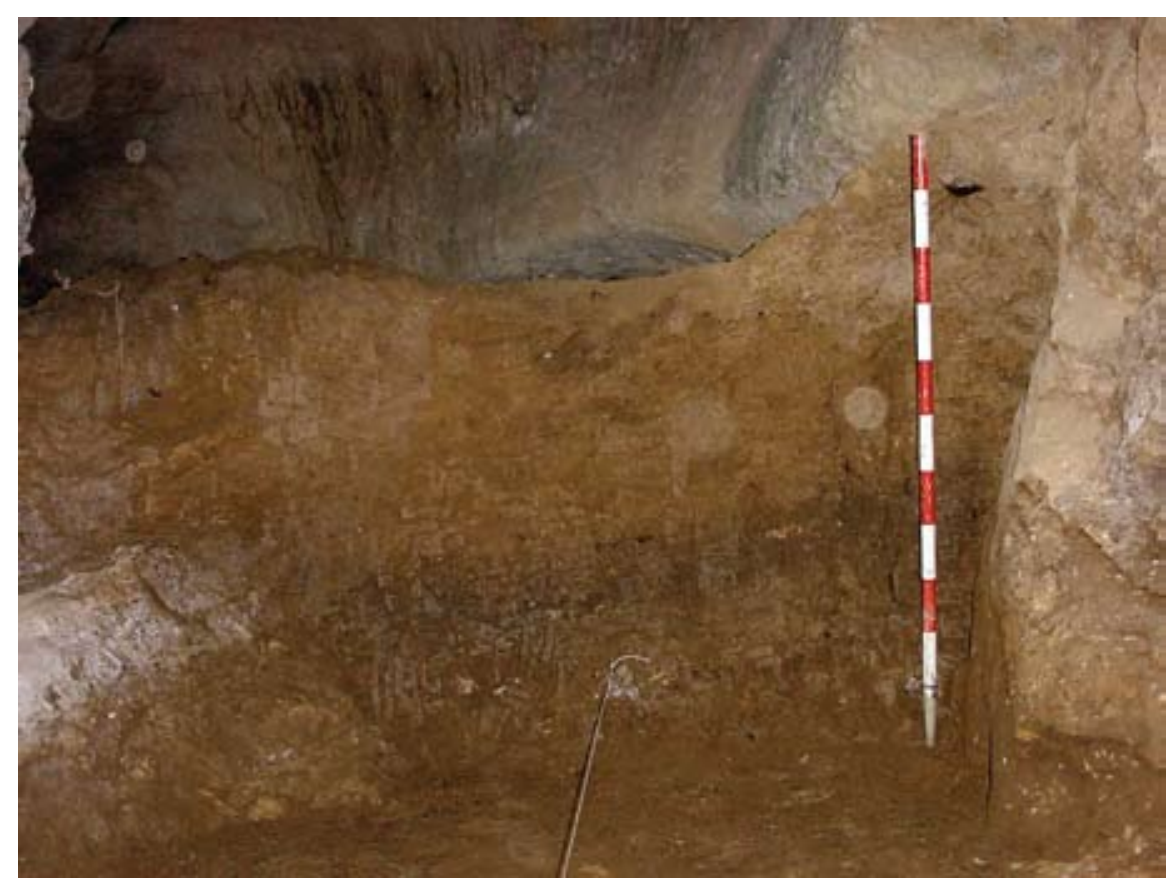




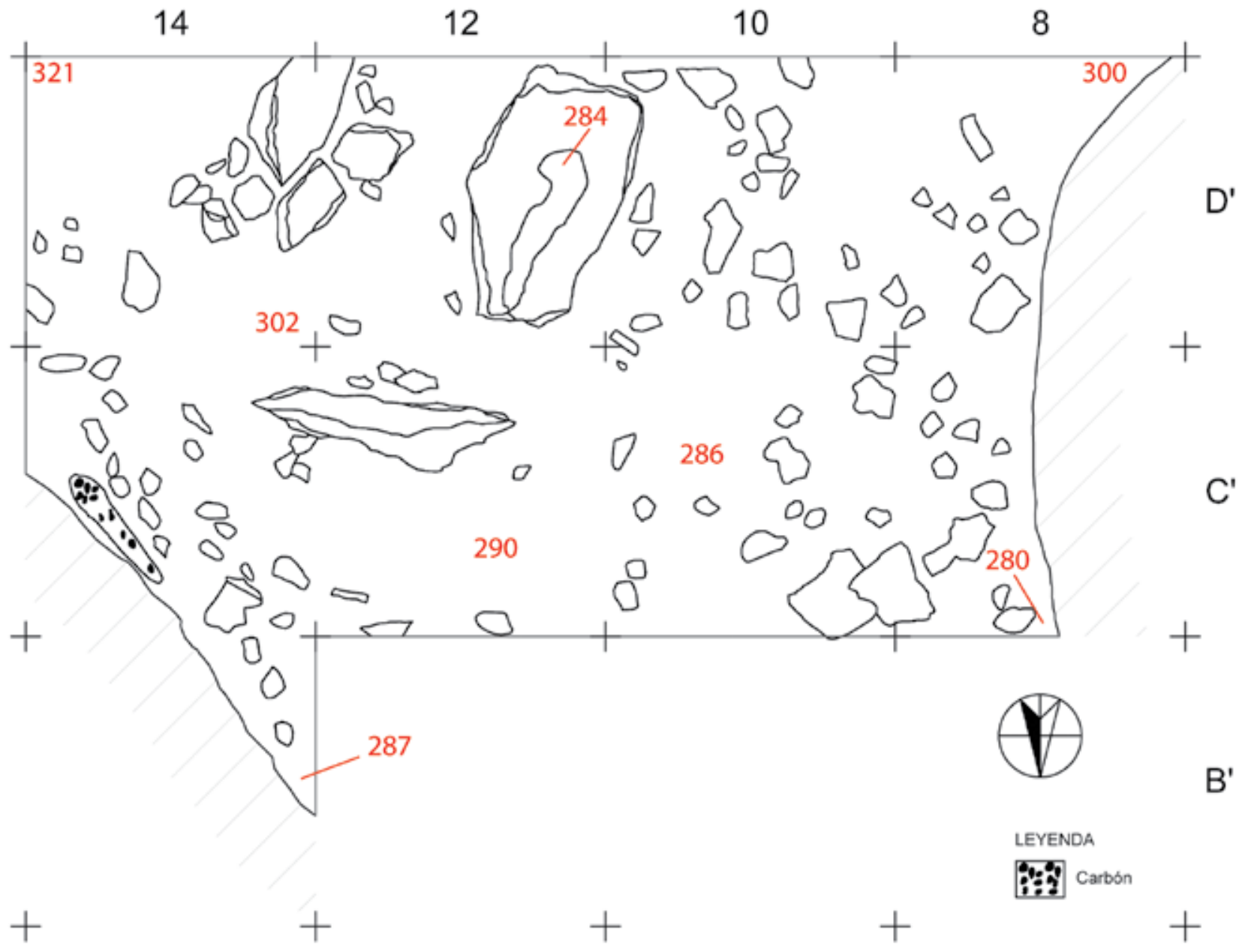

Figs. 72. Plano de la zona de tránsito entre el vestíbulo y la primera sala interior tras excavar el lecho 7 (nivel I) (Dibujo: X. Peñalver/Digitalización: J. Calvo). / Plan of the transit zone between the vestibule and the first inner room after excavating the layer 7 (Drawing: X. Peñalver/ Digitalisation: J. Calvo).

- Nivel II: formado por los subniveles I y II y ocupado el primero básicamente por un hogar, conteniendo el segundo gran cantidad de caracoles marinos.

- Nivel III: de escasa potencia y con presencia de industrias de tipología claramente diferenciada de los niveles anterior y posterior.

- Nivel IV: constituido por tierra arcillosa y piedras, prolongación del suelo de piedras que ocupa el vestíbulo.

- Nivel V: formado por tierra de color claro y piedras en disminución según se profundiza.

\subsubsection{Las bandas A, A' y B': el hogar}

\section{El nivel I}

Está formado por los subniveles I, II y III.

\section{Subnivel I.I}

El nivel superficial está ocupado en algunas zonas (banda B') por una fina capa de tierra de tipo arenoso y color amarillo claro, principalmente en las bandas centrales y occidentales (6 y 8 ), sin contener restos significativos.

\section{Subnivel I.II}

Está formado por una placa compacta de concreción que abarca la totalidad de la superficie con un espesor de entre 3 y $18 \mathrm{~cm}$, siendo más gruesa en la zona oeste del pasillo, principalmente en la parte más próxima a la pared.

\section{Subnivel I.III}

Por debajo de la capa de concreción aflora una tierra con una gama de colores que va del marrón oscuro (bandas 10 y 12) al amarillo (bandas 6 y 8 ) y que se ha excavado entre los lechos 2 y 7 (Fig. 72). En la parte inferior de este subnivel comienzan a aflorar carbones en algunas zonas de los cuadros 10D', 12C', 12D' y 14D', así como alguna piedra en los dos últimos, correspondientes al hogar del nivel II. 
Fig. 73. Plano de la zona de tránsito entre el vestíbulo y la primera sala interior tras excavar el lecho 9 (nivel II) (Dibujo: X. Peñalver/Digitalización: J. Calvo). / Plan of the transit zone between the vestibule and the first inner room after excavating the layer 9 (Drawing: X. Peñalver/Digitalisation: J. Calvo).

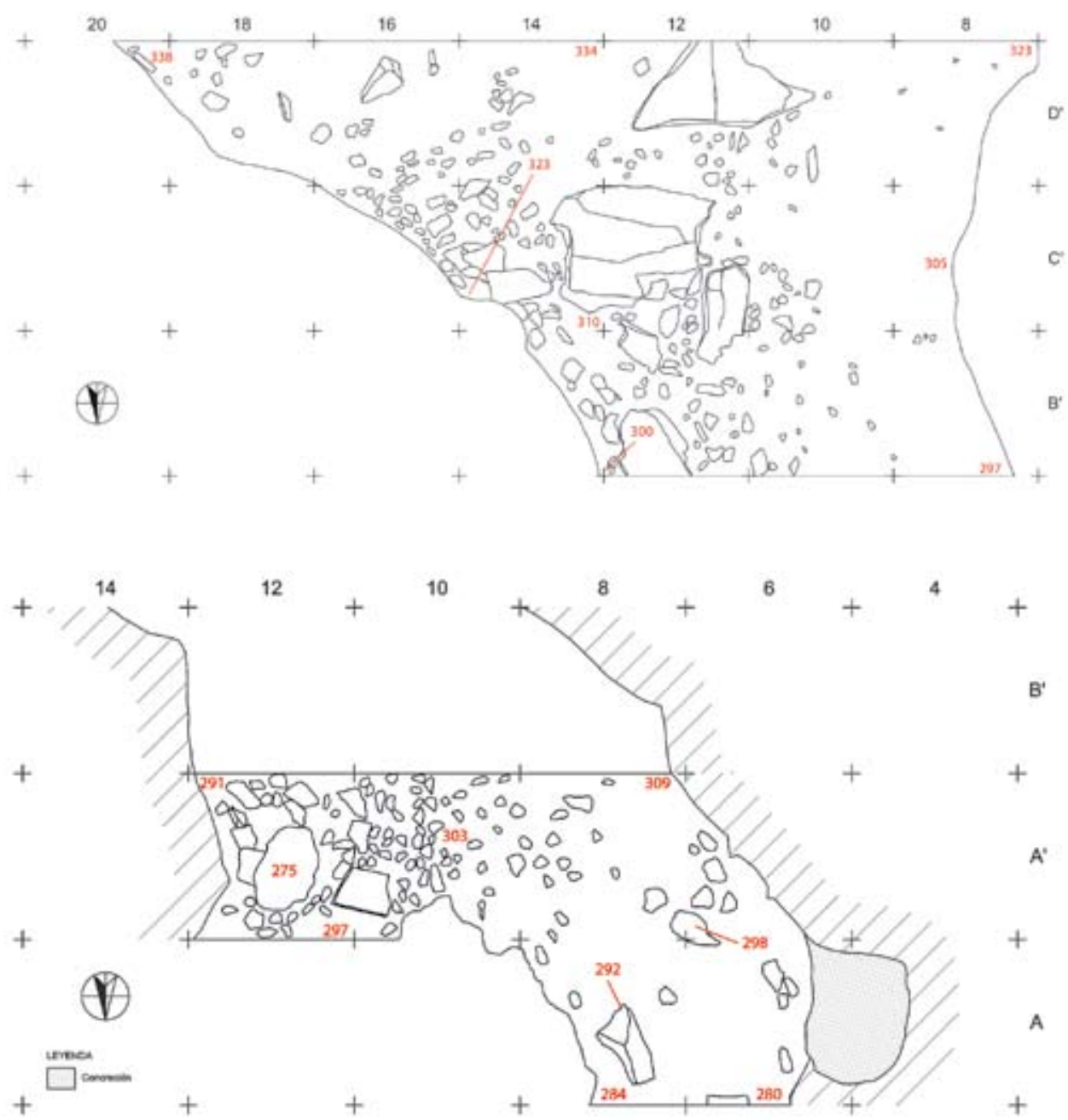

Fig. 74. Plano de la zona norte del tránsito entre el vestíbulo y la primera sala interior tras excavar el lecho 11 (nivel II) (Dibujo: X. Peñalver/Digitalización: J. Calvo). / Plan of the northern zone of the transit between the vestibule and the first inner room after excavating the layer 11 (Drawing: X. Peñalver/Digitalisation: J. Calvo).

\section{El nivel II}

Está constituido por los subniveles I y II.

\section{Subnivel II.I}

Está formado por un sedimento de color amarillo y de tipo arenoso. Se excava entre los lechos 8 y 12 (Figs. 73 y 74). A escasa profundidad aparecen los primeros restos de carbón (en las bandas A y A' -cuadros $6 A$, 8A y 8A'-, y en los cuadros 10B' y 12B'), así como algunas piedras de la estructura del hogar 1, en los límites del hogar 2.

\section{Descripción de las estructuras correspondientes al subnivel II.I}

En este nivel aparecen las estructuras relacionadas con el hogar que se detallarán a continuación. Durante los trabajos de excavación se han detectado dos unidades diferentes, interviniendo en ellas de forma separada, aunque posiblemente correspondan a un mismo hogar. A pesar de ello se describen como hogares 1 y 2, siguiendo el proceso de la excavación.

\section{Hogar 1}

Se localiza en la banda 8, dentro de los cuadros A, $A^{\prime}$ y B'; está adosado a la pared oeste de la zona de tránsito entre el vestíbulo y la primera sala interior, en la zona más próxima al vestíbulo. En su conjunto presenta una forma alargada, estando su eje mayor orientado en sentido norte-sur, y alcanza $3 \mathrm{~m}$ de longitud. El eje menor oscila entre 1,5 $\mathrm{m}$ en el extremo norte, y 0,50 $\mathrm{m}$ en el extremo sur. La parte norte está formada por carbones fundamentalmente ( $6 \mathrm{~A}, 8 \mathrm{~A}$ y $8 \mathrm{~A}^{\prime}$ y una pequeña parte del $\left.6 A^{\prime}\right)$, mientras que en la parte sur se localiza un conjunto de piedras (cuadros 8B' y mitad sur de 8A') entre las que destacan dos de forma alargada y parcialmente superpuestas. Presenta la inferior $70 \mathrm{~cm}$ de longitud y $35 \mathrm{de}$ anchura máxima, y la superior, $65 \mathrm{~cm}$ de longitud y 40 de anchura máxima. Las restantes son inferiores en dimensión, oscilando entre 4 y $40 \mathrm{~cm}$ de longitud máxima. En la zona norte de este conjunto de piedras destacan tres pequeñas lajas clavadas verticalmente (cuadro 8A'). Sus dimensiones varían entre 8 y $15 \mathrm{~cm}$ de longitud. Este conjunto de piedras está totalmente adosado a la pared (Figs. 75 a 77). 


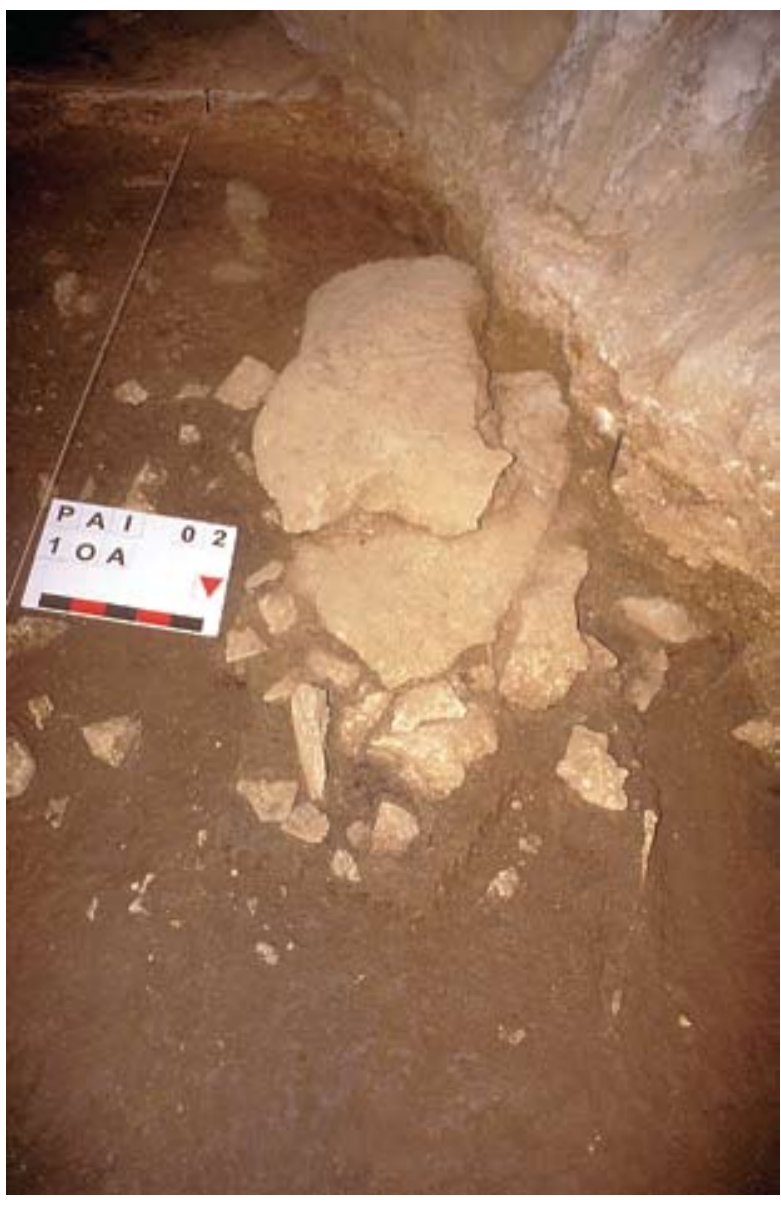

Fig. 75-76. Foto y dibujo de las piedras del hogar $n^{\circ} 1$ tras excavar el lecho 10 (nivel II) (Dibujo: X. Peñalver/Digitalización: J. Calvo). / Picture and drawing of the stones from the hearth no. 1 after excavating the layer 10 (Drawing: X. Peñalver/Digitalisation: J. Calvo).
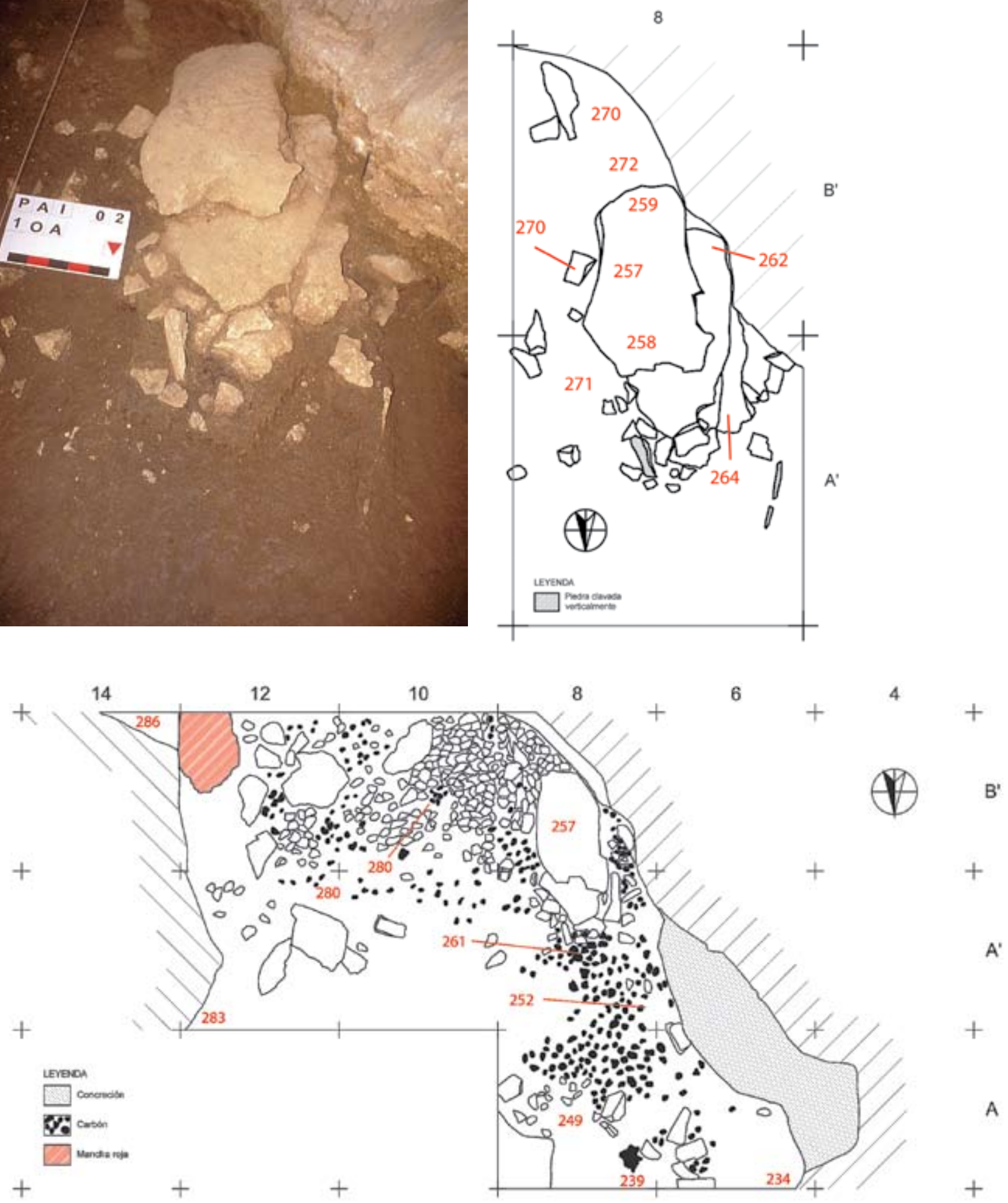

Fig. 77. Plano del hogar $n^{\circ} 1$ situado en la zona de tránsito entre el vestíbulo y la primera sala interior tras excavar el lecho 8 (nivel II) (Dibujo: X. Peñalver/Digitalización: J. Calvo). / Plan of the hearth no. 1 located on the transit zone between the vestibule and the first inner room after excavating the layer 7 (Drawing: X. Peñalver/Digitalisation: J. Calvo). 


\section{Subniveles correspondientes al hogar 1}

Está formado por varios subniveles sucesivos. De superior a inferior:

A: capa de sedimento con abundantes carbones en los cuadros 8A y 8A'.

B: nivel de piedras. Está constituido en su mayor parte por piedras planas de entre 10 y $25 \mathrm{~cm}$ situadas en las bandas A y A' (en los límites de lo que será el hogar 2). En el cuadro 8B', y en menor medida en el 8A', se sitúa una losa plana de 0,65 m de longitud máxima y una anchura de entre 0,45 y 0,30 m, dispuesta sobre otra losa situada en el cuadro 8A' de similares características. A su alrededor existen otras piedras de menores dimensiones, sobre todo en el cuadro 8A', todas ellas en posición muy horizontal, si bien en la zona central de este cuadro se localizan tres pequeñas lajitas clavadas verticalmente.

C: capa de carbones vegetales bajo las piedras planas del subnivel B de los cuadros 8A' y 8B'; aparecen más carbones que amplían los límites de esta parte del hogar.

D: nivel de piedras de menor tamaño, de entre 0,05 y $0,20 \mathrm{~m}$, totalmente planas. Forman la base de los carbones del subnivel $\mathrm{C}$.

\section{Hogar 2}

La excavación de esta estructura se ha realizado de forma conjunta, si bien previamente se ha efectuado una serie de ampliaciones hasta tener todo el hogar en planta. En un primer momento se han excavado las bandas $A$ y A' y la banda B', y una vez detectados los primeros restos, la excavación del mismo se ha paralizado, amplián- dose hacia el sur, a las bandas C' y D'. Estas dos bandas - una considerada como parte del tránsito entre el vestíbulo y la primera sala interior (C') y otra como parte de la primera sala interior (D')- se excavan conjuntamente con el fin de comprobar las dimensiones y características del hogar, hasta su nivelación con la banda B'.

Posteriormente, una vez definido el hogar 2 en su totalidad, se lleva a cabo su excavación de forma integral hasta el total vaciado de la cubeta en la que se sitúa. Esta intervención se ha realizado en sucesivas capas de entre 1 y $2 \mathrm{~cm}$ de potencia dejando en superficie la totalidad de los carbones vegetales, así como la tierra fuertemente enrojecida del entorno. Estos elementos van delimitando poco a poco la forma y las dimensiones del hogar situado en medio de la estrecha galería que, desde el vestíbulo, da paso a la primera sala interior, y que quedaría totalmente bloqueada por el mismo. Por otra parte la altura máxima del techo (bóveda) sobre el nivel del hogar en ese punto (cuadros 8B', 10B' y 12B' y 8C', $10 C^{\prime}$ y 12C') es muy escasa, no superando los $0,80 \mathrm{~m}$ en su punto central, lo que provoca el desprendimiento de pequeñas lajas de caliza del techo sobre el fuego en distintos momentos. Las dimensiones de esta estructura son de dos metros de diámetro (Figs. 78 a 83).

Fig. 78. Plano correspondiente al hogar epipaleolítico $n^{\circ} 2$ de la zona de tránsito entre el vestíbulo y la primera sala interior (lecho 12, nivel II) (Dibujo: X. Peñalver/Digitalización: J. Calvo). / Plan of the epipaleolithic hearth no. 2 from the transit zone between the vestibule and the first inner room (layer 12) (Drawing: X. Peñalver/ Digitalisation: J. Calvo).

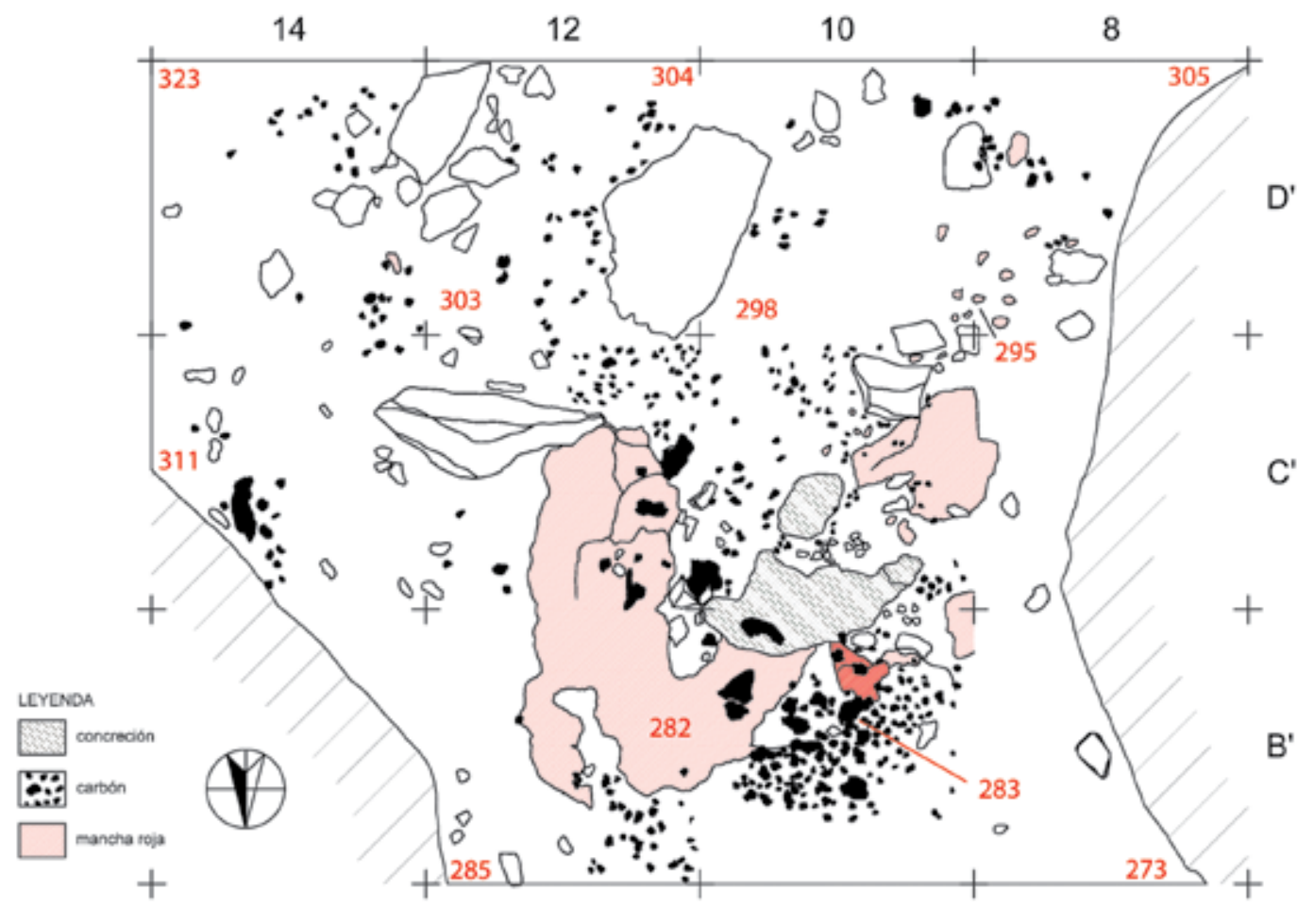



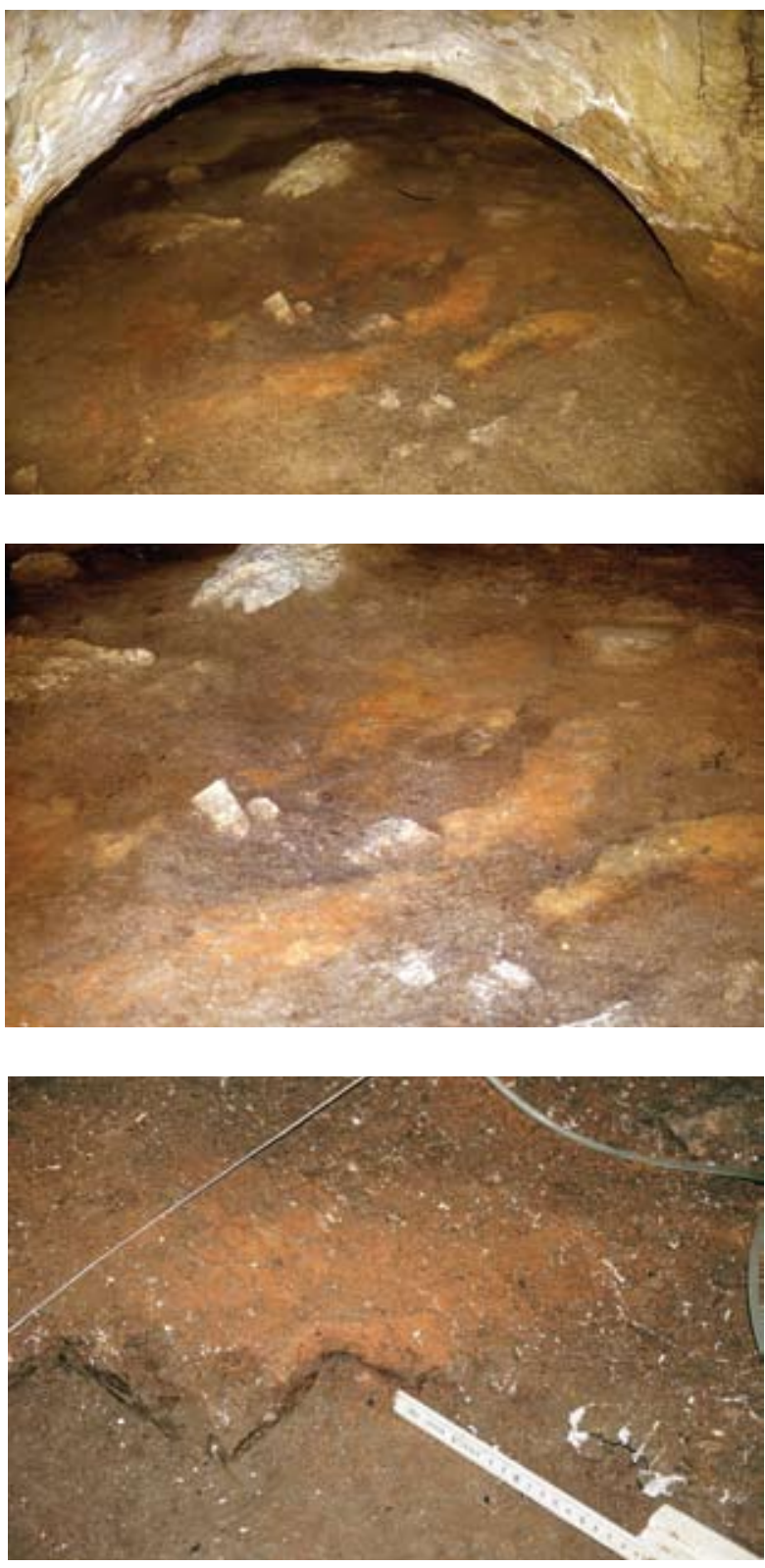

Fig. 79-83. Hogar epipaleolítico de la zona de tránsito entre el vestíbulo y la primera sala interior: diferentes aspectos de su excavación. / Epipaleolithic hearth from the transit zone between the vestibule and the first inner room: different views of its excavation."

\section{Subniveles correspondientes al hogar 2}

E: en los cuadros 8B' y 10B' y en una pequeña parte del 12B', se extiende un nivel de pequeñas piedras de entre 5 y $10 \mathrm{~cm}$ de dimensión. Están desprendidas de la bóveda situada encima del hogar, posiblemente por el calentamiento de este pequeño espacio.

F: nivel de carbones, los cuales se hacen progresivamente más abundantes según se desarrolla la excava-
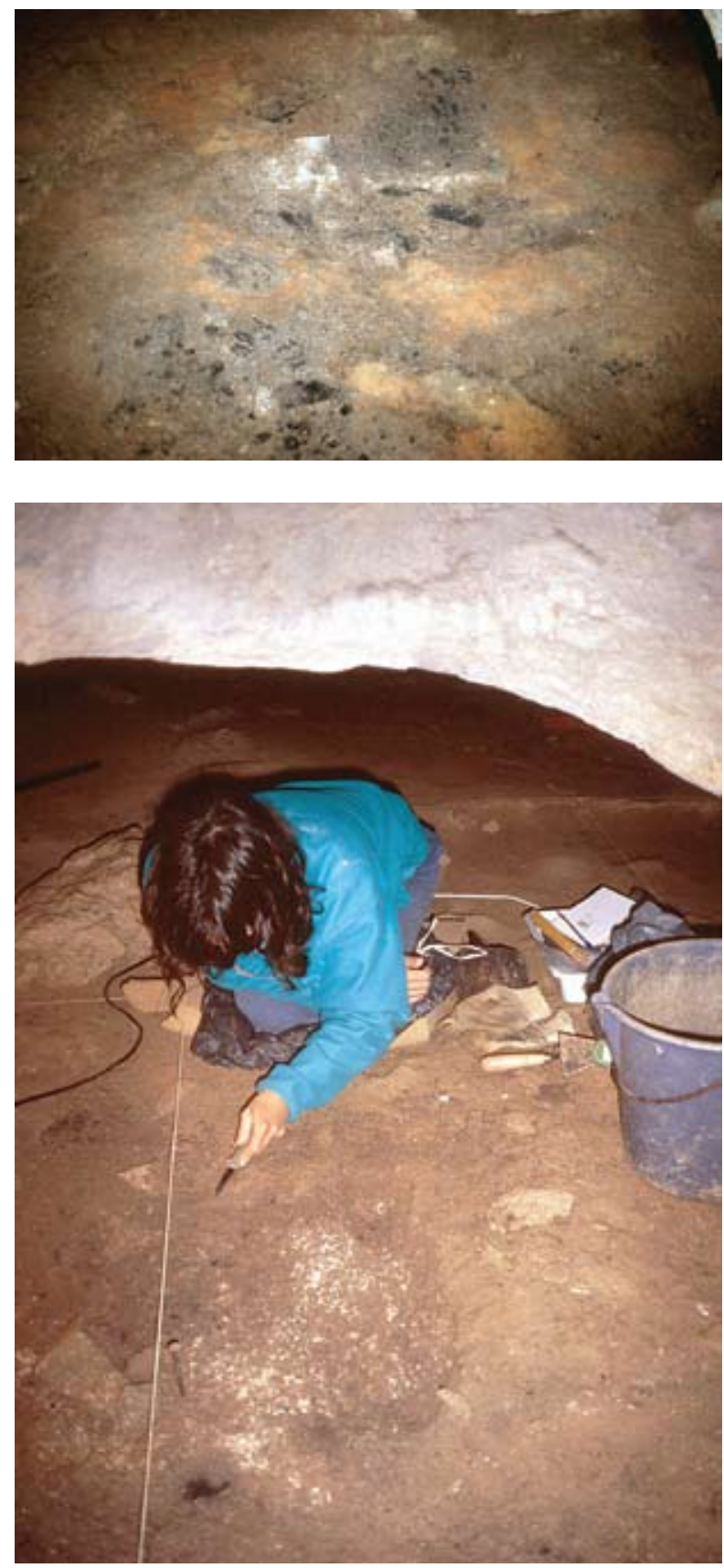

ción, a la vez que se extiende la superficie ocupada por los mismos.

G: nivel de tierra rubefactada por efecto del fuego del hogar. Destaca una mancha de tierra roja de $40 \mathrm{~cm}$ de lado del cuadro 12B'.

$\mathrm{H}$ : cubeta circular excavada en el subnivel II.II, que constituye la base sobre la que se asienta el hogar. Presenta una profundidad en el centro de entre 10 y $18 \mathrm{~cm}$. Por otra parte, esta zona, en su conjunto, tiene una ligera pendiente descendente en sentido norte-sur, mientras que en el eje este-oeste esa pendiente descendente es 
de oeste a este. Así, el eje norte-sur, que separa las bandas 10 y 12 en los cuadros B' y C', presenta una diferencia entre el extremo norte y el sur de $12 \mathrm{~cm}$, y entre el este y el oeste, de $14 \mathrm{~cm}$.

En la zona central de la misma afloran piedras similares a la cal, de color blanco, afectadas por el calor. Conforme se va delimitando la cubeta se observa en su interior plaquitas de piedra quemadas, probablemente desprendidas del cercano techo por la acción del calor.

Este hogar (hogar 2) ha sido datado por C14 a través de una muestra recogida en el cuadro 10B' proporcionado una fecha de $8940 \pm 50$ B.P.

\section{Fases del hogar 2}

A continuación se describen las fases en las que se ha llevado a cabo el proceso de excavación del hogar 2:

\section{Fase 1}

La superficie excavada abarca los cuadros 8B', 10B', 12B', 8C', 10C', 12C', 14C', 8D', 10D', 12D' y 14D', si bien la zona de máxima densidad de restos de la combustión corresponde a los 10B', 12B', 10C' y 12C'. En estos cuatro cuadros la mancha roja cubre la parte sur del cuadrante suroeste del 12C', la mayor parte del cuadrante noroeste del mismo cuadro, gran parte del suroeste del 12B' y del sector sureste del 10B', así como del suroeste del 10C'. Así mismo ocupa una estrecha banda de en torno a $10 \mathrm{~cm}$ de anchura de los sectores noreste y sureste de los cuadros 12B' y 12C'.

Las manchas de carbón se concentran principalmente en los sectores noroeste y suroeste del cuadro $12 C^{\prime}$, en el sector noreste del 10C' y en la totalidad del 10B'. En el resto de los cuadros son también abundantes los carbones, aunque formando concentraciones de menor densidad. En la zona de contacto de los cuadros 10C' y 10B' aflora una superficie con finas placas blancas de caliza con una longitud de $80 \mathrm{~cm}$ este-oeste y una anchura máxima de $40 \mathrm{~cm}$ norte-sur. En la zona central del hogar aparecen escasas piedras de entre 3 y $15 \mathrm{~cm}$, alcanzando un tamaño muy superior algunas de las ubicadas en la zona más periférica, incluso de hasta $80 \mathrm{~cm}$ en el caso de una situada entre los cuadros 10D' y 12D'.

\section{Fase 2}

Se mantienen en esta fase las distribuciones de carbones, manchas rojizas y plaquetas de caliza de la fase 1 con algunas variaciones: se define en este momento una mancha central de carbón que se sitúa en la zona de contacto entre los cuadros 10C' y 12C', alcanzado una dimensión de $65 \mathrm{~cm}$ en sentido norte-sur y de 20 $\mathrm{cm}$ en sentido este-oeste. A partir de ese núcleo central de carbones la mayor densidad se produce dentro del cuadro 10B' de una manera generalizada. Por lo que se refiere a las manchas rojas, se mantienen las descritas en la fase 1, extendiéndose a la zona sur del cuadro 10C' y a la norte del 10D'. Las plaquetas finas de caliza se abren hacia el sur ocupando gran parte de la mitad norte del cuadro 10C'.

\section{Fase 3}

Los trabajos de excavación realizados modifican en parte las superficies ocupadas por los diferentes restos, quedando del siguiente modo: los carbones situados en el núcleo central, entre los cuadros 10C' y 12C' van reduciéndose, quedando agrupaciones aún compactas pero separadas las unas de las otras, a diferencia de la fase anterior en que formaban una unidad. Sin embargo, aparecen algunas concentraciones importantes en el sector noreste del cuadro 10C' y en el sector noroeste del 12C'. La mancha roja se extiende en la fase 2 al cuadro 10C' cubriendo casi la totalidad del espacio, sustituyendo a la superficie de plaquitas de caliza además de otras zonas próximas. Así mismo se extiende por el área que ocupaban estas plaquitas en el sur del cuadro 10B'.

\section{Fase 4}

Se corresponde con la base arcillosa del hogar. Una vez eliminada la totalidad de restos de carbón vegetal, las manchas rojas y las placas finas de caliza, la superficie de la arcilla, base del hogar, presenta una cubeta de entre 10 y $18 \mathrm{~cm}$ de profundidad.

\section{Valoración de las estructuras correspondientes a los hogares}

Tal y como se ha mencionado anteriormente, la cercanía entre los dos hogares, así como la escasa diferencia en cotas con el que se acaba de describir, hace pensar que ambos sean parte de un mismo hogar.

\section{Subnivel II.II}

Se ha excavado entre los lechos 13 y 16 (Figs. 84 a 86). En las bandas B', C' y D' este nivel se corresponde con los lechos excavados bajo el hogar, siendo común en él la presencia de caracoles marinos -en su mayoría Littorina obtusata y Littorina saxatilis (RIGAUD et al., 2014)-. La parte superior de este subnivel presenta un sedimento de color marrón oscuro con presencia de piedras de pequeño tamaño repartidas por la mayor parte de los cuadros. Así mismo aparecen algunas piedras de en torno a $80 \mathrm{~cm}$ en los cuadros 10D' y 12D', 12C' y $14 C^{\prime}$. En este último cuadro aflora una placa de concreción de $50 \mathrm{~cm}$. En las bandas 8 y 10, concretamente en los cuadros 8B', 10B', 8D' y 10D', la tierra marrón, aquí menos oscura, presenta pequeños puntos blancos de fragmentación de caracoles terrestres. Inmediatamente por debajo el color de la tierra se aclara ligeramente en los cuadros 12D' y 14D', a la vez que en algunos 


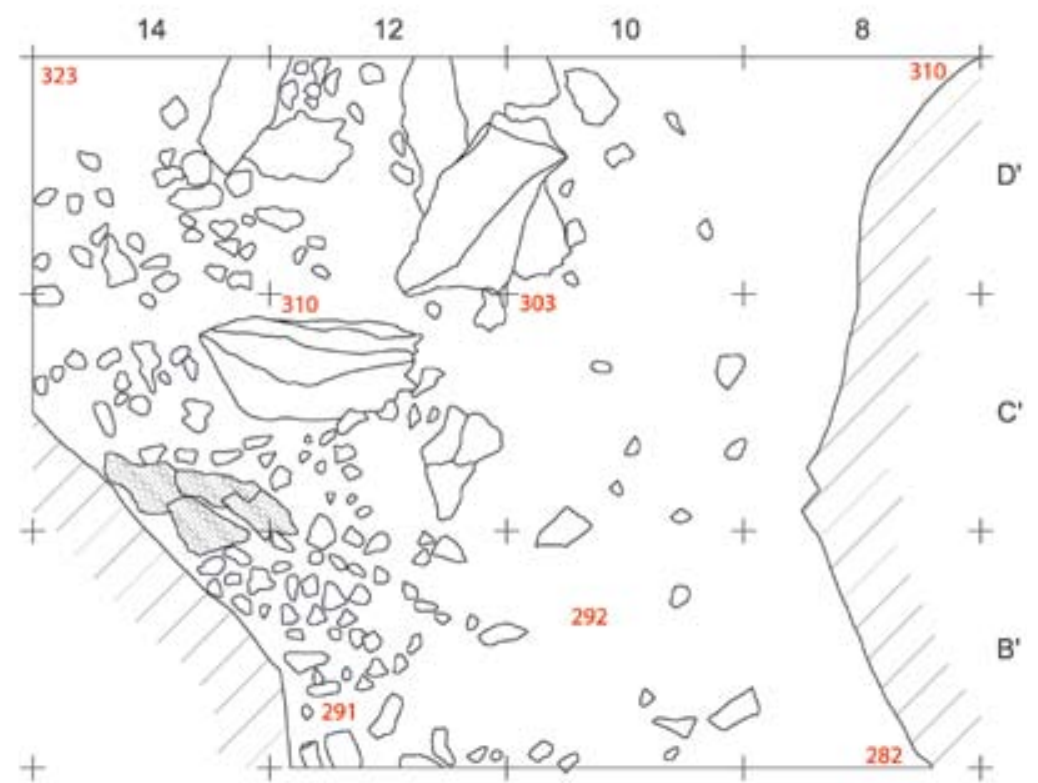

Fig. 84. Plano de la zona de tránsito entre el vestíbulo y la primera sala interior tras excavar el lecho 14 (nivel II) (Dibujo: X. Peñalver/Digitalización: J. Calvo). / Plan of the transit zone between the vestibule and the first inner room after excavating the layer 14 (Drawing: X. Peñalver/Digitalisation: J. Calvo).

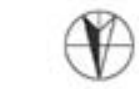

urveson

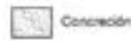

Fig. 85. Zona de tránsito entre el vestíbulo y la primera sala interior tras excavar el lecho 16 unificado. / Transit zone between the vestibule and the first inner room after excavating the layer 16 united.

Fig. 86. Plano de la zona de tránsito entre el vestíbulo y la primera sala interior tras excavar el lecho 16 (nivel II) (Dibujo: X. Peñalver/Digitalización: J. Calvo). / Plan of the transit zone between the vestibule and the first inner room after excavating the layer 16 (Drawing: X. Peñalver/ Digitalisation: J. Calvo).
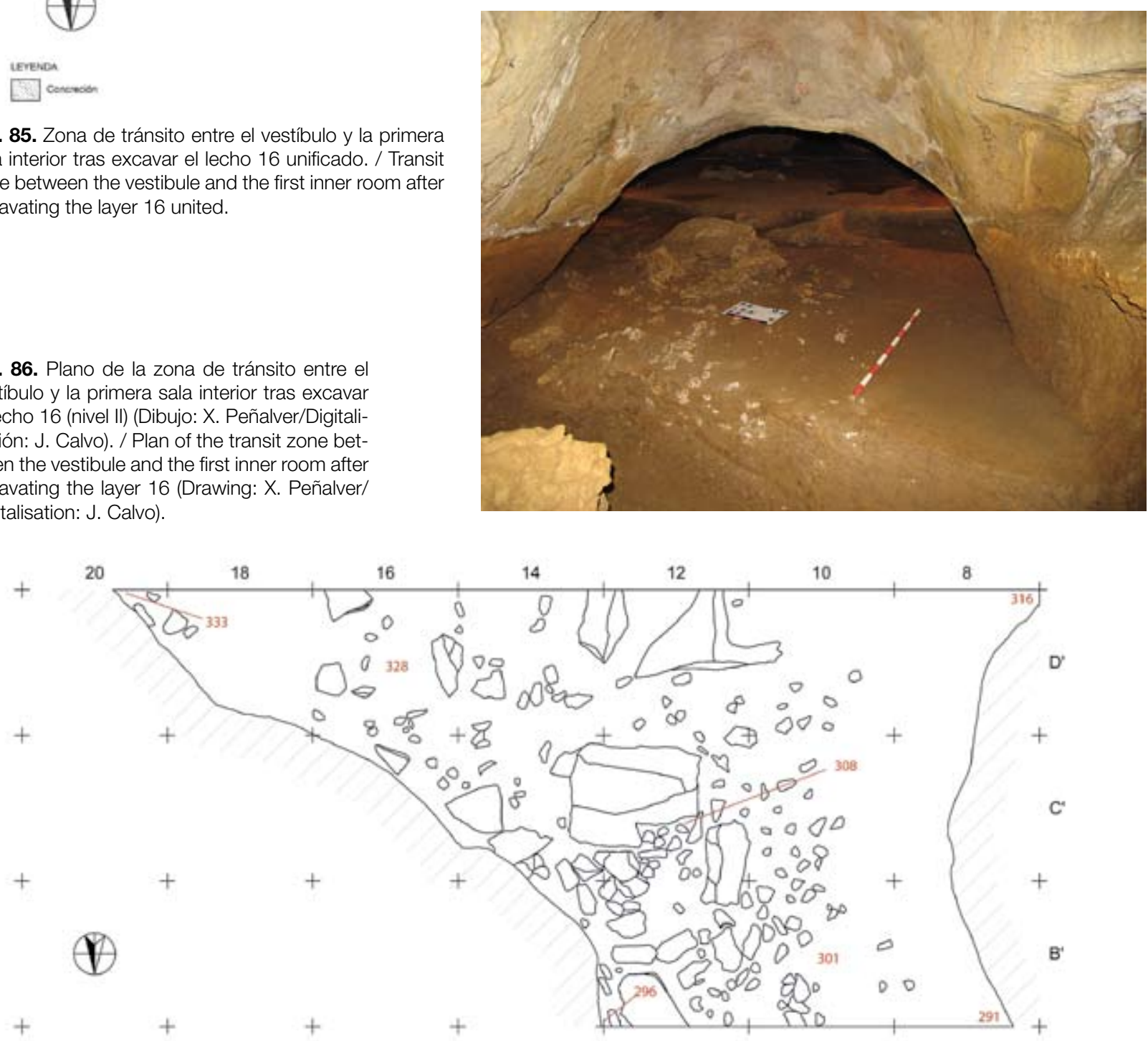

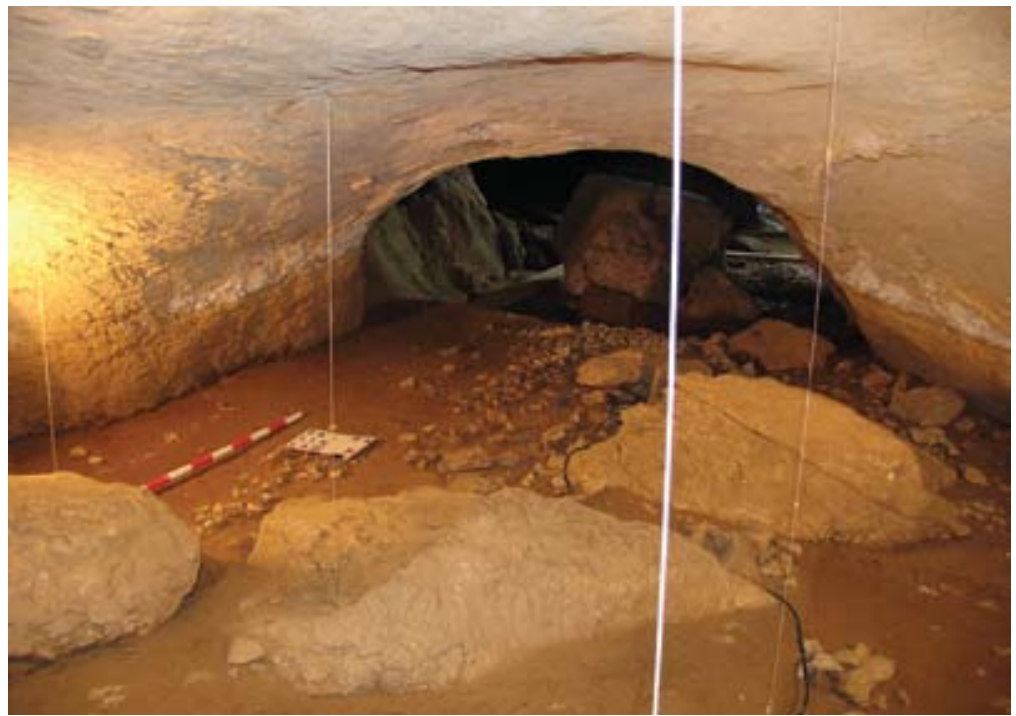

Fig. 87. Zona de tránsito entre el vestíbulo y la primera sala interior tras excavar el lecho 19 unificado. / Transit zone between the vestibule and the first inner room after excavating the layer 19 united. cuadros de las bandas 8 y 10 continúan los pequeños puntos blancos de caracolillos terrestres. El número de piedras de pequeño tamaño de las bandas 12 y 14 ha disminuido en parte, aflorando algunas de tamaño medio (en torno a $25 \mathrm{~cm}$ ). Continúa la presencia de caracoles marinos. Progresivamente el color del sedimento se va diversificando en esta zona y mientras en las bandas 18 y 20 está formado básicamente por tierra amarilla plástica muy limpia, en las bandas 12, 14 y 16, así como en la mitad este de la 10, presenta color marrón, siendo más suelto y con abundante piedra que alcanza tamaños medianos y grandes en las bandas 12 y 14. La banda 8 y la mitad oeste de la 10 no presentan piedras, siendo la tierra más oscura, suelta y manteniéndose los fragmentos de caracoles blancos.

\section{El nivel III}

Se ha detectado en las bandas A y A' a partir de la presencia de un arpón próximo a la zona de concreción en el cuadro 6A, en un nivel de piedras de tamaño medio. Se corresponde con el lecho 17.

\section{El nivel IV}

Se ha excavado entre los lechos 18 y 20, estando formado por un sedimento de tipo arcilloso plástico, en las bandas A y A', y color marrón con presencia de piedras, en ocasiones de tipo blanquecino, menos frecuentes en las bandas 6 y 8 (Figs. 87 y 88). En las bandas B', C' y D' el sedimento presenta un color que oscila entre el

Fig. 88. Plano de la zona de tránsito entre el vestíbulo y la primera sala interior tras excavar el lecho 18 (nivel IV) (Dibujo: X. Peñalver/ Digitalización: J. Calvo). / Plan of the transit zone between the vestibule and the first inner room after excavating the layer 18 (Drawing: X. Peñalver/Digitalisation: J. Calvo).

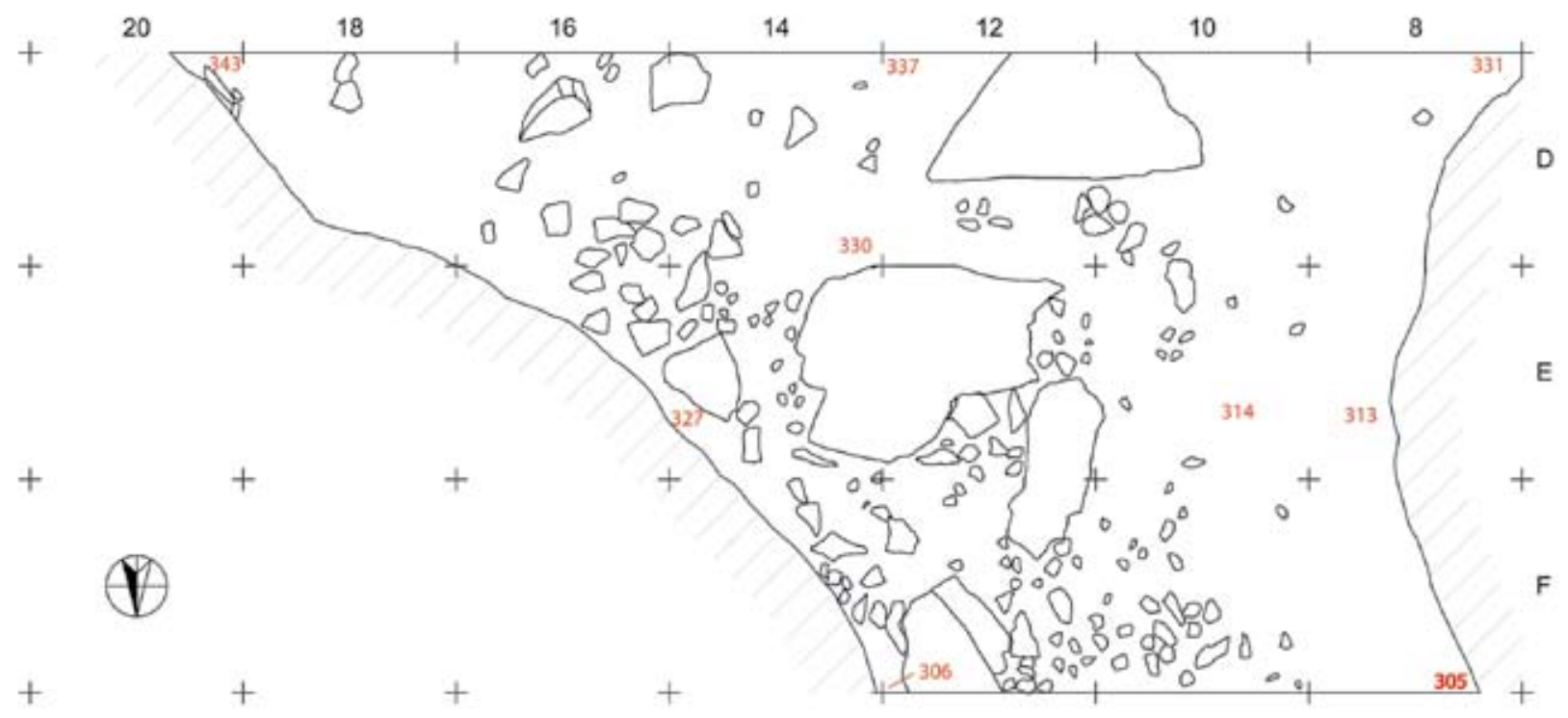


Fig. 89. Zona de tránsito entre el vestíbulo y la primera sala interior tras excavar el lecho $21 . /$ Transit zone between the vestibule and the first inner room after excavating the layer 21.

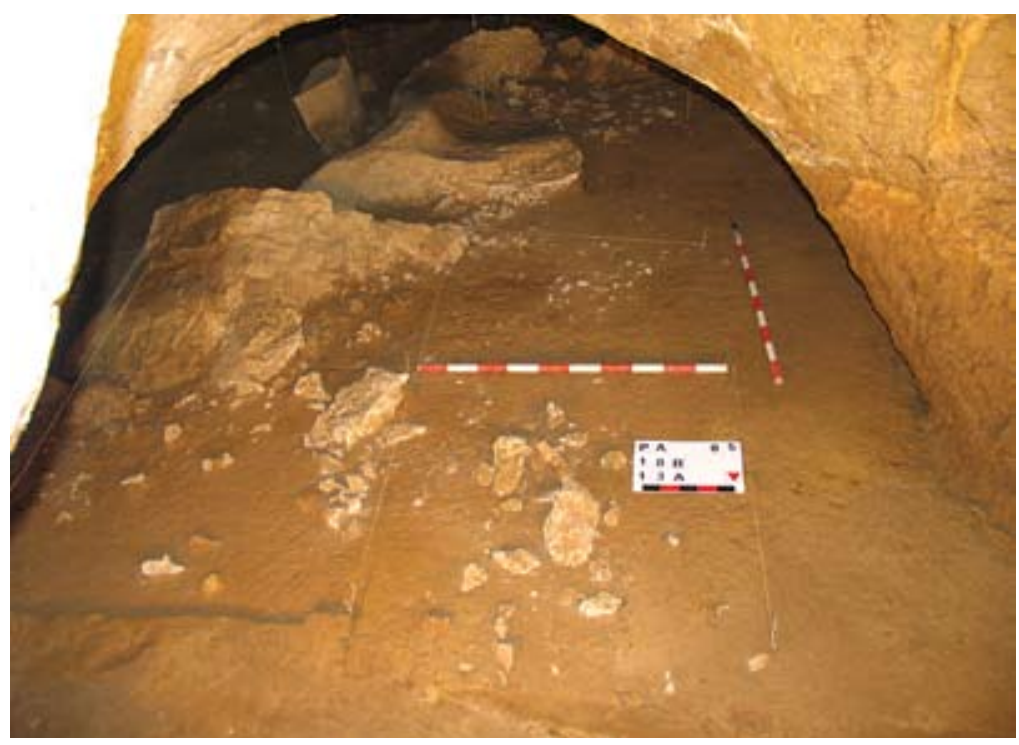

marrón y el amarillo, con piedras, sobre todo en las bandas situadas más al este, aunque muy escasas y en algunos casos inexistentes en las bandas 8 y 10. Destaca el hallazgo de un canto rodado negro (P.A.10A'.279.114) de características semejantes a los utilizados para la fabricación de colgantes.

\section{El nivel V}

Está constituido por los subniveles I y ||.

\section{Subnivel V.I}

Comprende los lechos 21 y 22, siendo el sedimento en las bandas A y A' de color amarillo tendiendo a naranja y de tipo plástico; cuenta con abundantes piedras calizas de color blanco, tanto de pequeño tamaño (entre 5 y $10 \mathrm{~cm}$ ) como grande (entre 25 y $50 \mathrm{~cm}$ ) (Fig. 89).

Por lo que se refiere a las bandas B', C' y D', el sedimento es muy semejante al inmediatamente superior si bien ahora las piedras de tamaño pequeño y medio disminuyen en las zonas que eran más abundantes, aunque se mantienen las de mayor tamaño.

\section{Subnivel V.II}

Comprendido entre los lechos 23 y 26; dentro del lecho 23 perduran algunas piedras en una tierra limosa y amarilla con pequeños cantos rodados, dando la impresión de que ha podido correr algún curso de agua entre la pared de la cueva y un gran bloque calizo existente en el sector. Esta tierra limosa continúa a lo largo de los lechos 24 y 25, desapareciendo casi totalmente las piedras en el último lecho.

Se aprecia también una concentración de gravilla en algunas áreas de los cuadros 8B', 8C', 8D', 10B', 10C' y 10D'.

\subsubsection{Adscripción cronocultural de los niveles del tránsito entre el vestíbulo y la primera sala interior}

Tras la unificación de los sucesivos lechos estratigráficos de esta zona de tránsito entre el vestíbulo y la primera sala interior, se han establecido cinco niveles, cuatro de ellos asociados a otros tantos momentos culturales:

- Nivel I: lo componen los subniveles I, II y III.

- Subnivel I.I: está formado por una fina capa de sedimento superficial que afecta a algunas zonas, coincidiendo con el lecho 1.

- Subnivel I.Il: se corresponde con la capa de concreción estalagmítica cuyo espesor oscila entre 2 y 18 centímetros, habiéndose excavado en el lecho 1 bis.

- Subnivel I.III: está constituido por capas de sedimento muy uniformes, sin restos significativos y se ha excavado entre los lechos 2 y 7.

Este nivel I no ha podido asignarse a un nivel cultural por la ausencia de restos.

- Nivel II. Lo componen los subniveles I y II.

- Subnivel II.I: está ocupado en gran parte de su superficie por un gran hogar, abarcando los lechos comprendidos entre el 8 y el 12. Corresponde al período Epipaleolítico.

- Subnivel II.II: afecta a una parte considerable de la zona, y predomina la presencia de caracoles marinos (Littorina obtusata y Littorina saxatilis) de pequeñas dimensiones. Se corresponde con los lechos comprendidos entre el 13 y el 16. Este subnivel pertenece asimismo al Epipaleolítico.

- Nivel III: ha sido detectado a partir de un pequeño número de restos, entre los que destaca un arpón, y coincide con el lecho 17. Se adscribe al Magdaleniense Superior-Final. 


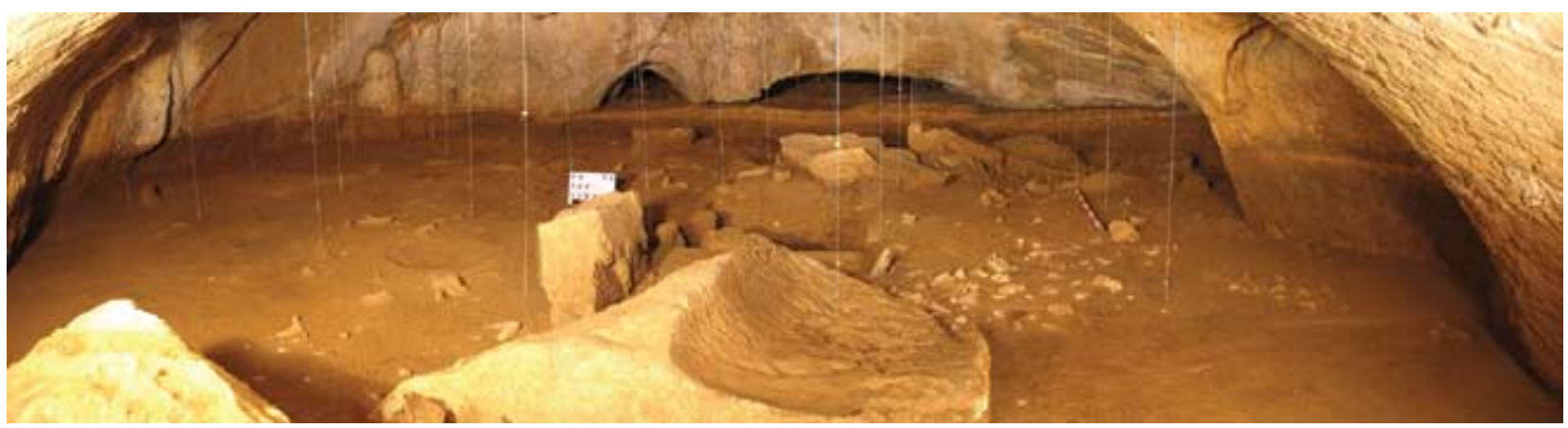

Fig. 90. Vista general de la primera sala interior durante su excavación. / General view of the first inner room during its excavation.

- Nivel IV: se corresponde con el nivel de empedrado del vestíbulo así como con la presencia de colgantes en el vestíbulo y en la primera sala interior. Se excava entre los lechos 18 al 20. Pertenece al Magdaleniense Inferior.

- Nivel V: lo componen los subniveles I y II.

- Subnivel V.l: está constituido por un sedimento de color amarillo, con escasas piedras según se profundiza, y que se ha excavado entre los lechos 21 y 22 en algunas zonas. Ha sido asignado al Solutrense.

- Subnivel V.II: está formado por un sedimento limoso con pequeños cantos rodados y gravillas. Comprende desde el lecho 23 al 26. Se adscribe al Solutrense.
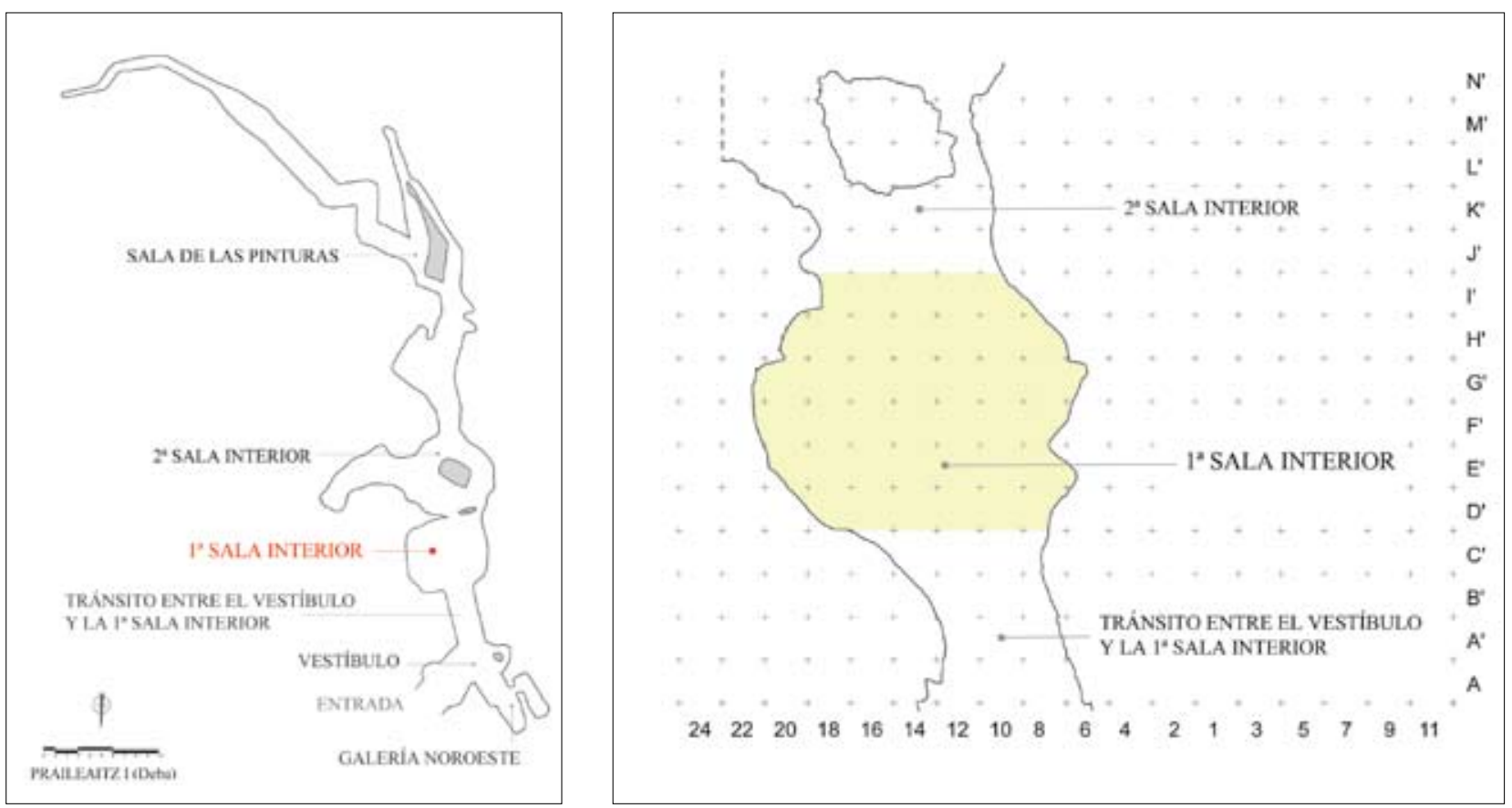

Fig. 91. Plano general de la cueva y ubicación de la primera sala interior (Dibujo G. Studer/Tx. Ugalde -Felix Ugarte Elkartea-). General plan of the cave and location of the first inner room (Drawing G. Studer/Tx. Ugalde -Felix Ugarte Elkartea-). 


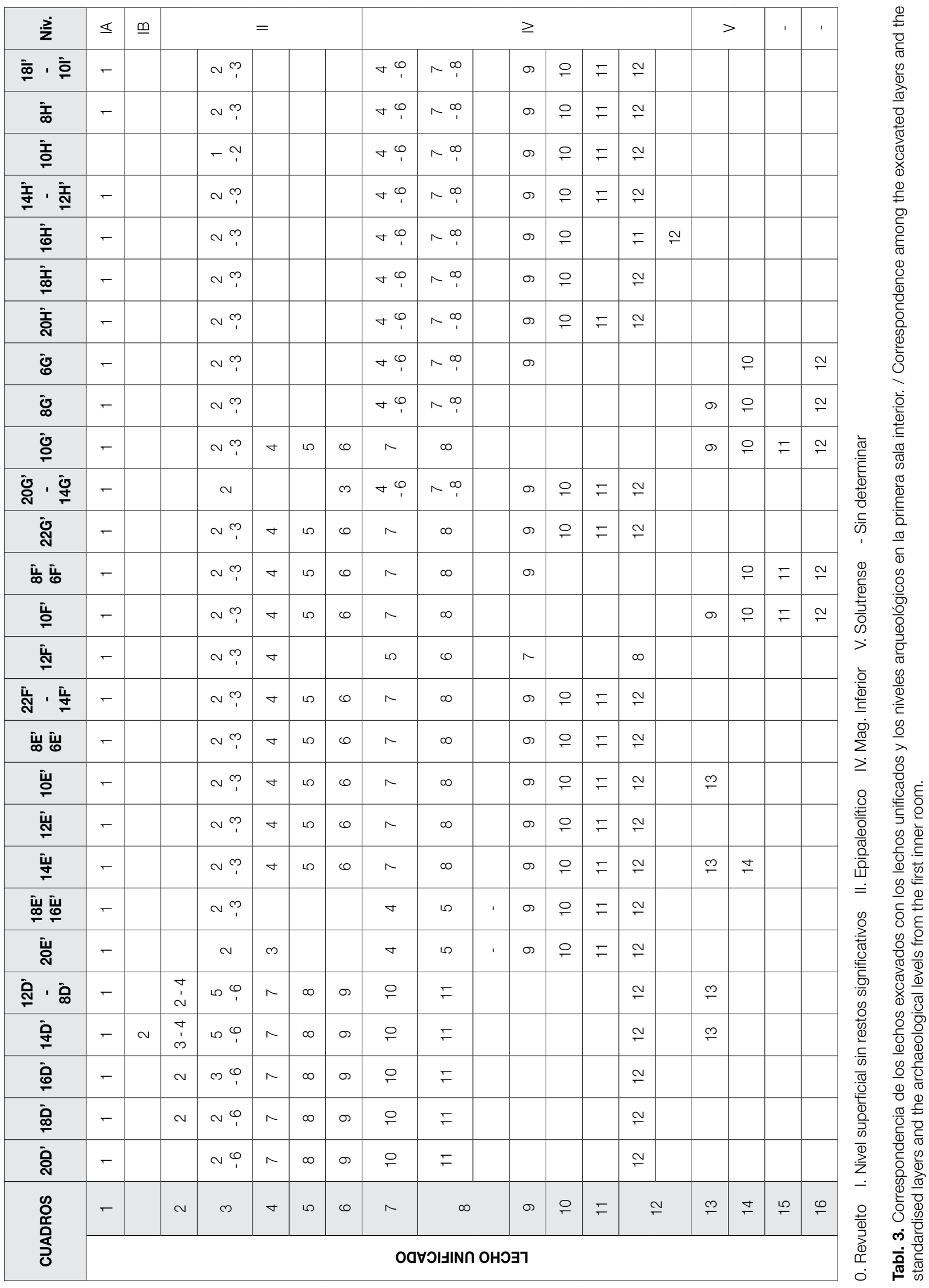


Fig. 92. Capa estalagmítica que cubría en su totalidad la primera sala interior. / Stalagmitic layer that used to cover the first inner room completely.

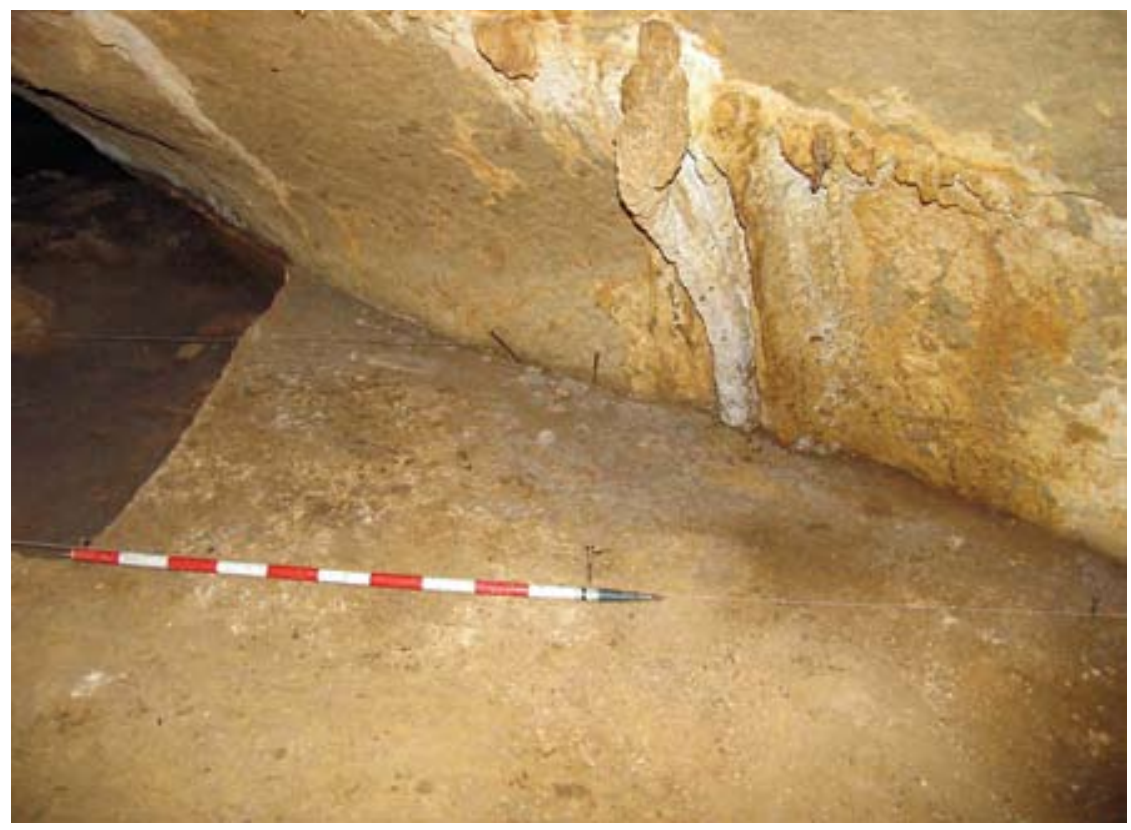

Con anterioridad a eliminar la capa de concreción presente en esta sala (Fig. 92), la inclinación del terreno es la siguiente: como característica general se puede decir que la sala es muy horizontal; sin embargo presenta un ligero descenso en dirección sur, que oscila entre los 8 y los $18 \mathrm{~cm}$. Dentro del extremo norte de la sala y en su zona central, se produce un descenso de oeste a este de en torno a $15 \mathrm{~cm}$, siendo casi horizontal en la zona sur de la sala, salvo un ligero levante del terreno en los cuadros más cercanos a la pared oeste.

En esta sala se había realizado, antes de iniciar este equipo los trabajos de excavación, una cata de 1x1 m que afectaba principalmente a los cuadros 18F' y 20E', y a parte del 18E' y 20F'; así mismo, en los cuadros $14 \mathrm{~F}^{\prime}$ y $16 F^{\prime}$ se aprecia la existencia de un agujero clandestino que se extiende hacia la banda G'. Presenta unas dimensiones de $60 \times 40 \mathrm{~cm}$, alcanzando una profundidad máxima de entre 25 y $30 \mathrm{~cm}$; se aprecia en el corte de la tierra la forma del azadón utilizado. Así mismo, antes de comenzar los trabajos de excavación en esta sala, se practicó una cata de $1 \times 1 \mathrm{~m}$ en el cuadro 12F' con el objetivo de conocer el potencial estratigráfico de la sala, rebajándose en lechos de entre 4 y $5 \mathrm{~cm}$ de potencia, un total de $65 \mathrm{~cm}$ de espesor, siendo los resultados los siguientes:

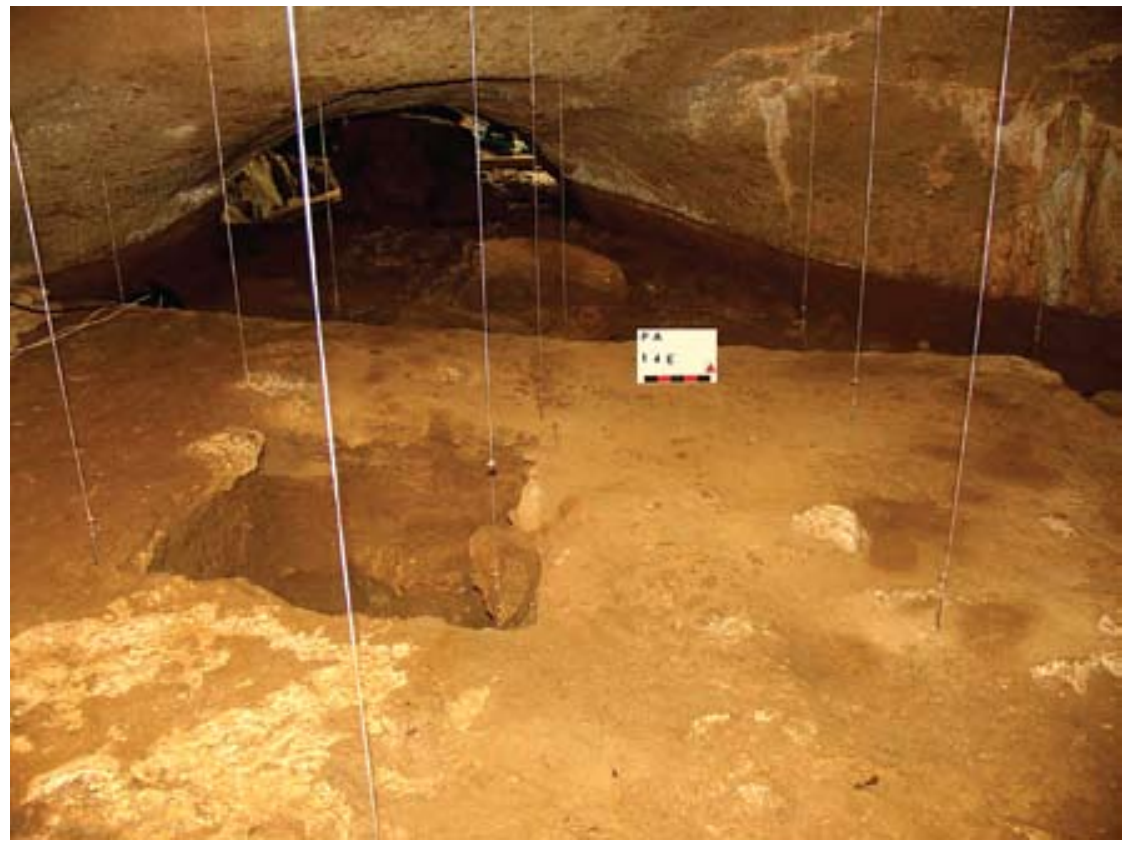

Fig. 93. Cata practicada en el cuadro $12 F^{\prime}$ de la primera sala interior. / Trial made in the square $12 F^{\prime}$ from the first inner room. 

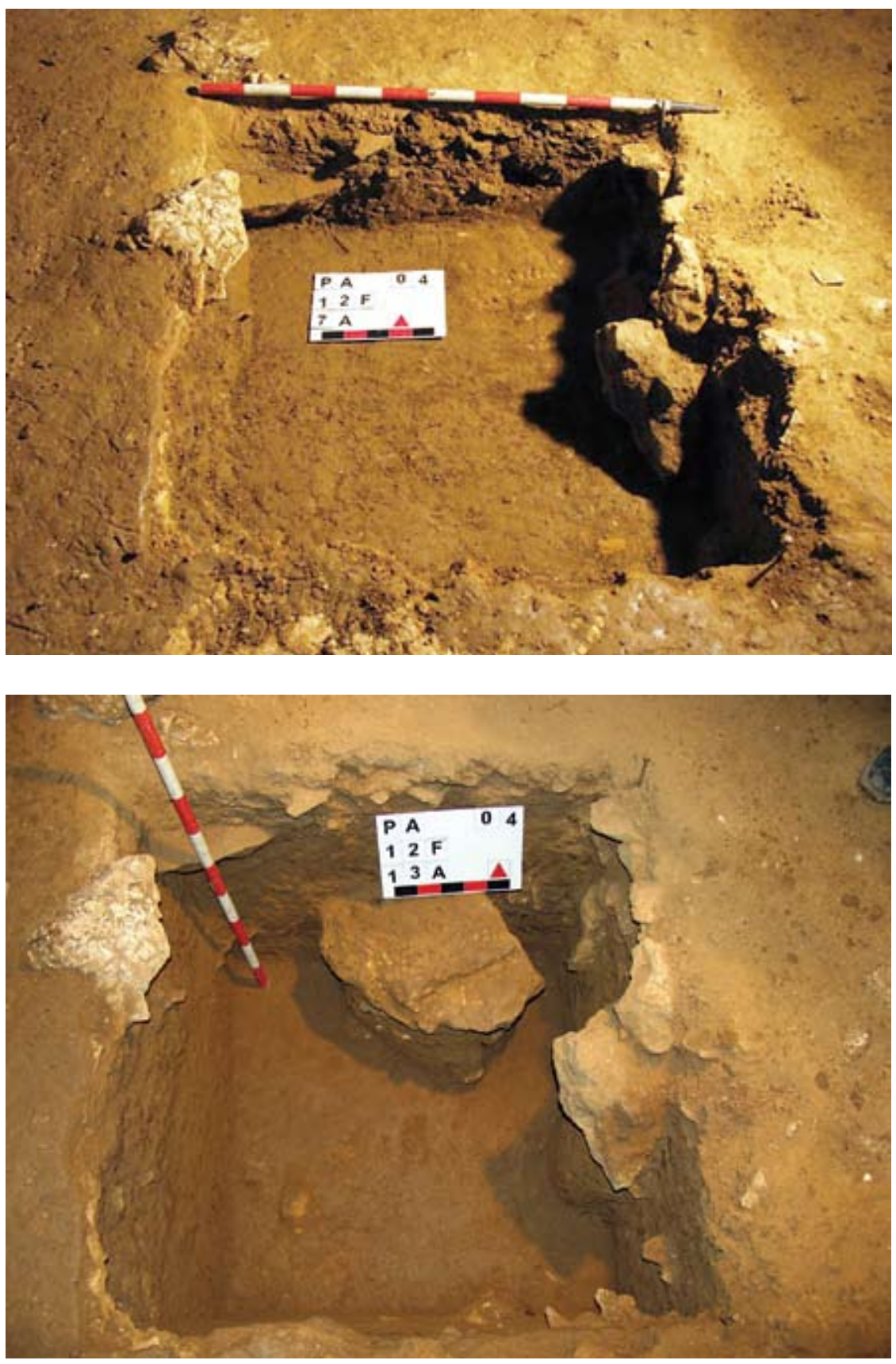

Figs. 94-95. Cata practicada en el cuadro 12F' de la primera sala interior. / Trial made in the square $12 F^{\prime}$ from the first inner room.
Se han efectuado un total de 13 lechos de los cuales los 8 primeros corresponden al paquete estratigráfico excavado en el conjunto de esta sala, el cual se sitúa en esta zona entre el Epipaleolítico y el Magdaleniense Inferior. Por debajo de esos 8 lechos se han excavado otros 5 más (Figs. 93 a 95).

La descripción de los niveles estratigráficos correspondientes a los 8 primeros lechos se incluyen en la estratigrafía general de esta primera sala interior en su conjunto (Tabl. 3).

Los últimos 5 lechos (del 9 al 13) presentan una tierra de color amarillento con una placa de $45 \times 50 \mathrm{~cm}$ de concreción y puntos de concreción en su base. Cuenta con algún fragmento de fauna pero carece de industrias, por lo que hasta la fecha no se ha podido precisar su adscripción cronocultural.

\subsubsection{La primera sala interior en su conjunto}

Los niveles diferenciados en esta sala (Figs. 96 y 97), con sus correspondientes lechos unificados, son los siguientes:

- Nivel superficial: compuesto por un sedimento revuelto. 

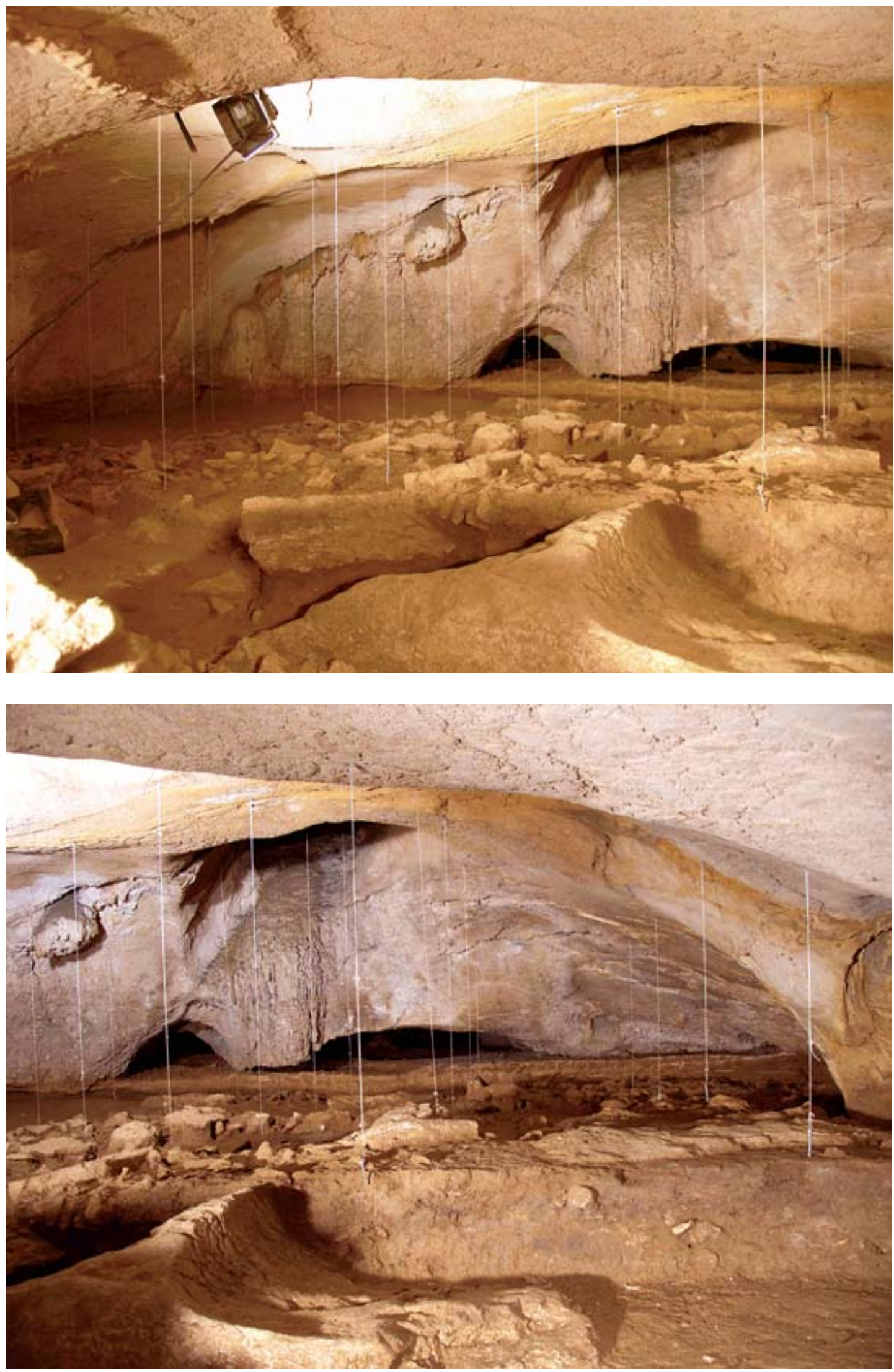

Figs. 96-97. Vista general de la primera sala interior. / General view of the first inner room. 

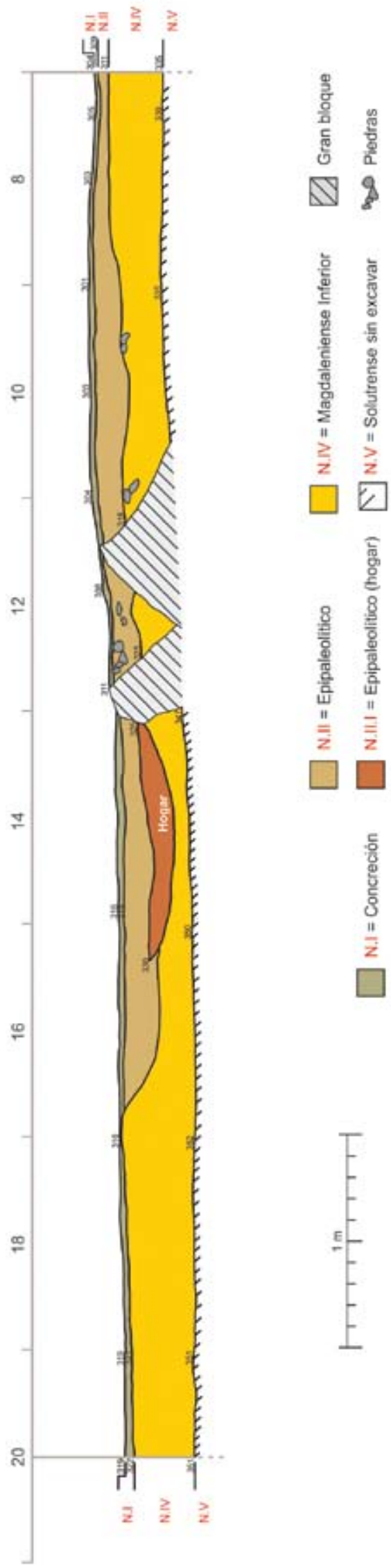

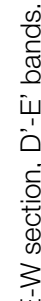

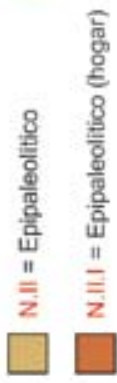


- Nivel I: incluye los subniveles I, II y III.

- Subnivel I.I: formado por sedimento sin restos y excavado en el lecho 1.

- Subnivel I.Il: constituido por una capa de concreción que afecta a la práctica totalidad de la sala.

- Subnivel I.III: consistente en un área de gours limitada a la parte noreste de la sala.

- Nivel II: incluye los siguientes subniveles:

- Subnivel II.I: capa de sedimento amarillo y arenoso en el ángulo noreste.

- Subnivel II.II: formado por sedimento de color marrón en toda la extensión de la sala excepto en el lateral este y en el ángulo noreste.

- Subnivel II.III: lo constituye un hogar en cubeta que alteró a los niveles inferiores.

- Subnivel II.IV: nivel de piedras localizado en la zona oeste de la sala.

- Subnivel II.V: sedimento de color marrón documentado debajo del subnivel II.IV.

- Nivel III: no está presente en esta parte de la cavidad, pero sí en el vestíbulo y en el pasillo de acceso entre éste y la primera sala interior.

- Nivel IV: compuesto por los subniveles I y || que comprenden los lechos que van del 7 al 12.

- Subnivel IV.I: está formado por un sedimento de arcilla amarilla.

- Subnivel IV.II: constituido por una capa de piedras planas que ocupa parte de la zona central de la sala.
- Subnivel IV.III: concentración de piedras irregulares en la zona oeste de la sala.

- Subnivel IV.IV: formado por tierra amarilla arcillosa.

- Nivel V: compuesto por un sedimento amarillo y algunas piedras, excavado en una zona del lado oeste de la sala, entre los lechos 13 y 16.

\section{Nivel I}

Este nivel se subdivide en 3 subniveles.

\section{El subnivel I.I}

Se corresponde con una fina capa de tierra superficial de color marrón presente en algunas zonas sobre una placa de concreción inferior (subnivel I.II).

\section{El subnivel I.II}

La mayor parte de la superficie de la sala está sellada por una capa estalagmítica de entre 5 y $15 \mathrm{~cm}$ de espesor, la cual, en algunas zonas, se transforma en una tierra concrecionada o se presenta en forma de finas capas con tierra intercalada. En los cuadros 18E' y 20E', tras eliminar la capa de concreción superficial, aún quedan algunos restos, existiendo carbones vegetales tanto sobre la concreción como bajo ella.

\section{El subnivel I.III}

Tras la eliminación de la totalidad de la concreción en los cuadros 18E' y 20E' (Fig. 99), bajo las zonas en don-

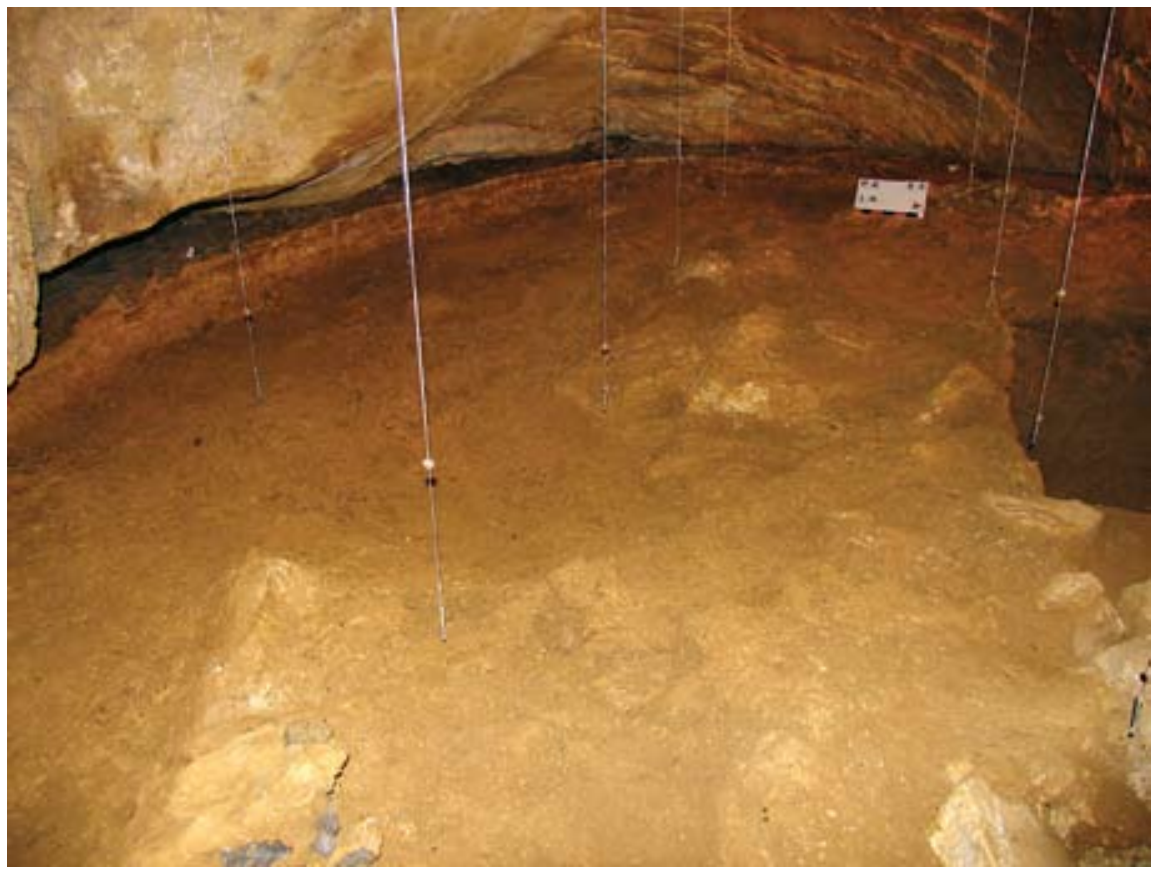

Fig. 99. Zona este de la primera sala interior tras excavar el lecho 1. / Eastern zone of the first inner room after excavating the layer 1 . 


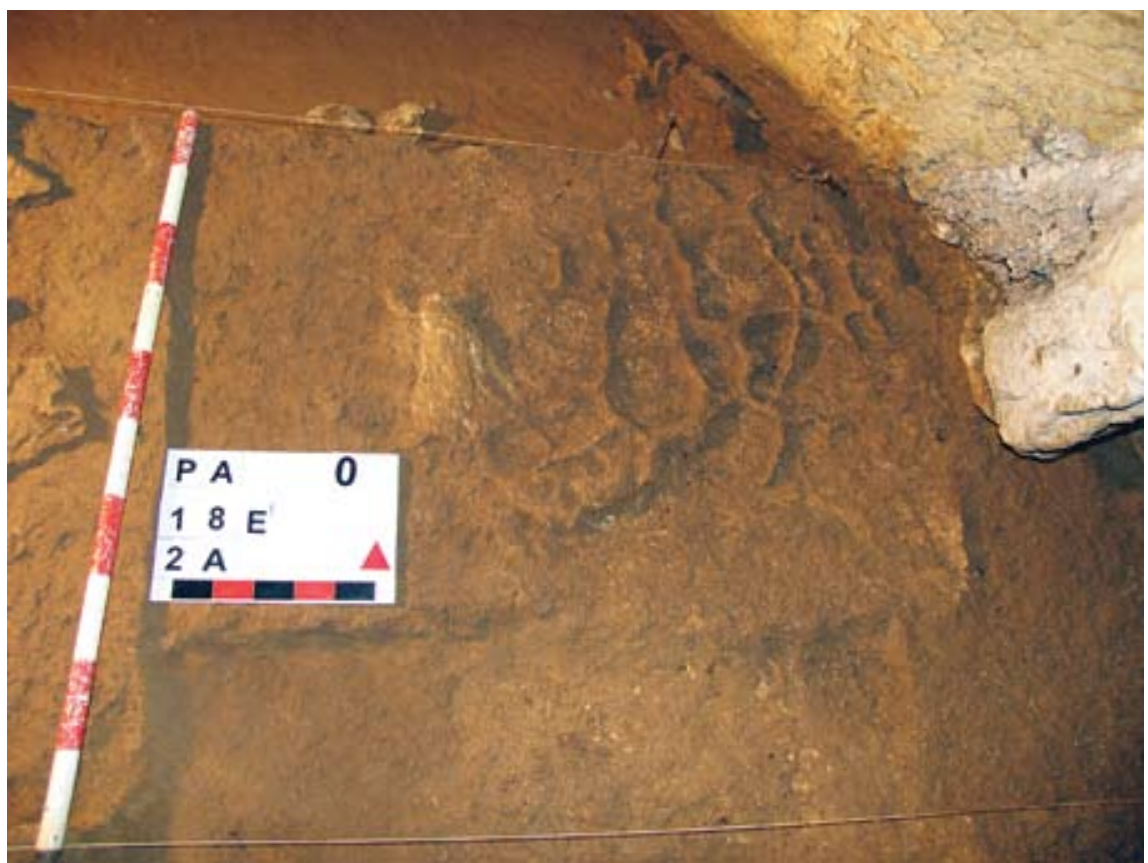

Fig. 100. Detalle del nivel superficial de la primera sala interior tras excavar el lecho 2. / Detail of the superficial level of the first inner room after excavating the layer 2.

de existía algo de tierra, aflora ahora un área de gours que afecta a la zona central del lado norte de ambos cuadros (Fig. 100).

Una vez eliminada la concreción, se observa que la sala cuenta con una gran horizontalidad, aunque con una pequeña bajada en los cuadros situados más al sur que dan paso a la segunda sala interior. Esta horizontalidad se va a mantener a lo largo de los sucesivos niveles de este espacio.
Por debajo del nivel I, y conforme va profundizando la excavación, se constata una clara diferencia entre las dos mitades este y oeste de esta primera sala interior a lo largo de los sucesivos niveles culturales, tal y como veremos a continuación.

\section{Nivel II}

Está formado por los subniveles II.I, II.II, II.III, II.IV y II.V, que se describen a continuación.
Fig. 101. Zonas central y oeste de la primera sala interior tras bajar el lecho 2. / Central and western zones of the first inner room after lowering the layer 2.

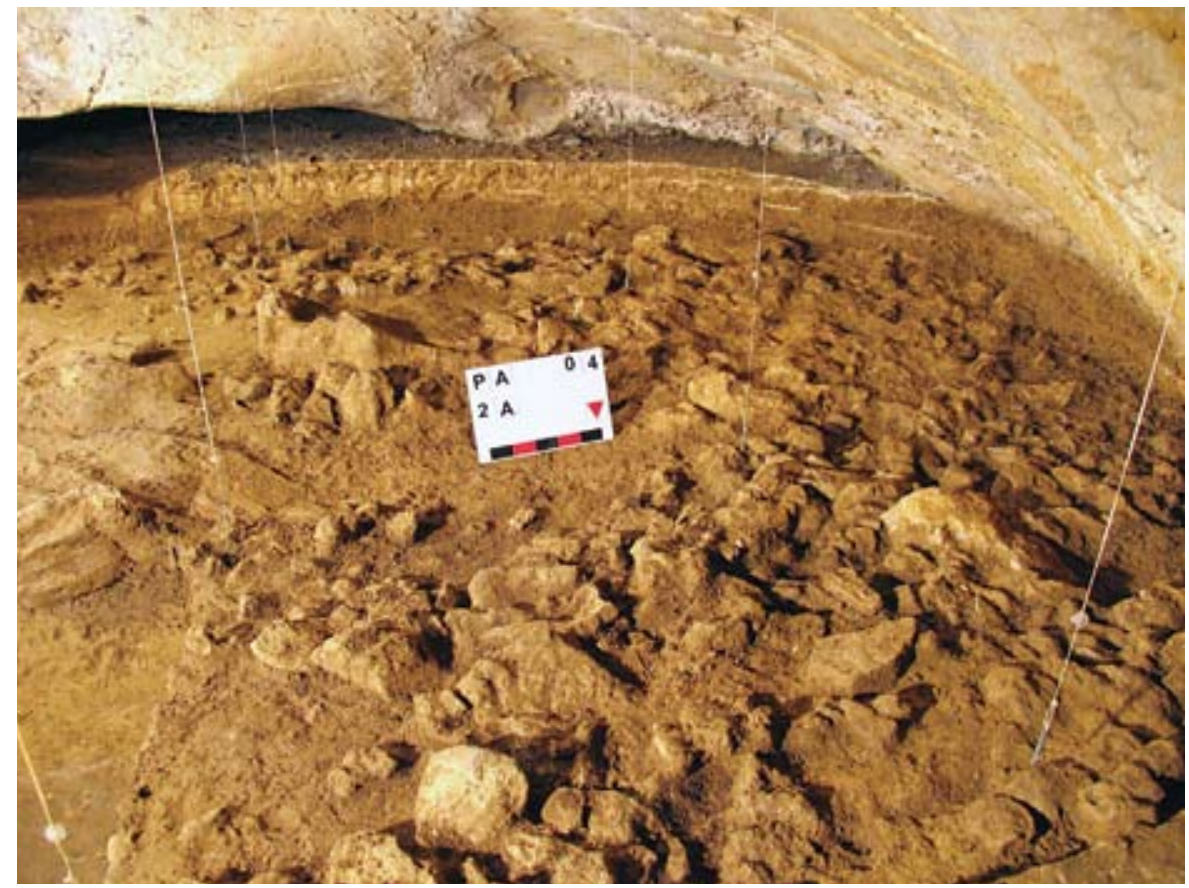




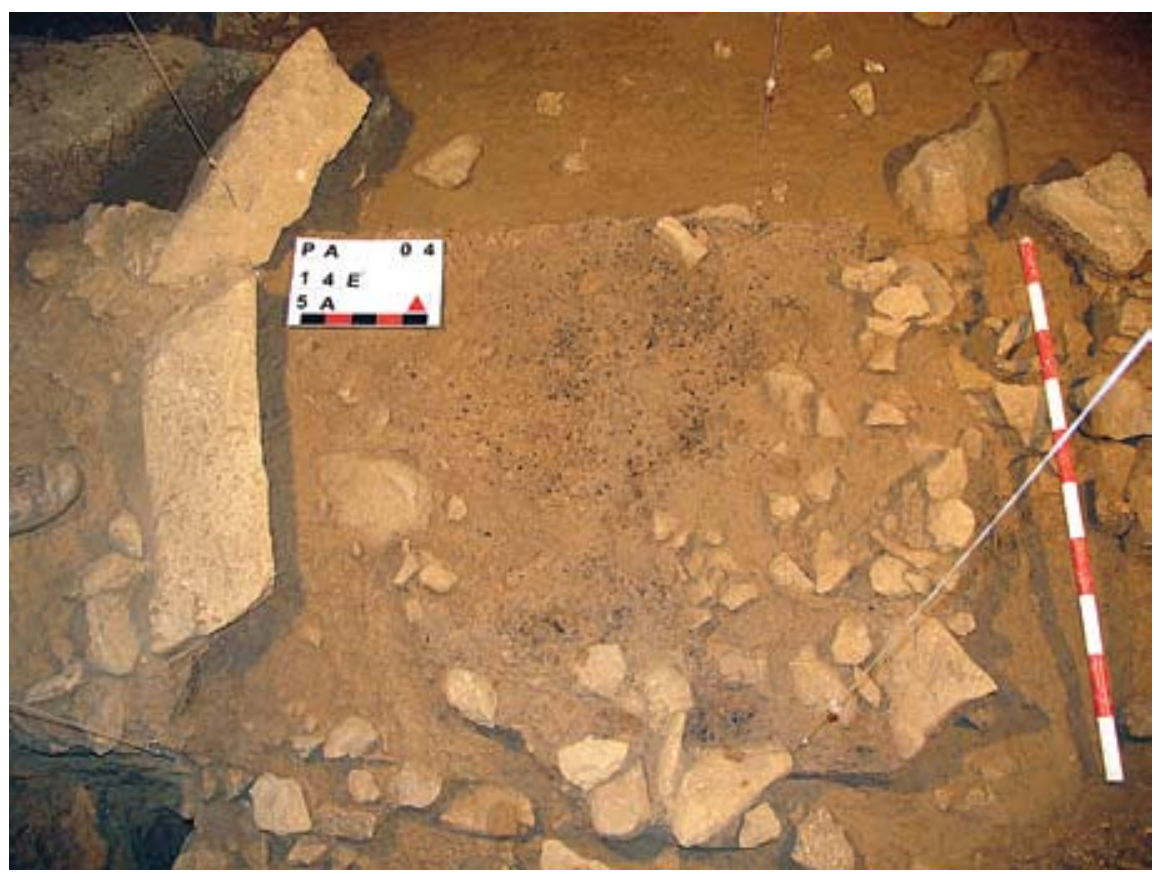

Fig. 102. Hogar de la primera sala interior. / Hearth from the first inner room .

todo en las zonas más próximas al hogar del subnivel II.III, y en los cuadros 6E', 8E' y $10 E^{\prime}$-en estos últimos la tierra tiene una coloración más oscura-, aunque también están presentes en las bandas F' y G'.

En la parte sur de esta mitad este de la sala este sedimento marrón tiende a hacerse más

\section{Subnivel II.I}

Se trata de una capa de sedimento situada bajo la cubierta estalagmítica superficial, consistente en tierra amarilla, seca y arenosa (lechos 2 y 3 ) . Se ha detectado únicamente en el ángulo noreste. En ella aparecen abundantes restos de carbón, que corresponden a la capa superficial del hogar localizado posteriormente en esa zona, tal y como se describirá más adelante.

\section{Subnivel II.II}

Formado por los lechos 4 a 6 , está constituido por un sedimento de color marrón de textura fundamentalmente arenosa. En la zona central presenta carbones en las bandas E' y F'. En esta misma área la tierra está en parte concrecionada con frecuentes piedras de tamaño pequeño-mediano. Presenta abundantes caracoles marinos, sobre

Fig. 103. Zona central de la primera sala interior durante la excavación del nivel IV. / Central zone of the first inner room during the excavation of the level IV. plástico con presencia de limonitas. En el lateral este y en el ángulo noreste, sin embargo, no se detecta este subnivel.

\section{Subnivel II.III}

En la zona norte, dentro del lecho 5 de los cuadros 14E' y 16E', se ha detectado un hogar intrusivo, excavado en cubeta, que afecta a los subniveles inferiores del nivel III y al nivel IV (Fig. 102).

La presencia de carbones es patente en estos cuadros desde el lecho 2, siendo más frecuente en los le-

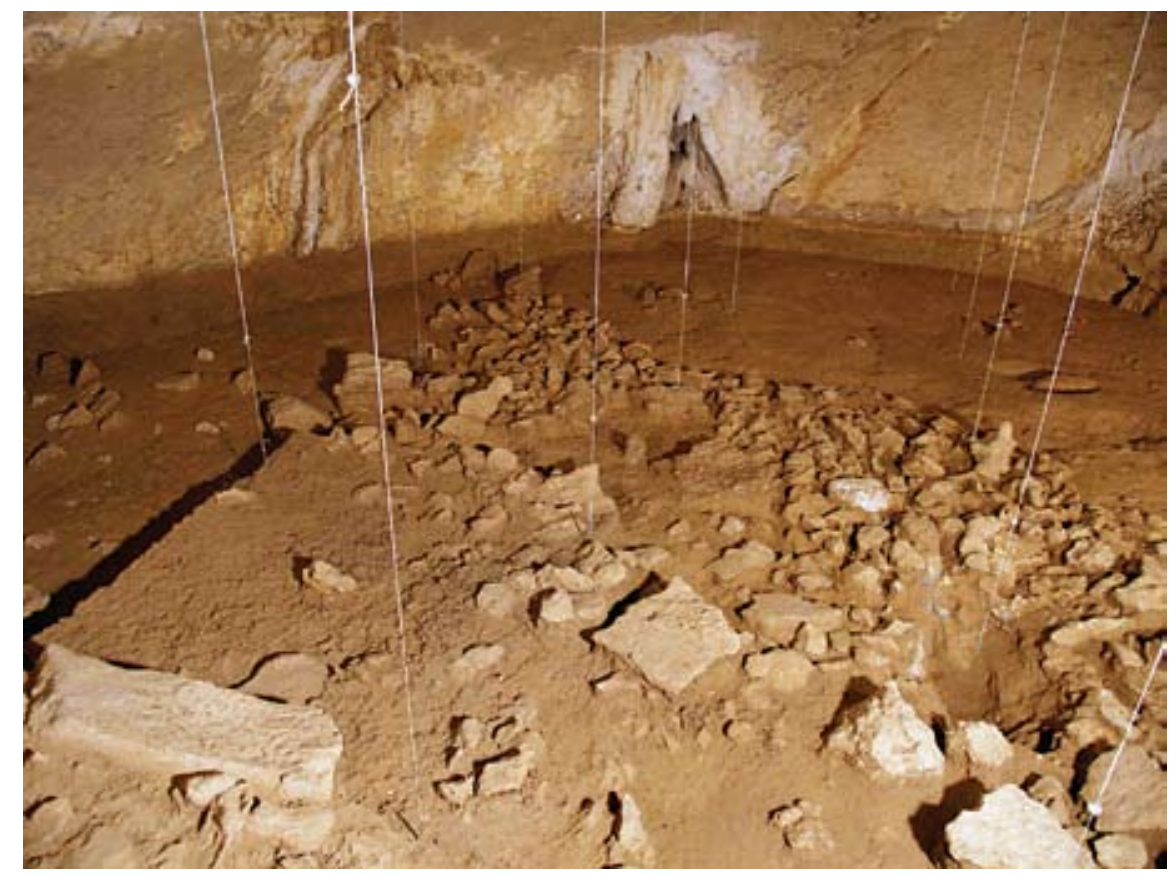



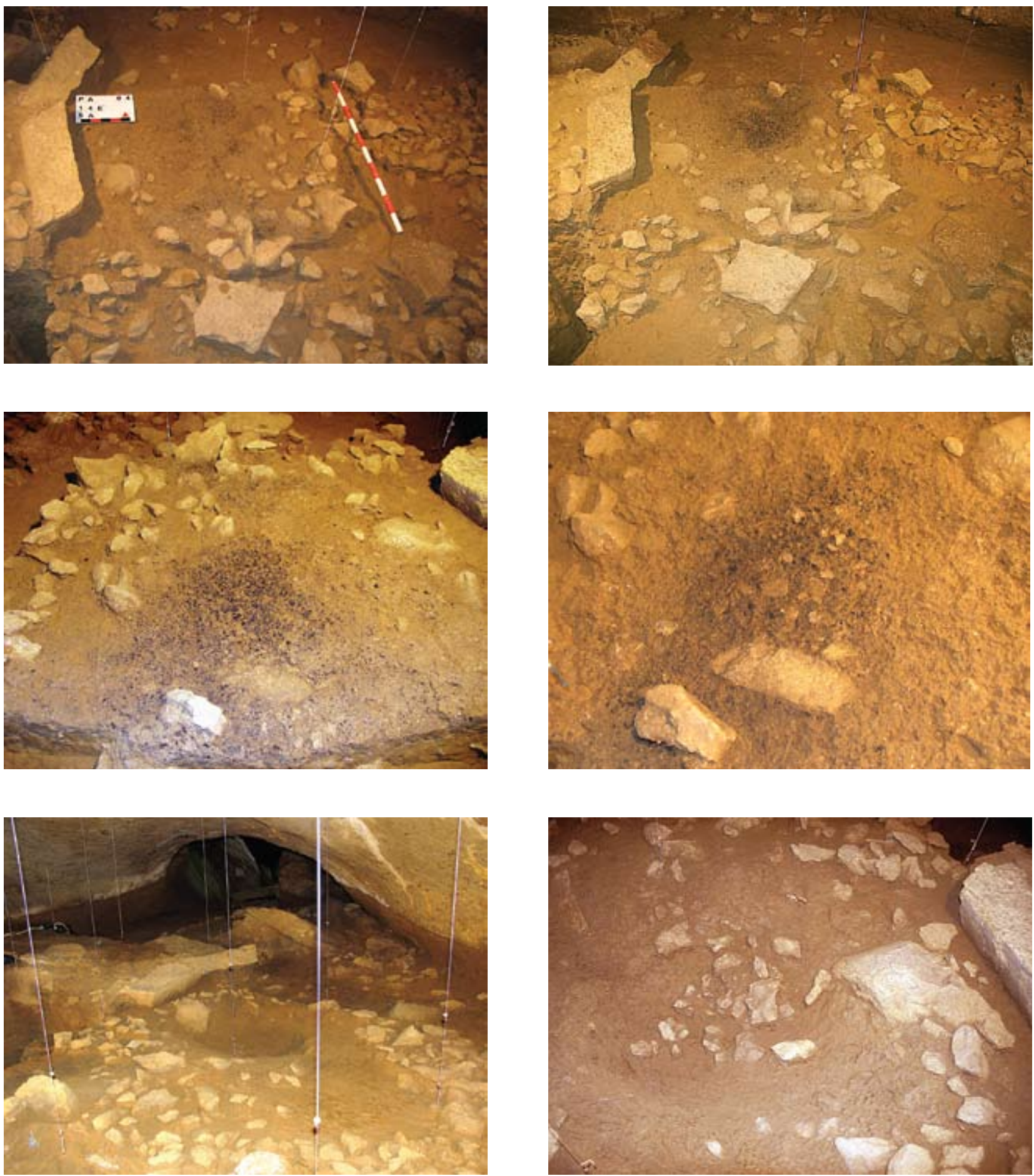

Figs. 104-109. Diversos fases de la excavación del hogar de la primera sala interior. / Various stages of the excavation of the hearth at the first inner room.

chos siguientes. Al excavar el lecho 5, en esa zona norte ya está bien definida un área de carbones que ocupa la mayor parte del cuadro 14E' (cuadrante noreste con mucha mayor densidad de carbón) y casi la mitad oeste del cuadro 16E'. Un anillo de piedras de entre 5 y 20 cm rodea este espacio de forma circular. La superficie dentro de esta zona de carbones, en este lecho, es prácticamente horizontal. Limitando a este hogar por el oeste y ocupando una parte de los cuadros 12E', 14E', 12D' y 14D', existen dos grandes piedras que por sus caracte- 
14

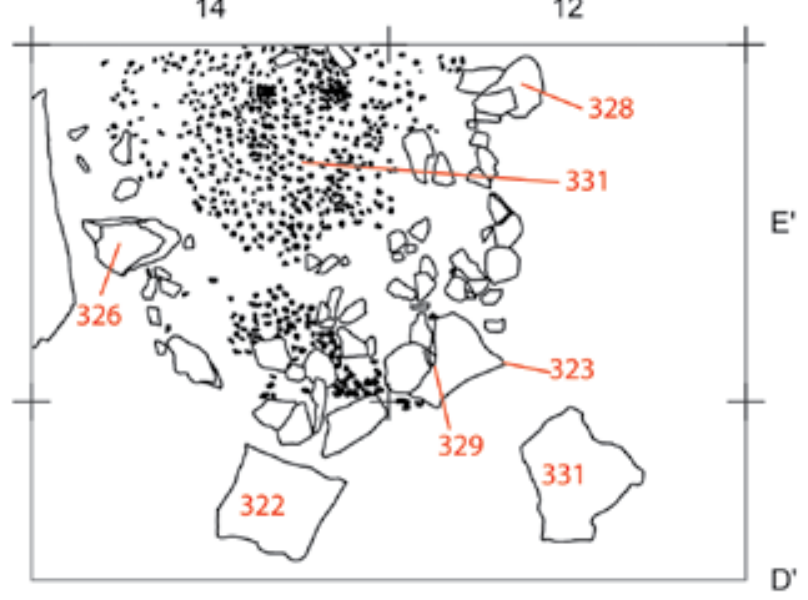

LEVEND 56. $+$

Fig. 110. Plano correspondiente al hogar epipaleolítico de la primera sala interior tras excavar el lecho 2 (nivel II) (Dibujo: X. Peñalver/Digitalización: J. Calvo). / Plan of the epipaleolithic hearth from the first inner room after excavating the layer 2 (Drawing: $X$ Peñalver/Digitalisation: J. Calvo).

rísticas pudieron haber servido de asientos; sus dimensiones son las siguientes: la situada más al sur, plenamente asentada en los cuadros 12E' y 14E', alcanza una longitud de $78 \mathrm{~cm}$ y una anchura de $20 \mathrm{~cm}$, siendo su altura de en torno a $20 \mathrm{~cm}$. La situada más al norte, y adosada a la anterior por su lado estrecho, tiene una longitud de $65 \mathrm{~cm}$ y una anchura de $20 \mathrm{~cm}$, oscilando su altura entre 10 y $15 \mathrm{~cm}$ (Fig. 102).
El hogar tiene un diámetro de entre 70 y $80 \mathrm{~cm}$ y una profundidad en su zona central de entre 15 y $20 \mathrm{~cm}$. Presenta una forma de cubeta excavada en la arcilla plástica de coloración amarilla que corresponde a niveles de ocupación anteriores (Magdaleniense Inferior) y está constituido por una base de piedras y plaquetas pequeñas en su base y por una acumulación de capas de carbón (Figs. 104 a 110).

La sucesión de los 9 lechos practicados desde la superficie de la estructura hasta su base, de una potencia aproximada de $2 \mathrm{~cm}$ cada uno, ofrece los siguientes resultados:

En el primero de los lechos se aprecia un área totalmente cubierta de carbones que ocupa gran parte del cuadrante noreste del cuadro 14E', habiendo, así mismo, abundantes fragmentos en el cuadrante sureste, y más diseminados en el eje central del cuadro en sentido norte-sur. Aparece un caracol marino junto a una de las piedras que delimitan esta estructura dentro del cuadrante suroeste del cuadro 14E'. Se aprecia una ligera depresión en la zona central del círculo de en torno a 5 $\mathrm{cm}$, en donde se produce la mayor concentración de carbón.

Tras la excavación del segundo de los lechos la zona central del hogar presenta una cantidad masiva de carbones, siendo menos denso su número en las zonas más periféricas. En el lecho siguiente la zona de carbones se hace menor, centrándose en la parte media de la estructura. Bajo esta capa de carbones aflora un débil estrato de tierra ennegrecida por el contacto del carbón, desapareciendo totalmente tras la excavación del lecho 6.

Paralelamente a este rebaje del sedimento de tierra y carbones afloran pequeñas piedras y plaquetas de entre 5 y $10 \mathrm{~cm}$ de dimensión máxima, sobre la estructura de

Fig. 111. Zona oeste de la primera sala interior tras bajar el lecho 5. / Western zone of the first inner room after lowering the layer 5 .

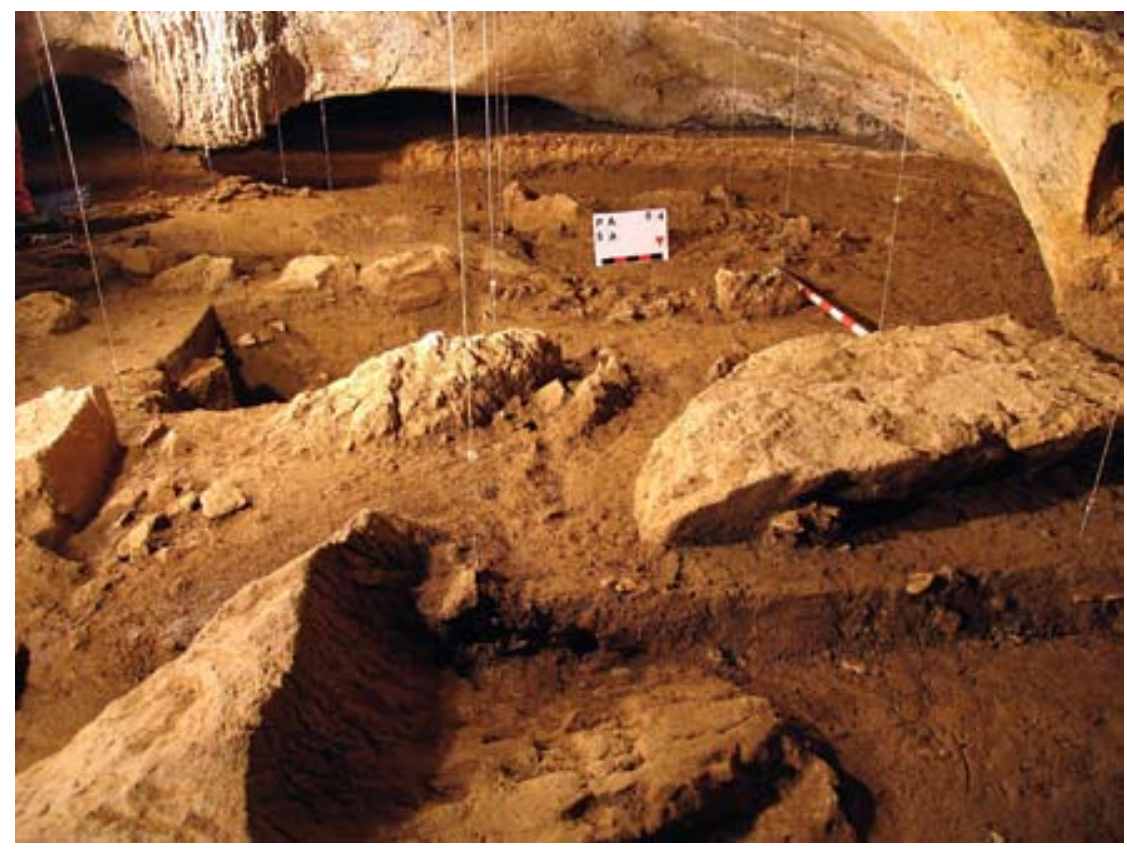




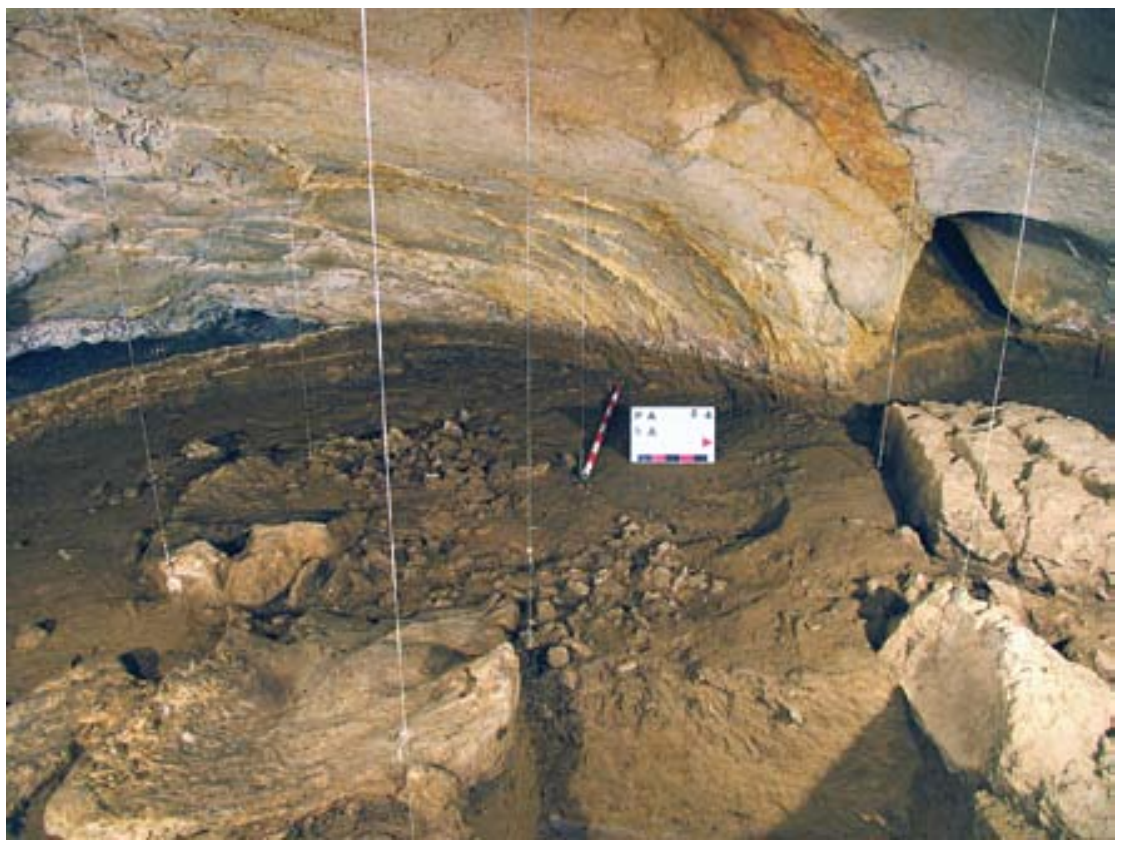

Fig. 112. Zona suroeste de la primera sala interior tras bajar el lecho 5. I Southwestern zone of the first inner room after lowering the layer 5 .

la cubeta que mantienen la inclinación de la hondonada. Aparecen, según avanzaban los trabajos en las zonas más periféricas durante los lechos iniciales y en las zonas más centrales al descender en cota la excavación, apreciándose finalmente cómo la totalidad de la base de la cubeta se halla cubierta por esta capa lítica.

Este hogar ha sido datado por C14 a través de dos muestras recogidas en el cuadro 14E', siendo los resultados los siguientes: $8840 \pm 45$ B.P. y $8845 \pm 40$ B.P.

\section{Subnivel II.IV}

Por debajo del subnivel II.II, se documenta un nivel de piedras, situado en la zona oeste de la sala, principalmente en las bandas E', G' y H'. Por lo general presentan unas dimensiones de en torno a los $10 \mathrm{~cm}$, aunque las hay de entre 20 y $40 \mathrm{~cm}$. Destacan cinco grandes bloques de entre 0,45 y 1,90 m de longitud máxima.

Tal y como se ha mencionado, este empedrado ocupa la práctica totalidad de los cuadros de la zona oeste. Las piedras correspondientes a los cuadros 8F', $8 G^{\prime}, 8 H^{\prime}, 8 l^{\prime}, 10 G$ ', 10H' y 10l' están concrecionadas y se encuentran apoyadas sobre la tierra de color marrón oscuro (Figs. 111 y 112). Esta zona de la sala es considerablemente horizontal en este lecho, aunque presenta un ligero descenso en la parte situada más al sur, coincidiendo con el contacto con la segunda sala interior.

\section{Subnivel II.V}

Bajo el nivel de piedras perteneciente al subnivel II.IV aparece un sedimento de color marrón, aparentemente sin diferencias respecto al subnivel II.II; continúan presentes los caracoles marinos.

\section{Nivel III}

Este nivel no se ha detectado en esta zona de la cavidad.

\section{Nivel IV}

Está formado por los subniveles IV.I, IV.II, IV.III y IV.IV que se describen a continuación.

\section{Subnivel IV.I}

Formado por los lechos 7 y 8 , está constituido por un paquete de arcilla amarilla generalmente plástica, sin apenas piedras. Presenta mayor plasticidad cuanto más al sur y al este de la sala, siendo más arenosa en la oeste y norte.

En el límite entre este subnivel y el inmediatamente superior del nivel II se detecta una pequeña concentración de tierra arenosa en torno al cuadro 8G', posiblemente correspondiente a una zona de encharcamiento en la que se ha localizado un pequeño fragmento de un colgante ${ }^{9}$ previamente descubierto en el nivel IV del vestíbulo.

\section{Subnivel IV.II}

Lo compone una capa de piedras que ha sido documentada bajo el subnivel IV.I. en la mitad este de la sala, afectando principalmente a la zona central de las bandas 14, 16 y parte de la 18 (Figs. 113 y 114).

Sobre esta concentración pedregosa, muy horizontal y uniforme, se han hallado gran parte de los colgantes,

\footnotetext{
${ }^{9}$ Las siglas del colgante hallado en el vestíbulo y del pequeño fragmento localizado en la primera sala interior son P.A.10G.256.65 y P.A.8G'.331.1 respectivamente.
} 

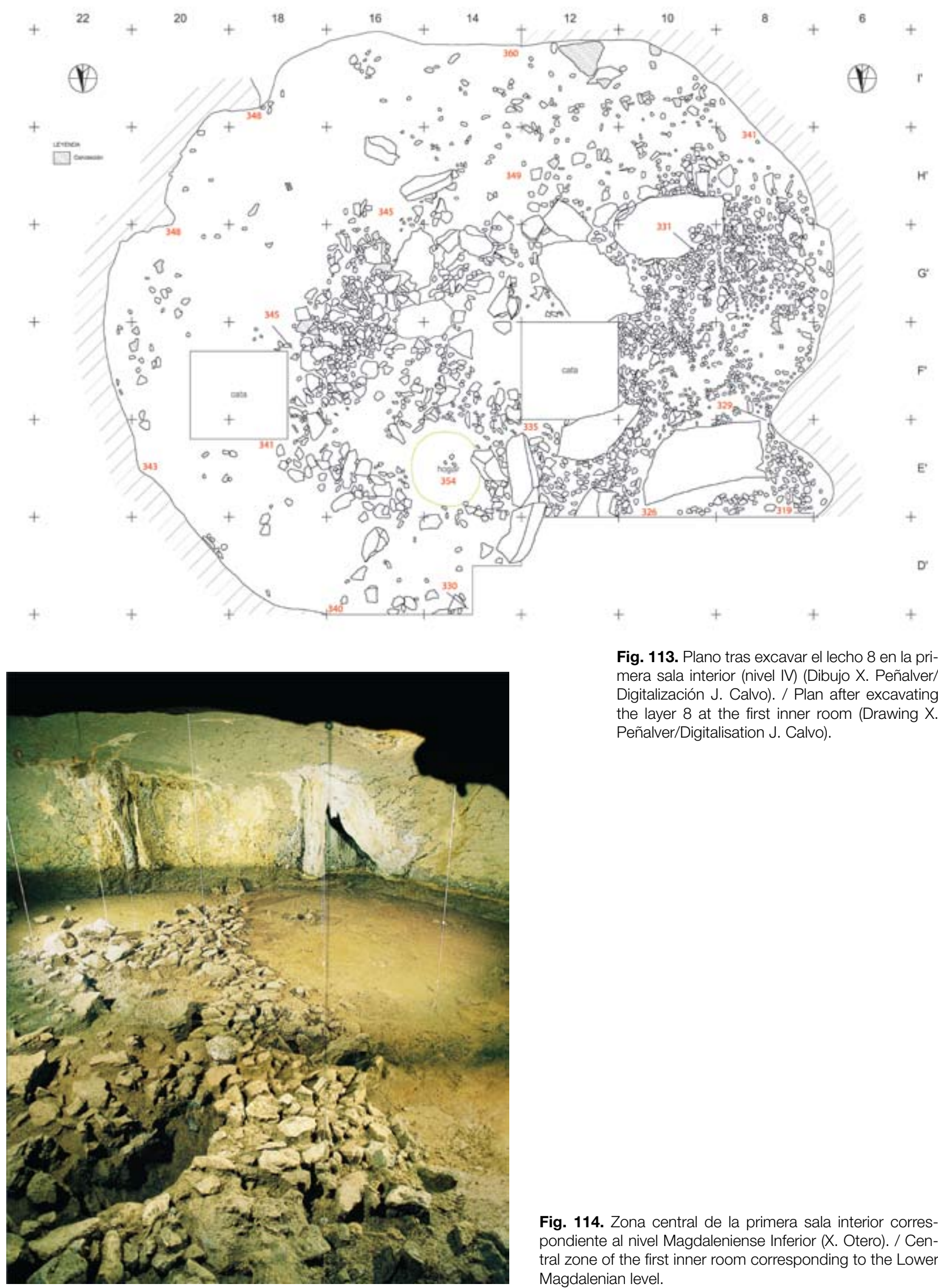

Fig. 113. Plano tras excavar el lecho 8 en la primera sala interior (nivel IV) (Dibujo X. Peñalver/ Digitalización J. Calvo). / Plan after excavating the layer 8 at the first inner room (Drawing $X$. Peñalver/Digitalisation J. Calvo).

Fig. 114. Zona central de la primera sala interior correspondiente al nivel Magdaleniense Inferior (X. Otero). / Central zone of the first inner room corresponding to the Lower Magdalenian level. 


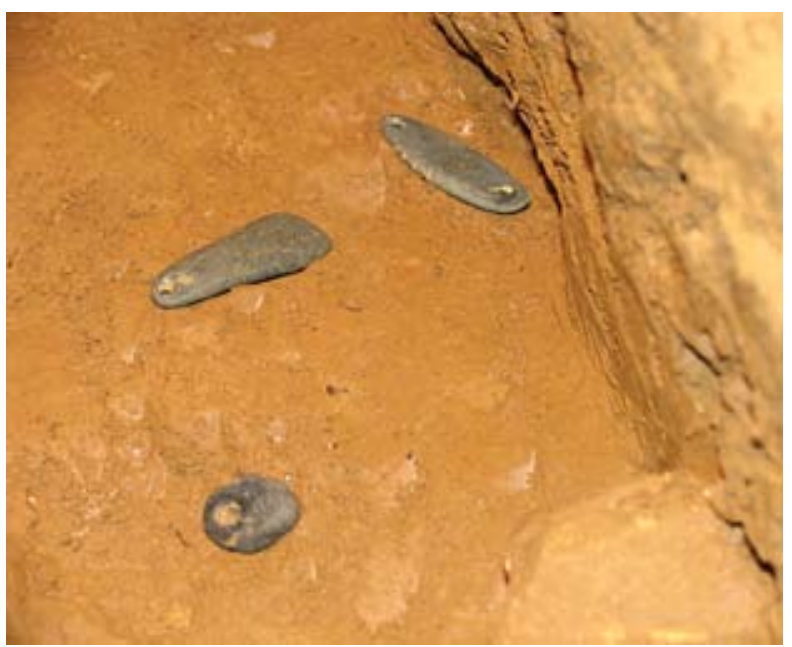

Fig. 115. Hallazgo de los tres primeros colgantes de la primera sala interior, pertenecientes a la agrupación de 14 piezas. / Discovery of the first three pendants from the first inner room, belonging to the group of 14 pieces.

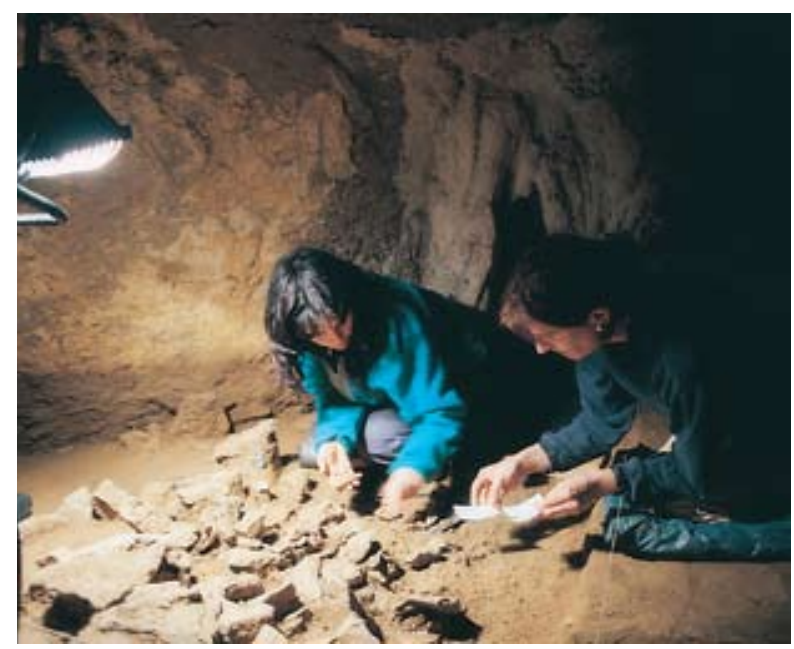

Fig. 116. Tarea de extracción de algunos de los colgantes de la agrupación de 14 en la primera sala interior (Foto X. Otero). / Extraction work of some of the pendants from the group of 14 in the first inner room (Picture $X$. Otero).

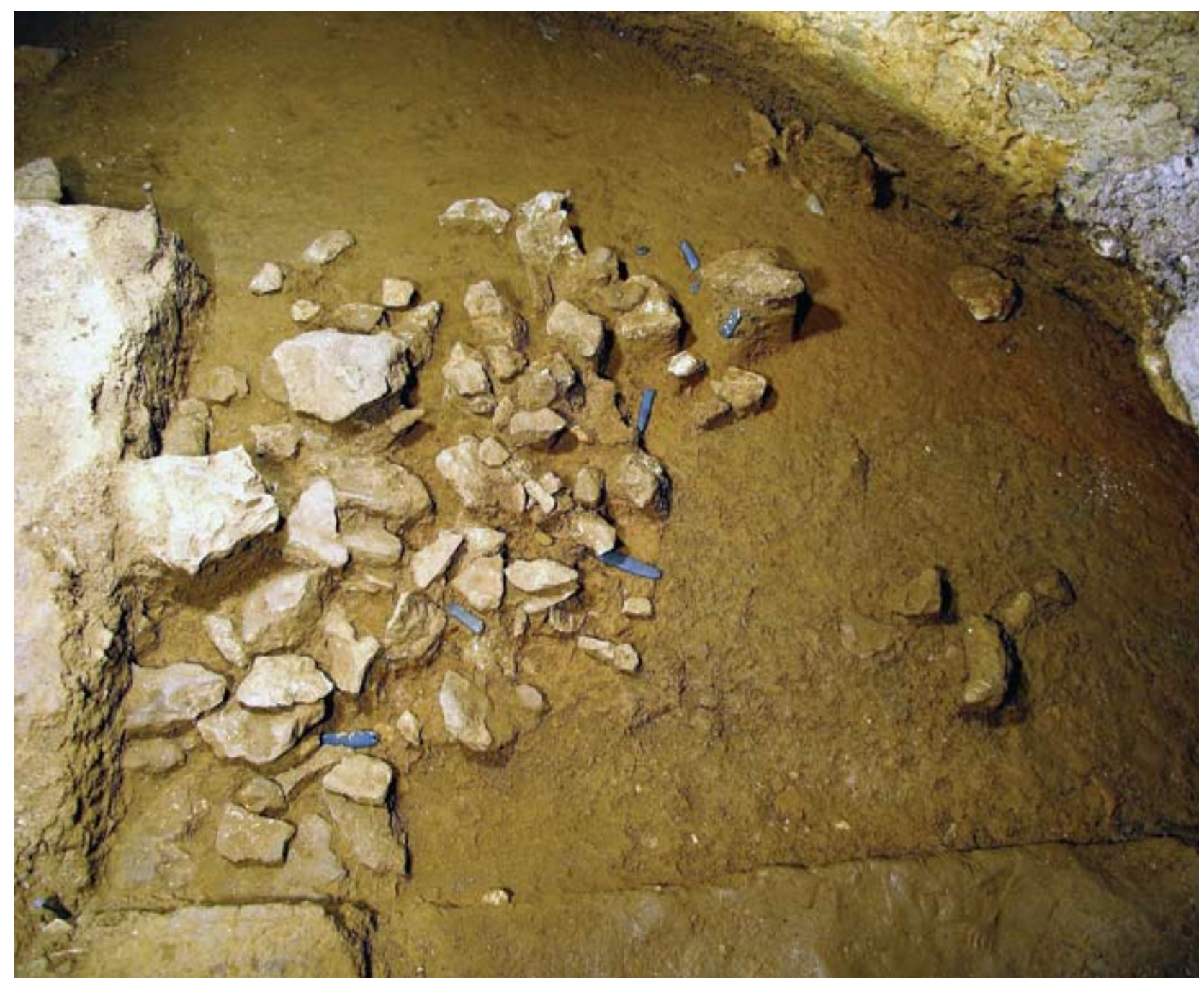

Fig. 117. Colgantes "in situ" en la zona este de la primera sala interior. / Pendants "in situ" on the eastern zone of the first inner room. 


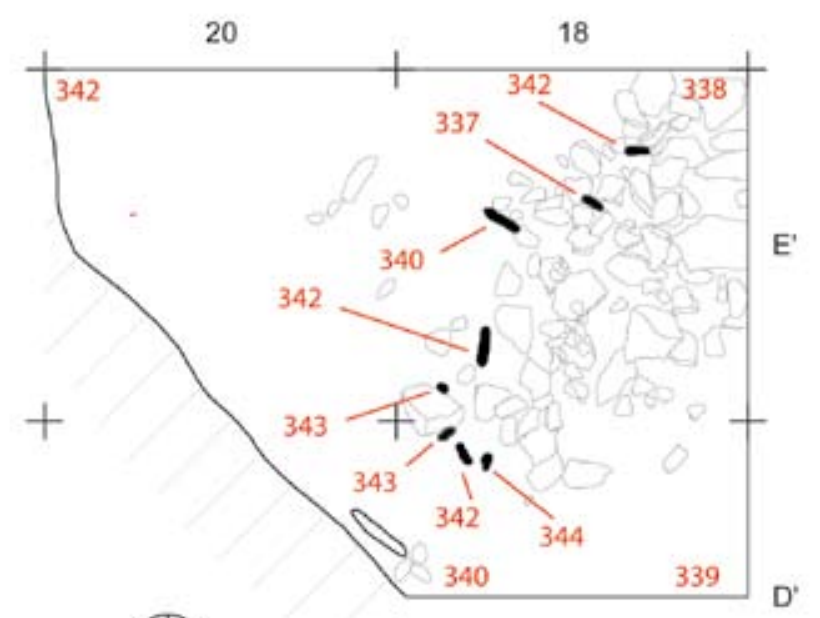

Fig. 118. Plano de detalle de la localización de 8 colgantes de la agrupación de 14 tras excavar el lecho 8 (nivel IV) (Dibujo: X. Peñalver/ Digitalización: J. Calvo). / Detailed plan of the location of 8 pendants from the group of 14 after excavating the layer 8 (Drawing: X. Peñalver/Digitalisation: J. Calvo).
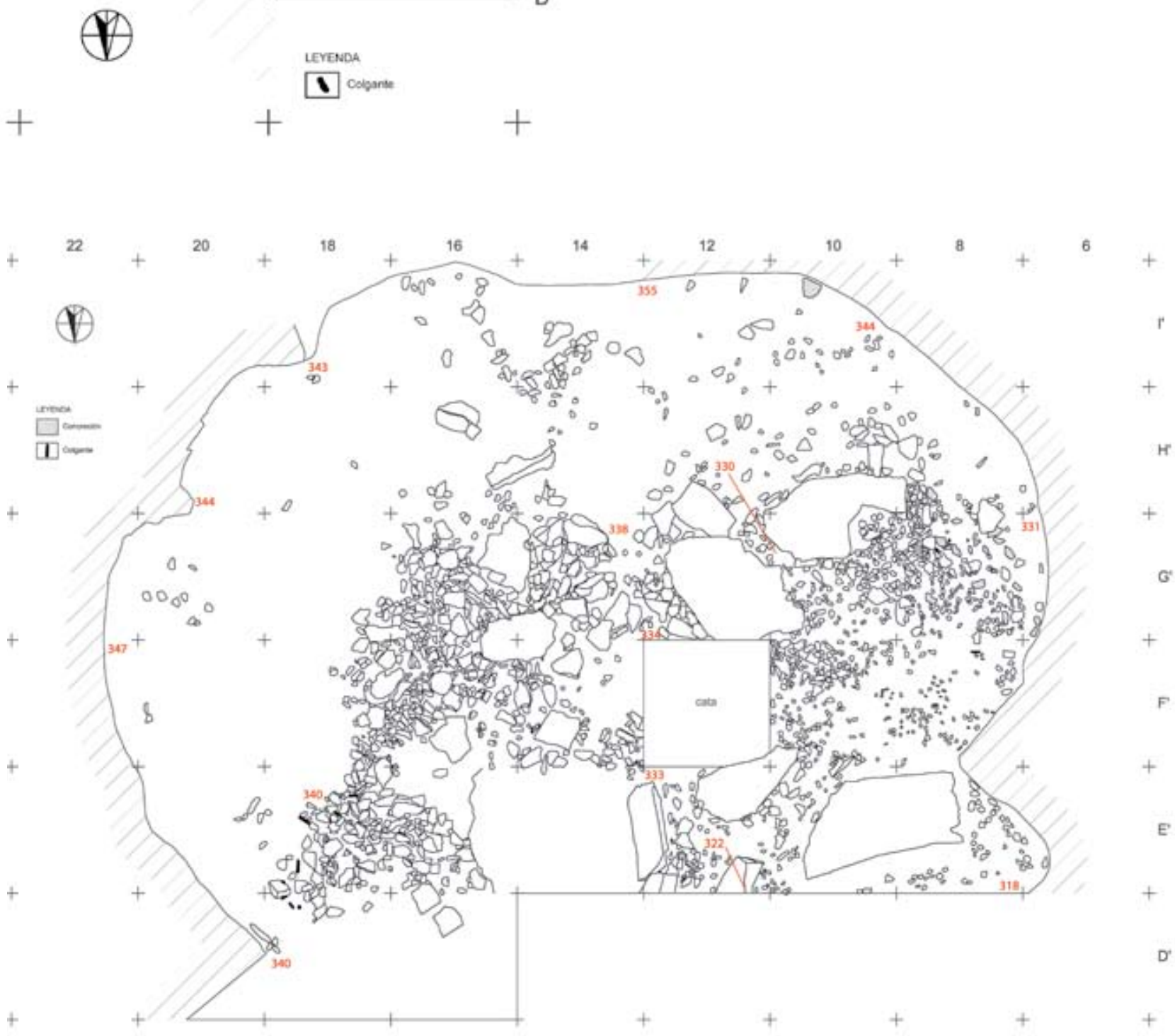

Fig. 119. Plano tras excavar el lecho 8 en la primera sala interior (nivel IV) (Dibujo: X. Peñalver/Digitalización: J. Calvo). / Plan after excavating the layer 8 at the first inner room (Drawing: X. Peñalver/Digitalisation: J. Calvo). 


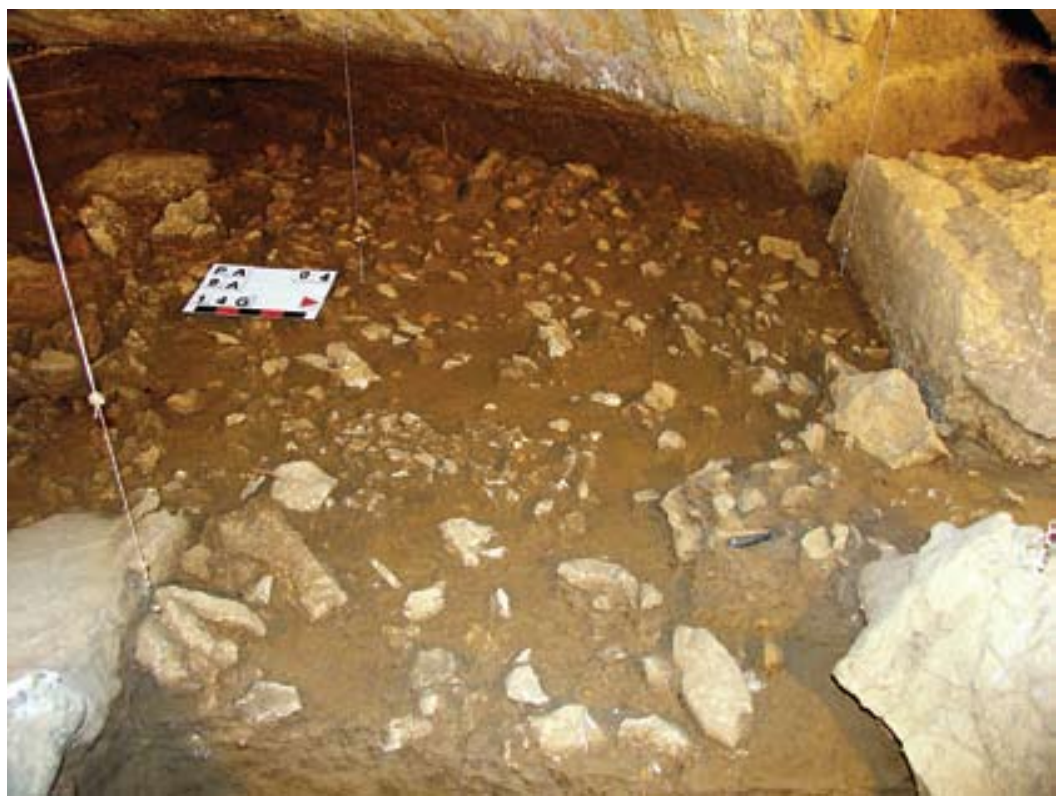

Fig. 120. Zonas central y oeste de la primera sala interior tras excavar el lecho 9. / Central and western zones of the first inner room after lowering the layer 9.

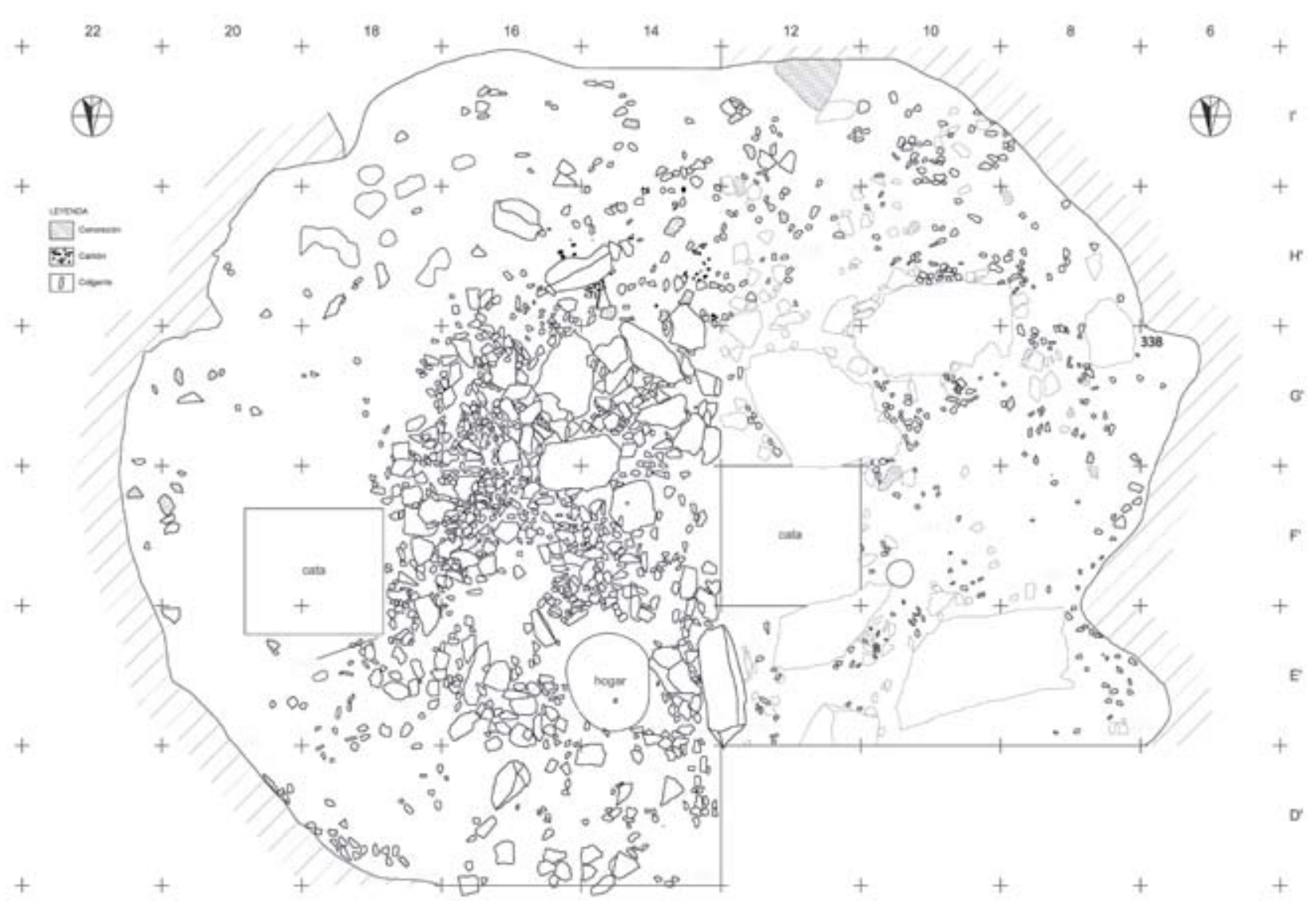

Fig. 121. Plano tras excavar el lecho 9 en la primera sala interior (nivel IV) (Dibujo: X. Peñalver/Digitalización: J. Calvo). / Plan after excavating the layer 9 at the first inner room (Drawing: X. Peñalver/Digitalisation: J. Calvo). 


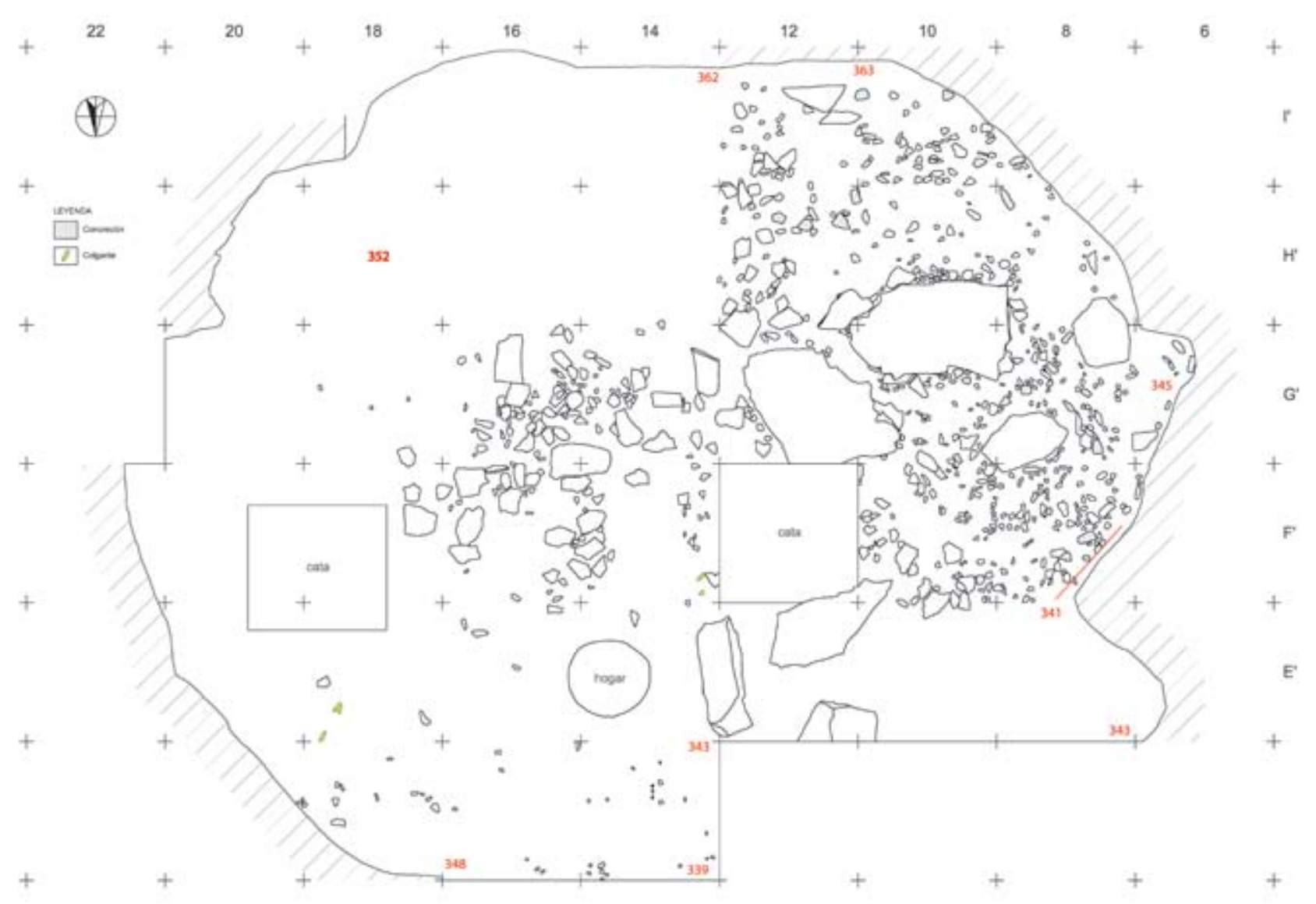

Fig. 122. Plano tras excavar el lecho 11 en la primera sala interior (nivel IV) (Dibujo X. Peñalver/Digitalización J. Calvo). / Plan after excavating the layer 11 at the first inner room (Drawing X. Peñalver/Digitalisation J. Calvo).

la mayoría correspondientes a una agrupación de 14 piezas $^{10}$ (subnivel IV.I) (Figs. 115 a 118). Esta acumulación de piedras forma un arco que cubre total o parcialmente los cuadros 16E', 18E', 14F', 16F', 18F', 14G' y 16G'. Las piedras que forman este nivel son relativamente planas y presentan dimensiones de entre 5 y $20 \mathrm{~cm}$, pudiendo ser este depósito de carácter antrópico.

En el lateral este de esta primera sala se aprecia una franja de entre 1 y 2 metros de anchura que discurre paralela a la pared de la cueva, en la que destaca la casi total ausencia de este subnivel de piedras.

\section{Subnivel IV.III}

En la zona oeste, sin embargo, bajo el subnivel IV.I aflora una capa de abundantes piedras, de menor tamaño y más irregulares que las del subnivel IV.II. Tienen unas dimensiones medias de entre 5 y $10 \mathrm{~cm}$, intercalándose con bloques de concreción de las mismas dimensiones, 10 Siglas: P.A.18E'.336.9, P.A.18E'.337.7, P.A.18E'.345.10, P.A.
18E'.337.6,P.A.18E'.342.3,P.A.18E'.339.8,P.A.18E'.347.11,P.A.
18E'.340.2, P.A.18D'-E'.347.12, P.A.18E'.336.4, P.A.18E'.343.5, P.A.18D'.343.3, P.A.18D'.342.4, P.A.18D'.344.5. situados entre las bandas 6 y 8, más próximos a la pared oeste de la sala (Figs. 119 y 122). Las bandas H' e l', al sur de la sala, contienen menor cantidad de piedras. En esta zona también se documentan cuatro grandes bloques de caliza que afectan a parte de las bandas E', G' y H'.

En las zonas más próximas a la pared oeste de la cueva existen fragmentos de placas de concreción de color amarillo de entre 5 y $10 \mathrm{~cm}$ entremezcladas con escasas piedras. En las bandas H' e l' no se produce la concentración de estas piedras salvo en el extremo sur del cuadro $8 \mathrm{H}^{\prime}$, existiendo, sin embargo, algunas de en torno a $10 \mathrm{~cm}$ de dimensión máxima. En este subnivel se han hallado tres colgantes rotos a la altura de la perforación. ${ }^{11}$

Los subniveles IV.II y IV.III, pese a sus diferentes características constituyen un único momento de ocupación contemporáneo, asociado a los colgantes líticos.

\section{Subnivel IV.IV}

Debajo de los subniveles IV.II y IV.III, está presente un sedimento arcilloso y plástico de coloración amarilla. Como tónica general la tierra es más arcillosa y plástica en la mi-

11 Siglas: P.A.8D'.333.5, P.A.8F'.333.3 y P.A.10F'.331.19. 


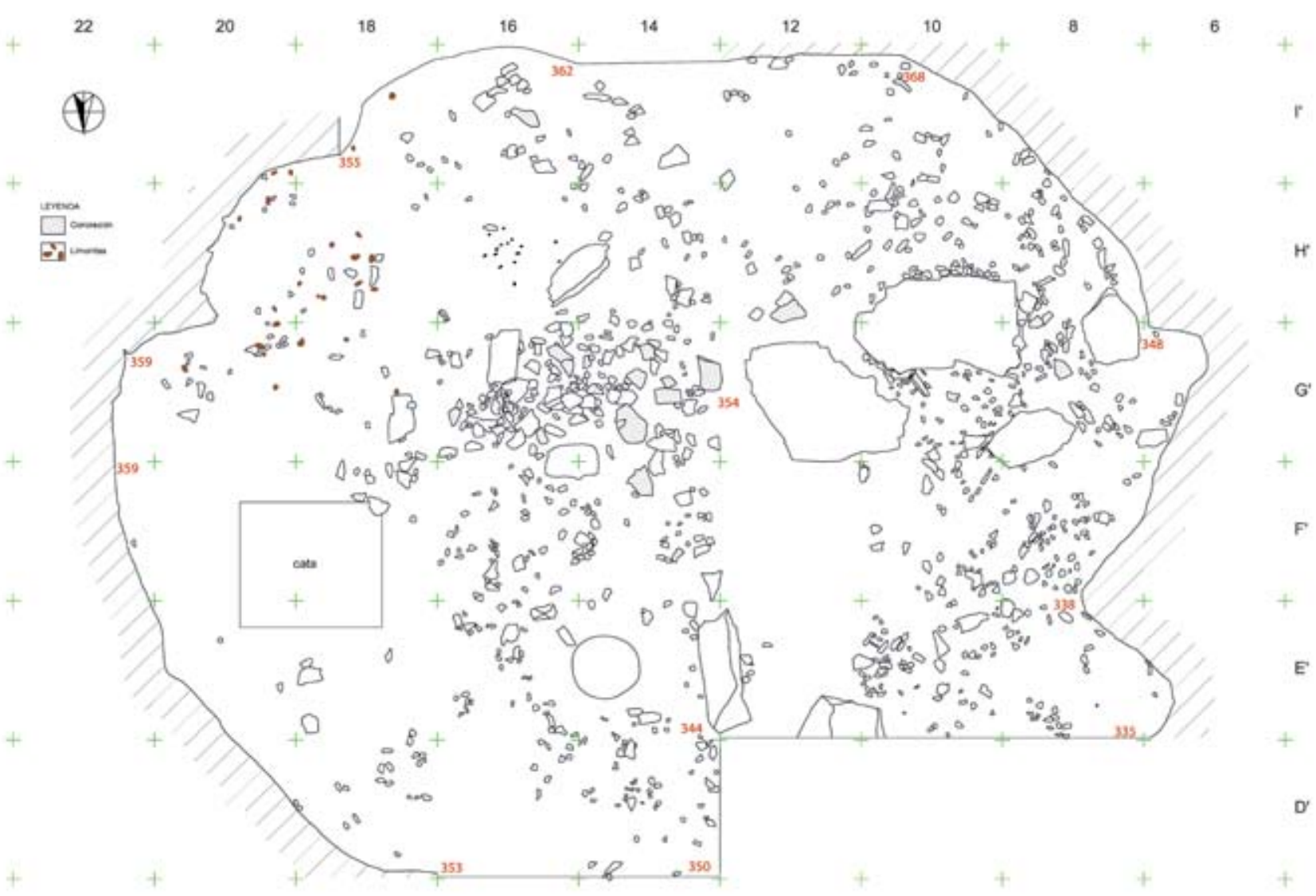

Fig. 123. Plano tras excavar el lecho 12 en la primera sala interior (nivel IV) (Dibujo X. Peñalver/Digitalización J. Calvo). / Plan after excavating the layer 12 at the first inner room (Drawing X. Peñalver/Digitalisation J. Calvo).

tad este de la sala, sobre todo hacia el sur. En esta zona son frecuentes los cantos y las limonitas, quedando huellas de la existencia de pequeños charcos (Fig. 123). Así, en algunas zonas puntuales se detecta arenilla con hoyitos de posibles goteras. Todo ello apunta a que por toda esa zona próxima a la pared, sobre todo en las bandas 20 y 22, en algún momento ha corrido agua o bien se ha depositado en charcos. En ese mismo lugar existe una grieta en el techo que en la actualidad filtra agua cuando llueve.

En el cuadro 20E', cercano a la pared, parte de la tierra amarilla tiene un tono más anaranjado, con zonas algo más oscuras y piedrecillas pequeñas, que se corresponde con un pequeño charco. En la banda D', la tierra, aunque amarilla, es más arenosa, escaseando las
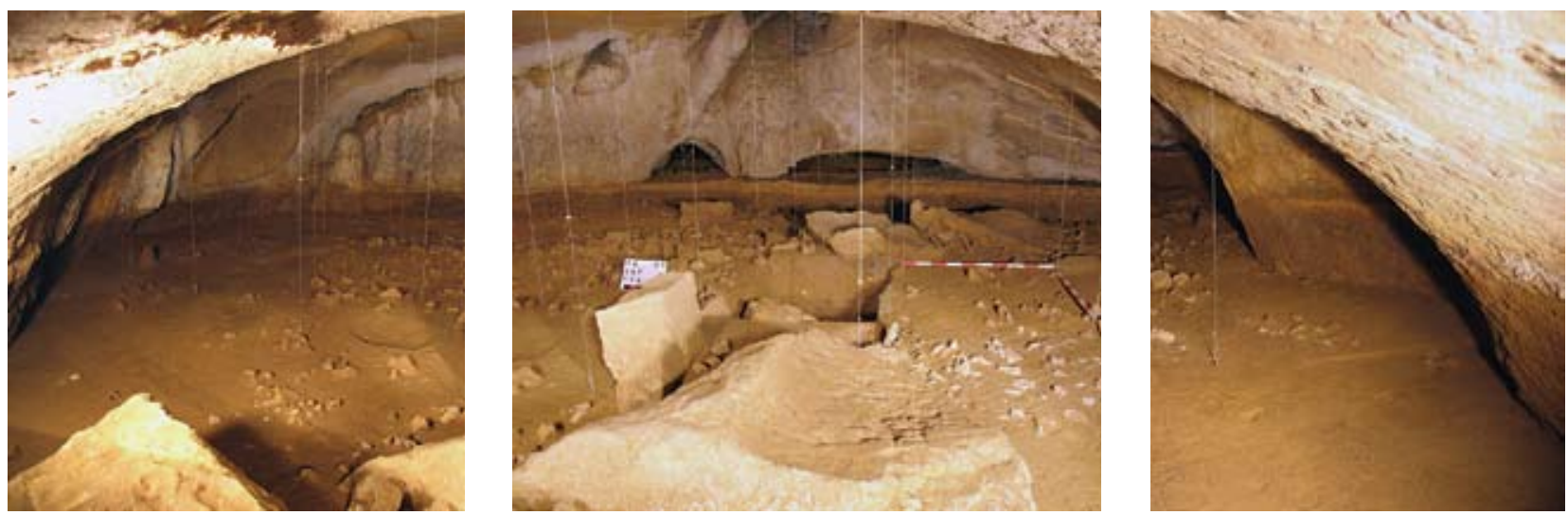

Fig. 124. Vista general de la primera sala interior. / General view of the first inner room. 
piedras. En el ángulo correspondiente a los cuadros situados al norte de la sala, 20E', 20F' y 22F', la tierra es plástica, acentuándose esta plasticidad hacia el sur.

En los cuadros 14F' y 16G' aparecen dos colgantes a escasos centímetros del aparecido en este mismo cuadro en el lecho $10^{12}$.

A pesar de que los colgantes están presentes en los cuatro subniveles, esto no significa que haya habido deposiciones de los mismos en momentos diferentes, sino que, dada su posición estratigráfica, todo indica que corresponden a conjuntos únicos contemporáneos, de los que algunas de sus piezas se han encajado y filtrado entre las piedras de los subniveles II y III.

\section{Nivel V}

En la mitad oeste de la sala se detecta un paquete de tierra amarilla y plástica, con piedrecilla muy pequeña, principalmente en los cuadros 8F', 8G', 10F' y 10G'; este sedimento corresponde a un período anterior. En el cuadro 10G' aparece una pieza de sílex con claras características solutrenses, muy próxima a un gran bloque.

\subsubsection{Adscripción cronocultural de los niveles de la primera sala interior}

Se ha establecido para este espacio de la cueva (Fig. 124) un total de cinco niveles relacionados con sus respectivos lechos unificados, pudiéndose asignar a tres de estos niveles una etapa cultural:

- Nivel superficial: de revuelto.

- Nivel I: compuesto por los subniveles I, II y III, están formados por una capa de tierra situada sobre la concreción, una placa estalagmítica y una zona de gours, sin restos significativos.

- Nivel II: compuesto por los subniveles I, II, III, IV y V, correspondientes todos ellos al Epipaleolítico.

- Subnivel II.l: capa de sedimento amarillo y arenoso en el ángulo noreste.

- Subnivel II.II: formado por sedimento de color marrón en toda la extensión de la sala excepto en el lateral este y en el ángulo noreste.

- Subnivel II.III: lo constituye un hogar en cubeta que alteró a los niveles inferiores.

- Subnivel II.IV: nivel de piedras localizado en la zona oeste de la sala.

- Subnivel II.V: sedimento de color marrón documentado debajo del subnivel II.IV.

- Nivel III: no está presente en esta zona de la cueva.

- Nivel IV: formado por los subniveles I, II, III y IV pertenecientes al Magdaleniense Inferior.

\footnotetext{
12 Siglas: P.A.14F'.349.2, P.A.14F'.347.3, P.A.16G'.329.3 y P.A 14F'.342.1; este último corresponde a un fragmento del anterior.
}

- Subnivel IV.I: está formado por un sedimento de arcilla amarilla.

- Subnivel IV.II: constituido por una capa de piedras planas que ocupa parte de la zona central de la sala.

- Subnivel IV.III: concentración de piedras irregulares en la zona oeste de la sala.

- Subnivel IV.IV: formado por tierra amarilla arcillosa.

- Nivel V: formado por tierra amarilla y algunas piedras, se localiza en una zona al oeste de la sala y pertenece al Solutrense.

\subsection{La segunda sala interior}

La zona excavada ha afectado a un total de 42 cuadros en el lecho inicial -reduciéndose a 40 en el lecho 18, último de los realizados en esta sala hasta el año 2009-, correspondientes a las bandas con números 10, 12, 14, 16, 18, 20 y 22 y a las letras J', K', L', M', N', O' y P' (Figs. 125 y 126). Se han diferenciado 9 niveles estratigráficos a partir de sus características geológicas. En la zona central la sala presenta una gran columna estalagmítica que ocupa total o parcialmente 10 cuadros, uno de los cuales queda íntegramente cubierto por la misma. Una vez finalizada la excavación todavía no se ha llegado a la base de esta columna.

En este espacio se han dejado varios cuadros sin excavar a modo de testigo: $10 \mathrm{~J}$ ', parte este del $16 \mathrm{~J}$ ' y $18 \mathrm{~J}$.

Esta sala tiene continuidad por su lado sureste, del cual parte una galería ascendente. Las labores arqueológicas se ha interrumpido en el arranque de esta galería, entre las bandas 22 y 24.

Antes de iniciar su excavación se practicó una cata de $1 \times 1 \mathrm{~m}$ en el cuadro 20 M', con el fin de determinar la potencia de la capa estalagmítica superficial. Se interrumpió al llegar al nivel de tierra.

Con anterioridad a eliminar la capa de concreción superficial, la inclinación del suelo en esta sala es la siguiente: la mayor parte de la zona abierta es bastante horizontal, principalmente en su mitad norte hasta el límite entre las bandas M' y N' en el lado oeste de la sala. A partir de ese límite, y hacia el sur, la tendencia es descendente, dándose una diferencia de cota de $40 \mathrm{~cm}$ entre el extremo norte y el sur de la zona cuadriculada. En la mitad este de la sala la superficie es más llana (apenas $10-12 \mathrm{~cm}$ de desnivel máximo entre el norte y el sur) aunque siempre descendente en dirección sur, es decir, hacia el interior de la cavidad.

En síntesis se aprecia una considerable horizontalidad en toda la superficie, con una tendencia descendente en la zona suroeste, que es la que da paso hacia las galerías interiores de la cueva. En sentido este-oeste hay una ligera bajada en dirección oeste, principalmente en la 


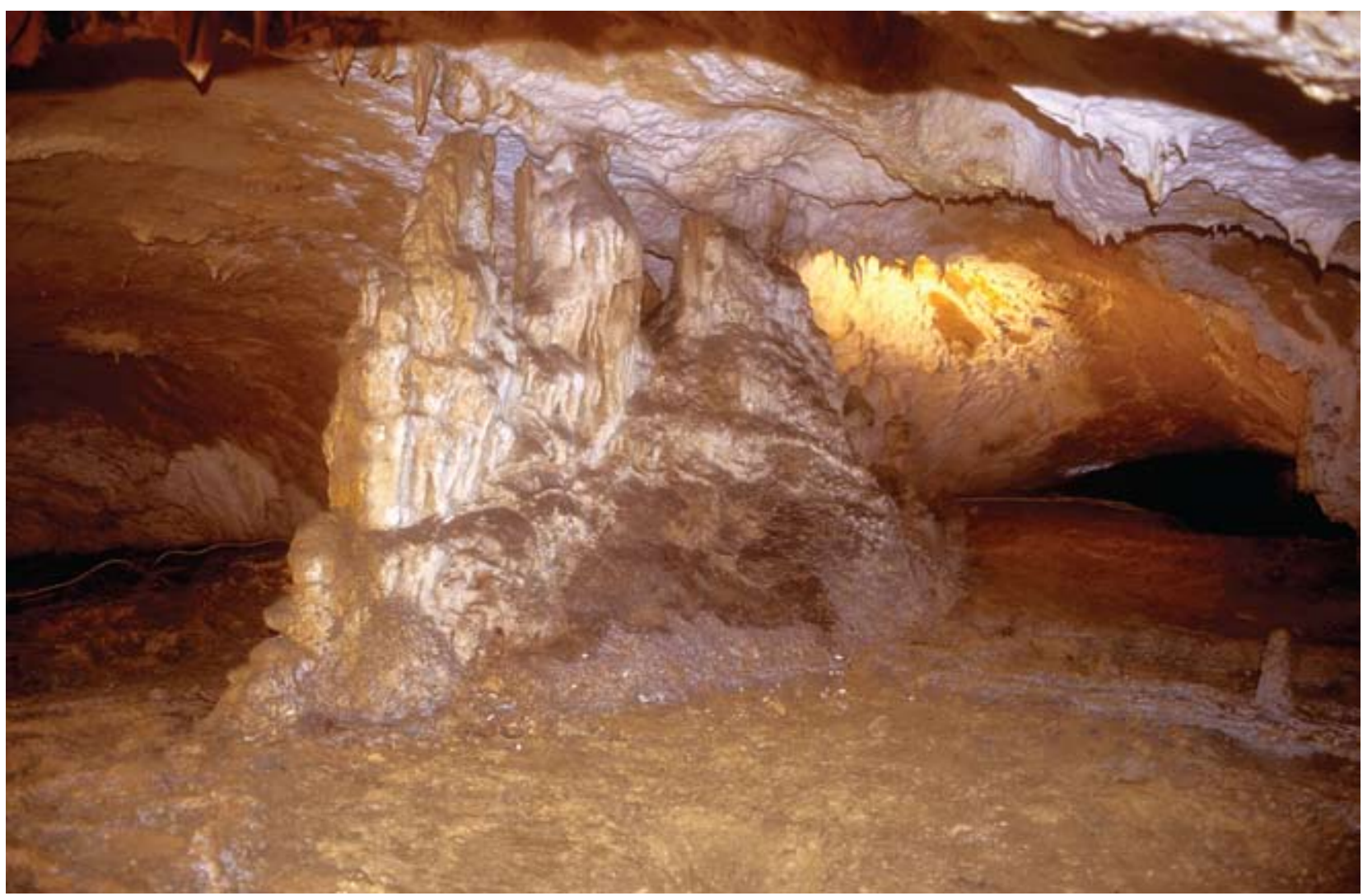

Fig. 125. Vista general de la segunda sala interior. / General view of the second inner room.
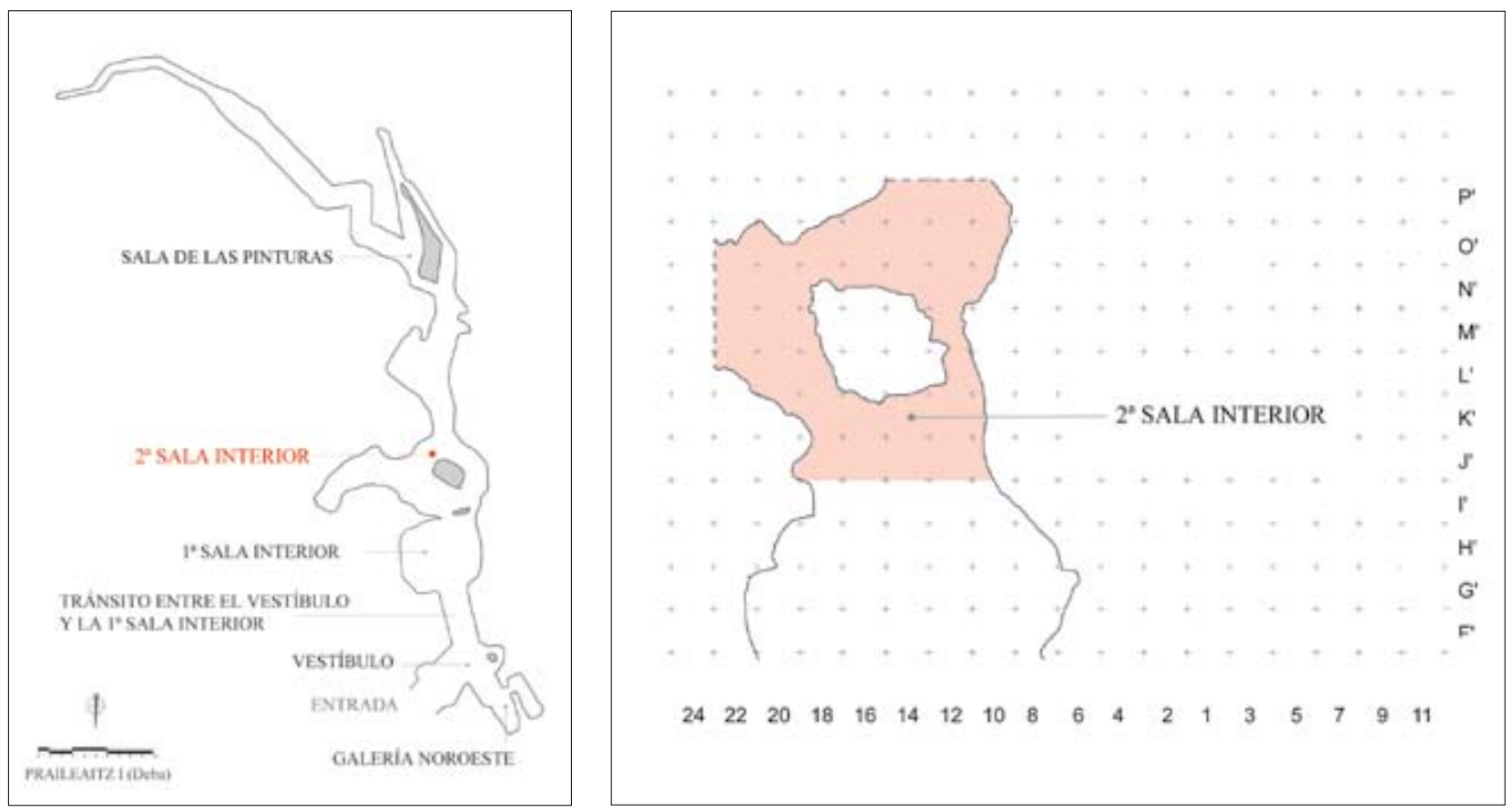

Fig. 126. Plano general de la cueva y ubicación de la segunda sala interior (Dibujo: G. Studer/Tx. Ugalde -Felix Ugarte Elkartea-). / General plan of the cave and location of the second inner room (Drawing: G. Studer/Tx. Ugalde -Felix Ugarte Elkartea-). 
parte sur de la sala, siendo muy horizontal el terreno en la mitad norte de la misma.

\subsubsection{Niveles estratigráficos}

\section{El nivel I}

La totalidad de la superficie que se excava está ocupada por una capa estalagmítica (Fig. 127). Su superficie, de coloración gris-azulada, está formada por abundantes gours, muy irregulares en cuanto a forma y tamaño.

Este paquete estratigráfico es muy compacto en algunas zonas, necesitándose de la ayuda de un martillo neumático para su extracción. Su grosor oscila entre 5 y $10 \mathrm{~cm}$ de media, aunque en zonas muy limitadas llega a superarlos e incluso a alcanzar los 15-17 cm de espesor.

En otras áreas esta concreción no es tan compacta y está formada por diversas capas de poco espesor, intercaladas por otras de tierra de color marrón con algún punto aislado de carbón vegetal, alguno de ellos incrustado en la concreción.

Tras eliminar este nivel de concreción superficial, y antes de comenzar a excavar el segundo lecho (el primero de tierra), se observa cómo las características del relieve son similares a las aparecidas antes de retirar la capa estalagmítica, apreciándose incluso una mayor horizontalidad general, aunque se mantiene la tendencia descendente, principalmente en dirección sur, acentuada en la zona más al sur, aunque ahora la diferencia de cota entre el norte y el sur disminuye a $35 \mathrm{~cm}$ (Fig. 128). A partir de este momento se excavan en esta sala un total de 17 lechos.

\section{El nivel II}

Se trata de la primera capa de tierra bajo la cubierta estalagmítica; consiste en un sedimento marrón oscuro, plástico, de $2 \mathrm{~cm}$ de espesor. Desde el inicio de su excavación comienzan a aparecer abundantes carbones y pequeños fragmentos de sedimento de coloración roja, así como algunos restos de fauna.

Se aprecian depresiones circulares en cuatro puntos de la zona excavada: una primera, la mayor, de 1,20 $\mathrm{m}$ de diámetro, cuyo centro se localiza en el cuadro 18K'; una segunda, algo menor, de $1 \mathrm{~m}$ de diámetro, con centro entre los cuadros 12K' y 14K'; una tercera, de 0,80 m de diámetro, con centro en el cuadro 160', y una cuarta, de 0,70 m de diámetro, con centro en el cuadro 120'.

Este segundo nivel, coincidente con el lecho 2, aparece únicamente en algunas zonas, principalmente de la mitad este de la sala, aunque también se documenta en algunos puntos del lado oeste.

\section{El nivel III}

El tercer nivel está formado por una fina capa estalagmítica de entre 1 y $5 \mathrm{~cm}$ de espesor, situado por debajo del nivel II de tierra marrón. Se detecta en zonas más o menos extensas de la sala, concretamente en la

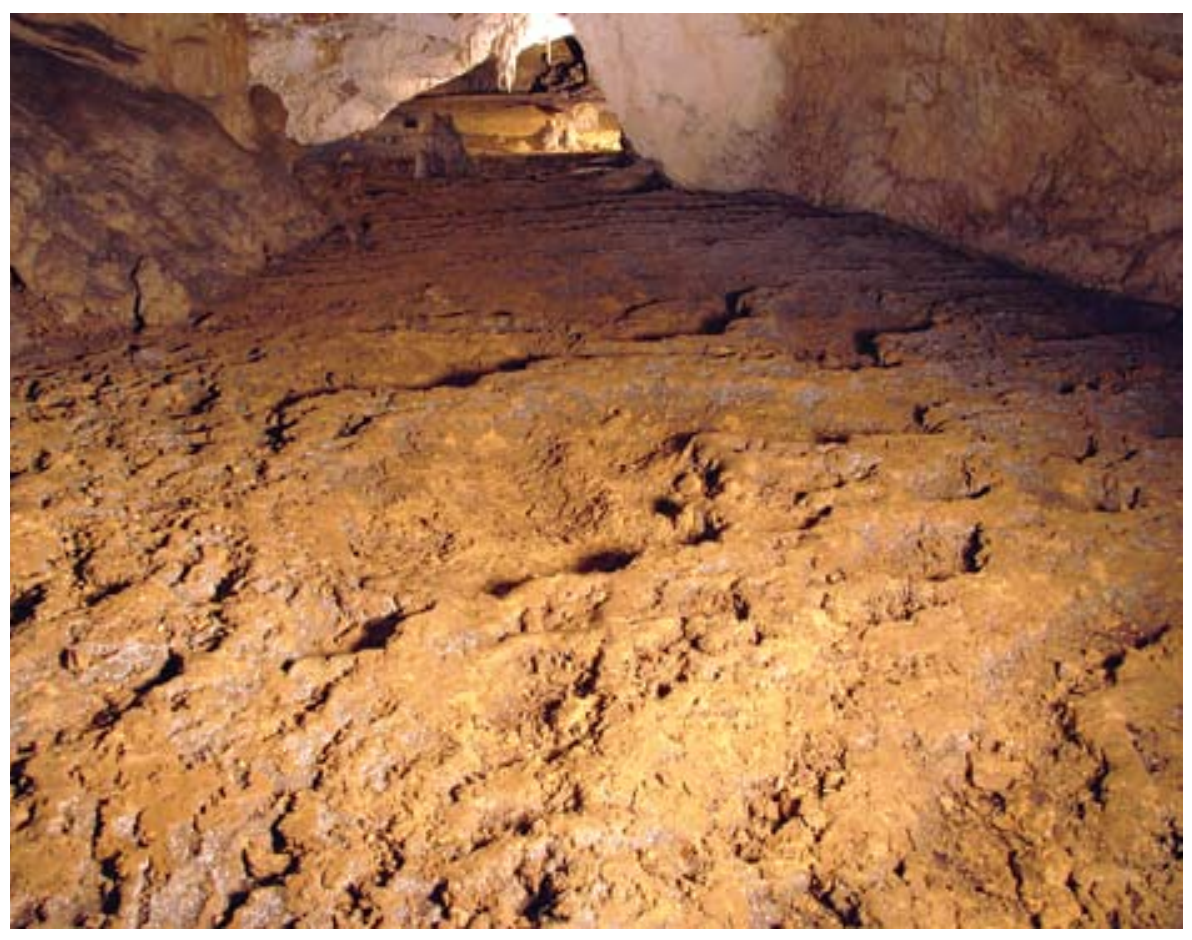

Fig. 127. Detalle de la concreción superficial que cubre la segunda sala interior. / Detail of the superficial concretion that covers the second inner room. 


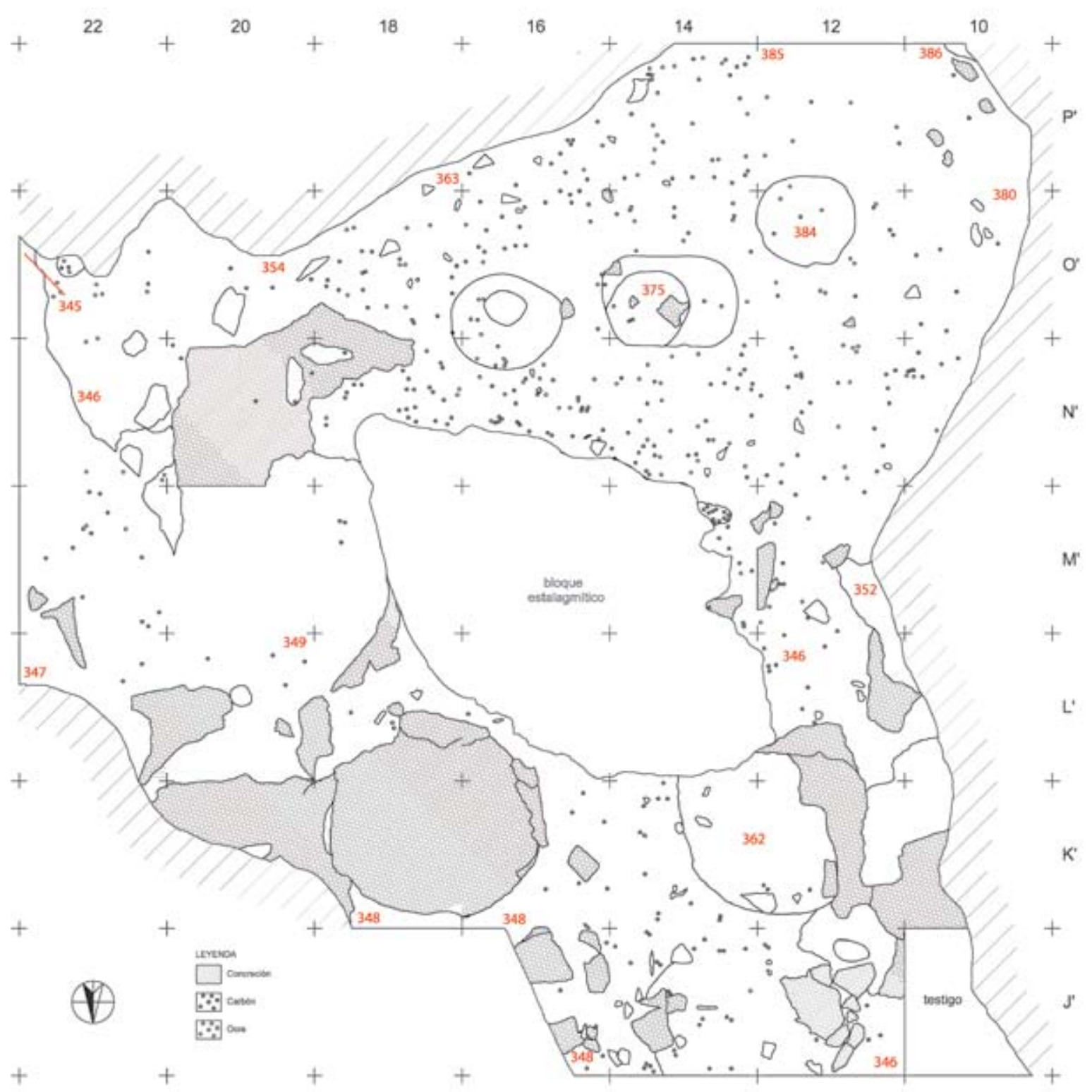

Fig. 128. Plano tras excavar el lecho 1 (bajo la capa de concreción) de la segunda sala interior (nivel II) (Dibujo: X. Peñalver/ Digitalización: J. Calvo). / Plan after excavating the layer 1 (under the layer of concretion) at the second inner room (Drawing: $X$. Peñalver/Digitalisation: J. Calvo).

mitad este y noroeste, apoyándose sobre una tierra amarilla plástica; se corresponde con el lecho 3.

\section{El nivel IV}

Está formado por un sedimento amarillo plástico que se extiende por todas las zonas de la sala con una potencia media de $15 \mathrm{~cm}$. A través de la excavación de los lechos 4 al 12, algunos de ellos de muy escasa potencia, se recuperan restos de fauna (Figs. 129 y 130). De todos modos, la característica principal que define a este nivel son los numerosos pequeños puntos de sedimento rojo y carbones; los primeros se concentran principalmente en la mitad sur de la sala. Se aprecian piedras de diferentes dimensiones en gran parte de la superficie, aunque no son muy abundantes. Tras bajar el lecho 9 la mayor parte de la sala se encuentra ocupada por el nivel IV, aunque con matices en el tipo de sedimento: en la parte sur de la sala, en su mitad oeste, la tierra tiende a ser más arenosa y grisácea que en el resto de la sala, que es arcillosa plástica. En los cuadros 200', 22O', 20M', 22M' y en la parte sur del 20L' el sedimento, con pequeñas piedras, apunta a la existencia de charcos. Las piedras, de dimensiones variadas, son frecuentes en este lecho.

Los carbones vegetales y los puntos de sedimento rojo son más numerosos en este lecho 9 que en el lecho anterior. Los primeros se concentran en mayor 


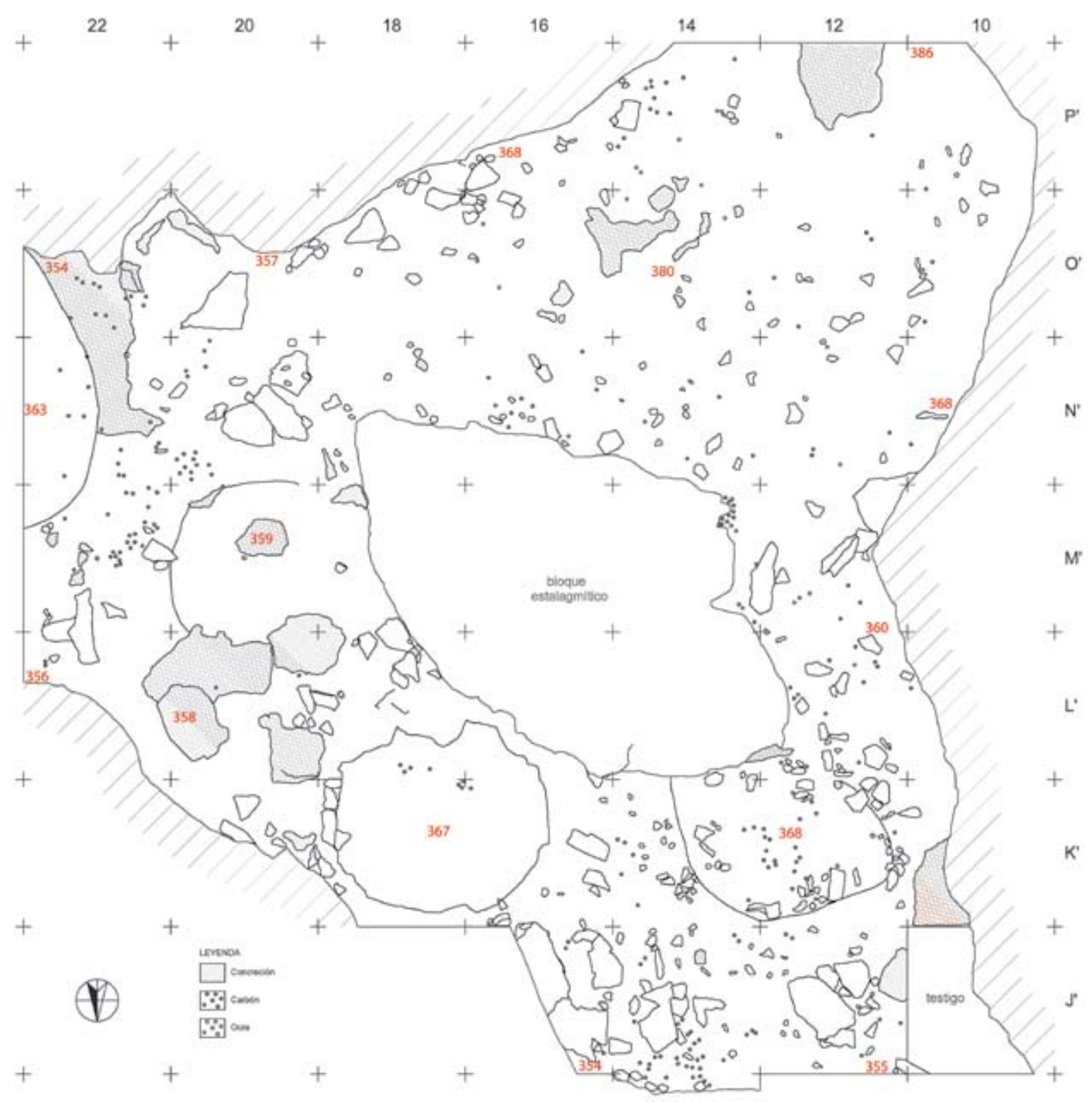

Fig. 129. Plano tras excavar el lecho 5 de la segunda sala interior (Dibujo: X. Peñalver/Digitalización: J. Calvo). / Plan after excavating the layer 5 at the second inner room (Drawing: X. Peñalver/Digitalisation: J. Calvo).

número en el norte de la sala, principalmente dentro de las hondonadas existentes en esa zona, y en el sur de la mitad oeste de la sala. Los segundos son numerosos en la mitad sur de la sala, principalmente en la depresión con centro en los cuadros 22N' y 24N' (Figs. 131 a 136).

En este nivel IV, ya en el lecho 12, se mantiene la misma tendencia en el tipo de tierra, aunque según zonas pasa de ser más arcillosa y plástica a más arenosa. El sedimento arcilloso y plástico ocupa gran parte de la mitad este de la sala salvo algunas zonas del este de las bandas M', L' y K', en donde es más arenoso, así como en la mitad oeste de la sala, a excepción de las bandas O' y P' y parte de la N'. Estas diferencias también se aprecian en el lecho 13; en este lecho ya han desaparecido casi totalmente los carbones, y los puntos de tierra roja se concentran en los cuadros 16N' y 160' y en la hondonada existente dentro del cuadro $22 \mathrm{~N}$ '.

La sala presenta en este nivel una considerable horizontalidad, principalmente en la mitad este. La mitad oeste tiene una tendencia descendente en sentido norte-sur, con un desnivel máximo de $28 \mathrm{~cm}$. En sentido este-oeste se produce un ligero descenso de cota hacia el oeste. 


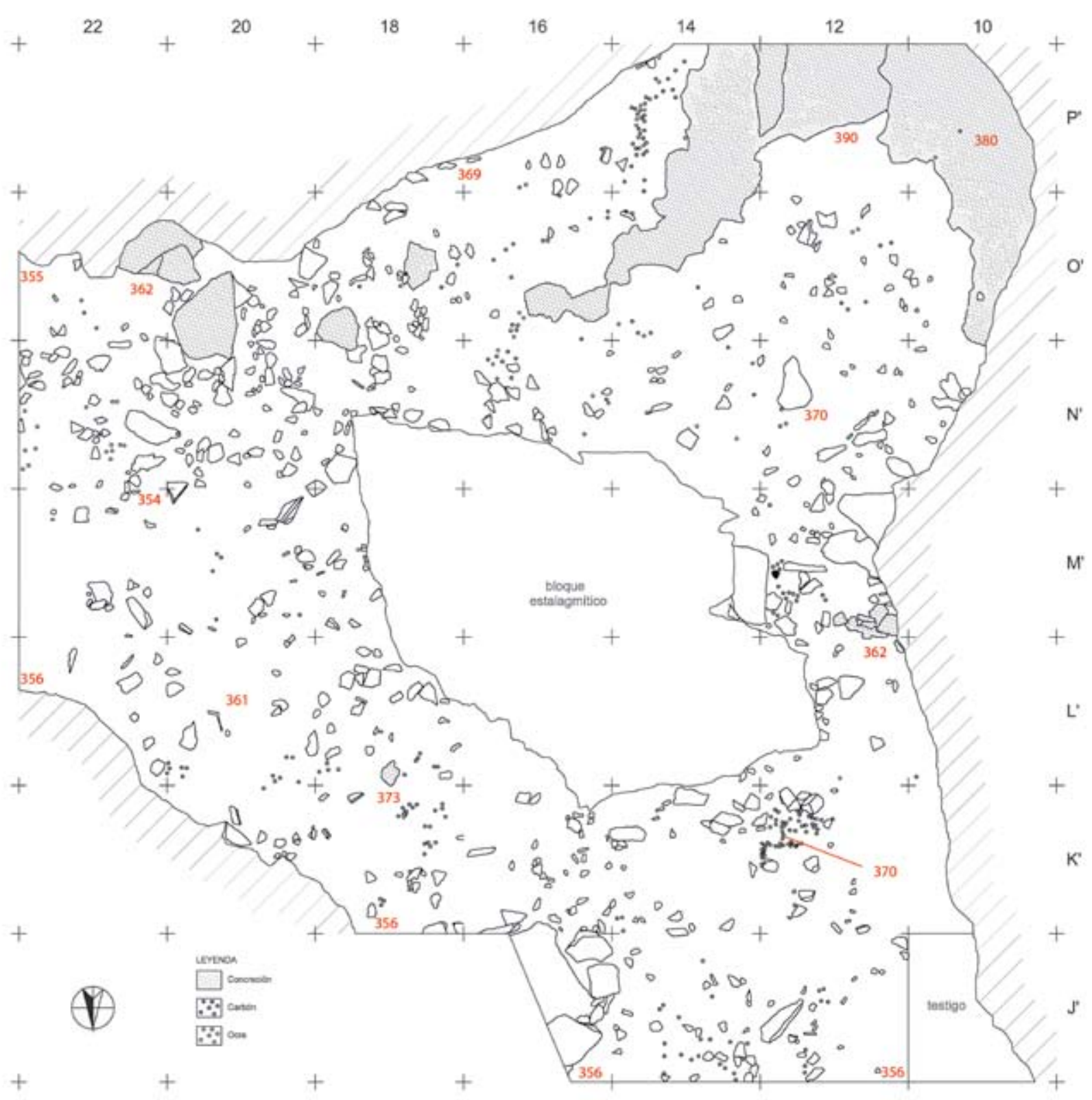

Fig. 130. Plano tras excavar el lecho 8 de la segunda sala interior (Dibujo: X. Peñalver/Digitalización: J. Calvo). / Plan after excavating the layer 8 at the second inner room (Drawing: X. Peñalver/Digitalisation: J. Calvo).

\section{El nivel V}

Detectado a partir del lecho 9, afecta a la zona central del oeste de la sala (cuadros 10K', 12K', 10L', 12L', 12M', 10N', 12N', 100' y 120') y está formado por un "suelo" natural de piedras calizas de entre 5 y $10 \mathrm{~cm}$ de dimensión máxima (Figs. 137 y 138). Se localiza contra la pared oeste de la sala, y forma un nivel muy homogéneo, sin que queden vacíos entre las piedras. Presenta una ligera inclinación hacia el sur $(26 \mathrm{~cm}$ en una distancia de $5,5 \mathrm{~m})$. En la eliminación de este nivel pedregoso se deja una zona como testigo en los cuadros 10N' y $12 \mathrm{~N}$ '.

\section{El nivel VI}

Se diferencia claramente en la parte sur de la sala un nivel formado por placas de concreción extensas que afecta a los cuadros 12P', 14P', 140', 160', 180' 200', 220'. Estas placas ya habían aparecido con anterioridad, ocupando una superficie menor. Así mismo afloran abundantes placas pequeñas de concreción en los cuadros 18N', 20N' y 22N'. Los cuadros 100' y 10P' están cubiertos en su casi totalidad por una tierra concrecionada. 


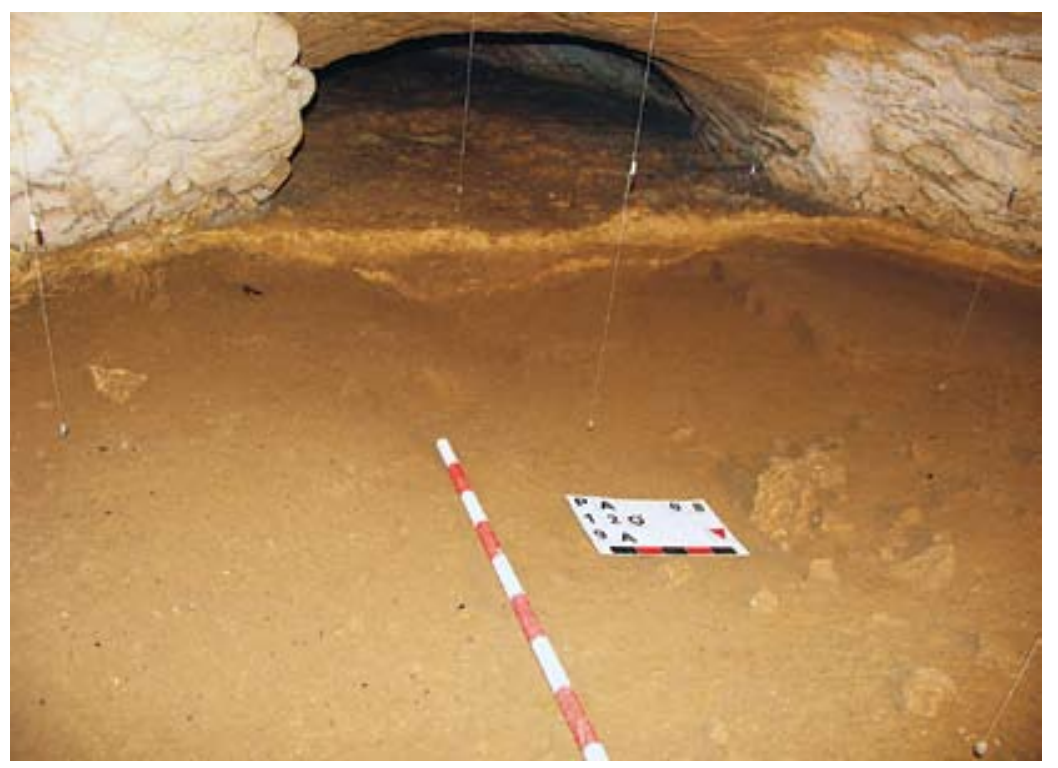

Fig. 131. Zona Sur de la segunda sala interior tras excavar el lecho 9. / Southern zone of the first inner room after excavating the layer 9 .

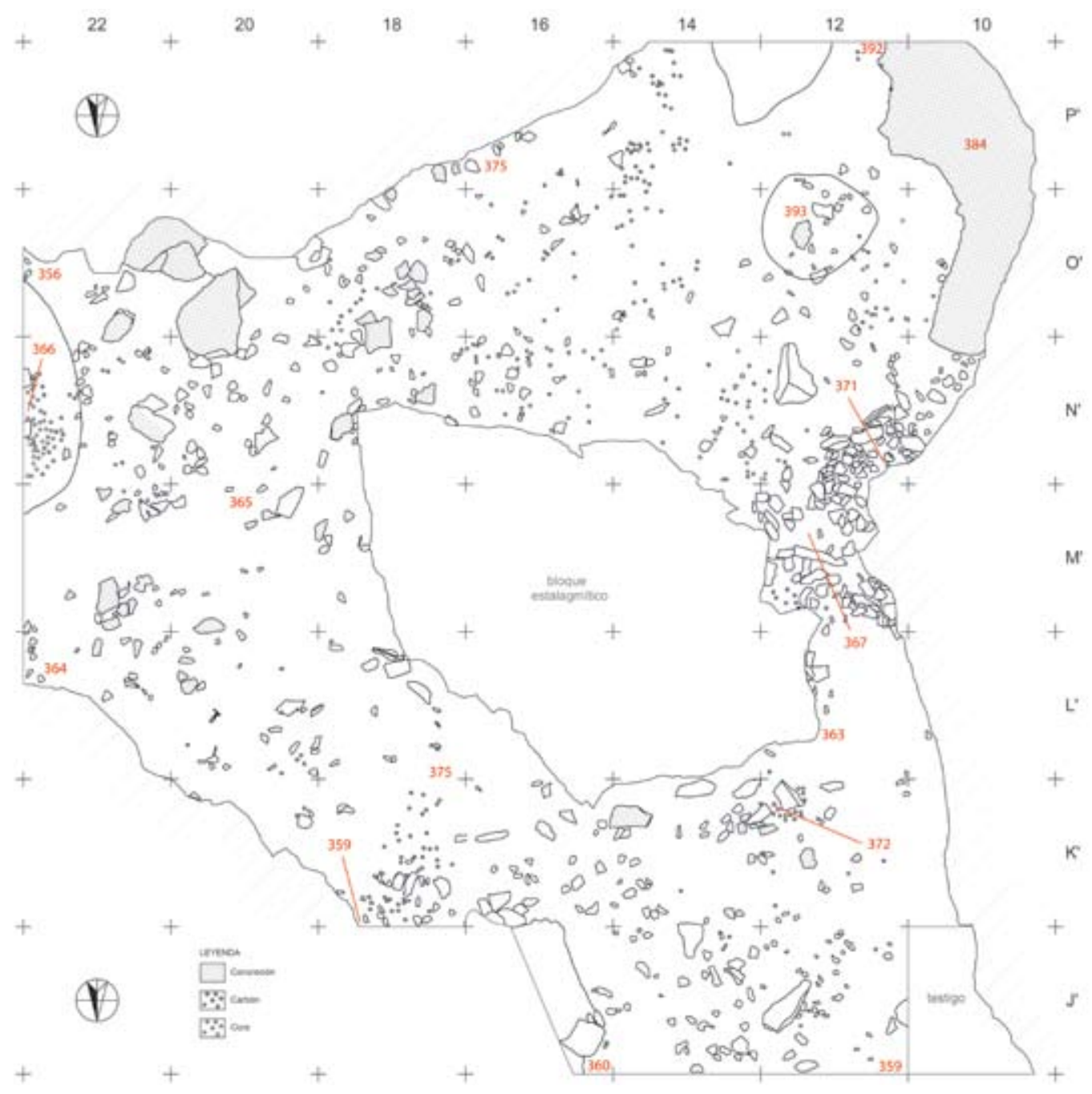

Fig. 132. Plano tras excavar el lecho 9 de la segunda sala interior (Dibujo: X.Peñalver/Digitalización: J. Calvo). / Plan after excavating the layer 9 at the second inner room (Drawing: X. Peñalver/Digitalisation: J. Calvo). 

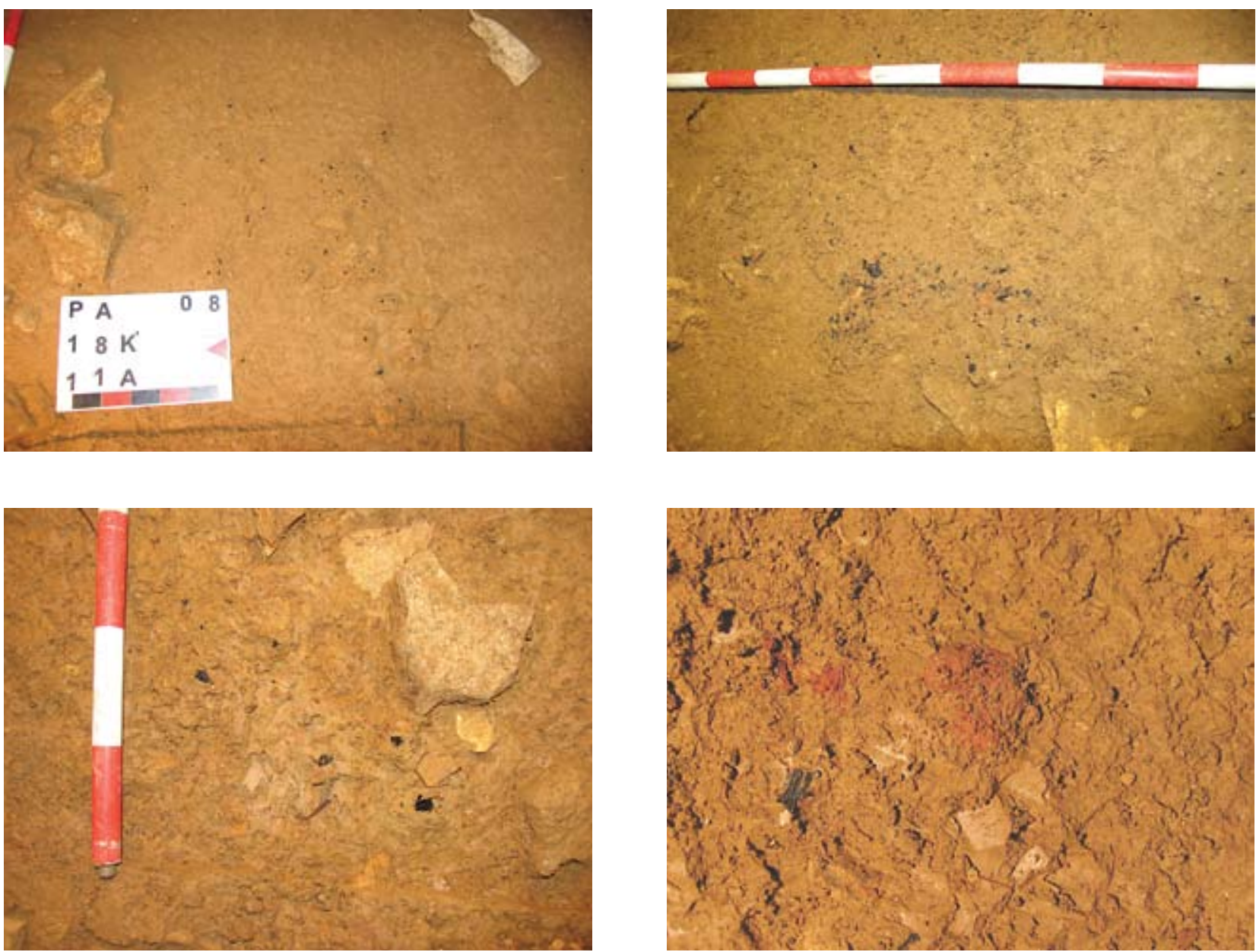

Figs. 133-136. Detalles de manchas de coloración roja y carbones en la segunda sala interior. / Details of red colouring stains and charcoal remains at the second inner room.
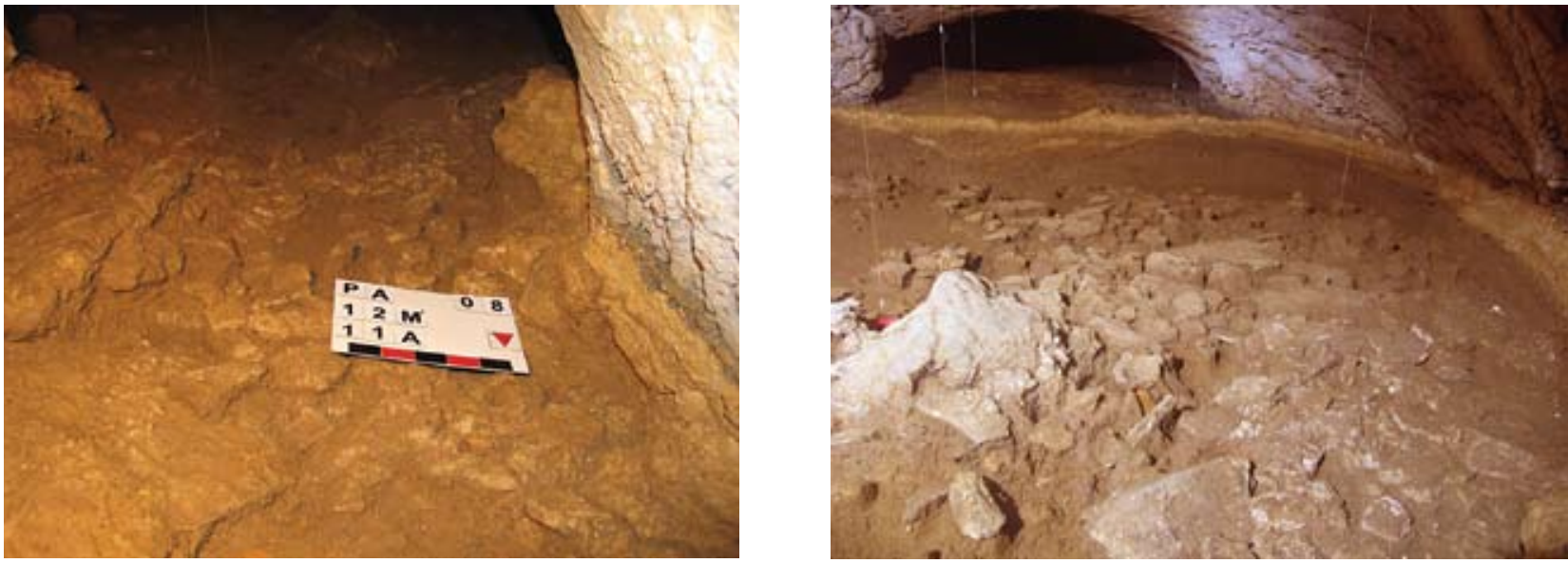

Figs. 137-138. Dos aspectos del nivel $\vee$ dentro de la segunda sala interior. / Two views of the level $V$ inside the second inner room. 


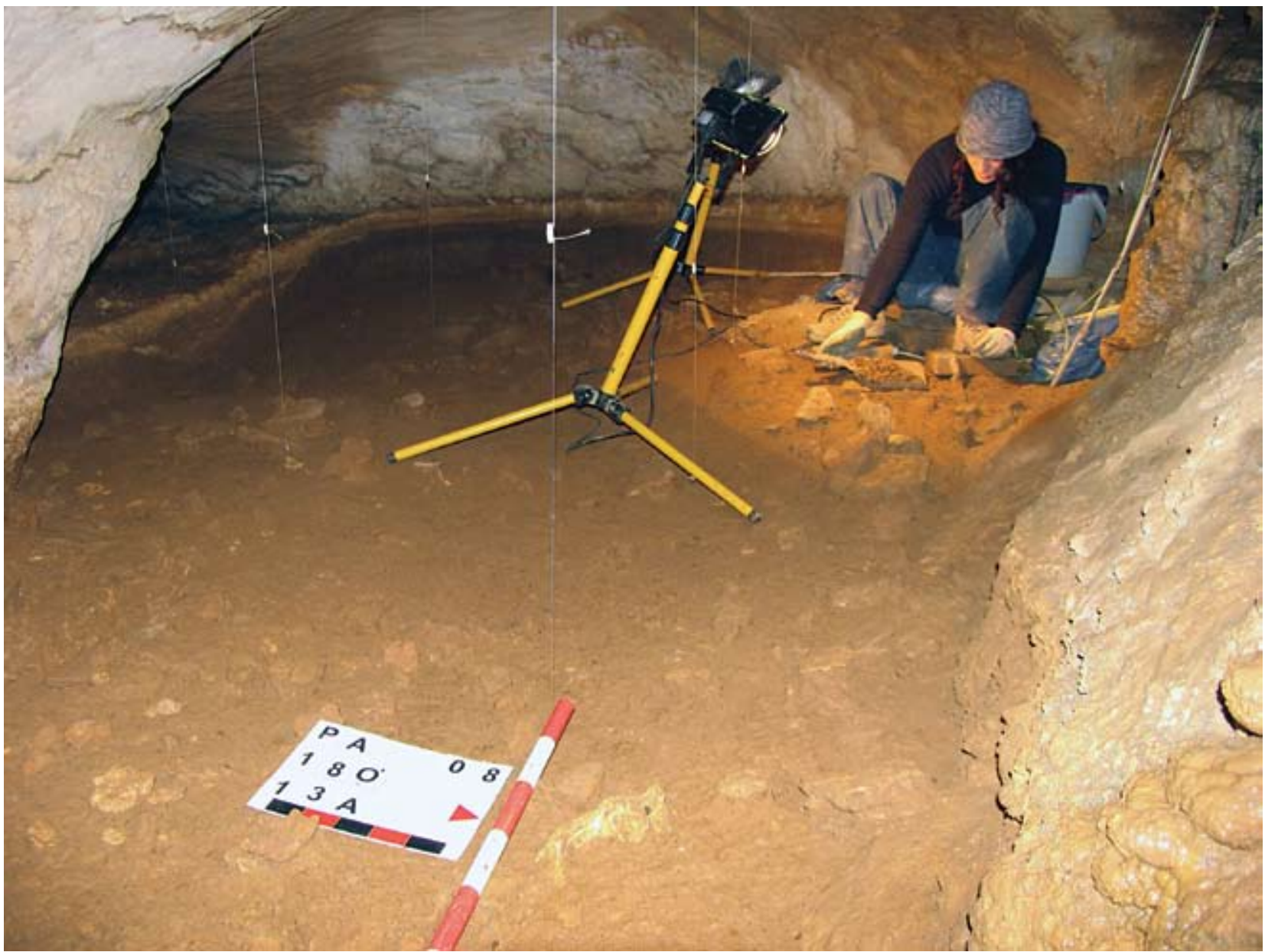

Fig. 139. Trabajos de excavación en el lecho 13 de la segunda sala interior. / Excavation works on the level 13 from the second inner room.

Este nivel apenas está representado en la mitad oeste de la sala, mientras que en la mitad este se presenta en forma de placas de menor tamaño. El nivel va adquiriendo diferente extensión a lo largo de los lechos hasta ser dominante en las bandas M', N' y O' de la mitad este de la sala. Así mismo, está presente en la zona sur de la mitad oeste, principalmente en la parte correspondiente a la hondonada cuyo centro se sitúa en el cuadro 120'. En las bandas J' y K', al norte de la sala, también existen pequeñas placas de concreción.

En el lecho 12 las placas se amplían en las bandas L', M' y N' de la mitad este de la sala, y en las N', O' y P' de la mitad oeste, al igual que lo hacen en el lecho 13.

Según se avanza la excavación, aumentan las placas de concreción en la mitad este de la sala, aunque tan solo en las bandas M', N' y O'. (Fig. 139) En la mitad oeste de la sala la concentración de placas de concreción se hace más densa y amplia, sobre todo en parte de los cuadros 160' y 16P' y en menor medida en el 14P'.

En las bandas 14 y 16 apenas afloran piedras ni concreción, formándose una especie de "pasillo"; lo mismo sucede al sur de la sala, aunque en esta zona hay presencia de algunas piedras. Por otra parte, en los cua- dros 16N' y 160' siguen apareciendo algunos restos de carbón vegetal y pequeños puntos de sedimento rojo.

Por otra parte en la zona suroeste de la sala, anexos a la pared, se documenta una gran concentración de fauna entremezclada con piedras (Figs. 140-142). Es posible que se trate de una acumulación natural producida por arrastre de agua. procedente de las salas anteriores situadas al norte.

\section{El nivel VII}

Está constituido por una placa de concreción que se extiende de forma homogénea y continua desde la pared sur de la sala hacia el norte, ocupando la totalidad de la mitad este de la sala. Aunque de forma irregular, presenta una suave pendiente descendente de sur a norte, de unos $10 \mathrm{~cm}$ de diferencia.

Este nivel se comienza a detectar por debajo del lecho 13 del nivel IV en los cuadros 22L' y 22M', según se van excavando los lechos 14, 15, 16, 17 y 18 (Fig. 143), correspondientes a los niveles VIII y IX, se va ampliando hacia el oeste, aunque también se amplía en menor medida hacia el norte y hacia el sur. 

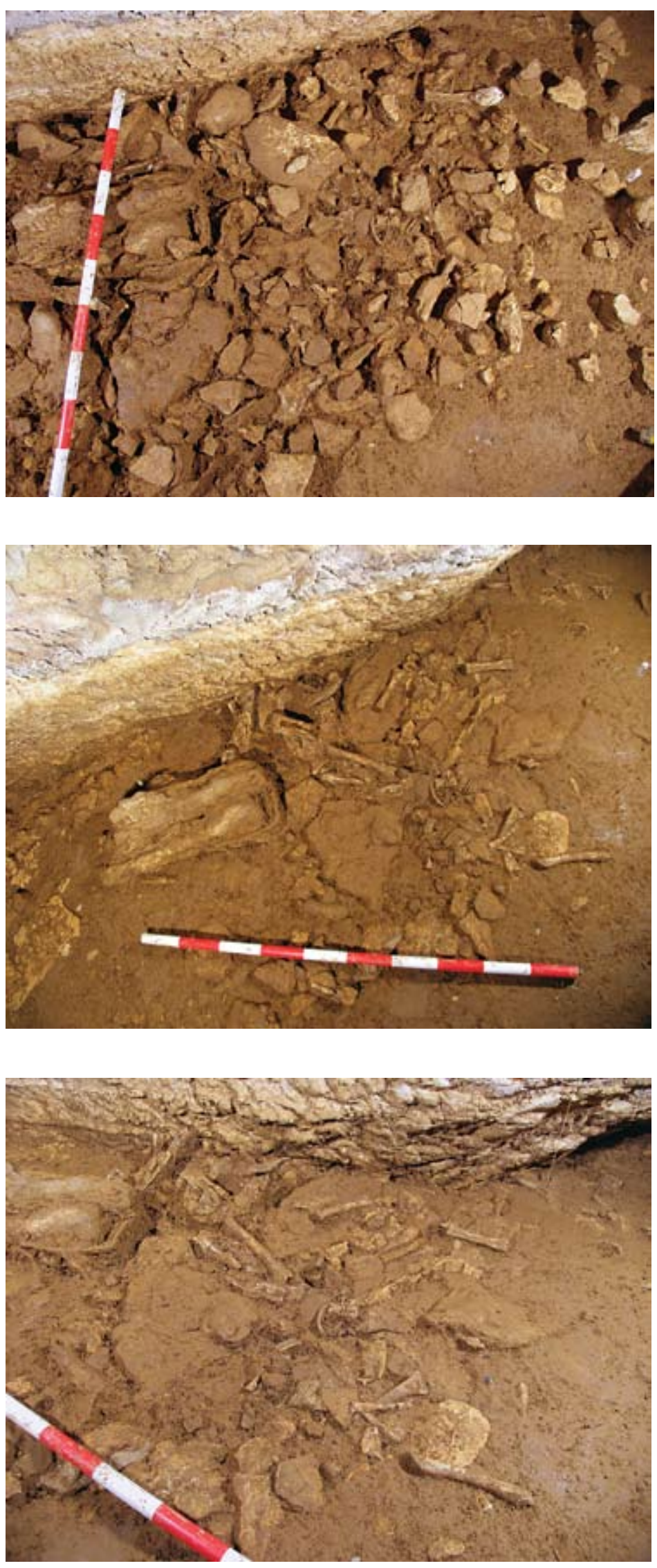

Fig. 140-142. Concentración de piedras y fauna del nivel VIII en diferentes fases de su excavación. 


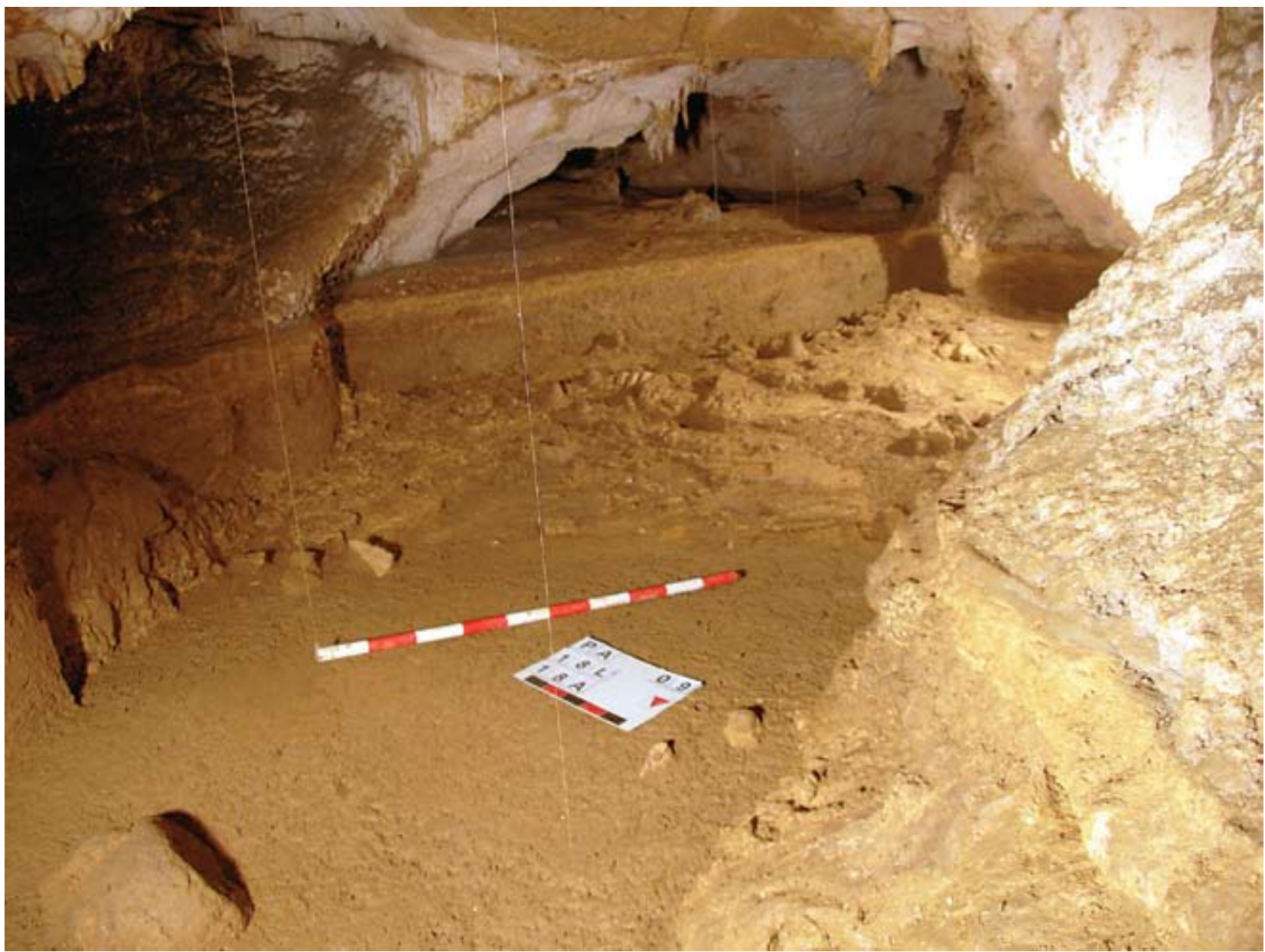

Fig. 143. Zona sur de la segunda sala interior tras excavar el lecho 18. / Southern zone of the second inner room after excavating the layer 18.

\section{El nivel VIII}

Tras eliminar gran parte de las placas de concreción de la mitad este de la sala, el sedimento es más arenoso, salvo en puntos concretos como los cuadros 18L' y 180', en donde es más plástico y arcilloso. En la mitad oeste de la sala, el sedimento es más arenoso, salvo en las bandas K', L', M' y N', en las que es más arcilloso y plástico.

Este nivel, además de significar un cambio en el tipo de tierra en algunas de las zonas, presenta otras características: ahora, los restos de carbón son prácticamente inexistentes, salvo escasos puntos en los cuadros 14N' y 16N', habiendo desaparecido totalmente los puntos de tierra roja de todas las zonas de la sala. En su mitad este, continúan presentes algunas placas de concreción, aún habiéndose eliminado en el lecho anterior la mayor parte de ellas.

En las bandas 16 y 18 del sur de la sala, en los cuadros 16P' y 160', se ha localizado una concentración muy homogénea de piedras y restos de fauna (Figs. 140 a 142 y 145) contra la pared sur de la sala, algunos de los huesos colocados en posición vertical.
En la mitad norte de la sala las piedras y las placas de concreción son más escasas. En esa zona se siguen manteniendo desde los primeros lechos las dos hondonadas (Fig. 144): la primera, centrada en los cuadros 16K' y $18 K^{\prime}$, con una profundidad máxima con respecto a su entorno de $14 \mathrm{~cm}$, y la segunda, con centro entre los cuadros 12K' y 14K', y una profundidad máxima de $13 \mathrm{~cm}$.

En el lecho 17, el sedimento sigue siendo predominantemente más arenoso en la mitad este de la sala, salvo en gran parte de las bandas L' y M'. En los cuadros 160' y 180', además de en la mayoría de la mitad oeste de la sala, el sedimento es más arcilloso y plástico.

\section{El nivel IX}

Se corresponde este nivel con el lecho 16 y 17 en las bandas J'y $\mathrm{K}^{\prime}$ y el lecho 18 en su totalidad. En ese nivel el sedimento ha desaparecido en gran parte de la mitad este de la sala, ocupando su lugar el nivel VII de concreción. Así, el nivel IX tan solo está presente en los cuadros situados más al norte como el 18K' y el 18L' y en parte en los 20K', 20L' y en los 18M' y 20M'. Así mismo, este nivel ocupa la hondonada del cuadro 22N'. 


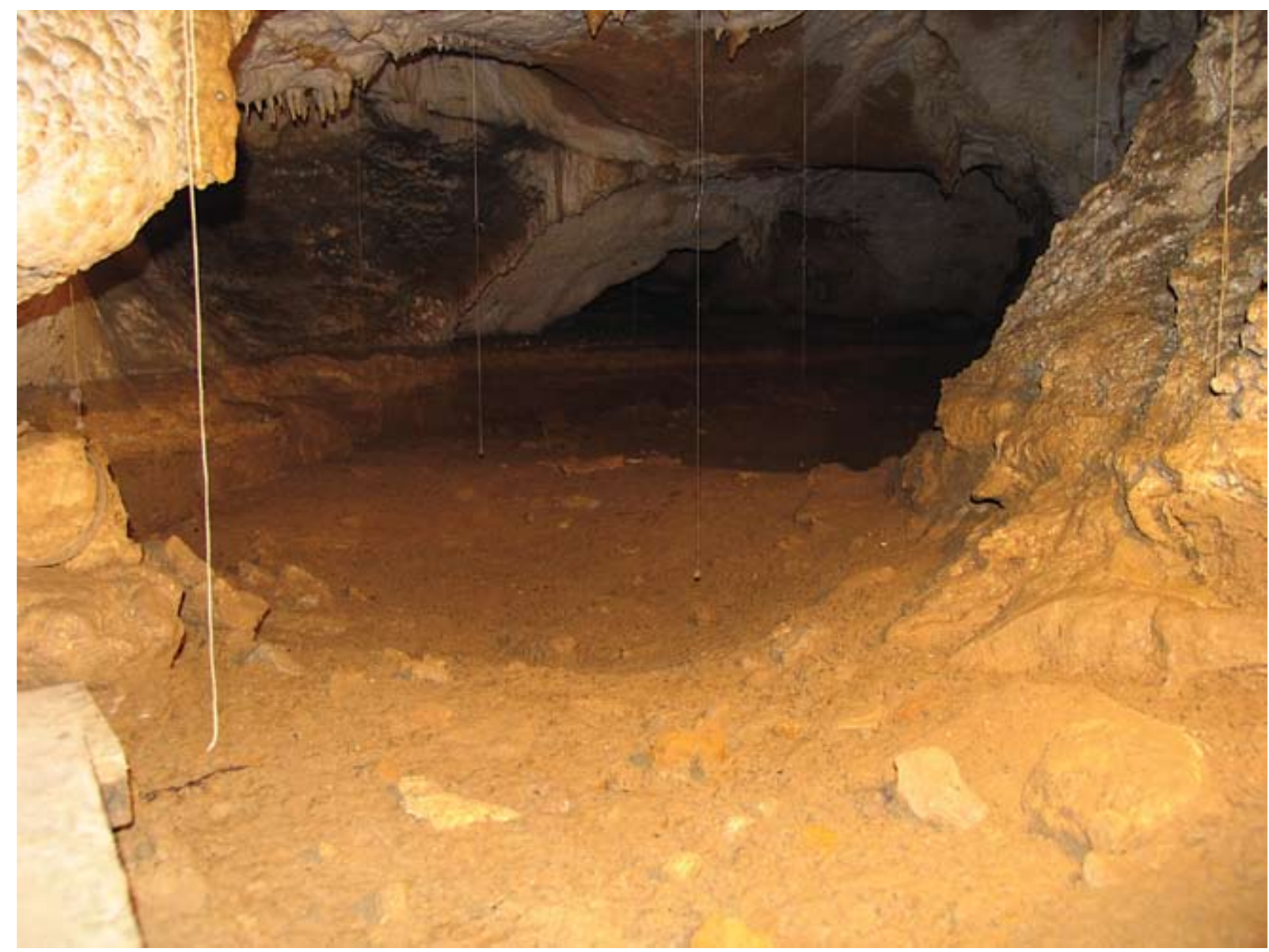

Fig. 144. Hondonada dentro de la segunda sala interior. / Hollow inside the second inner room.

Finalizado el lecho 18, la placa de concreción del nivel VII alcanza hacia el oeste la práctica totalidad de la banda 18 en el sur de la sala. A partir de ahí desaparece, tal vez descendiendo y por tanto ocultándose bajo el nivel IX; esa zona, situada al oeste, la ocupa una concentración de placas de concreción de tamaño pequeño y medio. En el lado norte de la sala no aparecen apenas piedras, aunque sí algunas placas de concreción en los cuadros 14J', 14K', 16J' y 16K' (Fig. 145).

Después de este último lecho se aprecian claramente las tres hondonadas de la sala, presentes desde los primeros lechos. La inclinación de los suelos de esta sala, al concluir el lecho, es de una relativa horizontalidad.

\section{Adscripción cronocultural de los niveles de la segunda sala interior}

Del estudio de los 9 niveles diferenciados en esta sala -algunos de ellos consistentes en placas estalagmíticas alternadas con pequeñas capas de tierra-, parece desprenderse que el depósito está en parte alterado, procediendo probablemente en ocasiones de zonas más exteriores de la cueva que habría sido arrastrado por el agua hasta esta segunda sala interior. La totalidad de los carbones datados en los niveles comprendidos entre el II y el VII de esta zona corresponden al período Epipaleolítico, pudiendo proceder del arrastre de los hogares de este mismo momento situados tanto en el pasillo entre el vestíbulo y la primera sala interior, como del ubicado en esta primera sala.

Por otra parte, determinados restos óseos hallados pueden ser atribuidos, tanto por las especies a las que corresponden como por su datación, a momentos mucho más antiguos que los de los carbones hallados en los distintos niveles hasta ahora excavados. Estos huesos están presentes en el paquete estratigráfico inferior de la sala, si bien en algún caso se han hallado en cotas superiores, tal vez a causa de haber sido removidos con posterioridad por determinados animales presentes en distintos momentos (tejón, zorro, oso, etc.). Así, los restos de especies más antiguas determinados en estas zonas se sitúan muy próximos a dos de las hondonadas presentes en esta sala.

Por otra parte, en el último lecho (18) excavado en esta sala hasta el 2009, perteneciente al nivel IX, 


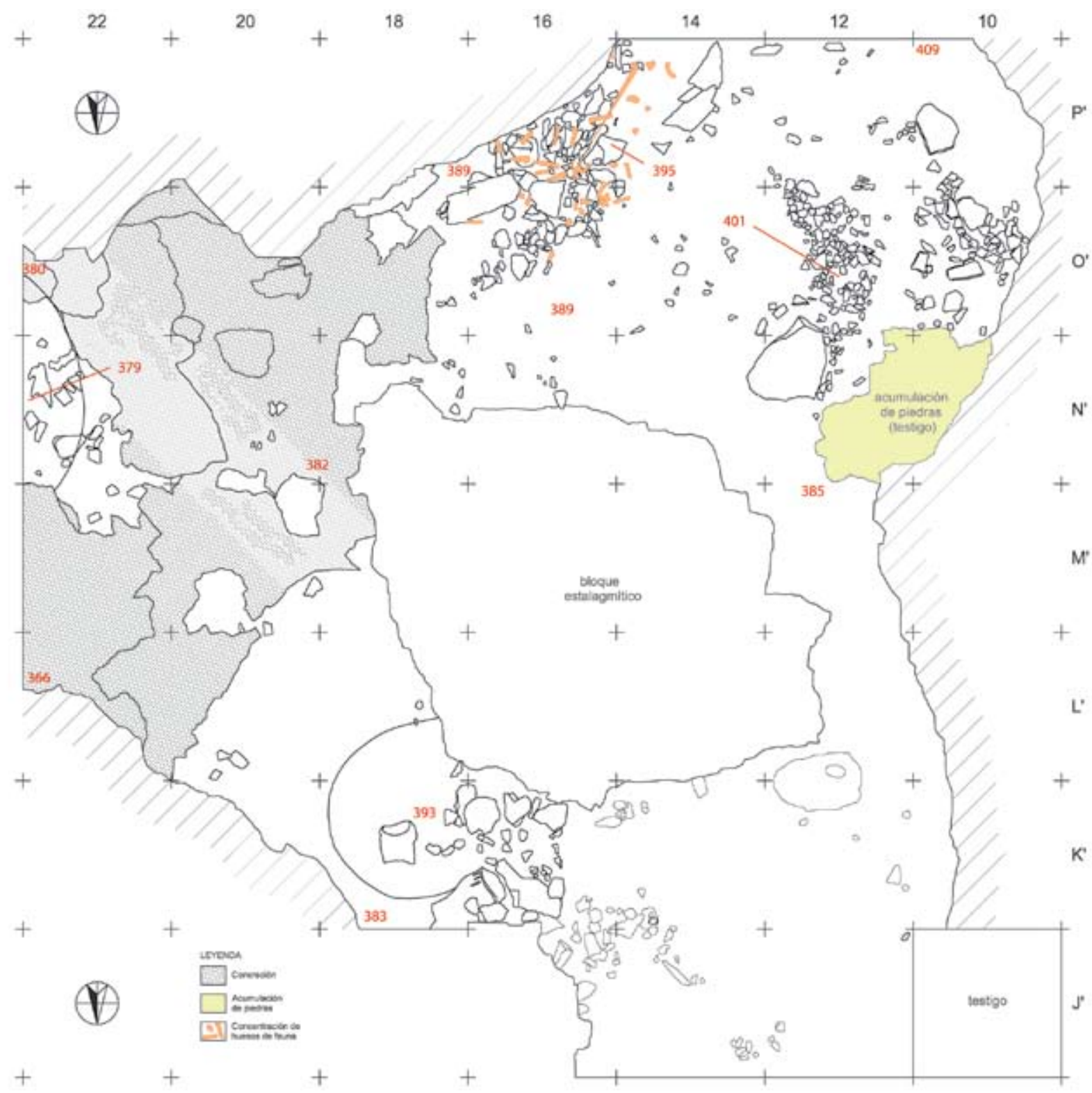

Fig. 145. Plano tras excavar el lecho 18 de la segunda sala interior (nivel IX) (Dibujo: X. Peñalver/Digitalización: J. Calvo). / Plan after excavating the layer 18 at the second inner room (Drawing: $X$. Peñalver/Digitalisation: J. Calvo).

se ha localizado un fragmento de bastón de mando (P.A.14J'.382.45) que nos indica, a través de su datación por C14 (17530 \pm 70 B.P.), la posible presencia de un nivel de ocupación del Solutrense, al menos en el extremo norte de esta sala. Los estudios palinológicos apuntan a que los lechos 16 y 17 de esta misma zona también corresponderían a este período (IRIARTE, 2017).

\subsection{Distribución de las fases de ocupación en el conjunto de la cavidad}

La zona intervenida afecta, además de al pequeño abrigo exterior, a diferentes espacios del interior de la cueva, interrelacionados entre sí, aunque con características específicas muy variadas.

En la totalidad de esas zonas se han recogido testimonios de la actividad humana en distintos momentos desde el Epipaleolítico hasta el inicio del Paleolítico Superior, si bien, con distinta intensidad.

Así, durante la fase epipaleolítica, todo apunta a la presencia humana desde el vestíbulo hasta la segunda sala interior, dejando huella mayoritariamente en el tránsito entre el vestíbulo y la primera sala interior así como en esta sala. Esta fase se ha detectado principalmente por dos hogares de gran tamaño, sin apenas evidencias arqueológicas. 
Por el contrario, la escasa documentación correspondiente al Magdaleniense Superior Final parece centrarse básicamente en el vestíbulo y en la zona de tránsito hacia la primera sala interior, siendo prácticamente nula en otras zonas de la cavidad.

Más extensa es la huella dejada por las gentes del Magdaleniense Inferior, afectando tanto al vestíbulo como a la primera sala interior; su presencia ha sido detectada en las distintas zonas de estos espacios tanto por su intervención en la preparación de un suelo en el vestíbulo -asociado a un hogar y un asiento-, como por la distribución de 29 colgantes principalmente líticos ricamente decorados.

La estancia de humanos durante el Solutrense ha podido documentarse tanto en algunas zonas del vestíbulo como en otras de la primera sala y en el arranque de la segunda sala interior. La escasez de los restos hallados se puede deber a que la intervención arqueológica no ha profundizado en este nivel, interrumpiéndose de momento los trabajos en estas áreas al identificarse esta ocupación.

Por último, y aunque no se ha detectado nivel arqueológico, tanto en el vestíbulo como en la galería noroeste se han hallado restos industriales que apuntan al Paleolítico Medio y procederían de galerías interiores colmatadas.

\section{4-. LAS DATACIONES ABSOLUTAS}

Las 26 dataciones obtenidas pertenecientes a diferentes niveles y zonas de la cavidad se corresponden con los datos procedentes del estudio de la estratigrafía y de los contenidos materiales de la misma, definiendo las sucesivas fases de ocupación que van del Paleolítico Medio al Epipaleolítico.

Las fechas absolutas obtenidas a lo largo de estos años a partir de restos óseos o de carbón vegetal han permitido complementar las informaciones que se iban acumulando de las sucesivas campañas de excavación en el yacimiento de Praileaitz I. Los resultados de estos análisis se recogen ordenados según han sido recibidos de los diferentes laboratorios.

En un primer momento se procede a datar por $\mathrm{C} 14$ algunas muestras óseas procedentes del vestíbulo, espacio en donde se inician los trabajos de excavación en el año 2000. Las enviadas al laboratorio Beta Analytic de Miami aportan en 2002 los siguientes resultados:

- Beta 162880: esquirla ósea recogida junto al hogar del vestíbulo.

P.A.10F.269: 15190 \pm 50 B.P. (AMS), 15300 \pm 50 (Convencional). Lecho 11. Nivel IV: Magdaleniense Inferior.

- Beta 162879: corresponde a una esquirla ósea hallada en la proximidad de los colgantes 1 y 2.

P.A.10B.298 17760 \pm 70 B.P. (AMS) 17850 \pm 70 (Convencional). Lecho 21. Nivel V: Solutrense.
Con el fin de interpretar de la forma más certera posible el contexto del que proceden las muestras, se envían al Centrum voor Isotopen Onderzoek de Groningen otras dos muestras para ser datadas por AMS, proporcionando en 2002 los siguientes resultados:

- GrA 20462: esquirla ósea recogida junto a los colgantes 1 y 2. P.A.12B.285: 14700 \pm 100 B.P. Lecho 11. Nivel IV: Magdaleniense Inferior.

- GrA 20464: esquirla ósea del hogar. P.A.10F.269: $15460 \pm 100$ B.P. Lecho 11. Nivel IV: Magdaleniense Inferior.

En definitiva, creemos que las más aceptables para fechar el suelo de ocupación asociado a los colgantes, así como estas piezas líticas, son las obtenidas en el hogar y en sus proximidades. En nuestra opinión las dos fechas menos coherentes proceden de contextos en los que la relación entre los objetos y las muestras no está suficientemente bien definida.

Partiendo de los resultados obtenidos en estas cuatro dataciones planteamos las siguientes consideraciones:

1.- Las dos fechas proporcionadas por las esquirlas de las cercanías del hogar son casi sincrónicas y servirían para confirmar la contemporaneidad del suelo, el hogar y los colgantes 3 y 4, además de otros restos arqueológicos.

2.- Las muestras que pretenden una aproximación a la cronología absoluta de los colgantes 1 y 2 y su relación con el hogar y demás elementos del otro extremo de la sala han aportado dataciones dispares entre sí y alejadas de las anteriores. Estas fechas las consideramos válidas en cuanto que se ajustarían a la cronología de dichas esquirlas, pero dudamos de su exacta relación con el contexto de las piezas que deseamos datar. Las causas que han producido este hecho podrían ser las que enumeramos a continuación:

- La escasez de restos óseos en el lugar dificulta la obtención de una muestra que consideraríamos ideal.

- El suelo de piedras claramente definido en el vestíbulo presenta en la zona en que se recogen las muestras una mayor irregularidad en cuanto a su densidad y relieve por lo que los criterios estratigráficos no son tan evidentes, no permitiendo diferenciar de forma neta las ocupaciones correspondientes al Solutrense (al que correspondería la esquirla ósea) y al Magdaleniense Inferior. Esta ocupación sería coetánea con la que está presente en el resto del vestíbulo (el hogar, la azagaya y los colgantes 3 y 4, además de otros restos).

- La debilidad de la potencia del sedimento acumulado en dicha zona explica que en una diferencia de cota máxima de sólo $12 \mathrm{~cm}$ entre dos cuadros contiguos (10B, z:298 y 12B, z:285) hubieran transcurrido 3000 años, haciendo caso omiso de la existencia de posibles buzamientos no detectables en la actualidad.

- La esquirla P.A.12B.291, utilizada para datar el colgante $\mathrm{n}^{\circ} 1$ (cuadro 12B, z: 285), se encuentra $6 \mathrm{~cm}$ 


\begin{tabular}{|c|c|c|c|c|c|c|c|}
\hline REF. LAB. & SIGLA & ZONA & MATERIAL & FECHA BP & $\begin{array}{c}\text { CAL BP } \\
2 \text { sigma }^{[1]} \\
\end{array}$ & NIVEL & PERÍODO \\
\hline GrA-38339 & int.6 & G. Pinturas & Carbón & $4010 \pm 30$ & $\begin{array}{l}4566-4560 \\
4530-4417 \\
\end{array}$ & - & Calcolítico \\
\hline GrA-38340 & 120'.377.1 & $2^{\mathrm{a}}$ Sala & Carbón & $8800 \pm 35$ & $\begin{array}{c}10120-1064 \\
10005-9995 \\
9940-9678\end{array}$ & IV & Epipaleolítico \\
\hline GrA28030 & $14 E^{\prime} .330$ & $1^{\mathrm{a}}$ Sala: hogar & $\begin{array}{c}\text { Quercus subg. } \\
\text { Quercus }\end{array}$ & $8840 \pm 45$ & $\begin{array}{c}10157-9734 \\
9717-9709\end{array}$ & $\|$ & Epipaleolítico \\
\hline GrA-38266 & 14E'.335.4 & $1^{a}$ Sala: hogar & & $8845 \pm 40$ & $10157-9741$ & $\|$ & Epipaleolítico \\
\hline GrA- 38794 & 16K'.359.3 & $2^{\text {a Sala }}$ & Carbón & $8925 \pm 40$ & $\begin{array}{c}10201-10111 \\
10098-9915 \\
\end{array}$ & IV & Epipaleolítico \\
\hline GrA 28028 & 10B'.287 & Pasillo: hogar & Carbón & $8940 \pm 50$ & $10217-9912$ & II.I & Epipaleolítico \\
\hline GrA-44404 & $160^{\prime} .400 .514$ & $2^{\mathrm{a}}$ Sala & $\begin{array}{l}\text { Quercus subg. } \\
\text { Quercus }\end{array}$ & $8985 \pm 45$ & $\begin{array}{c}10238-10119 \\
10065-9927\end{array}$ & VIII & Epipaleolítico \\
\hline GrA 28031 & 20E'.340 & $1^{\text {a }}$ Sala & No conífera & $9010 \pm 50$ & $\begin{array}{c}10250-10122 \\
10064-10005 \\
9995-9931\end{array}$ & $\|$ & Epipaleolítico \\
\hline GrA- 38267 & 16P'.368.2 & $2^{\text {a Sala }}$ & & $9200 \pm 40$ & $\begin{array}{l}10491-10455 \\
10440-10249 \\
\end{array}$ & $\|$ & Epipaleolítico \\
\hline GrA-38265 & 14N'.367.5 & $2^{\text {a Sala }}$ & & $9225 \pm 40$ & $10505-10260$ & IV & Epipaleolítico \\
\hline KIA-39657 & & Pasillo & $\begin{array}{l}\text { Littorina } \\
\text { saxatilisis] }\end{array}$ & $9320 \pm 40$ & $10571-10252$ & $1 \mathrm{llb}$ & Epipaleolítico \\
\hline KIA-39658 & & Pasillo & L. obtusata & $10560 \pm 50$ & $12621-12114$ & llb & Epipaleolítico \\
\hline GrA 28029 & 10D.217.19 & Vestíbulo & & $10740 \pm 50$ & 12738-12594 & $\|$ & Epipaleolítico \\
\hline BETA 341897 & 8F.211.6 & Vestíbulo & $\begin{array}{l}\text { Rangifer } \\
\text { tarandus }\end{array}$ & $12920 \pm 50$ & $15667-15231$ & III & Magd. Sup.-Final \\
\hline GrA 20462 & B12.285 & Ves.: colgantes & Hueso & $14700 \pm 100$ & 18153-17614 & IV & Magd. Inferior \\
\hline Beta 162880 & F10.269 & Ves.: hogar & Hueso & $15190 \pm 50$ & $18611-18311$ & IV & Magd. Inferior \\
\hline Beta 162880 & F10.269 & Ves.: hogar & Hueso & $15300 \pm 50$ & 18721-18428 & IV & Magd. Inferior \\
\hline GrA 20464 & F10.269 & Ves.: hogar & Hueso & $15460 \pm 100$ & 18920-18517 & IV & Magd. Inferior \\
\hline GrA 24685 & 12F.306 & Vestíbulo & & $15530 \pm 100$ & 18982-18578 & IV & Magd. Inferior \\
\hline GrA 24688 B & 14F.296 & Vestíbulo & & $15810 \pm 110$ & $19397-1827$ & IV & Magd. Inferior \\
\hline BETA 341898 & 14J'.382.45 & $2^{\text {a Sala }}$ & Bastón perf. & $17530 \pm 70$ & 21440-20919 & IX & Solutrense \\
\hline Beta 162879 & B10.298 & Ves.: colgantes & Hueso & $17760 \pm 70$ & 21785-21244 & V & Solutrense \\
\hline Beta 162879 & B10.298 & Ves.: colgantes & Hueso & $17.850 \pm 70$ & $21860-21391$ & V & Solutrense \\
\hline GrA 24687 & 12F.309 & Vestíbulo & & $19330 \pm 150$ & $23680-22890$ & V & Solutrense \\
\hline BETA 341896 & $6 A^{\prime} .298 .21$ & Pasillo & Cervus elaphus & $22900 \pm 110$ & 27493-27005 & IV & Gravetiense \\
\hline GrA 28025 & 2G.248.135 & Galería NO & & $25320 \pm 140$ & 29774-28976 & $\mathrm{Vl}$ & Gravetiense \\
\hline BETA 341895 & 3В.107.21 & Exterior & Pantera pardus & $35010 \pm 280$ & 40225-38853 & IV & Chatelperroniense \\
\hline Racemización & $200^{\prime} .372 .49$ & $2^{\mathrm{a}}$ Sala & Ursus spelaeus[3] & 50.100 & & VII & Paleolítico Medio \\
\hline
\end{tabular}

Tabl. 4. Dataciones radiométricas y su correspondencia con la estratigrafía de la cueva de Praileaitz I (Deba). / Radiometric dates and their correspondence with the Praileaitz I (Deba) cave's stratigraphy.

[1] Calibración efectuada según Intcal13. https://c14.arch.ox.ac.uk/oxcal.html. [2] Littorinas calibradas y corregidas considerando el efecto reservorio marino y un delta $\mathrm{R}$ de 7450 , calculado a partir de la muestra de San Juan de Luz (Marine Reservoir Correction Database, TISNERAT-LABORDE, 2010) (fuente: RIGAUD et al., 2017). [3] Datado mediante racemización de aminoácidos en el Laboratorio de Estratigrafía Biomolecular (LEB) de la E.T.S.I. de Minas de Madrid. 
por encima de ésta, razón por lo que la fecha obtenida, $14700 \pm 100$ B.P., pudiera corresponder a una "ocupación" posterior. La otra fecha (relacionable con la ocupación infrayacente -Solutrense-), sin embargo, se halla a la misma cota que el colgante $n^{\circ} 2$.

Posteriores dataciones recibidas en febrero de 2004, correspondientes también al vestíbulo de la cueva, proporcionan los siguientes datos:

- GrA 24685 P.A.12F.306: 15530 \pm 100 B.P. Lecho 11. Nivel IV: Magdaleniense Inferior.

- GrA 24688 B P.A.14F.296: 15810 \pm 110 B.P. Lecho 11. Nivel IV: Magdaleniense Inferior.

- GrA 24687 P.A.12F.309: 19330ะ150 B.P. Lecho 21. Nivel V: Solutrense.

En abril de 2005 se dispone de una fecha correspondiente a un nivel inferior de la galería que se abre al noroeste del vestíbulo, proporcionando el siguiente resultado:

- GrA 28025 P.A.2G.248.135: 25320ะ140 B.P. Lecho 14. Nivel VI: Gravetiense.

Otras dataciones obtenidas a partir de muestras recogidas en el vestíbulo, en la primera sala interior y en el tránsito entre ambos espacios, recibidas en abril de 2005, son las siguientes:

Dentro del espacio correspondiente al vestíbulo:

- GrA 28029 P.A.10D.217.19: 10740 \pm 50 B.P. Lecho 7. Nivel II: Epipaleolítico.

En la estrecha galería de tránsito entre el vestíbulo y la primera sala interior, en la zona del hogar, una muestra de carbón proporciona el siguiente resultado:

- GrA 28028 P.A.10B'.287: 8940_50 B.P. Lecho 12. Nivel II.I: Epipaleolítico.

En la primera sala interior, las fechas obtenidas son las siguientes:

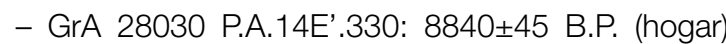
(Quercus subg. Quercus-Roble tp. Caducifolio/mascescente). Lecho 4. Nivel II: Epipaleolítico.

- GrA 28031 P.A. 20E'.340: 9010ะ50 B.P. (no conífera). Lecho 6. Nivel II: Epipaleolítico.

Se datan también, en mayo de 2008, cinco muestras correspondientes al nivel Epipaleolítico: una de la primera sala interior y cuatro de la segunda sala interior. Los resultados son los siguientes:

\section{Primera sala interior:}

- GrA-38266 P.A. 14E'.335.4: 8845 40 B.P. (hogar). Lecho 5, sublecho 3. Nivel II: Epipaleolítico.

\section{Segunda sala interior:}

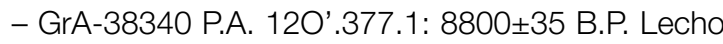
3. Nivel III: Epipaleolítico.

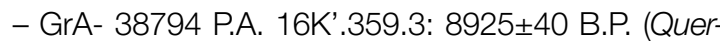
cus subgénero Quercus). Lecho 8. Nivel IV: Epipaleolítico.

- GrA- 38267 P.A. 16P'.368.2: 9200 \pm 40 B.P. Lecho 2. Nivel II: Epipaleolítico.
- GrA-38265 P.A. 14N'.367.5: 9225+40 B.P. Lecho 8. Nivel IV: Epipaleolítico.

En una zona interior de la cueva, rebasada el área de las pinturas, en las proximidades de la galería ascendente existente en ese lugar, se recoge una muestra de carbón superficial que proporciona la siguiente fecha:

- GrA-38339 P.A. int.6: 4010ะ30 B.P.

En diciembre de 2009 una nueva datación en la segunda sala interior da el siguiente resultado:

- GrA-44404 P.A. 160'.400: 8985 \pm 45 B.P. (Quercus subgénero Quercus). Lecho 17. Nivel VIII: Epipaleolítico.

En este mismo año, P. M. Grootes envía dos muestras correspondientes a sendas littorina a KIA para su datación, obteniéndose las siguientes fechas:

- KIA-39657 (L. saxatilis): 9320 \pm 40 B.P.

- KIA-39658 (L. obtusata): 10560ะ50 B.P.

Paralelamente, en diciembre de 2009, T. de Torres y J. E. Ortiz datan mediante racemización de aminoácidos en el Laboratorio de Estratigrafía Biomolecular (LEB) de la E.T.S.I. de minas de Madrid un molar primero superior de Ursus spelaeus hallado en la segunda sala interior, obteniendo el siguiente resultado:

- P.A.200'.372.49: 50100 B.P. (LEB 8819) Lecho 14. Nivel VII. Zona con restos en posición secundaria.

En marzo de 2013 se recibe el resultado de las cuatro muestras enviadas a los laboratorios Beta de Miami (EEUU) procedentes de diversas zonas del yacimiento para ser analizadas por AMS:

\section{Area exterior a la cueva:}

- BETA 341895 P.A.3B.107.21: 35010 \pm 280 B.P. (Ulna de Pantera pardus). Lecho 7. Nivel IV: Chatelperroniense.

\section{Vestíbulo:}

- BETA 341897 P.A.8F.211.6: 12920 \$50 B.P. (Cráneo de Rangifer tarandus). Lecho 9. Nivel III: Magdaleniense Superior-Final.

Tránsito entre el vestíbulo y la primera sala interior:

- BETA 341896 P.A.6A'.298.21: 22900 \pm 110 B.P. (Carpal radial de Cervus elaphus). Lecho 18. Nivel IV (bajo ocupación del Magdaleniense Inferior): Gravetiense.

\section{Segunda sala interior:}

- BETA 341898 P.A.14J'.382.45: 17530 \pm 70 B.P. (Bastón perforado). Lecho 18. Nivel IX: Solutrense.

\section{5.- BIBLIOGRAFÍA}

\section{BARANDIARAN, I.}

1988 Prehistoria. Paleolítico. Historia General de Euskalerria. Auñamendi, Enciclopedia General Ilustrada del País Vasco. San Sebastián. 
GONZÁLEZ SAINZ, C.; UTRILLA, P.

2005 Problemas actuales en la organización y datación del Magdaleniense en la Región Cantábrica. O Paleolitico. Actas do IV Congresso de Arqueologia Peninsular (Nino Ferreira Bicho), 39-49. Faro. Univ. Do Algarve.

IRIARTE, M. J.

2017 Praileaitz I (Deba, Gipuzkoa): el estudio paleopalinológico, en PEÑALVER, X., SAN JOSE, S., MUJIKA-ALUSTIZA, J.A. La cueva de Praileaitz I (Deba, Gipuzkoa, Euskal Herria). Intervención arqueológica 2000 - 2009. Munibe Monographs. Anthropology and Archaeology Series 1. 193-199.

\section{PEÑALVER, $X$.}

2001-2002-2003-2004-2005-2006-2007-2008a-2009a-2013-

2014a Praileaitz I haitzuloa (Deba). I, II, II, IV, V, VI, VII, VIII, IX, X, XI kanpaina. Arkeoikuska 2000, 01, 02, 03, 04, 05, 06, 07, $08,12,13,84-87,446-447,115-116,115-116,391$ 426-427, 468-469, 340, 366, 275-277, 293-294.
PEÑALVER, X.; MUJIKA, J. A.

2003 Suelo de ocupación magdaleniense en la cueva de Praile Aitz I (Deba, Gipuzkoa): evidencias de arte mobiliar. Veleia 20, 157-181.

PEÑALVER, X; ; SAN JOSE, S

2009 La cueva de Praileaitz (Deba): un caso paradigmático de los déficits en la conservación del patrimonio vasco. Medio siglo de arqueología en el Cantábrico Oriental y su Entorno: actas del Congreso Internacional, 1049-1060. Gasteiz.

RIGAUD, S., D'ERRICO, F., VANHAEREN, M., PEÑALBER, X.

2014 A short-term, task-specific site: Epipalaeolithic settlement patterns inferred from marine shells found at Praileaitz I (Basque Country, Spain). Journal of Archaeological Science 41, 666-678.

UTRILLA, P.

1990 La llamada "facies del País Vasco" del magdaleniense inferior cantábrico. Apuntes estadísticos. Munibe (Antropologia-Arkeologia) 42, 41-54. 